University of Szeged

Faculty of Humanities and Social Sciences

Doctoral School of Education

\title{
TEACHING, LEARNING AND ASSESSING STUDENTS' ENGLISH LANGUAGE RECEPTIVE SKILLS IN MONGOLIA
}

\author{
$\mathrm{PhD}$ Dissertation \\ by \\ Jargaltuya Ragchaa
}

Supervisor: Prof. Dr. Benő Csapó

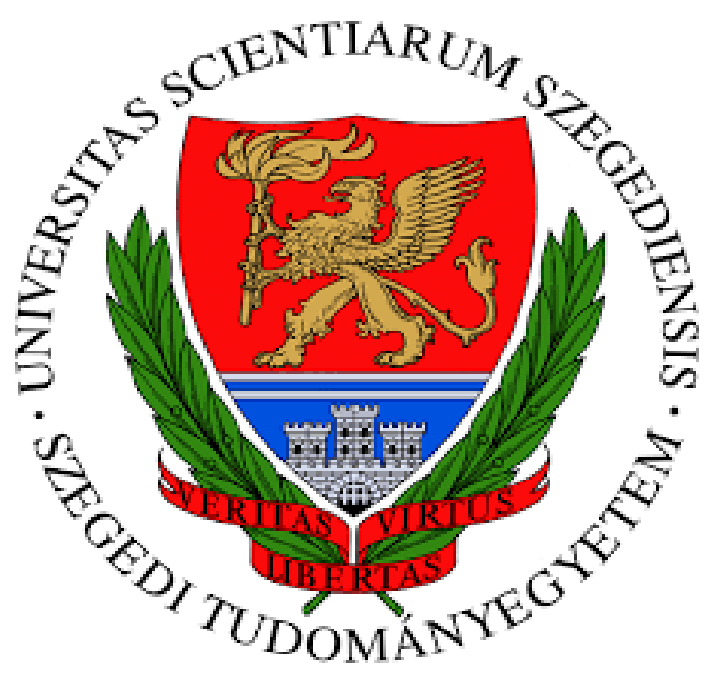

Szeged, Hungary, 2020 


\section{TABLE OF CONTENTS}

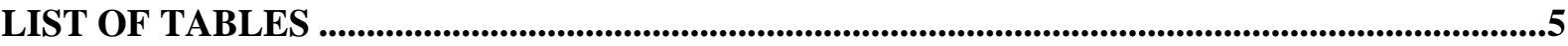

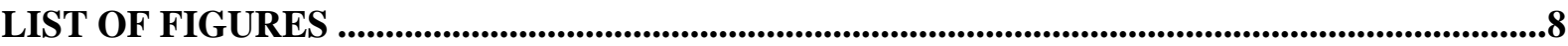

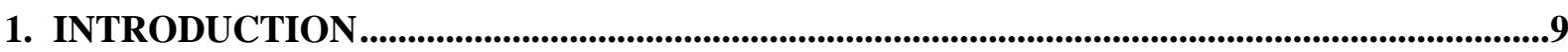

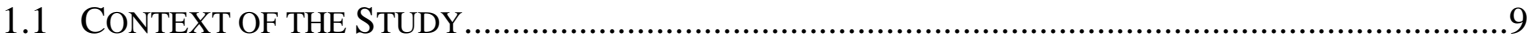

1.2 DEVELOPMENTAL CHARACTERISTICS OF 6TH- AND 8TH-GRADE STUDENTS ............................11

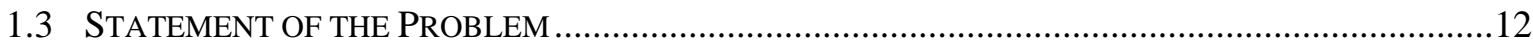

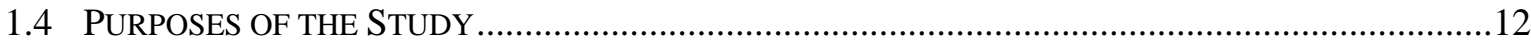

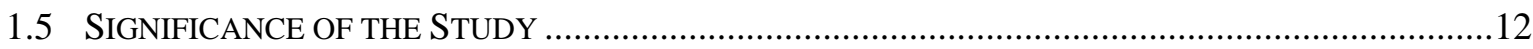

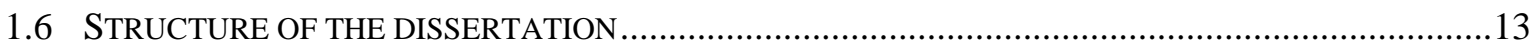

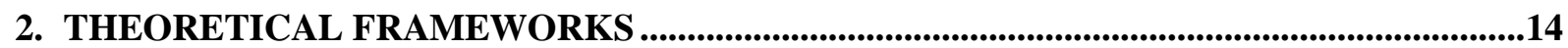

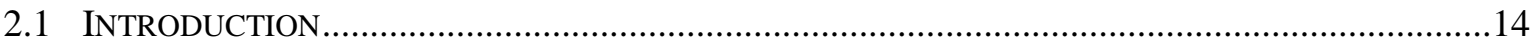

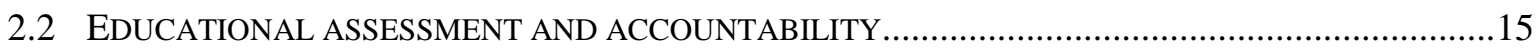

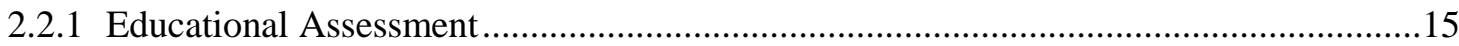

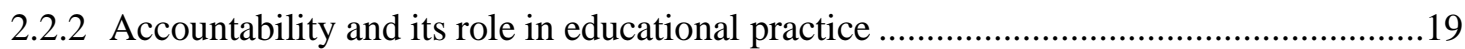

2.2.3 Teachers' beliefs and views about large-scale assessments ............................................21

2.2.4 Teachers' instructional change based on assessment and accountability.......................22

2.2.5 Teachers' test preparation strategies based on assessment and accountability ...............25

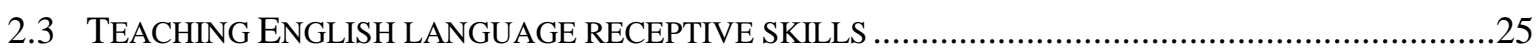

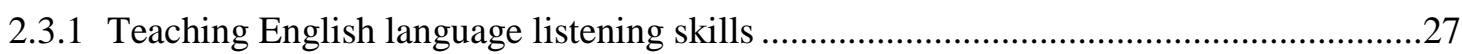

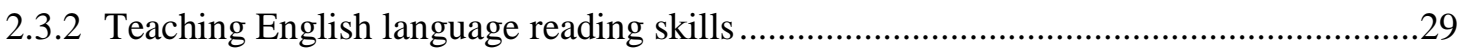

2.3.3 Teaching materials used for developing English receptive skills ...................................31

2.3.4 Out-of-class activities for developing English receptive skills ......................................33

2.4 LEARNING STRATEGIES AND ATTITUDES TOWARDS ENGLISH LANGUAGE RECEPTIVE SKILLS .34

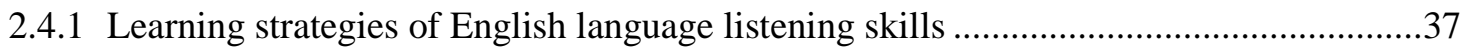

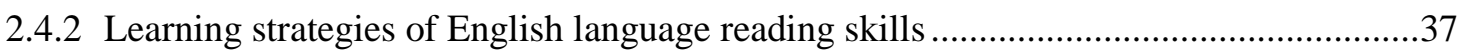

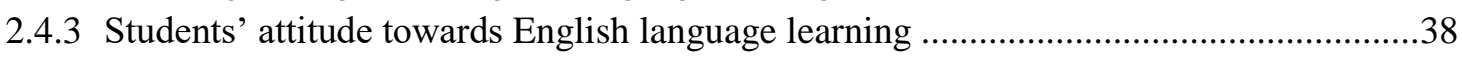

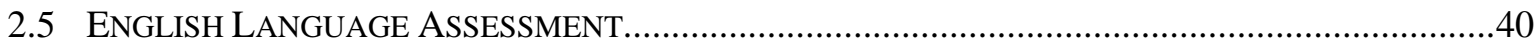

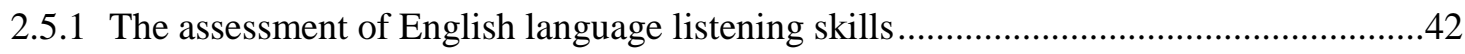

2.5.2 The assessment of English language reading skills..........................................................48

2.5.3 Computer-Based and Online Language Assessment.................................................54

2.6 FACTORS AFFECTING STUDENTS' ENGLISH LANGUAGE LEARNING ACHIEVEMENT ..................58

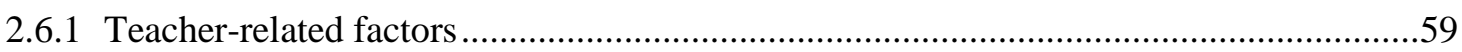

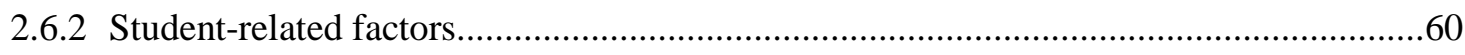

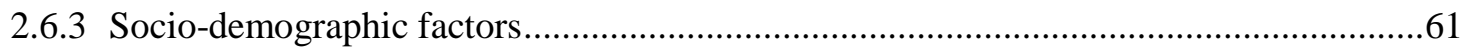

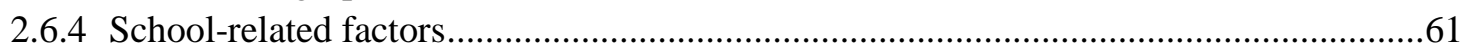

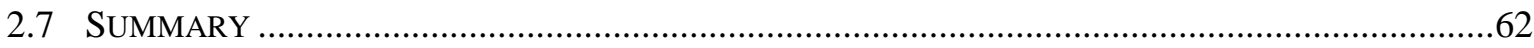

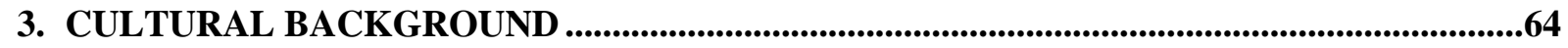

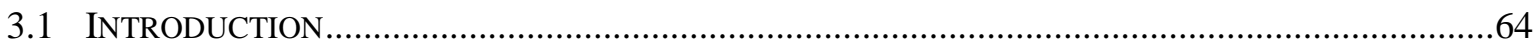

3.2 EDUCATIONAL ASSESSMENT AND ACCOUNTABILITY IN MONGOLIA ……...................................65

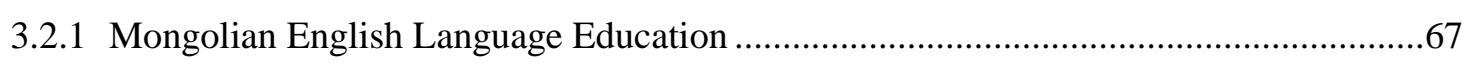

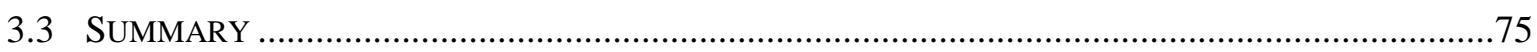




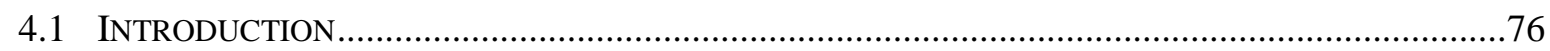

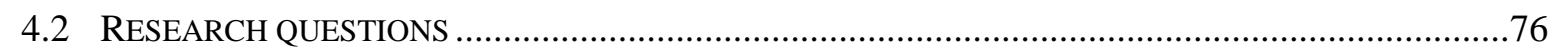

4.2.1 How is educational assessment and accountability used in the Mongolian Education

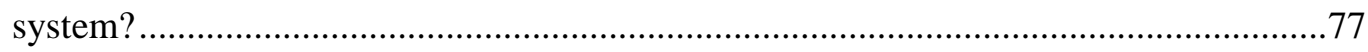

4.2.2 How do assessment and accountability influence English language instruction and

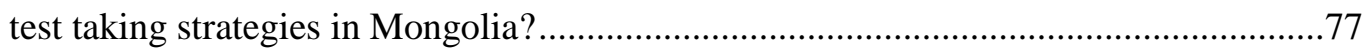

4.2.3 What are the English language teachers' perceptions of teaching ELRS? ........................77

4.2.4 How do students identify their strategies and attitudes towards ELRS? ..........................78

4.2.5 How are the teaching and learning strategies of English language receptive skills

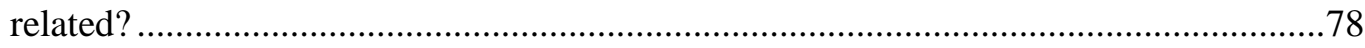

4.2.6 How did students perform on an online test developed for this study to assess their

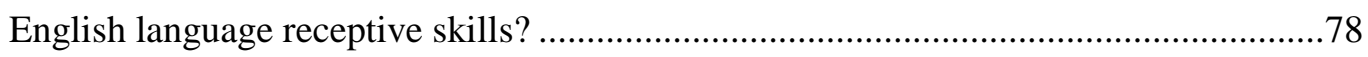

4.2.7 What are the factors affecting students' test performance? .......................................... 79

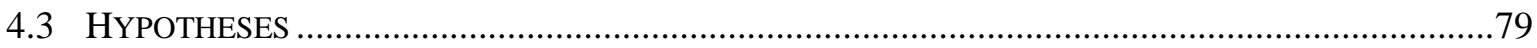

4.4 METHODS

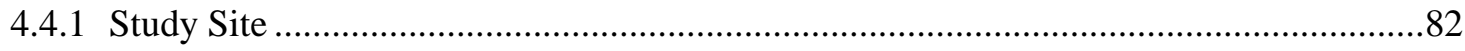

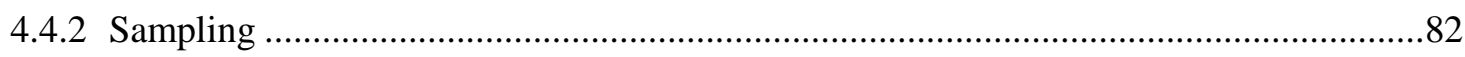

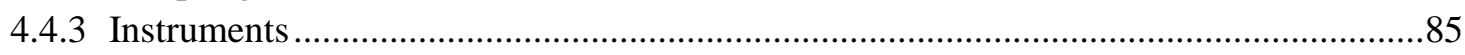

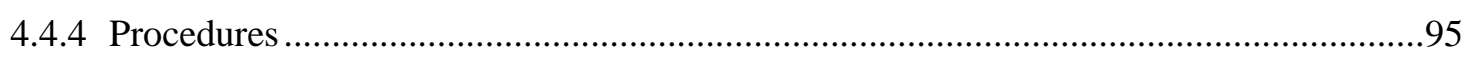

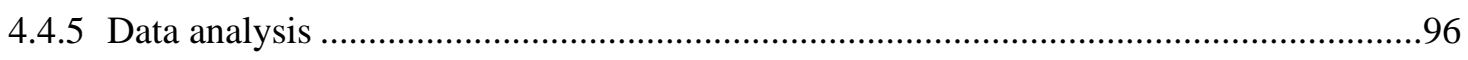

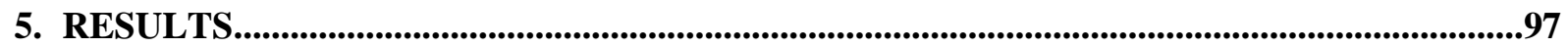

5.1 STUdy 1: How ARE EDUCATIONAL ASSESSMENT AND ACCOUNTABILITY USED IN THE

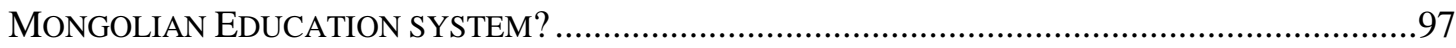

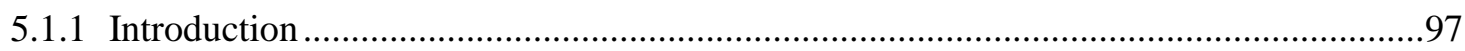

5.1.2 What are the primary and secondary school teachers' beliefs about the usefulness

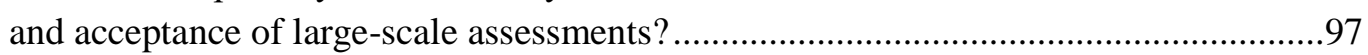

5.1.3 To what extent do teachers feel pressured by the different forms of achievement

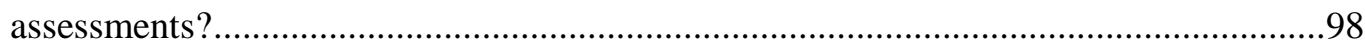

5.1.4 How do teachers reflect on the shift in their teaching practices influenced by the assessments?.

5.1.5 What is the relationship between teachers' view on educational assessment and

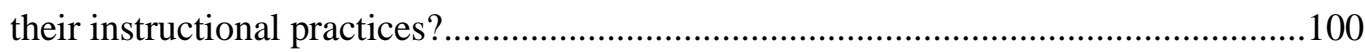

5.1.6 Which test preparation strategies do teachers mostly use? ..........................................101

5.1.7 Who puts pressure on primary and secondary school teachers in order to increase their pupils' achievement? To what extent does this happen? ....................................102

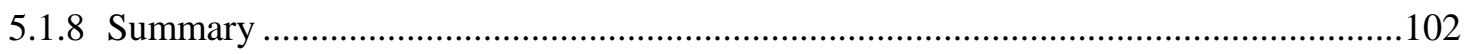

\subsection{STUDY 2: HOW DO ASSESSMENT AND ACCOUNTABILITY INFLUENCE ENGLISH LANGUAGE} INSTRUCTION AND TEST PREPARATION STRATEGIES IN MONGOLIA? .......................................104

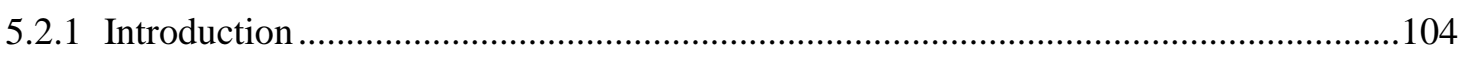

5.2.2 What beliefs do English language teachers have about the usefulness and acceptance

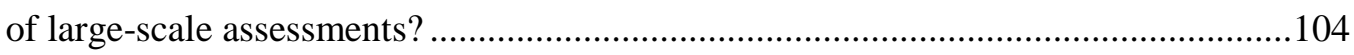

5.2.3 How do English language teachers reflect on the shift in their teaching practices influenced by the assessments?

5.2.4 What is the relationship between English language teachers' view on Educational assessment and their instructional practice in teaching English? 
5.2.5 Which test preparation strategies do English language teachers mostly use?

5.3 StUdy 3: WhAt ARE ENGLISH LANGUAGE TEACHERS' PERCEPTIONS OF TEACHING

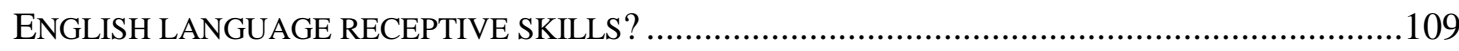

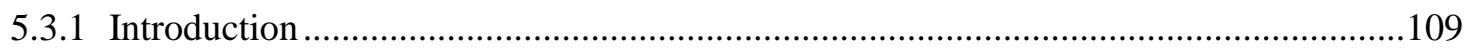

5.3.2 Which teaching English language listening strategies are mostly used? ......................109

5.3.4 Which teaching English language reading strategies are mostly used? ........................110

5.3.5 What teaching materials are frequently used in teaching English receptive skills?......113

5.3.6 How do teachers encourage their students to learn English receptive skills out of class?

5.3.7 What are the relationships between teaching strategies and teaching materials and teachers' encouragement of out-of-class activities? ...................................................114

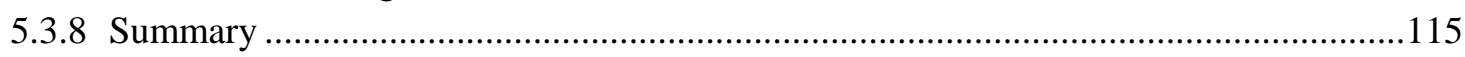

5.4 STUDY 4: How do STUDENTS IDENTIFY THEIR LEARNING STRATEGIES AND ATTITUDES

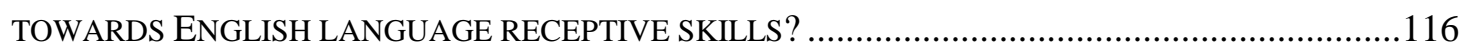

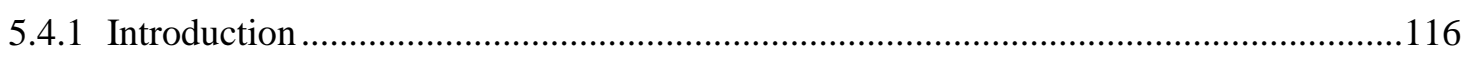

5.4.2 What learning strategies are frequently used for English listening skill by 6thgraders?

5.4.3 What learning strategies are frequently used for reading skills by 6th- and 8thgraders?

5.4.4 What are the students' attitudes towards learning English language receptive skills?

5.4.5 What is the relationship between students' learning strategies and attitudes towards ELRS?.

5.4.6 Summary

5.5 STUDY 5: HOW ARE TEACHING AND LEARNING STRATEGIES OF ENGLISH LANGUAGE

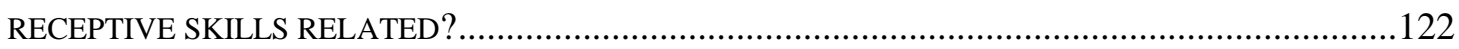

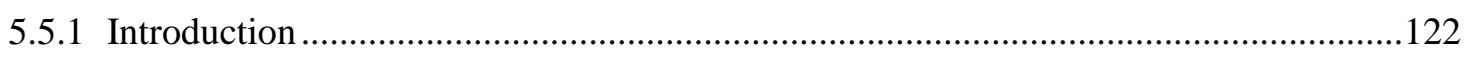

5.5.2 What is the relationship between teaching and learning strategies in English listening class?

5.5.3 What is the relationship between teaching and learning strategies in English reading class?

5.5.4 What is the relationship between teaching strategies and students' attitude towards ELRS?.

5.5.5 What is the relationship between learning strategies and teaching materials and

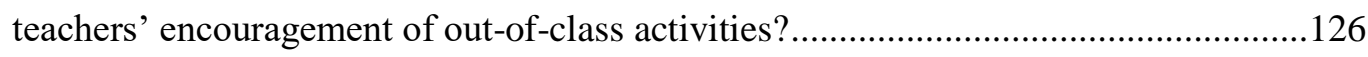

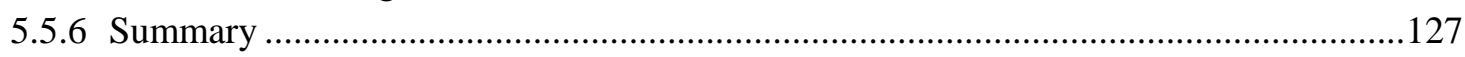

5.6 STUDY 6: HOW DID STUDENTS PERFORM ON AN ONLINE TEST ASSESSING THEIR ENGLISH

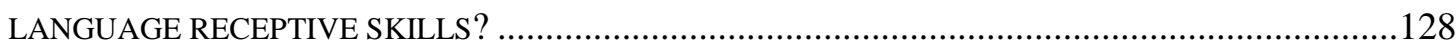

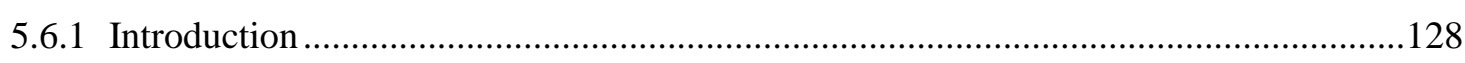

5.6.2 What are the 6th- and 8th'graders' performances in the ELRS test?...........................128

5.6.3 Which tasks and skills are difficult for the 6th-graders?.............................................130

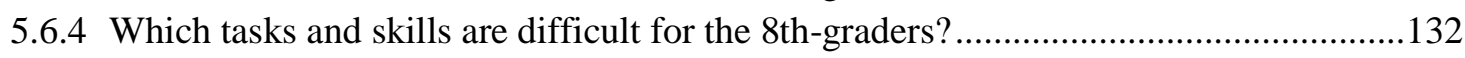

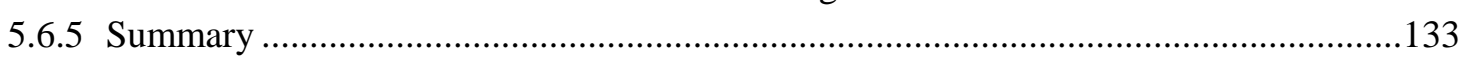

5.7 STUdy 7: WHAT ARE THE FACTORS AFFECTING STUDENTS' TEST PERFORMANCE?................134

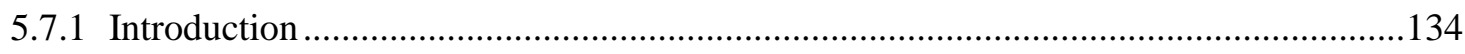

5.7.3 How do teacher-related factors affect students' test performance? ...............................135 
5.7.2 How do student-related factors affect students' test performance?...............................136

5.7.4 How do school-related factors affect students' test performance?.................................137

5.7.5 What is the difference between students who have positive and those who have negative attitude test performances of ELRSs?.

5.7.6 What is the difference between the students who have effective and those who have ineffective use of learning strategies' test performance of ELRSs? .....................140

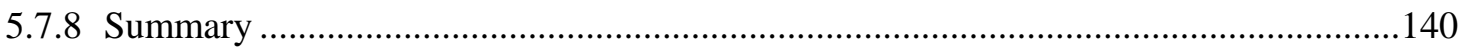

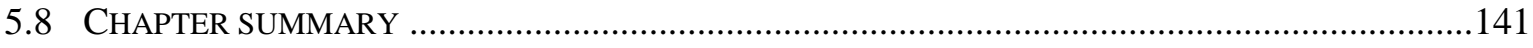

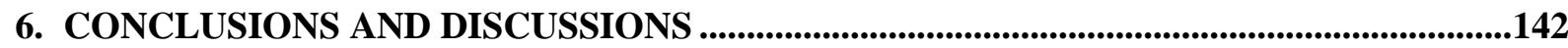

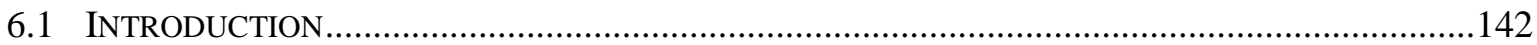

6.2 STUdY 1: How IS EDUCATIONAL ASSESSMENT AND ACCOUNTABILITY USED IN THE MONGOLIAN EDUCATION SYSTEM?

6.3 STUdY 2: HOW DO ASSESSMENT AND ACCOUNTABILITY INFLUENCE ENGLISH LANGUAGE INSTRUCTION AND TEST TAKING STRATEGIES IN MONGOLIA? ............................................143

6.4 STUDY 3: WHAT ARE TEACHERS' PERCEPTIONS OF TEACHING ELRSS? ..................................144

6.5 STUDY 4: HOW DO STUDENTS IDENTIFY THEIR STRATEGIES AND ATTITUDES TOWARDS

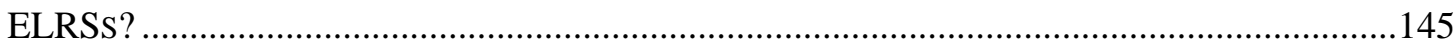

6.6 STUDY 5: HOW ARE TEACHING AND LEARNING ENGLISH LANGUAGE RECEPTIVE SKILLS

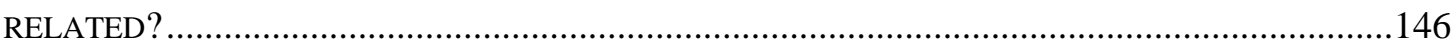

6.7 STUDY 6: HOW DID STUDENTS PERFORM ON AN ONLINE TEST ASSESSING THEIR ENGLISH

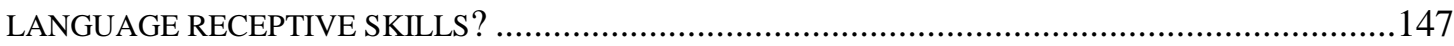

6.8 STUDY 7: WHAT ARE THE FACTORS AFFECTING STUDENTS' TEST PERFORMANCE? ?................148

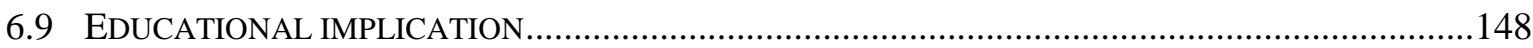

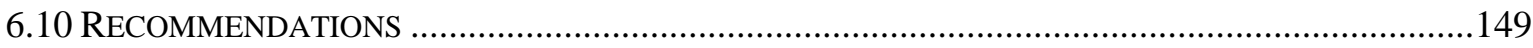

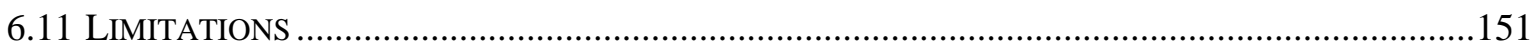

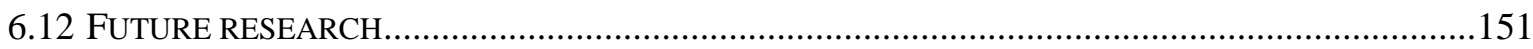

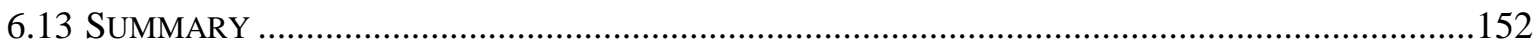

ACKNOWLEDGEMENT ..................................................................................................................153

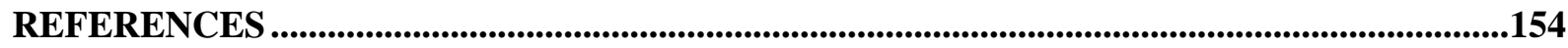

APPENDIX A TEACHERS' OPINION ABOUT EDUCATIONAL ASSESSMENT AND

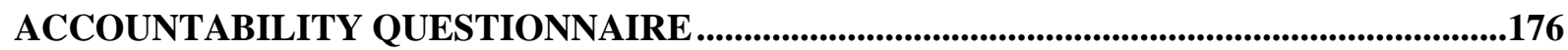

APPENDIX B QUESTIONNAIRE FOR TEACHING STRATEGIES OF ENGLISH

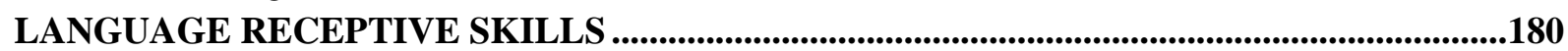

APPENDIX C LANGUAGE LEARNING STRATEGY QUESTIONNAIRE .............................186 APPENDIX D SIXTH GRADE TEST ..........................................................................................................190

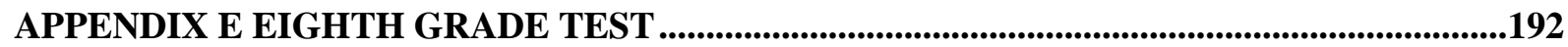

APPENDIX F SCHOOL INFRASTRUCTURE SURVEY .........................................................195 


\section{LIST OF TABLES}

Table 1. Canale's (1983) adaptation of the Canale and Swan's (1980) model (p. 41).....................16

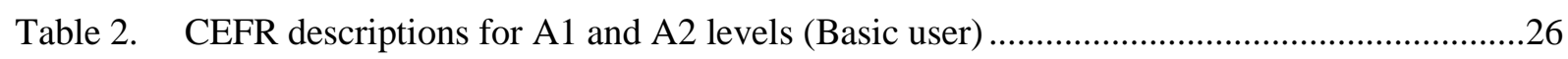

Table 3. The ability of English language listening comprehension for A1-A2 levels .......................29

Table 4. The ability of English language reading comprehension for A1-A2 levels

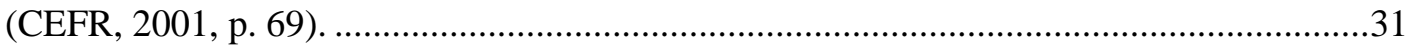

Table 5. Strategy classification system (Oxford, 1990 as cited in Oxford, 2003, p. 12)...................35

Table 6. Models of the listening comprehension process and difficulties..........................................4

Table 7. Micro- and macro skills of listening (Simplified list, Brown, 2003, p. 121) .......................45

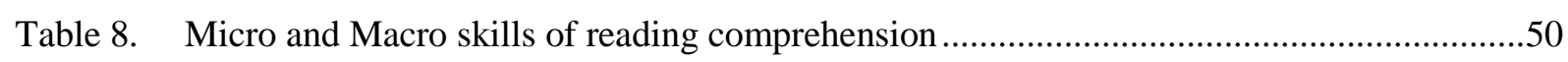

Table 9. Assessment of a Reading Comprehension Instrument as It Relates to Cognitive Abilities as Defined by Bloom's Revised Taxonomy .................................................................52

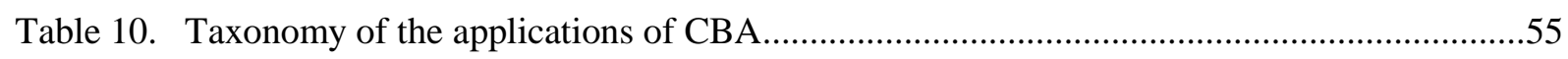

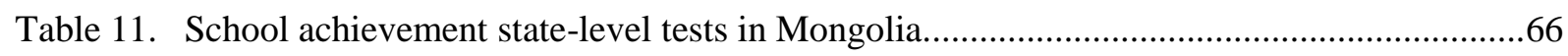

Table 12. Formal and informal assessments taken in schools for different purposes in Mongolia......66

Table 13. Competence codes in Foreign Language Standard (2004)...............................................69

Table 14. The testing criteria of listening and reading skills for 6 th and 8 th grade students...............70

Table 15. The Content and the assessment criteria of EL listening and reading skills for the 6th and

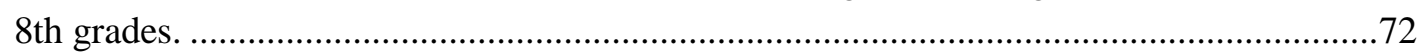

Table 16. Learning objectives of listening skill for 6th and 8th grades. .............................................73

Table 17. Learning objectives of reading skills for 6 th and 8th grades................................................74

Table 18. A summary of the subjects in the main studies and sub-studies .........................................85

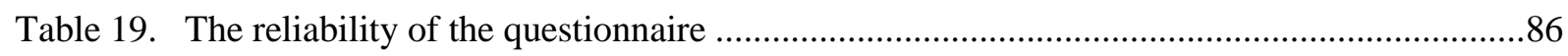

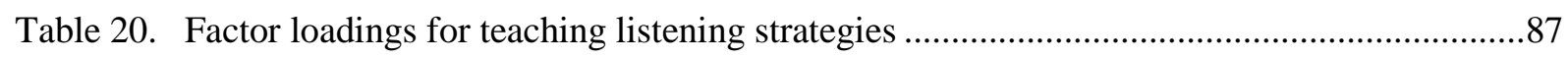

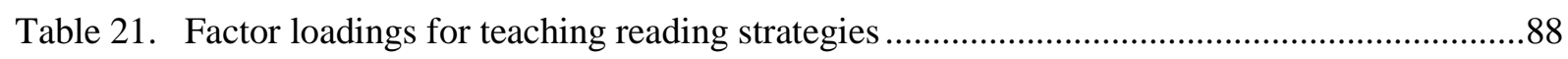

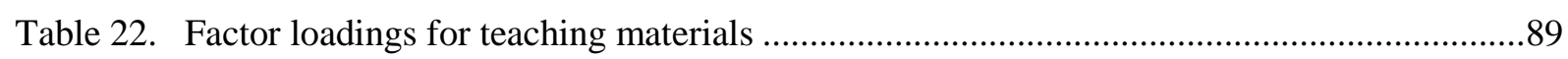

Table 23. Eliminated items from teaching strategy questionnaire …................................................90

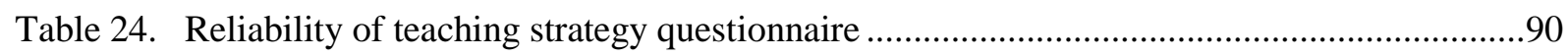

Table 25. Questionnaire classifications of learning strategies based on Oxford (1990). ....................92

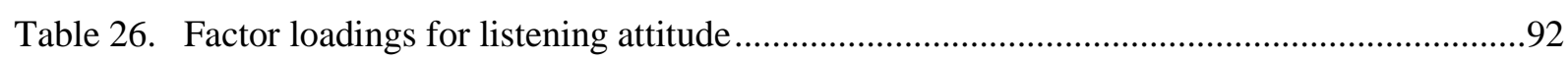

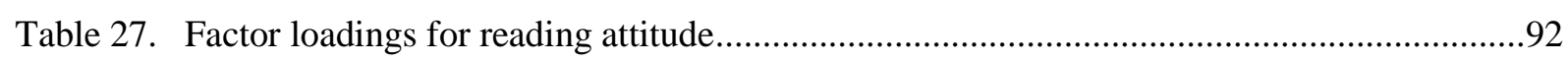

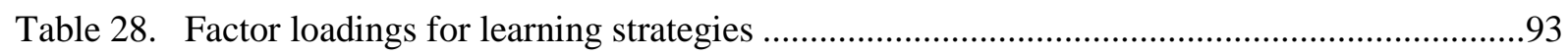

Table 29. Discarded items from learning strategy questionnaire. ......................................................93

Table 30. Reliability of the learning strategy and attitude questionnaire ...........................................94

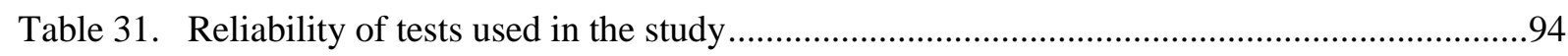

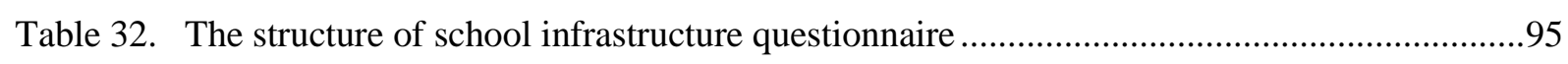

Table 33. The summary of data collection procedure …....................................................................95 
Table 34. Research Questions, Data Source, Focus of Analysis, and Methods of Analysis of the

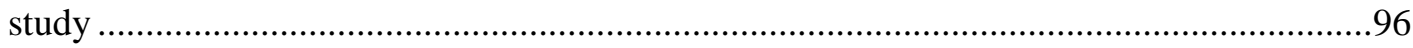

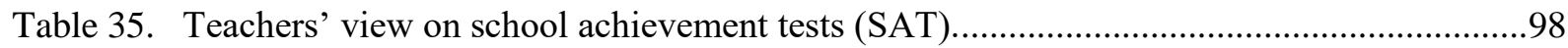

Table 36. The extent of teachers' pressure from different forms of assessments................................99

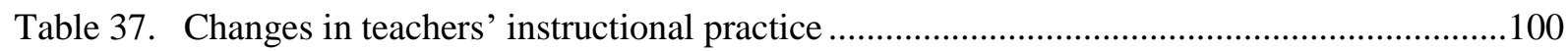

Table 38. The relationships between teachers' view on large-scale assessments and teachers'

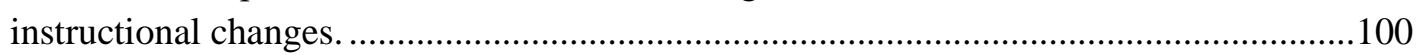

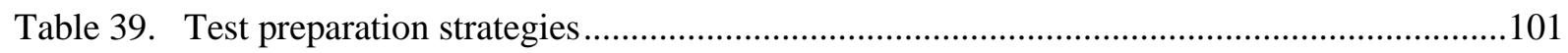

Table 40. The difference between the two levels of teachers' perceived pressure by different

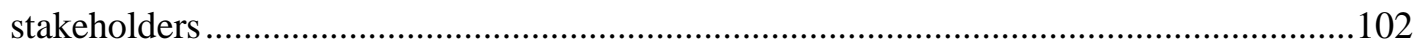

Table 41. Overall teachers' perceived pressure by different stakeholders ........................................102

Table 42. English language teachers' view on school achievement tests.........................................105

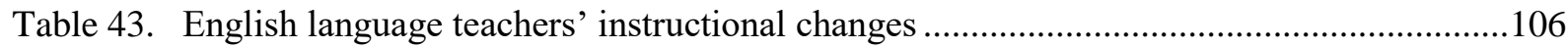

Table 44. The relationship between assessment attitude and teachers' instructional changes ...........107

Table 45. English language teachers' test preparation strategies ......................................................108

Table 46. Five most frequently used teaching listening strategies in each stage of teaching

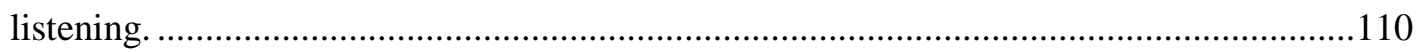

Table 47. The five most frequently used teaching reading strategies.

Table 48. The efficiency of instructional strategies along the factors emerging from the factor

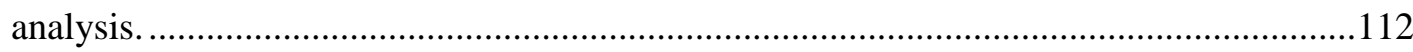

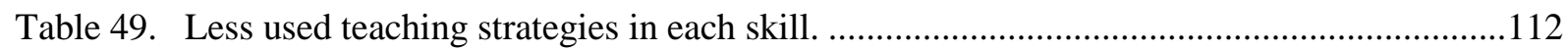

Table 50. Three most frequently used teaching materials for teaching receptive skills .....................113

Table 51. Teachers' encouragement of out-of-class activities. ........................................................114

Table 52. The relationship among teaching strategies and teaching materials and teachers'

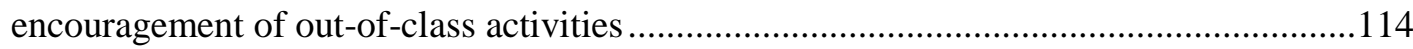

Table 53. Correlations among overall teaching-related factors.........................................................115

Table 54. The frequencies of listening skill strategies by 6 th-graders...........................................117

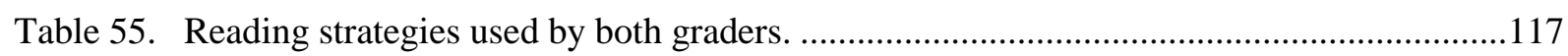

Table 56. The difference between 6th- and 8th-grades' reading attitude ........................................119

Table 57. Correlation between students' attitude towards language skills and language learning strategies.

Table 58. Correlations among six learning-related factors

Table 59. A comparison table for the most frequently used teaching and learning strategies of English listening skills

Table 60. The comparison table for the most frequently used teaching and learning strategies of English reading skill.

Table 61. The relationships between teaching listening strategies and students' attitude towards learning listening skill.

Table 62. The relationship between teaching reading strategies and students' attitude towards learning reading skills. 
Table 63. The relationship among learning strategies, teaching materials and out-of-class activities.

Table 64. Descriptive statistics of test performance .......................................................................130

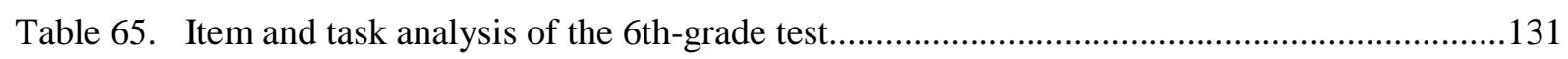

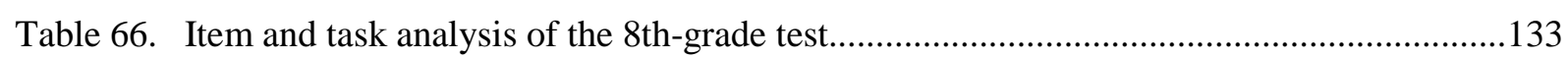

Table 67. Teachers' background and teaching listening strategies affecting test performance. ........135

Table 68. Teaching reading strategies affecting test performance ...................................................136

Table 69. Teaching materials and out-of-class activities affecting test performance.........................136

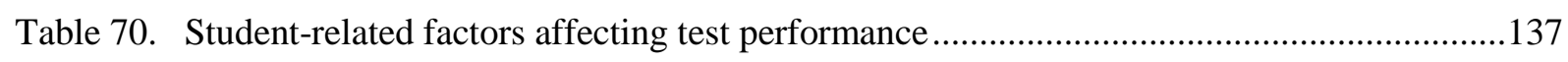

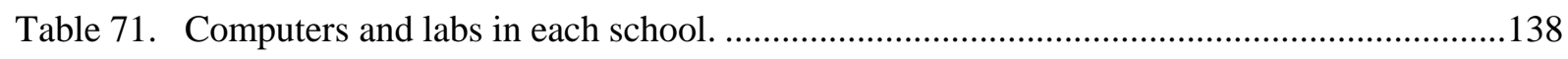

Table 72. School-related factors affecting students' test performance............................................139

Table 73. Difference between two groups of attitudes' test performance of ELRSs in each grade.

Table 74. Difference between two groups of use of learning strategies' test performance of ELRSs in each grade. 


\section{LIST OF FIGURES}

Figure 1. Components of Communicative language ability in language use (Bachman, 1990, p. 42).

Figure 2. Components of Communicative language ability (Bachman \& Palmer, 1996, p. 46).

Figure 3. A model of second language listening comprehension

(Flowerdew \& Miller, 2005, p. 23).

Figure 4. The simple view of reading (based on Gough \& Tunmer, 1986)........................................ 49

Figure 5. Simple view of reading (Hoover \& Gough, 1990, p. 133)............................................... 49

Figure 6. General processing model for multiple-choice paragraph comprehension items adopted from Embertson \& Wetzel, 1987, p. 177)........................................................ 51

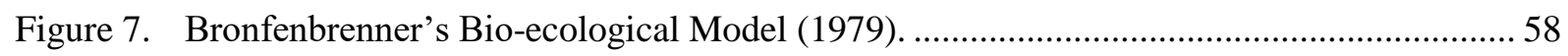

Figure 8. 6th-grade students' attitude towards learning listening skill ........................................... 118

Figure 9. 6th- and 8th-grade students' attitude towards learning reading skill.............................. 119

Figure 10. Item difficulty map for 6th-grade test ........................................................................ 129

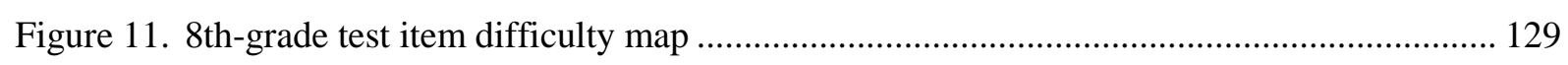

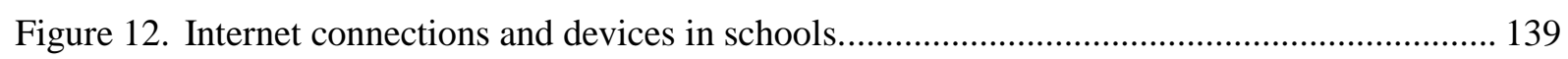




\section{INTRODUCTION}

\subsection{Context of the Study}

Assessment, especially Mongolian educational assessment, related to the learning and instruction of English language education, is the main topic to be discussed in this study. Today's assessment goals are changing from the aspect of selecting and ranking students according to their individual development. Nikolov (2016), commenting on these changes, stated that modern trends in language teaching and assessment are focusing on the contextbased approach which is school curricula and assessment should be context-based and related to the real-life context. Educational assessment and its accountability is currently a major topic that has to be discussed in research trying to improve teachers' instruction related to individual development and students' learning outcomes. The change of instruction in teaching practices and the methods of reducing teachers' feelings of pressure coming from different tests and stakeholders are relevant issues of educational assessment research.

The Ministry of Education, Culture, Science and Sport (MECSS) is the executive administrative body that makes national educational policy and sets the standards for each level of formal education in Mongolia. The general scheme of the education system consists of preschool or kindergarten, primary- (1 - 5), lower secondary- (6 - 8), upper secondary- (9 - 10), high school (11 - 12), technical education and vocational training, and higher education. State level exams are administered by the Educational Evaluation Center (EEC). The EEC's goal is to assess the level of implementing the programs of pre-, primary- and secondary education, to appropriately analyze the national quality of assessment at specific grade levels, and to substantially assess students' knowledge and skills. Statewide exams are given in the 5th, 9th and 12th grades in Mathematics, Mongolian Language, Natural Science, and Foreign Language (English or Russian; EEC, 2016). Other grades are given exams by local educational centers, school boards and teachers at the end of each semester. The aim of these exams is to examine the implementation of each grade's standard. The results are recorded in the students' grade books.

The major documents used in all types of schools in Mongolia include the educational standards, syllabi for each grade, the calendar of the academic year, and the core curricula. Each course in each level of education has their own standards for teachers to follow along with a syllabus, recommended teaching methods, and assessments teachers should use. The standards are guides for teachers as they develop their lesson plans and evaluate students. For example, 
the standard for English language teaching aims to give students the opportunity to handle reallife situations by learning the competencies of socializing, self-confidence, and creating and using English based on their needs in these situations. According to the standard, teachers are expected to use a communicative approach, use student-centered teaching methods, and assess their students' learning achievement based on their competence with language skills, and socialcultural skills. The standards aim to develop students' learning process, establish a successful learning environment, and help teachers develop teaching materials based on their students' age, characteristics and needs.

Core curricula are important documents for educational assessment. They include guidelines for assessment methods and criteria for pre-, primary-, secondary- and postsecondary education. Each core curriculum also has assessment methods and criteria for the final exams and progress evaluation. The progress test is part of a class which aims to support the student learning process, to give students a self-assessment, and to help improve their learning efforts and styles by grading their participation and improvement in learning. The final test is used to assess students' knowledge and skills that should be acquired in each subject based on the educational evaluation standard.

The purpose of educational assessments in the Mongolian educational documents, such as the core curriculum guide or the Educational evaluation standard, is stated using similar meanings. In the educational evaluation standard, there is a requirement for (1) the assessment content to be selected based on the right level of cognitive skill; (2) the tasks to be made to meet with the right skills of the course competency; (3) the methods of assessment to suit the assessing of students' knowledge, ability, and attitude; (4) including students' self-assessment to evaluate teaching and learning results and progress; and (5) the assessment to be respectful, open, and have flexible versions. In the core curriculum document (MECS, 2015, 2016) the purpose of the assessment is defined as "to assess the students' learning process of knowledge, skills and achievement and to improve the quality of education based on the assessment result" (p. 20). The Evaluation of Education Quality (EEC, 2018) is taken every year to assess the school achievement of 5th-, 9th- and 12th-grade students. This evaluation is the base for assessing the implementation of primary-, basic- and complete secondary education programs and curricula.

Additionally, the literature states that assessment is now used for ranking teachers and schools, leading to fears about salary and morale. Those who are more afraid will be less innovative and may be less effective in their teaching and this association can show up in measuring the effectiveness of student's performance on receptive skills. 


\subsection{Developmental characteristics of 6th- and 8th-grade students}

The targeted samples of this study are the 6th and 8th-grade students who are enrolled in the lower secondary education level in Mongolia. Sixth-grade students are in the first year, and eighth-graders are in the last year of lower secondary education. Therefore, it is possible to get a picture of what they have learned during their primary and lower secondary education. Some important studies about the characteristics of those age groups are summarized here for understanding the specialty of the sample.

Some authors have claimed that the 6th and 8th grades are the most sensitive periods in childhood development. In this period, students develop and learn more than in other grades. For example, Piaget (as cited in Hurley, 2008) identified four stages of cognitive and affective development in childhood and adolescence. According to his classification, 6th-grade students are involved in the stage of concrete operations (age 7 to 11 years). During these years, the children develop the ability to apply logical thinking to concrete problems. He also stated that concrete experiences help children understand new concepts and ideas and become more social and less egocentric. The 8th-graders are in the stage of formal operations (age 11 to 15 years or older). Piaget noted that during this stage, the children's cognitive structures reach their highest level of development. They are able to apply logical reasoning to all classes of problems, including abstract problems not arising directly from the child's own experience. He suggested that it is important for language teachers working with children to keep the characteristics of each cognitive stage in mind because the child develops cognitively through active involvement with the environment and each new step in development builds on previous steps.

According to Egan's definition (as cited in Schueler, 1980), 6th and 8th-graders are both in the "romantic layer" of educational development and stated that they begin to seek other ways to explore the world. They make decisions on their own and become more autonomous learners. He suggested instructors to use interesting stories which have complex plots, realistic details and imaginary heroes, and present elements of bravery, power, and creativity to motivate their exploration of an autonomous world.

Similarly, Papaefthymiou-Lytra (2012) stated that students aged 12 to 15 are in a transitional stage between childhood and early teens. They are able to notice changes in their learning process and are motivated by exploring something new and understanding the world around them in a social context.

By narrowing the research to these English language receptive skills (listening and reading) for early (6th and 8th grade) language learners it was possible to give more attention 
and depth in assessing the students' English language receptive skills (ELRSs) than in a larger study that included writing and speaking.

\subsection{Statement of the Problem}

English was deemed to be an official Second Language in Mongolia in 2005. However, it has not reached the goal of universal second language usage; therefore, it is still a Foreign Language in Mongolia. Research is needed to find out the issues behind the slow process of English language education and adoption. Also, little is known about how English language skills are taught currently. Research into what is learned and assessed, especially the quality of teaching and learning fundamental skills, is needed. The role of receptive skills, which people's communication is based on, needs to be developed through certain studies and research. In addition, a lot of tests and assessments are taken in schools for different purposes in Mongolia. English language instruction is more focused on testing than on the students' learning process. This may be caused by the Educational assessment and accountability system, teachers' instructional methodologies, students' learning strategies, or other unknown factors that affect students' learning achievement in Mongolia.

\subsection{Purposes of the Study}

Through my study, I will identify the issues and the reasons behind the instruction, learning and assessment of English language receptive skills (ELRS) in a Mongolian metropolitan area. Also, the study aims to recommend some important considerations for English language teachers and school administrators to improve English language education. These topics have been presented by researchers under the categories of assessment and accountability systems, teachers' instruction, students' learning strategies, and investigations into factors of language learning achievement. Each of these aspects potentially has something important to contribute to Mongolian English language education.

\subsection{Significance of the Study}

Studying English language assessment, learning and instruction at the same time will help the educational administrators and teachers know where their English language education stands, what issues need to be considered in improving English language education, and how can these issues be addressed to improve the assessment and instruction of English language education in Mongolia. Finally, using an online assessment instrument will motivate teachers 
and students to develop their online and computer-based testing and to consider using this resource in their classes for future assessments.

\subsection{Structure of the dissertation}

This dissertation is structured into six main chapters. In the first chapter, the context of the study, the studies' goals, general research questions, statement of the problem, and the significance of the study are introduced. The second chapter is a theoretical reflection consisting of an overview of recent studies about educational assessment, English language assessment, and English language instruction and learning. Chapter three explains how the English language is assessed, taught and learned in Mongolia based on current curricula and standards. Chapter four presents the samples, the instruments, the data collection procedures, and chapter five includes the results of the case studies including the individual results and the results of descriptive statistical analysis, correlation, regression, and test-statistics. A summary of the main results and conclusions, and some recommendations are presented in chapter six. 


\section{THEORETICAL FRAMEWORKS}

\subsection{Introduction}

A lot of children are learning English language in different schools around the world. English language knowledge is increasingly perceived as a basic competence to succeed in life. Mongolia has adopted English language as a second language, and schools are offering English as the main mandatory subject. English is included as one of the main subjects in school achievement tests. The majority of parents often search for schools that offer English Language and that have better quality programs for their children.

Given the recognized importance of English, language education and its assessment are changing from developing students' academic skills to the use of English in real life. Nikolov (2016) noted that one of the best programs of English, documented recently, is content and language integrated learning. Johnstone (2009) and Rixon $(2013,2016)$ remarked that this new development poses new opportunities and challenges for assessment. Nikolov (2016) added that this shift towards assessment and accountability is not limited to foreign language programs. However, there is an international trend in educational assessment for accountability in public education policies in all subjects and competencies. Assessment and its accountability have become inseparable parts of education and, based on the assessment, program accountability calls for the quality of education to be continually improved. However, recent studies indicate that in most cases, assessment is administrated to see that the implementation of standards and curriculum are being met. Based on the results of the study, assessment can be used for ranking the schools, teachers, and students in a bid to improve the teaching and learning process (Nikolov, 2016).

For language education, communicative language teaching has been used as a basic methodological approach for many years. This methodology is a representation of collaborative learning and seeks to improve students' communicative competence and their critical thinking skills, so students can express their ideas, interpret the implied information, and negotiate and solve problems cooperating with others in a foreign language. In the framework of communicative competence, English language receptive and productive skills are usually taught with the stages of before, during, and after activities. It is increasingly recognized that it is important for teachers to take into account their students' language learning strategies and their needs so that the instruction can use appropriate methods that correlate with students' needs and interests based on their preferred learning strategies (Weng, Yunus \& Embi, 2016). 
Despite these best practices, some researchers found that receptive skills are taught based on terminology and standard forms since teachers do not apply methods that improve students' ability to use the language in real life.

Another important issue in language education is to identify what factors can affect students' learning achievement. Many researchers have found factors that influence students' success in language learning. In his literature review Zare (2012) reported the following factors which influenced students' language learning strategies: age, sex, attitude, motivation and language proficiency. Crosnoe, Johnson and Elder (2004) also identified multiple factors and grouped them as student factors, family factors, school factors and peer factors. A number of studies (Lightbown \& Nina, 2013; Macaro, 2010; Fidler, 2002) have investigated the factors that affect students' learning achievements and test performances.

In this section, I will discuss the theories and some important studies about how English language assessment is administered, what is done based on the assessment results, how English language instruction and learning are changed based on assessment accountability, and what common factors affect students' language learning achievement.

\subsection{Educational assessment and accountability}

\subsubsection{Educational Assessment}

Educational assessments and high-stakes tests are used in the classroom for different purposes based on three interconnected elements: the aspect of achievement (cognition), the tasks used to collect information about students (performance), and the methods used to analyze the result (interpretation) (Pellegrino et al., 2001). Vavla and Gokaj (2013) stated the following:

Assessment is an ongoing process which lies in a much wider domain. Every time a student answers a question, gives a comment, or tries to pronounce a new word, phrase or concept the teacher unconsciously makes an assessment of the student's performance. (p. 509)

Additionally, Newton (2007) noted policy makers need to understand the purposes of the assessment system which include the technical aim of the assessment to derive standards, the use of the assessment judgment (decision and action), and the intended impacts of the assessment to ensure that students remain motivated. Therefore, Pedder et al. (2012) noted when teachers and students use assessment for supporting students' learning improvement, they are approaching the true educational purposes of assessment. For the purposes of this paper, assessment in educational practice refers to evaluating each students' academic achievement, 
learning progress, and skills in all educational levels using both formal (tests, journals, audio recordings) and informal (observation, peer feedback, participation) methods. Before assessing students' knowledge and skills, test makers need to consider basic models and frameworks of educational instruction and learning. The most influential model for instruction and assessment of language education is a communicative competence model by Canale and Swain (1980) showing the interaction between grammatical competence and sociolinguistic competence. Later Canale expanded the model, in 1983, distinguishing between communicative competence and communicative performance, the later referring to the actual use of language in real communicative situations. Fulcher and Davidson (2007) noted that Canale's model showed that communicative competence is an effective goal in second language teaching, and this approach allows a more valid and reliable measurement of second language communication skills than trying to measure actual communication or communicative performance. They claimed Canale's model could be used to develop criteria for the evaluation of actual language performance, at different levels of proficiency. See Table 1.

Table 1. Canale's (1983) adaptation of the Canale and Swan's (1980) model (p. 41)

\begin{tabular}{c|c}
\hline Communicative competence & Actual communication \\
\hline Knowledge and skill & \\
Grammatical competence & \\
Sociolinguistic competence & \\
Strategic competence & \\
Discourse competence & \\
\hline
\end{tabular}

This model predicts people communicate effectively when they use their knowledge and skills, grammatical, sociolinguistic, and strategic and discourse competencies together.

Figure 1 below shows an updated version of the Bachman (1990) language communication model created by Fulcher and Davidson (2007). Fulcher and Davidson felt Bachman's model made a distinction between knowledge and skill and they included the processes and components that interact with each other in their model based on the context of the language situation. 


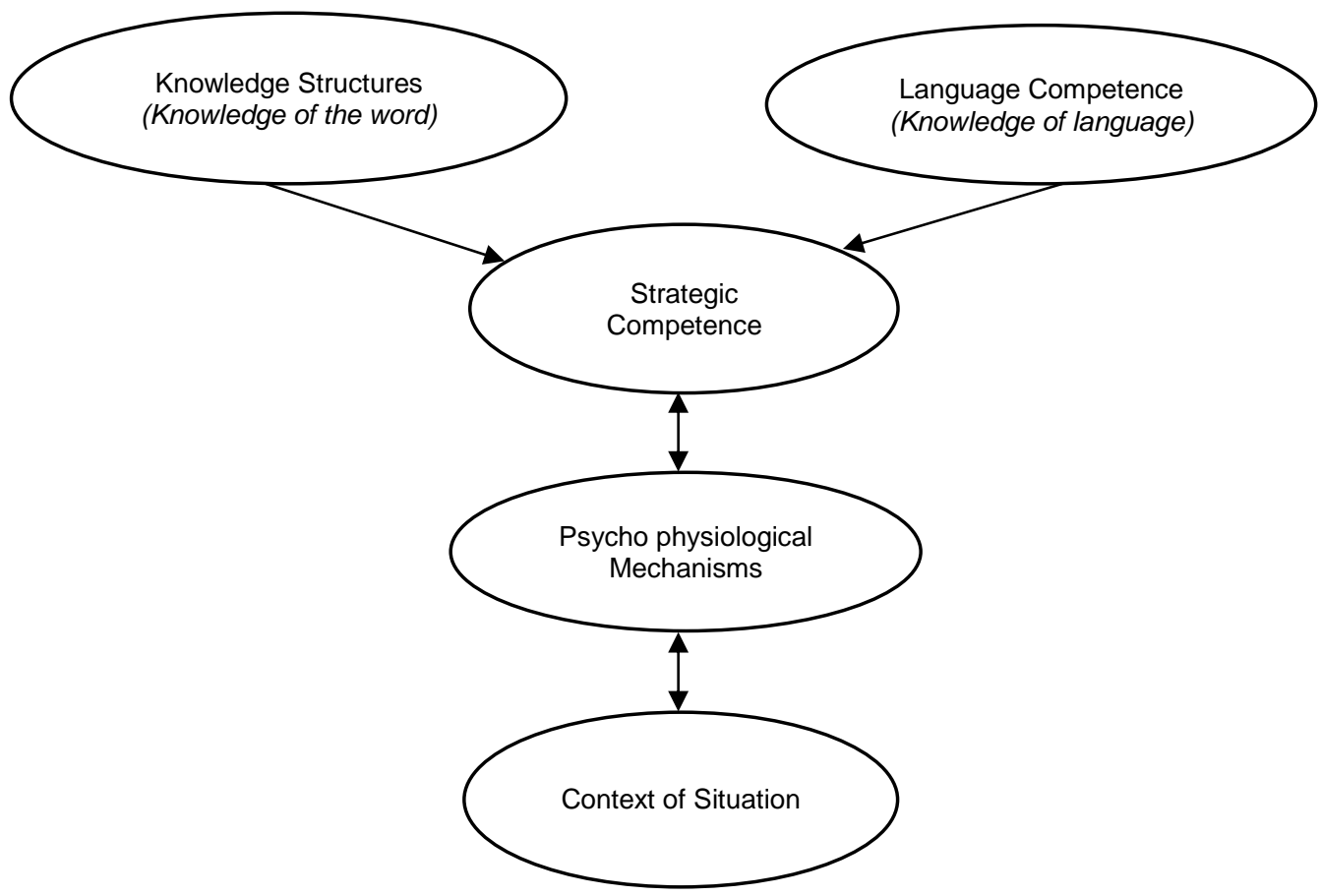

Figure 1. Components of Communicative language ability in language use (Bachman, 1990, p. 42).

We can see from Bachman's model above that knowledge should influence students' strategic competence, psycho physical mechanisms, and their understanding of the context of the situation. This model suggests strategic competence, psycho physical mechanisms, and context are all involved in effective communication.

Improving on this model, Bachman and Palmer (1996) expanded it by adding a strategic competence component in the central role with an affective schemata added to account for the student's interaction with topical knowledge (background knowledge) to produce reactions to which the test developer should be sensitive. See Figure 2.

Bachman and Palmer (1996) suggested their model can be used directly as a checklist to aid in the design and development of language tests (Fulcher \& Davidson, 2007). This model clearly shows that the most influential factor on the language usage is effective strategic competence, and then topical knowledge, language knowledge, personal characteristics are the next influential factors on the usage of language or doing the tasks. 


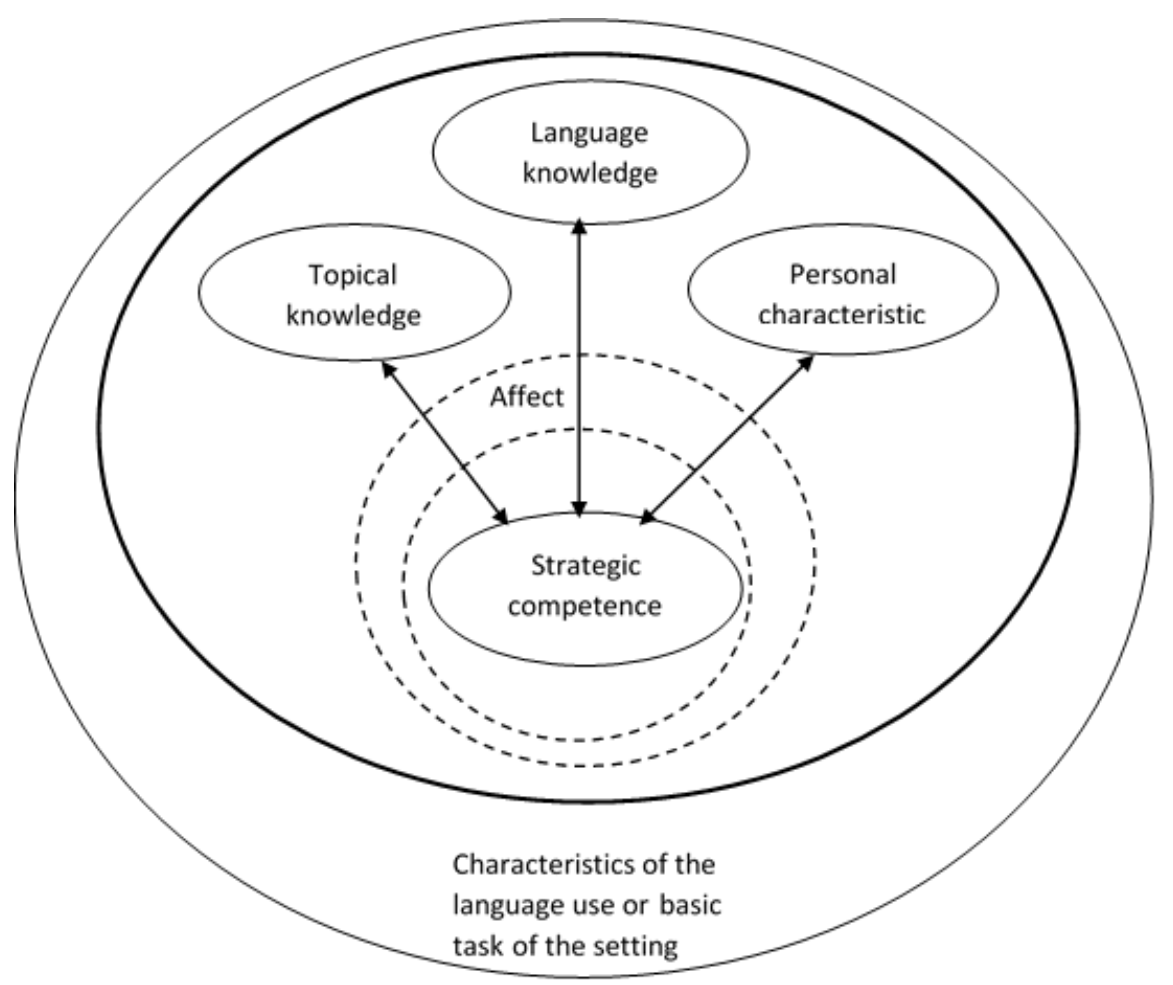

Figure 2. Components of Communicative language ability (Bachman \& Palmer, 1996, p. 46).

In World Language Standards (2010), it was stated that "assessment of student progress is a continual process that teacher[s] employ to reflect on the effectiveness of their instructional design, set high and worthwhile goals for student learning, and determine instructional strategies appropriate to student needs" (p. 41). McNamara and Roever (2006) noted that today's assessment shifts emphasis from how children can benefit from classroom testing to how teachers can scaffold their student's development. They added assessment should be sensitive to the issue of readiness to develop. Hence, it is interesting to consider that these models are really used to create tests to assess students' language competences and the purpose of the assessment is to improve the language competencies and the learning process.

However, other researchers have found the assessment role has deviated from the goal of improving student learning. West and Tsagari (2004) argued assessment and testing practices in schools have followed testing rather than a learning orientation. As a result, teachers and learners have been interested in the product of learning rather than in the process of learning. A focus on the process of learning allows students to become autonomous and independent learners for life. Conley (2015) criticized state-level reading and math tests as these were often the only indicators of student achievement in the past few years and these tests measured only a subset of what was taught and learned, not the students' ability to apply what they knew in 
the real world. The reliability has been taken into account in the creation of tests that include particular skills and knowledge (Fox et al., 2007; Fulcher \& Davidson, 2007). Even though traditional multiple choice tests are more reliable than other tests, don't need much time and cost, and are more familiar to educators to score, they are not able to evaluate the test takers' usage of language skills.

It is important to know for teachers how assessment is categorized and how these categories differ from each other. Summative assessments are given to examine what students know and do not know based on standardized tests; on the other hand, formative assessment is a part of the classroom instruction (Garrison \& Ehringhaus, 2010). Therefore, teachers need to pay more attention to formative assessments to improve instructional practices. There are many types of formative assessments, but teachers need to apply the appropriate ones that match students' needs and the situation when they are assessing a unit or a lesson. For example; a student record engages students and helps them to see how their learning progress is making toward their learning goal.

\subsubsection{Accountability and its role in educational practice}

Assessment and accountability are related aspects because assessment results and the accountability system based upon these results are the tools for teachers to change their teaching behaviour. The role of assessment in educational practice involves four key elements: how accountability interacts with assessments, how teachers conduct and use classroom assessment, how states and districts use assessments for accountability, and how assessments influence postsecondary education choices (National Research Council, 2001). Scott and Paul (2015) stated that state-led school accountability systems have become a prominent feature of the educational landscape. In the USA requirements for such accountability systems were first implemented with the passage of the Elementary and Secondary Education Act in 1965 and it was later reauthorized in 1994, and then in 2001 the No Child Left Behind Act was developed. However, many US educational leaders (Meijer, 2004; Kolodziej, 2011; Hodge \& Welch, 2016; Holbein \& Ladd, 2017) believe the No Child Left Behind Act negatively impacted student learning. Ideally, educational accountability is used for improving the quality of education and it aims to increase student achievement, reduce achievement gaps, and increase efficiencies (Betebener \& Linn, 2009).

In addition, Darling-Hammond, Wilhoit, and Pittenger (2014) stated that "genuine accountability must both raise the bar of expectations for learning — for children, adults, and the system as a whole - and trigger the intelligent investments and change strategies that make 
it possible to achieve these expectations" (Darling-Hammond et al., 2014, p. 5). Anderson (2005) noted three main types of accountability are (1) compliance with regulation, which views the school as the embodiment of constant process and educators are accountable for adherence and bureaucracy; (2) adherence to professional norms, which is based on adherence to elevate education as a profession; and (3) results driven, which is based on results of student learning where educators are accountable to the general public.

Some researchers suggested how assessment accountability can be developed and what the most important thing is that should be used in an accountability system. For example, Hargreaves and Braun (2013) suggested that a competency-based approach to instruction, learning and assessment, integrated with an internally oriented approach to accountability would be better for school improvement. Also, Braun (2012) stated that utility (usefulness in practice) is the most important technical criterion by which we can judge the quality of accountability systems and Hargreaves and Braun (2013) mentioned that utility can change the accountability from labeling and sorting to using the results to bring about improvements in schools and student learning. Terenzini (1989) stated, since assessments measure the learners' acquisition of particular knowledge or skills that were taught in the classroom, these results should be used as a mechanism for improving instructional quality and student achievement. Similarly, Gardiner (2000) explained that assessment is best used not only for developing individual students but also for improving the quality of educational programs. Also, according to the National Research Council (2001), reporting assessment results to students, teachers, parents, policymakers, and the public can be useful for making consequential decisions about students, teachers, or schools.

Another tool used in accountability systems is the Innovative Laboratory Network which has been introduced to the current accountability system with a goal of deepening and improving student learning (Marion \& Leather, 2015). Looney (2011) highlights the following three primary objectives of accountability systems among OECD countries: (1) accountability, (2) support for institutional and system-level improvement, and (3) classroom-based formative assessment in support of the teaching and learning process. A test-based accountability system provided rewards and sanctions based on large-scale achievement tests and it played a key role in an accountability system to improve students' test achievement. The tests used for such purposes were "high-stakes" tests administered by external proctors to a particular classroom or school, along with "low-stakes" tests, which were used only to provide information on student performance (Hamilton, Stecher, \& Klein, 2002). Other researchers note that low-stakes 
assessments have been administered by stakeholders with institutional-level dissemination of assessment results (Figlio \& Loeb, 2011; Hamilton et al., 2002).

In Mongolia, state level exams are administered by the Ministry of Education to monitor the level of implementing educational standards for primary, lower secondary, and upper secondary education. The exams are taken by 5th-, 9th-, and 12th-graders in Mathematics, Mongolian language, Science, and Foreign (English) language. In addition, there are other official exams to assess students' achievement levels in different subjects for different purposes administered by local educational centres. In the core curriculum, the purpose of the assessment is defined as "to assess the students' learning process of knowledge, skills, and achievement and to improve the quality of education based on the assessment result.” (MECS, 2015, p. 20)

Assessing students' learning progress is an important tool for developing the quality of curricula, instruction, and students' learning outcomes. On the other hand, frequent state assessments may influence teachers' instruction and test preparation strategies depending on how the results are reported, how accountability measures are applied, and how teachers and students feel about the pressure from the assessment accountability report. Brown (2015) concluded that the challenge for school leaders is substantial. He mentioned school leaders must lead their teachers into changing classroom practices based on analyzing assessment data, must have deep expert knowledge in the content areas being considered, and must understand how teachers think about accountability pressures, and must be adept at leading school-based assessment efforts for educational improvement by raising teachers to a professional view about the use of assessment data.

\subsubsection{Teachers' beliefs and views about large-scale assessments}

Barnes et al (2014) stated that understanding teachers' conceptions and beliefs about the national assessment context can help to explain cross-cultural differences in their opinions about large-scale assessments. Teachers' beliefs from similar school context and socio-political background can result in shared beliefs about the purpose of assessment. Earl and Katz (2006) defined the purposes of assessments to help to identify how to plan instruction; to acquire learning documents that show what students have achieved, and to engage students and teachers in educational learning experiences themselves. Earlier, Brown (2002) identified four major conceptions of assessment given by teachers. First, assessment improves both teaching and learning. Second, it makes students accountable by grading them. Third, it is used to hold schools and teachers accountable by showing the quality of education. Fourth, it does not play a significant role in education because it affects learning negatively. Similarly, some 
researchers, for example, Remesal (2011), noted that conceptions of assessment might be related to the structure of the assessment system and the role of assessment used in teaching and learning. Önalan and Karagül (2018) found that Turkish EFL teachers' beliefs on assessment were strongly in favor of using assessment for formative purposes and selfassessments to improve the quality of the instruction. However, these teachers felt that summative assessment was not necessary in language teaching. Barnes et al. (2017) also conducted research among US teachers and found that teachers believe assessment was significant for accountability and informing teaching and learning. Different beliefs about assessment may influence teachers' engagement with assessment practices and impact their professional growth as teachers.

Brown and Gao (2015) found that Chinese teachers think policymakers should pay more attention to some high-stakes examinations and of the role exam marks play as the only standard for enrolment into higher levels of schooling. These teachers felt such administration models and ranking of schools according to their resources and student performance in public examinations plus large class sizes reduced their active implementation of the true academic purposes of assessment.

These conceptions and beliefs about assessment, as the literature indicates below, impacts the effects assessments have on the content of instruction such as the strategies used to deliver instruction, test preparation, and the psychological (pressure) impacts of the test on both teaching and student learning.

\subsubsection{Teachers' instructional change based on assessment and accountability}

Early research indicates different directions of the impacts of high-stakes tests. Thus, they have both negative (anxiety and fear) and positive (changes of teaching instruction and test taking strategy) effects on learning and teaching practices. External pressure can lead teachers to critically revise their practices and adapt effective teaching strategies (Terhart, 2013). In contrast, Hamilton et al. (2002) argued that test-based accountability can also lead to negative reallocation of instructional time to focus on tested aspects of the standards to the exclusion of untested aspects of the standards. English language instructors are encouraged (Baker \& Westrup, 2000) to use many methods to teach receptive skills in pre-stages and post-stages. On the other hand, Alkaff (2013) noted that students concentrate more on terminology and that they are usually tested with multiple choice questions because of limited practice on everyday interactions in the classroom. 
Tóth and Csapó (2011) explored how Hungarian teachers in elementary schools felt pressured by different stakeholders than their counterparts in upper secondary schools. However, they claimed that greater incentives and heightened external pressure were needed to induce school agents to raise educational quality. Hamilton et al. (2005) noted that the integration of mechanisms of educational accountability system can positively affect the quality of education. As they reported,

the mechanisms — incentives, information, and assistance — are likely to affect student achievement primarily by altering what occurs in the classroom: Incentives are intended to motivate teachers to focus on the goals embodied in the standards, information from tests should provide data to guide instructional decision making, and assistance should help them improve their practice (Hamilton et al., 2005, p. 3).

According to Hamilton et al. (2002), test-based accountability can lead educators to work harder and to adopt better curricula or more-effective teaching methods. It can lead to coaching students to perform better by focusing on aspects of the test that are relevant to the domain the test is intended to represent. Due to a test-based accountability system, teachers may pay more attention to test-taking strategies. Often, multiple-choice state school achievement tests differ widely from the format used in classroom tests. Pederson and Yager (2014 in Ngang, Hong \& Chanya, 2014, p. 536) remarked that

becoming a highly qualified teacher in today's educational system is dependent on how well teachers work together with their principals and colleagues. Through collective work, teachers explore the potential to practice more effective decision making as a skill for supporting acquisition of additional professional knowledge and skills.

A number of other studies have shown that test-based accountability programs have had a positive impact on students' test scores (e.g. Carnoy \& Loeb, 2002; Jacob, 2005; Linn \& Dunbar, 1990; Nichols, Glass \& Berliner, 2012).

In contrast, Boyd et al. (2008 in Fuller \& Ladd, 2012, p. 13) noted that teachers avoid high-stakes tests that may induce teachers' anxiety of unwanted inquisition, loss of flexibility in classroom practices, a feeling of coercion to teach based on the test, and fear for their jobs. Tóth and Csapó (2011) found that in Hungary, teachers' beliefs about changes in their teaching are rather similar in elementary and lower secondary schools. However, the level of agreement in the case of many of the statements differs between elementary and upper secondary school teachers. In Hungary, teachers typically refuse to narrow down the curriculum due to the national assessment system; they focus their efforts more on students with poor results in the state tests by giving extra-curricular tutoring. 
Koretz et al. (2001) found that test-based accountability has no effect, or even a negative effect on students' knowledge and skills. Hamilton et al. (2002) points out that test-based accountability can also lead to negative reallocation of instructional time to focus on tested aspects of the standards to the exclusion of untested aspects of the standards. In addition, highstakes testing may become a barrier to the development of intrinsic motivation as its implementation is generally accompanied by a high amount of pressure on students and teachers (Moore \& Waltman, 2007). Thus, the various studies reviewed above show the usefulness of test-based accountability systems. Herman and Golan (1991) noted that high-stakes testing leads to a narrowing of curricula and instruction, and such testing appears to influence teaching and learning within schools. Teachers spend most of their time and attention on increasing students' test scores rather than focusing on student learning. Thus, state test results, under conditions of accountability pressure, remain a critical issue to understand when designing and implementing accountability measures. Meaningful learning requires a critical approach based on the productive use of assessment in stimulating educational reform.

The NBETPP (National Board on Educational Testing and Public Policy) (2003) reports that teachers often spend more time on subjects that are tested with high stakes, and less time on non-tested subjects. Therefore, students have limited time to practice with fine arts, physical education, foreign language, and other extra-curricular activities. Similarly, Abrams, Pedulla and Madaus (2003) and Abrams (2004) conducted a survey among Florida teachers and the result showed that teachers had reallocated instructional schedules, allowing for more time to be spent on tested content while reducing the time for the material that would not appear in the large scale assessment. Hence, they reduce the time spent on fostering activities in order to prepare students for the state test.

Hadley (2010) carried out a survey among 12 school principals from eight different district schools in the state of Utah to explore their opinions about how high-stakes testing impacts teaching and learning. The findings showed that principals were concerned that teachers should teach a curriculum that would result in improved test scores. Additionally, the principals encouraged teachers to use the results of large-scale assessments to guide their instruction to produce high test scores. Eslami-Rasekh and Valizadeh (2008) conducted a survey on Iranian young EFL teachers. They responded that they felt more successful in applying instructional strategies than in managing an EFL class. They also reported that their ability to motivate and engage students to learn English was not as high as their ability to use instructional strategies. 


\subsubsection{Teachers' test preparation strategies based on assessment and accountability}

Clearly, educational researchers should pay attention to teachers' test preparation strategies caused by large-scale assessment and accountability systems. In the NBETPP report (2003), teachers responded to some questions related to preparing their students for the statelevel test such as test preparation methods and amount of time spent on test preparation. They stated that more time is spent due to high-stakes tests with intense preparation using materials that closely resemble the test. Also, they try to motivate their students to do well in the state test.

In addition, the majority of teachers changed their assessment practices by modeling their own classroom tests following the format of the state test. Abrams et al. (2003) report that teachers from high-stakes states spend more time than do their counterparts in low-stakes states preparing students for the state test. Abrams (2004) also found that in Florida, many teachers and schools are highly stressed by the pressure to improve student test performance. Sixty-three percent of teachers indicated that the pressure was so high that they had little time to teach anything that would not appear on the test. Furthermore, the majority of them reported that they found ways to raise test scores without improving learning. Hadley (2010) remarks that test subjects and test preparation activities restrict the amount of time spent on a particular subject, and the tests dictated the kind of teaching strategies used, resulting in fewer activities, less creativity, and less benefit to the students.

Besides test preparation strategies, instructors also need to encourage students to set their goals for meaningful learning. Support the mastery goals to understand the materials by the deeper learning process, not by practicing on tests. Mayer (2008) cited that the students who have performance-approach goals tend to memorize to do well on tests and avoid new, challenging and cooperative tasks (Midley et al., 2001).

\subsection{Teaching English language receptive skills}

When people learn a second language, they usually learn to listen first, then to speak, then to read, and finally to write like the way learning their native language (Levine, Howard \& Moss, 2014). In this model, learners should first be equipped with receptive language skills before working on productive language skills. They gain access to language input through listening and reading receptive skills. The skills needed to engage in speaking and writing are described as productive skills while listening and reading skills are said to be receptive skills. Prasad (2013) stated that the terms "productive" and "receptive" are an improvement over 
earlier active and passive skill representations, which are now used to describe the collaborative nature of one of the aspects of communicative competence as students engage in interpretation, expression, and negotiation communication activities.

English language instructors are encouraged to use many practices and methods to teach receptive skills. A recommendation outlined by Grow and Leblanc (2015) contains five overarching best practices for teaching receptive skills:

First, the instructor should require the learner to attend (i.e., observing response) prior to presenting the antecedent stimulus. Second, the task should be presented in a way that eliminates or substantially reduces the risk of the instructor providing inadvertent cues. Third, the instructor should arrange the antecedent stimuli to increase the likelihood that appropriate stimulus control will be established. Fourth, the instructors should select an effective prompt fading and use differential reinforcement to transfer stimulus control from prompts to the relevant antecedent stimuli. Fifth, if faulty stimulus control is suspected, the instructor should troubleshoot the existing problems with stimulus control to determine if a strategy should be implemented to remediate the faulty control. (pp. 56-

On the other hand, receptive skills are often taught based on terminology and forms, not in active settings using real-life communication. Alkaff (2013) said in these cases, students concentrate more on terminology and they are usually tested with multiple choice questions because of limited practice on everyday interactions in the classroom. This results in lower receptive skills and suggests that the quality of teaching receptive skills in the classroom needs to continue to be studied and improved.

The target group of this study is 6th and 8th-grade students at the secondary school level in Mongolia. For this group, English is taught based on the Common European Framework of Language Reference (CEFR; 2001) at the A1-A2 levels. In these levels students are asked to acquire the following general abilities as described in CEFR (2001). See Table 2.

In this framework of A1 and A2 levels, students are expected to use everyday phrases to introduce themselves, their family and relatives, and surroundings, and to have simple conversations in some public places such as shops and workplaces. These are considered the very basic levels of English language acquisition. CEFR encourages a communicative approach to teaching but it isn't broken down by grade levels. Each country has to create lessons, textbooks, and assessments based on the framework. Mongolia has core curriculums for each education level including each grade, subjects, and its learning objectives, assessment criteria. This will be discussed in the section on the context of the study. 
Can understand sentences and frequently used expressions related to areas of most immediate relevance (e.g. very basic personal and family information, shopping, local geography, employment). Can communicate in simple and routine tasks requiring a simple and direct exchange of information on familiar and routine matters. Can describe in simple terms aspects of his/her background, immediate environment and matters in areas of immediate need.

\section{A1}

Can understand and use familiar everyday expressions and very basic phrases aimed at the satisfaction of needs of a concrete type. Can introduce him/herself and others and can ask and answer questions about personal details such as where he/she lives, people he/she knows and things he/she has. Can interact in a simple way provided the other person talks slowly and clearly and is prepared to help.

Note. From CEFR, 2001, p. 26.

\subsubsection{Teaching English language listening skills}

Frequently used similar definitions of English language listening skills can be found in Field (2008), Nation and Newton (2009), and Vardergrift and Goh (2012). For example; Vardergrift and Goh (2012) provided the following definition: "listening is the ability to extract information from spoken English and it is a complex, dynamic, active and two-sided (bottomup and top-down) process during which learners deduce and attribute meaning and interpret what they heard" (p. 23). According to Nor (2014), listening skills are a foundation for language learning and cognitive development, and they play an important role in communication in life. As mentioned in the definition of listening, the activity requires top-down processes listening for the main idea, predicting, drawing an inference, summarizing, and bottom-up processes concentrating on specific details while listening, and recognizing word-order patterns, etc. Listening skills are interrelated to speaking and instructors can use their spoken instructions to augment audio materials in listening activities to improve their students' listening ability. Also, Thomson (2012) suggested giving five seconds to students after asking a question to think about what has been asked and to provide students with the opportunity to comprehend. He added repeating key instructions or points, paraphrasing, and using slower and clear speech in the targeted language helps students better comprehend what is being said and helps students become familiar with many different examples of authentic language.

There are many methods and techniques recommended by researchers to teach English listening skills. Lakshmi and Reddy (2015) noted that computer-assisted language learning (CALL) can give shy and inhibited students the opportunity to better understand spoken 
language; CALL has been shown to improve students' listening skills as well as their academic achievement. It also raises students' motivation by increasing their confidence, encouraging them, and broadening their listening and oral skills. Similarly, Majid (2011) suggested using a social network to improve listening skills. Rich media, for example, can promote and maintain student motivation, curiosity, and interest in listening to lessons. He stated that once student motivation has been maintained, students will become autonomous learners and studentcentered learning can be achieved. In addition, songs help language learners to develop both their listening comprehension and their pronunciation. Ghanbari and Hashemian (2014) stated that if most lyrics of the songs are interpreted with regular practice this may improve students' prediction and comprehension skills. Also, songs can make learning more enjoyable and interesting and, students learn the target language by feeling comfortable in a relaxed atmosphere. Liao (n.d) addressed the importance of collaborative learning in listening acquisition. He stated that students not only listen to one another but they also learn from one another about how the ideas form, about how to express their point of view, and about how to clarify their own thinking. He also noted teachers need to pre-teach new vocabulary, give students questions to follow, and they should not spend too much time on grammar structure in listening tasks.

Palmer (2014), Gilakjani (2011), Liao (n,d), Baker and Westrup (2000), and Lindsay (2000) suggested that English language instructors need to use before, during, and after listening strategies in the classroom to let students better comprehend the spoken text. They suggested that before-listening activities ask students to think of things they already know about a topic. This helps students to build connections in their mind between what they know and new information they will hear; to make guesses about what they may learn as they listen; to go through the list and think about what they know about the topic. If they don't know the words, ask them to talk with a friend or use a free audio dictionary, for example; www.dictionary.com. During listening activities ask students to identify questions to ask from other classmates, to preview activities they need to complete after they listen, or to turn the title of an assignment into a question. Students can also write notes while listening so that these notes can help them remember ideas later. In after-Listening activities ask students to say what was difficult or easy to understand using their notes, to summarize what the assignment was about by testing themselves on their notes, and to read and listen to other sources for more information about the topic and share these ideas with other students.

Teachers, according to Lindsay (2000), should identify the purpose of the listening activity and think about the skills required and the level of the listening activity as they prepare 
their lesson. Teachers should adjust the lesson to fit the needs and abilities of their students. Lindsay states that one purpose of listening, in addition to helping with pronunciation, is to help students understand "authentic language." Authentic language is the language used by everyday speakers, which is different from sound files created for use in the classroom. Students should have a chance to listen to authentic language, maybe from Internet news or TV shows, YouTube, or English songs that were not created just to teach English. However, Lindsay warns that teachers will need to keep these listening materials very short and do a lot of pre-teaching to help students understand authentic language.

As mentioned above, the targeted groups for this study are 6th and 8thgrade students. Their goal is to acquire the ability of English language listening comprehension for A1-A2 levels described as follows in CEFR (2001). We can see that when speech is clearly and slowly articulated, students should be able to easily understand the appropriate text at both levels. See Table 3.

Table 3. The ability of English language listening comprehension for A1-A2 levels (CEFR, 2001, p. 66).

\section{A2}

Can understand enough to be able to meet needs of a concrete type provided speech is clearly and slowly articulated.

Can understand phrases and expressions related to areas of most immediate priority (e.g. very basic personal and family information, shopping, local geography, employment) provided speech is clearly and slowly articulated.

\section{A1}

Can follow speech which is very slow and carefully articulated, with long pauses for him/her to assimilate meaning.

At these lower levels, the CEFR states that the speech should be slowly and clearly articulated and based on topics about students' personal and family relationships and on short conversations held in common public places. However, this doesn't say how age-appropriate our listening test for 6th graders is, or how it would differ from an 8th-grade listening assessment.

\subsubsection{Teaching English language reading skills}

Grabe and Stoller (2011) described the term 'reading' or 'reading comprehension' as "the ability to extract information from written English texts. This includes various simultaneous 
processes of understanding in the course of which readers construct meaning with the help of information given in the text (bottom-up), word knowledge gained from experience (top-down) as well as reading strategies" (p. 3). Nation (2008), Urquhart and Weir (1998) described reading comprehension in similar terms. According to Alqarni (2015), reading is a complex process for learners in comprehending new information even when learning reading in their mother tongue. When reading in English as a Foreign Language (EFL), it is important to use prior knowledge, past experiences, and learners' backgrounds to assist learners to comprehend written texts. Reading lessons can follow the practice and fluency model. Practice reading activities give students a chance to work on gaining skills to read more difficult texts. Fluency reading activities are designed to help students read faster so that reading in English becomes easier (Campbell \& Ragchaa, 2013).

Researchers have investigated effective strategies used for teaching reading. Nejabati (2015) found that teaching self-regulated learning strategies is an effective factor in developing reading comprehension and also in general achievement. He suggested policymakers provide handbooks for teachers which contain guidelines to self-regulated learning that can help learners to be more independent and lifelong learners in the language learning process. Some studies (Oxford, 2011; Cohen, 2010) have concluded that strategy-based teaching could be a good method to enhance comprehension. Cohen (2010) and Oxford (2011) found strategybased instruction can help students to understand how, when, and why they are learning and to integrate the strategies into class materials. For teaching reading, Bamanger and Gashan (2014) found guessing the meaning of words, explaining vocabulary with similar words, scanning the text, and checking comprehension were important strategies.

Stoller, Anderson, Grabe, and Komiyama (2013) stated five key elements of reading instruction made notable improvements in students' reading abilities. They were (1) extensive practice and exposure to print, (2) commitment to building student motivation, (3) attention to reading fluency, (4) vocabulary building, and (5) comprehension skills practice and discussion. Similarly, Aguilera and Filologia (2012) identified reading for specific information or scanning to find specific pieces of information, reading for gist or skimming to get a general idea of what is being discussed, reading for detail to get the meaning out of every word, and extensive reading to read long pieces of text are common and effective strategies to teach reading. Furthermore, the National Reading Panel (2000) also highlighted the reciprocal teaching approach which includes strategies such as using graphic and structure for new vocabulary and story events, answering questions, and summarizing as significant approaches for developing English reading skills. 
Research shows that practice with easy texts and rereading the same text helps improve reading fluency. Reading easy text lets the person's mind work on the larger task of understanding the meaning behind the words. Reading easy texts and rereading the same text is very important: it helps students improve reading fluency by becoming faster at automatic word recognition (Grabe \& Stoller, 2002). Baker and Westrup (2000), and Lindsay (2000) suggested practice reading lessons should include before-reading activities, during-reading activities, and after-reading activities. Before-reading activities are important but they should be short, perhaps five minutes or less.

Additionally, collaborative reading strategies that enable students to read the texts in groups support learners in active learning activities such as brainstorming, predicting, monitoring understanding, and finding the main idea within group discussions (Alqarni, 2015). For this study's target group (6th and 8th grades) the goal for English language reading comprehension is described in CEFR (2001) as follows in Table 4.

Table 4. The ability of English language reading comprehension for A1-A2 levels (CEFR, 2001, p. 69).

\section{A2}

Can understand short, simple texts on familiar matters of a concrete type which consist of high frequency every day or job-related language.

Can understand short, simple texts containing the highest frequency vocabulary, including a proportion of shared international vocabulary items.

\section{A1}

Can understand very short, simple texts a single phrase at a time, picking up familiar names, words and basic phrases and rereading as required.

Within these levels, students are able to understand short simple texts with familiar vocabularies that are used every day and are related to their real life situations. Again, this doesn't say how age-appropriate our reading test for 6th'graders is, or how it would differ from an 8th grade reading assessment. For the Mongolian context, it will be discussed in more details.

\subsubsection{Teaching materials used for developing English receptive skills}

Tomlinson (2011) argued that language learning material is not limited to course books even though people associate this term with course books that are used for everyday instruction. He preferred to define the term teaching material as "anything which is used by teachers and students to facilitate the learning of a language". Nunan and Carter (2001) discuss teaching 
materials that could be "videos, DVD, emails, YouTube, dictionaries, grammar books, workbooks or photocopied exercises, newspapers, food packages, photographs, live talks, instructions, or tasks on cards" (p. 66). Also, they added that learning styles can be catered to when selecting language materials and the materials could be visual, auditory, kinesthetic, experimental, analytic, global, dependent, and independent in order to match students' learning style.

Many language teaching experts and researchers suggest using online authentic materials to increase students' language receptive skills. Erbaggio (2012) found that online authentic materials help learners understand the material better with less fear without teachers' guidance and this helped them become more self-confident with their learning. An authentic material contains more vocabulary than found in the textbooks and gives students immediate feedback. Similarly, Omid and Azam (2016) noted that using authentic materials for teaching receptive skills is effective; the materials expose students to real language and are more related to the natural needs of the language learners. Omid and Azam note that teachers tend to use more authentic materials in reading rather than listening classes. In their study, the Internet and TV would be the most used sources for obtaining authentic listening materials.

Gilakjani (2011) stated that in order to increase listening content, teachers need to select a wide range of materials besides using textbooks. Using only textbooks make students passive during listening and lead to students feeling nervous about taking chances. To avoid being passive learners, students need to listen to different types of English language materials that are natural and lively with rich language. Examples include listening to English songs or seeing films with English subtitles. Using these materials, students' enthusiasm raises; they cultivate their listening interests. Nunan and Carter (2001) said the selection of input sources for the teaching of listening is important. Such sources need to be appropriately authentic, interesting, varied, and challenging. They may be live or recorded on audio or video, and the chunking of input into segments for presentation is another important consideration.

For reading skills, Xiao and Liquan (2006) suggested the following seven principles need to be considered in selecting teaching reading materials: (1) moderate difficulty, (2) the-morethe-better, (3) applicable content, (4) diversity, (5) linguistic authenticity, (6) combining learning with acquisition, and (7) a sense of success. Hayes (2014) also mentioned that reading materials should be prepared by teachers to match with the specific needs of their classes or, if the materials are prepared by others, they should be created based on an understanding of how young children learn languages and provide stimulating, theme-based activities while promoting communicative language use. Gao (2009) also suggested that reading English 
literature and English newspapers can play an important role in enhancing students' reading ability. Literature and newspapers promote students' cultural awareness and improve their cross-cultural communicative competence. According to the findings of Khoshbakht and Gorjian's (2017) study in Iran, EFL learners tend to use authentic-based reading materials to improve their L2 reading and rely less on non-authentic-based materials. They noted that using authentic-based materials may help learners to achieve the purpose of developing language learners' abilities in communicative skills.

However, some studies show that teachers still use only texts in textbooks for developing students' reading skills. For example, Omuna, Onchera and Kimutai (2016) conducted a survey at the secondary school level in Kenya. They found the textbooks are the most available instructional resources for teaching English reading skills and Internet material, class libraries, and magazines are the least available instructional resources. They concluded teachers are still conservative, relying mostly on students' textbooks to teach English reading skills and so it is highly essential to provide adequate and varied instructional resources for teaching and learning English reading skills. In addition to textbooks, they recommended Internet materials, newspapers, encyclopedias, and class readers.

\subsubsection{Out-of-class activities for developing English receptive skills}

Out-of-class activities, also termed as Extramural English (EE) by Sunqvist (2009), refers to English learners involved in activities outside the classroom. Hyland (2004) emphasized language can be learned not only in the classroom but also outside the classroom. He found that most pre-service teachers in Hong Kong improve their listening skills by watching TV, videos, and listening to VCDs, songs, and radio. They improved their reading skills by reading newspapers, magazines, novels, and academic articles. Few students had the opportunity to speak to native speakers in English. Lai, Zhu and Gong (2014) studied Chinese middle school students' out-of-class activities. They found that the class instruction was dominated by a formfocused approach, so a variety of meaning-focused out-of-class learning activities and a diversity of technology were needed to help English learning students succeed with out-of-class activities. It was also found that the students' out-of-class learning experiences were greatly influenced by parents and teachers.

Gao (2009) stated English clubs; he termed 'English corner activities' used in Chinese middle school are also considered out-of-class learning activities and they should be brought into a holistic, humanistic learning program aiming to support students' autonomous and strategic learning. Such learning activities help students develop community cohesion and 
motivate students' autonomous learning efforts. Murray and Kojima (2007) used life history research methods to investigate if out-of-class learning can benefit researchers, teachers and learners based on a Japanese experience on how he learned English and German. The participant's experience suggested learners could combine listening and reading skills by reading recorded books or procuring the scripts of popular movies or television programs, by taking advantage of students' interest in pop culture while listening to DVDs, music, CDs, or by reading magazines, and by seeking out clubs or interest groups such as international associations.

Also, Sunqvist (2009) found among Swedish learners of ESL in grade 9 that out-of-class activities such as playing video games, surfing the Internet, reading books, or reading newspapers/magazines have a greater impact on learners' oral proficiency and vocabulary than listening to music, watching TV, or watching films. Sayer and Ban (2014) found students tend to listen to popular songs, watch movies in English, play video games, use the Internet, and use Google Translate outside the class to improve their language skills in Mexico. Butler, Someya, and Fukuhara (2014) investigated online games and found they had a positive effect on language learning among young learners in Japan. Thékes (2016) stated the following in his dissertation regarding access to English outside the classroom in Hungary:

Józsa and Imre (2013) investigated out-of-school activities of Hungarian YLs [young learners] and secondary school learners. They discovered that students in Hungary encounter English language while listening to music and watching films, and searching for information on Google followed the first two activities in ratio and occurrence and Doró and Habók (2013) found that metacognitive strategies are the most frequently used ones by YLs, while compensation strategies were the least often used ones in Hungary. (pp. 21-22)

These studies show that students actively engage in English listening and reading outside the classroom following their natural interests at home without the teachers' guidance. These results clearly show that there is a need to encourage teachers to effectively include out-of-class tasks for students.

\subsection{Learning strategies and attitudes towards English language receptive skills}

The strategic competence in Canale and Swan's (1980) model infering students' learning strategies can also impact their development of language competence. A number of studies (e.g. 
Nation, 2013; Pavičič, 2008; Thékes, 2016) explored learning strategies involving English language vocabulary; however, these studies did not focus on receptive skills. People need to respond to somebody based on their comprehension. Therefore, Koch (2016) indicated strong receptive skills can be a solid base for achieving success in productive skills and learners need to use effective strategies to develop their receptive skills. Bandpay (2016) also highlighted that students developing their own learning strategies that suit their learning style can be a good way to improve their receptive skills.

Many attempts to define language learning strategies (LLS) can be found in educational research. The most commonly used LLS definition is by Scarcella and Oxford: "Language learning strategies are specific actions, behaviors, steps, or techniques — such as seeking out conversation partners, or giving oneself encouragement to tackle a difficult language task used by students to enhance their own learning" (as cited in Oxford, 2003, p. 2). Other researchers have slightly different LLS definitions. Griffiths and Cansiz (2015) defined language learning strategies as "activities consciously chosen by learners for the purpose of regulating their own language learning" (p. 475). Schmidt and Watanabe (2001) identified four types of learning strategies: cognitive, social, study, and coping. Oxford, on the other hand, subdivided Rubin's strategies into six categories: memory, cognitive, compensation, metacognitive, affective and social strategies in her Strategy Inventory for Language Learning (Oxford, 2003). See Table 5.

Table 5. Strategy classification system (Oxford, 1990 as cited in Oxford, 2003, p. 12).

Direct strategies: Memory, Cognitive and Compensation Strategies.

\begin{tabular}{|c|c|c|}
\hline Memory Strategies & Cognitive Strategies & Compensation Strategies \\
\hline $\begin{array}{l}\text { They help students store and retrieve } \\
\text { new information }\end{array}$ & $\begin{array}{l}\text { They involve more } \\
\text { direct manipulation of } \\
\text { the learning material } \\
\text { itself. }\end{array}$ & $\begin{array}{l}\text { They help learners to understand } \\
\text { or produce messages in the target } \\
\text { language despite limitations of } \\
\text { knowledge. }\end{array}$ \\
\hline
\end{tabular}

Indirect strategies: Metacognitive, Affective and Social Strategies.

\begin{tabular}{l|l|l}
\hline Metacognitive Strategies & Affective Strategies & Social Strategies \\
They involve planning, thinking \\
$\begin{array}{l}\text { about the learning process as it is } \\
\text { taking place, and monitoring, and } \\
\text { evaluating one's progress. }\end{array}$ & $\begin{array}{l}\text { They help students to } \\
\text { regulate emotions, } \\
\text { motivations and } \\
\text { attitudes. }\end{array}$ & interaction with others. \\
\hline
\end{tabular}


In the current study, the above Oxford 1990 classifications were used. These classifications have been widely adopted and are useful for identifying LLSs for receptive skills. Receptive language skill refers to answering appropriately to another person's spoken language (Bandpay, 2016). Receptive skills are a base for achieving success in language learning. Both reading and listening involve much more internal mental processing than productive skills (Koch, 2016). Many researches seek to discover how learners learn something, what makes learners successful at learning something, and why some people are more effective at learning than others (Khalil, 2005; Säälik, 2015; Weng., Yunus \& Embi, 2016). Researchers also focus on factors that can affect students' language learning skills. Khamkhien (2010), Zare and Nooreen (2011), and Zare (2012) mentioned in their studies that many factors influence students' language learning strategies such as age, sex, attitude, motivation, aptitude, learning styles, individual differences, cultural differences, beliefs about language learning, and language proficiency.

Research shows it is important that teachers know their students' learning strategies and interests so that teachers can improve students' current skills using appropriate methods matched with their students' attitude and interests based on their learning strategies. Weng, Yunus and Embi (2016) concluded in their study that it was essential for teachers to understand LLS and the relationships between LLS and English language achievement. Hence, teachers were expected to know not only how to teach English but also how to strengthen learners' LLS in order to improve teaching and learning efficiency. In order to know the students' attitude, interests, and learning strategies, teachers can use observations, surveys, and interviews to explore students' knowledge of learning strategies.

Hong (2008) suggested that teachers can use classroom research as a tool to explore students' needs and to identify the strategies that best meet their learners' immediate needs. Successful learners mostly use effective strategies which lower their anxiety and encourage them to stay focused on reading and listening tasks (Koch, 2016). This research suggests good English instructors should train students in using effective strategies. English language learning and teaching are always under discussion in Mongolia since the Mongolian government added English as a second language to its language policy in 2005. However, while conducting this survey to explore the issues in English language learning and instruction in Mongolia, we found that language learning strategies (LLS) in Mongolia have not been well researched or adopted. 


\subsubsection{Learning strategies of English language listening skills}

According to Renukadevi (2014), "listening strategies are techniques or activities that contribute directly to the comprehension and recall of listening input" (p. 61). Goh (1998) identified three notable strategies of listening skills which learners frequently adopt: inferencing, elaborating and predicting. He suggested more time should be spent on metacognitive strategies because the weaker listeners were less able to manage their listening process, especially when they encountered problems. Pre-listening activities are the most important aids for comprehending a spoken text because they prepare students to listen to a text properly for further understanding. National Capital Language Resource Center (NCLRC), (n.d.) reported teachers need to focus more on pre-listening activities because these activities helped students to predict, to relate, and to interpret the incoming content based on their previous knowledge and experience. Graham (2017) stated that for listening, teachers need to put more focus on their learners' ability to extract specific details from texts, to recognize opinions, to understand passages that include different tenses, and to assess whether students can gain global understanding, infer meaning, and generally employ listening strategies effectively.

Many foreign language learners found listening to be the most difficult skill to learn and they felt it was the most difficult skill to improve (Graham \& Macaro, 2008). Goh (2008) found language learners who pay attention to their own listening problems are usually motivated to find ways to solve them. Renukadevi (2014) noted the following reasons why students felt listening was difficult: lack of effort to understand every word while listening, laziness in improving their vocabulary, trouble with different pronunciations and accents, lack of concentration or listening stamina, an uncomfortable physical setting or environment, or spending too little time on the listening activity. These results suggest there is a need to raise second language learners' awareness about listening strategies and tactics that they can apply.

\subsubsection{Learning strategies of English language reading skills}

"A reading comprehension strategy is a cognitive or behavioral action that is enacted under particular contextual conditions, with the goal of improving some aspect of comprehension" (Graesser, 2007, p. 6 as cited in Kolic-Vehovic, Bajsaski \& Zubkovic, 2011). Jeon and Yamashita (2014) mentioned that "the recent investigations of first (L1) and second language (L2) reading abilities have largely owed to the component-skills approach to reading" (p. 161). This approach views reading as multiple cognitive processes (e.g. decoding, vocabulary knowledge, syntactic processing, metacognition) and involves separate 
measurements of subskills of reading. For reading, two fundamental types of learning strategies, metacognitive and cognitive, are mostly used. According to Oxford (2011), metacognitive strategies include activities to plan, obtain, organize, coordinate, monitor, and evaluate the construction based on cognitive processes. Nandi (2011) mentioned "in English language teaching (ELT), the students without metacognition have been treated as learners without direction who cannot monitor their process of learning." (p. 175) In recent years, researchers have used the method of meta-analysis to investigate issues regarding bilingual reading, such as cross-linguistic transfer across various language variables (Melby-Lerv ${ }^{\circ}$ ag $\& \operatorname{Lerv}^{\circ}{ }^{\circ}$ g, 2011) or the role of phonological skills in word reading ability among bilingual children (MelbyLerv ${ }^{\circ}$ g, Lyster \& Hulme, 2012). These studies show that native language and its phonology affect second language reading skills and comprehension.

Extensive reading in English helps children to overcome these phonological issues. Carrel (1998) found it is important for learners to know what strategy to use, how to use it, why to use it, when to use it and where to use it when developing their reading skills. He also noted that lots of practice and re-explanations are useful for learners to develop their cognitive and metacognitive skills. Afflerbach, Pearson and Paris (2008) also stated that young readers must learn decoding strategies before they apply them accurately and automatically while developing readers must learn metacognitive strategies so these readers can understand how reading works and how to identify and fix problems.

Reading-related strategies and strategy-training are emphasized mostly in recent studies of language education. Singhal (2001) stated that strategy training leads to improved reading performance and teachers must care about the processes involved in reading and model these strategies in the classroom while observing students as they read in order to determine students' strengths and weaknesses in their use of strategies. Other related methods for improving reading include presenting strategies as applicable to texts and tasks, teaching strategies regularly, providing students with opportunities to practice strategies they have been taught, and letting students teach one another about the reading and the studying process.

\subsubsection{Students' attitude towards English language learning}

Language attitude is defined in the Longman Dictionary of Language Teaching and Applied Linguistics (2002) as follows:

The attitude is which speakers of different languages or language varieties have towards each other's languages or to their own language. Expressions of positive or negative feelings towards a language may reflect impressions of linguistic difficulty or simplicity, 
ease or difficulty of learning, degree of importance, elegance, social status, etc. Attitudes towards a language may also show what people feel about the speakers of that language. (Richards et al, 2002, p. 286)

Additionally, an evaluation of the course, teaching materials, and the teaching environment can elicit the learner's attitudes (Riyanto, 2015). Riyanto stated that students' reading comprehension achievement and understanding vocabulary effectively influence their attitude to language learning. Researchers highlighted that language learning attitude is purely related to the social community. For example, Gardner (1968) emphasized that the truly successful student is motivated to become integrated with the other language community and this integrative motive derives from the attitudinal characteristics at the home fostered by the parents and other language groups. Padwick (2010) and Abidin (2012) similarly stated learners' intellectual capacity is one aspect of their achievement in language learning, and another important aspect found was learners' attitude towards learning. Also, Sadiku (2015) said attitude is another important factor to achieve listening skills. Also, Ali et al. (2012) indicated that the use of computers changed students' attitudes in learning English vocabulary compared to using paper-based Contextual Clues and dictionaries. When students use CALL (Computer Assisted Language Learning) they feel more comfortable.

Therefore, language researchers such as Ahmed (2015) suggested that teachers need to involve students actively in classroom activities and raise student interest by their own attitude toward class participation, by their conscientiousness, by their humor, by their seriousness, and through their own behavior and enthusiasm so that students remain positively involved in classroom activities. Gajalakshmi (2013) found that students' learning attitudes are different because of their gender, school location, school type, management, and parents' education levels. According to Ming, Ling and Jaafar (n.d), it is important to consider student's attitude in teaching because their study results showed better students had more positive attitudes than weak students.

The specific attitudes in one section of the Learning language strategy questionnaire used in this study were focused on both positive and negative attitudes towards learning English language receptive skills. Eshghinejad (2016) noted students' attitude (feelings, beliefs, likes, dislikes, and needs) should be considered in teaching and learning language. Joseph (2004) highlighted that children who have positive reading attitudes tend to be willing to listen and read, enjoy listening and reading, become proficient, and even become lifelong learners. Therefore, we tried to identify students' positive attitudes towards learning English receptive skills by asking whether they like to listen to English songs, to fill in gaps, to improve their 
English receptive skills, to understand the speaker and to improve their vocabulary, etc. Eshghinejad (2016) also mentioned that English reading is difficult and boring for students, thus it produces negative attitudes that might weaken students' reading ability. Subsequently, students who have negative attitudes toward reading may read only when they have to read and otherwise think it is a waste of time. Therefore, I also aimed to identify whether students have negative reading attitudes that might influence their reading achievement.

\subsection{English Language Assessment}

Tran (2012) highlighted the importance of validity, reliability, practicality, equivalency, authenticity, and wash back of second language assessment. He explained that test validity needs to measure the test takers' real ability based on empirical and theoretical research. Bachman and Palmer (1996 cited in Tran, 2012) say that reliability refers to similar results when the test is administered on different occasions. Practicality refers to the relationship between the resources (human and materials, time, and location) and the use of the test. Equivalency and authenticity indicate whether the test is directly based on curriculum standards or instructional activities. Brown and Hudson (1998 cited in Tran, 2012) pointed out that a wash back is the reflection of testing and assessment on the language teaching curriculum and instruction. These studies show that including all these criteria for writing tests is really important to assess students' actual skills and their learning outcome. Second language testing assesses learners' progress and their specific skills. Therefore, language instructors need to design tests to measure the learners' functional use of language, not a specific linguistic point.

Consequently, the most important thing test makers need to consider in language assessment is to understand the roles of abilities and contexts, the interactions between them, and the influence of ability and context on the performance of language assessment tasks (Fox et al., 2007). Powers (2010) observed that language receptive (reading and listening) and productive skills (speaking and writing) are assessed differently. Receptive skills are usually assessed through computer-based and paper-pencil tests with multiple choice items, while productive skills are assessed with performance-based tests. Language testing experts and language researchers such as Hakuta and Beatty (2000), Bailey and Butler (2003), and Garcia, McKoon and August (2006) have criticized previous English language assessments used for ESL students. This is because those assessments do not measure up with the development of the academic English language skills that students need to become successful in a school setting. Language educators noted that an interactional approach was becoming more important 
in language teaching and assessment. For example, Bachman (2007) and Chapelle (1998) noted that the English language program includes skill-based, trait-based, task-based, and interactional approaches in a given context. Chapelle (1998) remarks that an interactional approach to language learning improves communicative language abilities. Chalhoub-Deville (2003) noted that language competence is a process involving improvement over time in combining knowledge and context with language performance.

Across the world, English teachers have different assessment views. Language assessments can be different or similar in different countries. Rixon (2013) found that, at the end of primary school years, English language assessments were different in some countries. For instance, in France, at the end of primary school years, teachers complete an evaluation which covers five skills areas: (1) listening comprehension, (2) oral interaction, (3) individual speaking with no interaction (e.g. reproducing a model, a song, a rhyme, a phrase, reading aloud, giving a short presentation), (4) reading comprehension, and (5) writing. In Taiwan, instructors are now developing their own English proficiency tests (Rixon, 2013) at the primary school level. The purpose of their proficiency test is to assess the effectiveness of English instruction and to identify those in need of remedial teaching. In Finland, many primary schools use a voluntary "national" test of English designed by the English teachers' association of Finland to guide their final grading of students and to get some information for them about how they are doing against the average of other schools (Rixon, 2013). A New National Curriculum in Cyprus was implemented in September 2011. It introduced English at the primary level, emphasized the role of portfolio assessment, and introduced content and language integrated learning (Rixon, 2013).

In addition, language assessment has been used as a tool for exploring issues in language instruction and learning in Hungary. Recent research projects of Bacsa and Csikos (2016), Mihaljevic-Djigunovic (2016) and Nikolov (2016) have used the second language (L2) tests as one type of data collection instrument in order to find out how learners' individual differences, including attitudes, motivation, aptitude, anxiety, self-perceptions, self-confidence, strategies, etc., contribute to their development in their L2 studies. Another important exploration (Nikolov \& Csapo, 2010; Wilden \& Porsch, 2016) investigated how learners' first language (L1) and other languages interact with one another over time. Also, some empirical studies (Garcia Mayo \& Garcia Lecumberri, 2003; Munoz, 2006; Nikolov, 2009a, 2009b; EneverMoon \& Roman, 2009; Enever, 2011) applied assessment tests and analyzed the test results in interaction with other variables. 
Also, international projects have been implemented to collect test data for comparative purposes and to answer questions related to the rate and level of L2 development. For example, a longitudinal study, the Early Language Learning in Europe project, aimed to examine what level young learners achieved in a foreign language at public schools in England, Italy, the Netherlands, Poland, Spain, Sweden, and Croatia. Assessment projects are also often designed to look for answers to research questions emerging from practice. For example, Peng and Zheng (2016) studied how teachers apply achievement tests, and Butler (2016); Hung, Samuelson and Chen (2016) researched how teachers change their instructions because of innovative assessment techniques. Other projects use tests in order to build new models or to test existing ones to find out to what extent they can reflect realities in early foreign language classrooms (Mihaljevic-Djigunovic, 2016; Bacsa \& Csikos, 2016).

Also, a lot of data on English language teaching and learning were collected from observations and interviews (Bors, Lugossy \& Nikolov, 2001; 2008) and large-scale national testing projects (Csapo \& Nikolov, 2009; Nikolov \& Jozsa, 2006) in Hungary. The main findings of these surveys indicated that the most typical classroom activities were rarely in line with age-appropriate teaching methodology. Instead, teachers tended to focus on grammar, translation and reading out loud and these topics were the focus of lessons and tests. Hild and Nikolov (2011) conducted a survey among English teachers and asked them to analyze 119 tasks from an English test. As a result of this work, they compiled the task and text types and compared them against criteria of EL skills for young learners using the 'can do statements' of the Common European Framework of Reference (CEFR) A1-A2 levels and topics appropriate for the diagnostic assessment of young learners. As a result of these projects, online diagnostic assessment and teachers training programs have been started implemented in schools.

\subsubsection{The assessment of English language listening skills}

\subsubsection{Nature of English language listening comprehension}

Listening is the fundamental skill to learn a language and comprehending based on this skill allows people to start to communicate with others. Anckar (2011) noted listening is a fundamental part of communication; in its most basic form to comprehend a spoken text requires a cognitive as well as a physiological and neurological response. Listening comprehension involves distinguishing sounds, interpreting sound sequences as meaningful units, and building up meaning in a larger sense going from lexical units to larger entities. Field (2008), Nation and Newton (2009), and Vardergrift and Goh (2012) defined listening similarly as the ability to extract information from spoken English and they each noted listening is a 
complex (bottom-up and top-down) process that learners draw a conclusion of meaning and interpret what they heard. Flowerdew and Miller (1997) stated that academic listening comprehension skills are important for L2 learners engaged in academic tasks. Also, Ferris and Tagg (1996) said lecture comprehension ability is one of the most important skills for L2 learners' academic success when classes are taught in English.

Based on the fundamental processes involved in comprehending spoken text as mentioned above, Brown (2003) identified four types of listening performance: (1) intensive listening for perception of the components, (2) responsive listening to make short stretch of language (a greeting, commands, etc.), (3) selective listening to look for global or general meanings, and (4) extensive listening to listen to a lecture or a conversation for the main idea and to make inferences. During the listening process, problems occurred depending on some external and internal factors. The problems involved in comprehending spoken text have been an important research area for a long time. Clerehan (1995) and Olsen and Huckin (1990) stated many pieces of research demonstrated that L2 learners' difficulties in understanding lectures lie at the discourse level as well as at the sentence level. Olsen and Huckin (1990), for example, reported that most L2 learners with the proper comprehension of English at the sentence level had difficulty identifying the main ideas in a lecture. These students were unable to utilize discourse-level cues that signaled the organization of the lecture.

Similarly, Clerehan (1995) observed that L2 learners failed to recognize how the lecture discourse was structured as a whole and, thus, was unable to identify relationships between ideas and to distinguish major from minor ideas. According to Clerehen (1995), discourse signaling cues indicate the organization of the text signaling relationships between ideas, indicating the relative importance of ideas, and evaluating the given ideas. Early researcher Lado (1961) felt that listening was purely an aural skill and hence, it should be assessed with as few contextual cues as possible. Buck (2001), however, maintained that the listening process depends on everything in a listener's mind that could influence how a message is understood. This view suggests that listening should be assessed with as much context as possible; that is, listening assessments should match the way listeners are expected to use language in the real world as closely as possible.

\subsubsection{Models for language listening comprehension process}

According to Mayer (1984) and Sternberg (1984), three kinds of active cognitive processes which are selecting relevant information, organizing the new material by building coherent internal connections among incoming pieces of information, and then constructing 
coherent external connections by linking new information with existing knowledge make learning meaningful (as cited in Mayer, 2008, p. 34).. Anckar (2011) summarized several theoretical models of listening comprehension in Table 6 below. He explained that Anderson's (1985) model shows perceptual processing that focuses on the oral text and the sounds, parsing to identify the parts of speech, syntactic relations, and utilization to relate the text meaning to existing knowledge. Brown's four-stage model shows, after the information is identified, that existing files in memory are searched in an effort to relate the new information to old information. Then the information is stored in memory to set up a new file for new information, and finally, the information is put into use and acted upon. Turner's model proposes the listener attempts to organize sounds into segments or chunks in the echoic memory and then holds onto the units of meaning in the short-term memory in order to make a more detailed inspection. Then what the listener hears is considered in light of what is known by reference to the information held in long-term memory, and finally, a listener continues to take in more information through the ears, and stores the meaning of what (s)he has heard in the long-term memory if it seems appropriate.

Flowerdew and Miller (2005) introduced a model of second language listening comprehension as a cognitive model of listening with the central dimension being a bottom-up, top-down interactive process participating in cognition. They noted the importance of this model allows for the possibility of individual variation in linguistic processing. Individualized variation refers to differences in proficiency stages, texts, and task types as well as learning styles. They pointed out that some individuals may prefer focusing on bottom-up processing, whereas others emphasize top-down processing. See Figure 3.

Table 6. Models of the listening comprehension process and difficulties associated with each stage

\begin{tabular}{c|c|c}
\hline $\begin{array}{c}\text { Anderson's } \\
\text { (1985) three phase } \\
\text { comprehension } \\
\text { model }\end{array}$ & $\begin{array}{c}\text { Brown's } \\
\text { (1995) four stage } \\
\text { Model }\end{array}$ & $\begin{array}{c}\text { Turner's (1995) } \\
\text { mental processes } \\
\text { involved in listening } \\
\text { comprehension }\end{array}$ \\
\hline $\begin{array}{c}\text { Perceptual } \\
\text { processing }\end{array}$ & Identifying stage & $\begin{array}{c}\text { Taking in a "stream of sound" Organization into } \\
\text { segments or chunks in the echoic memory }\end{array}$ \\
\hline Parsing & Memory searched & $\begin{array}{c}\text { Short-term memory: inspection, relationships, } \\
\text { retention and rejection }\end{array}$ \\
\hline Utilization & Storing information & $\begin{array}{c}\text { Review with information \& possible storage in } \\
\text { long-term memory }\end{array}$ \\
\hline & $\begin{array}{c}\text { (Information put into use } \\
\text { and enacted upon) }\end{array}$ & \\
\hline
\end{tabular}

Note. From Anckar, (2011, p. 32) 


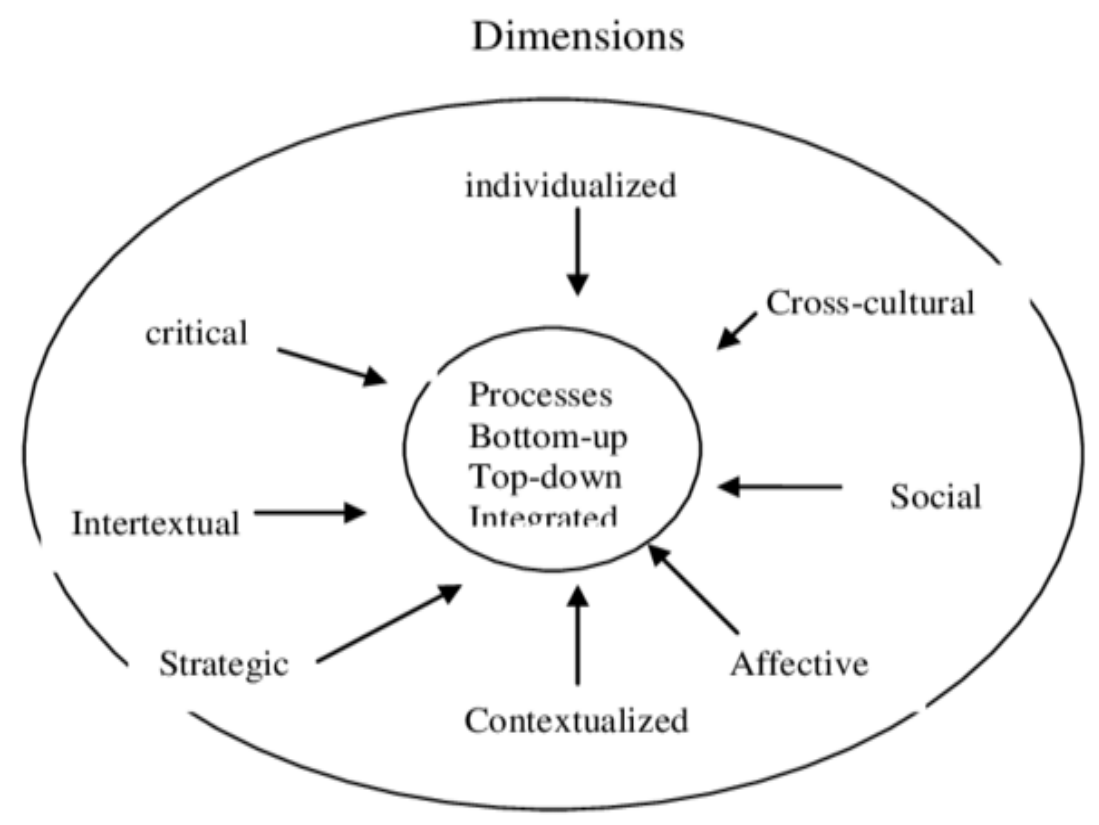

Figure 3. A model of second language listening comprehension (Flowerdew \& Miller, 2005, p. 23).

Richards (1983) created a list of micro and macro skills of listening comprehension to specify learning objectives and to recommend that test makers carefully identify specific assessment objectives when creating tests. From the list, note that micro skills are more related to a bottom-up process while macro skills require a more top-down process. Later, Brown (2003) simplified Richards' list. See Table 7.

Table 7. Micro- and macro skills of listening (Simplified list, Brown, 2003, p. 121)

\section{Micro skills}

1. Discriminate among the distinctive sounds of English.

2. Retain chunks of language of different lengths in short term memory.

3. Recognize English stress patterns, words in stressed and unstressed positions, rhythmic structure, intonation contours, and their role in signaling information.

4. Recognize reduced forms of words.

5. Distinguish word boundaries, recognize a core of words, and interpret word order patterns and their significance.

6. Process speech at different rates of delivery.

7. Process speech containing pauses, errors, corrections, and other performance variables.

8. Recognize grammatical word classes (nouns, verbs, etc.), systems (e.g., tense, agreement, pluralization), patterns, rules, and elliptical forms.

9. Detect sentence constituents and distinguish between major and minor constituents.

10. Recognize that a particular meaning may be expressed in different grammatical forms.

11. Recognize cohesive devices in spoken discourse. 


\section{Macro skills}

1. Recognize the communicative functions of utterances, according to situations, participants, goals.

2. Infer situations, participants, goals using real-world knowledge.

3. From events, ideas, and so on, describe, predict outcomes, infer links and connections between events, deduce causes and effects, and detect such relations as main idea, supporting idea, new information, given information, generalization, and exemplification.

4. Distinguish between literal and implied meanings.

5. Use facial, kinesthetic, body language, and other nonverbal clues to decipher meanings.

6. Develop and use a battery of listening strategies, such as detecting key words, guessing the meaning of words from context, appealing for help, and signaling comprehension or lack of thereof.

\subsubsection{Framework for the language listening construct}

A framework for describing listening ability was introduced by Buck (2001). He included language competence as the basic competence involving grammatical knowledge, discourse knowledge, pragmatic knowledge, and sociolinguistic knowledge. Grammatical knowledge involves understanding short utterances on a literal or semantic level, recognizing phonology, stress, intonation, spoken vocabulary, and spoken syntax. Buck described discourse knowledge as understanding longer utterances or interactive discourse between two or more speakers, pragmatic knowledge as understanding the function or the intention of an utterance or a longer text, and sociolinguistic knowledge as understanding the language in particular socio-cultural settings and particular contexts recognizing slang, idiomatic expressions, cultural references, and levels of formality.

Buck (2001) also discussed strategic competence, cognitive strategies related to comprehending and storing input in memory, and metacognitive strategies, activities performing an executive function in the management of cognitive strategies. Ableeva (2008) stressed that Buck's (2003) discrete point approach helps learners to identify individual features of the language while listening. However, an integrative approach helps learners to understand the language use while listening, and the communicative approach helps learners to make references while listening.

\subsubsection{The educational practices of English language listening assessment}

Ockey (2007) noted that the uses of visual input on listening assessments help test takers to comprehend the message. Visual inputs included lip movements, facial gestures, hand movements, and other body languages. In contrast, others (Gruba, 1989; Ockey, 2007; Wagner, 2007) reported that visual input does not help learners better understand the intended message, 
and some even stated that visual input distracted from aural input just as it would in many realworld tasks. In addition, some studies also focused on the assessment of English listening skills. For example, Taylor and Geranpayeh (2011) examined many different considerations and constraints involved in assessing L2 academic listening skills. Their considerations and constraints were placed within a socio-cognitive framework for developing and validating tests. They believed that such a framework, with its core components of test-taker characteristics, cognitive validity, content validity, and scoring validity, offered test designers a useful, coherent, and systematic approach for considering the many different factors that need to be taken into account when developing and validating tests of academic listening ability.

Shabani (2014) explored qualitative changes interacting with different novel tasks. She felt an assessment taking into account student development was useful for seeing students' improvement on innovative tasks. Hemmatia and Ghaderi (2014) looked at three formats for questions (preview, answer option, and question stem). They found no significant difference between these question types on student performance. Understanding the need for assessing student improvement on novel tasks and knowing that the question format doesn't impact test results can be useful for EFL teachers creating novel materials and designing assessments for these materials.

Another longitudinal project by Bacsa and Csikos (2016) examined the development of listening comprehension and the role of individual differences in an early language learning context in Hungary. They found the variables of individual differences are themselves multifactor constructs; the components are in constant interaction with one another and with their environment thus changing and creating a complex developmental pattern. The results indicated that language aptitude emerged as one of the main cognitive factors and parents' education was another strong predictor of listening performance. Listening anxiety which is an effective factor and emotions were found to be interrelated and also played a decisive role in the development of listening skills.

Although computers are capable of delivering a larger variety and more authentic tasks for assessing listening than traditional paper-and-pencil assessments, most computer tests of listening have been slow to adopt such authentic tasks. Language researchers and test makers Buck (2001) and Ockey (2007) suggest that computer technology can include context cues which are not possible with most paper-and-pencil tests to assess English language listening skill. For instance, traditional academic listening tests designed to assess the ability to comprehend a classroom lecture have mostly used aural-only input. The information to be tested has been delivered via cassette tape or other aural-only input devices. Such assessments are in 
line with the view that listening is an aural-only skill. Computers make it feasible to include visual context along with the aural input. Video allows students to observe speakers communicating the intended message.

The assessment of English language listening is always under discussion and language researchers have been paying more attention to this skill, but it still needs more study. Alderson and Bachman (2001, p. n. d.) stated that "the assessment of listening abilities is one of the least understood, least developed and yet one of the most important areas of language testing and assessment" (as cited in Renandya and $\mathrm{Hu}, 2018$ ). It is notable that very little published research exists about designing, validating, and evaluating the language listening test.

\subsubsection{The assessment of English language reading skills}

\subsubsection{Nature of language reading comprehension}

Koda (2005; 2007), Grabe (2009), and Bernhardt (2011) have identified key predictors of L2 reading comprehension and described the nature of their contribution to reading comprehension. Good reading comprehension, according to Snowling, Cain, Nation and Oakhill (2009), requires processing the words on the page, retrieving their meanings from memory, and making sense of each sentence. They propose that understanding written text requires readers to build internal coherence and external coherence that allows the reader to understand how all the pieces fit as a whole. To accomplish this understanding, readers must use background knowledge and facts stored in their long-term memory in order to fill in details that were only implied in the original text. Urquhart and Weir (1998), Nation (2008), and Grabe and Stoller (2011) described similarly the term "reading" as the ability to extract information from written English texts. This includes various simultaneous processes of understanding in the course of which readers construct meaning with the help of information given in the text (bottom-up), word knowledge gained from experience (top-down) as well as reading strategies.

Brown (2003) similarly noted that English language learners need to be able to master fundamental bottom-up strategies for processing separate letters, words, and phrases, as well as top-down strategies for comprehending appropriate content using background information and cultural experience.

\subsubsection{Models of the language reading comprehension process}

Figure 4 and 5 display models based on the Simple View of Reading (Gough \& Tunmer, 1986; Hoover \& Gough, 1990). Gough and Tunmer (1986) showed the process and skills 
required when comprehending texts; word recognition and language comprehension have four possible outcomes which depend on the students' level of text comprehension. See Figure 4.

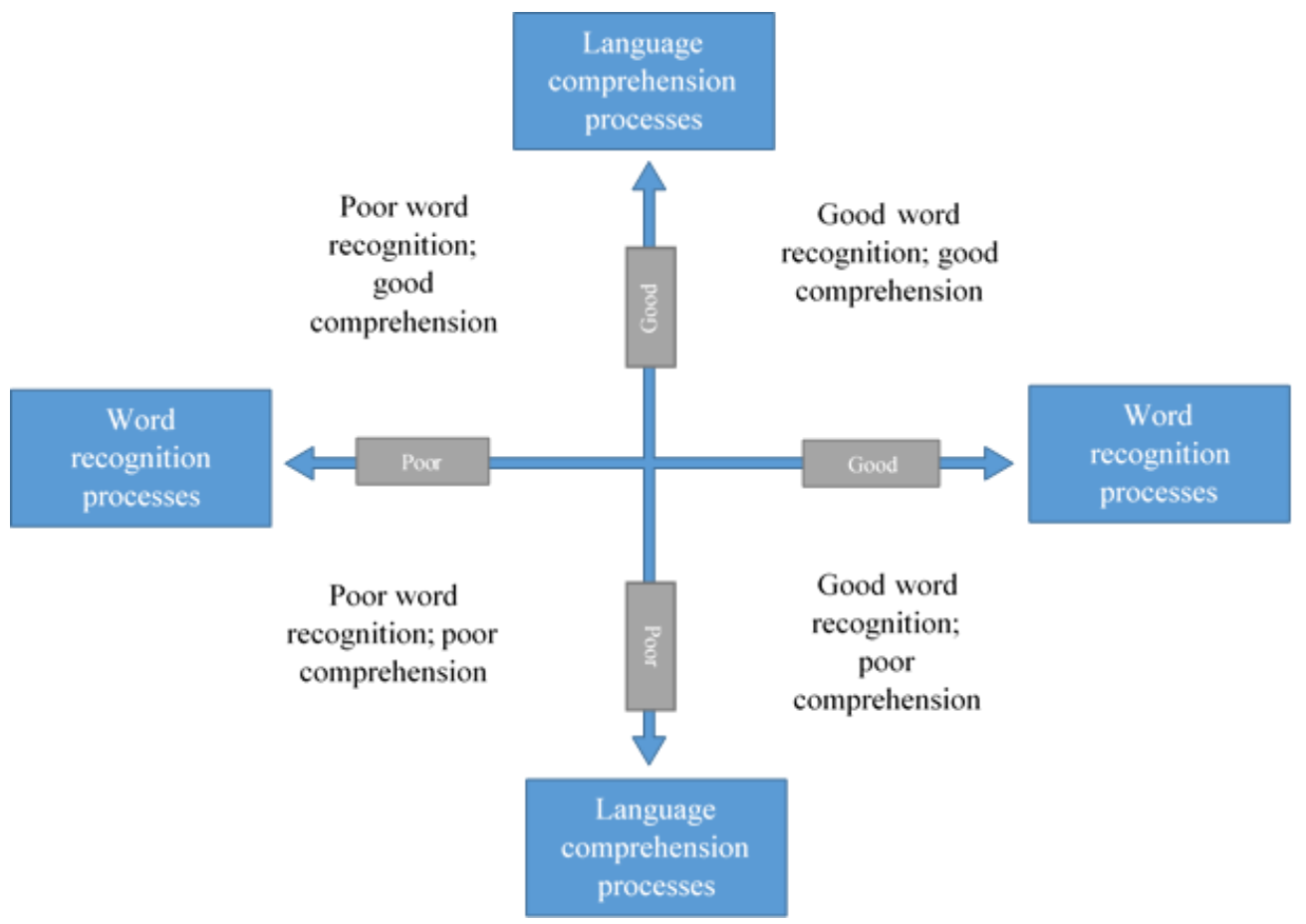

Figure 4. The simple view of reading (based on Gough \& Tunmer, 1986).

Hoover and Gough (1990) added linguistic comprehension to this model. They stated that if students cannot recognize the words that comprise the written text, they cannot recover the lexical information necessary for activating the linguistic processes that lead to comprehension (Rose, 2006, p. 76). See Figure 5.

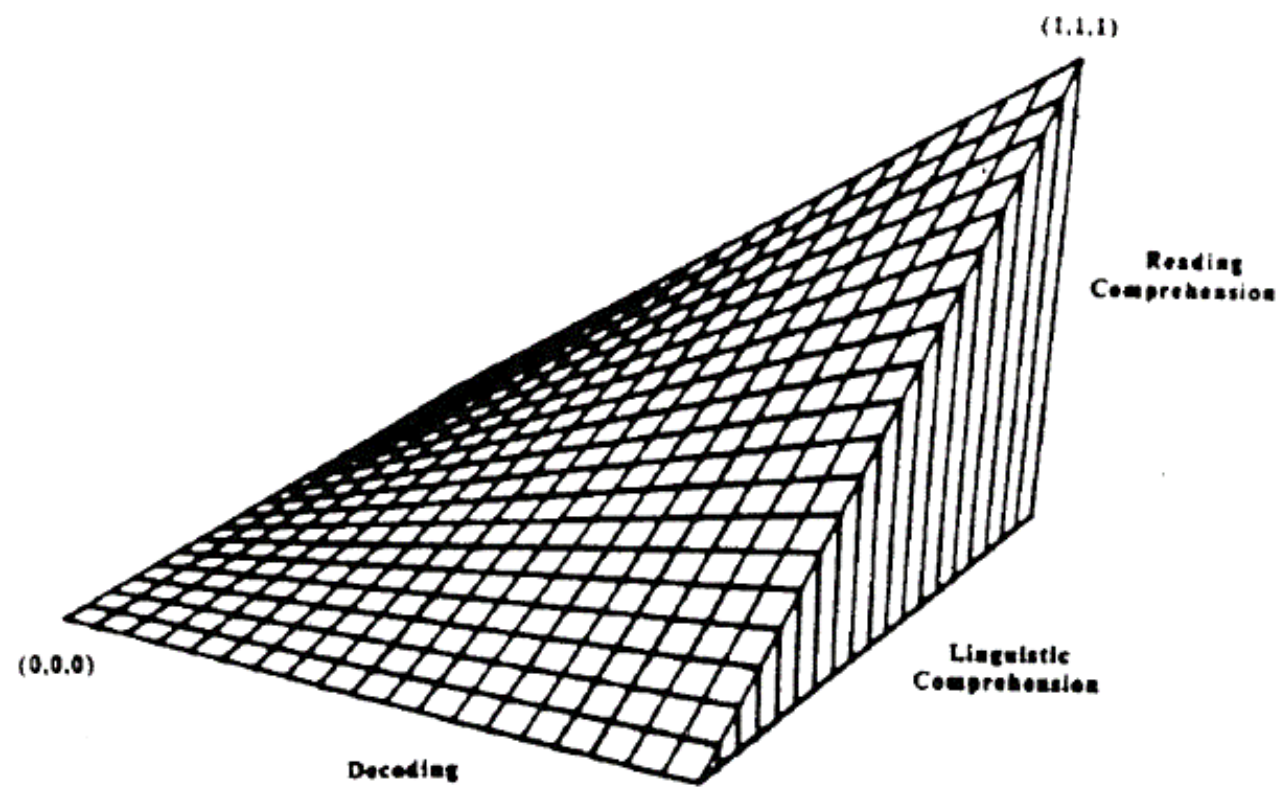

Figure 5. Simple view of reading (Hoover \& Gough, 1990, p. 133). 
Snowling et al. (2009) stated that an assessment should include tests to measure both decoding and comprehension. As highlighted by the Simple View of Reading (Gough \& Tunmer, 1986), performance in reading comprehension can be considered as the product of decoding skills and listening comprehension skills. Reading comprehension is a complex process involving visual processing, relating textual elements to sound elements. Successful readers continually scan the text forward and backward to help construct meaning from what they are reading (Gersten, Fuchs, Williams \& Baker, 2001; Kolić-Vehovec \& Bajšanski, 2006b).

\subsubsection{Framework for reading comprehension construct}

Janovsky (n.d.) believes reading comprehension is not only complex but also something that can not be observed. The constructs and processes occurring in each student's brain as they try to comprehend their reading is not directly available to the teacher. Reading assessment, therefore, must focus on simply evaluating the students' ability to understand the text. Janovsky mentioned some ways to assess students' reading skills such as predicting, making an educated guess about what might happen; identifying, indicating important elements of a reading such as the author's purpose and the selection's themes or messages; visualizing, seeing in one's mind all the details from the story and helping students connect the written words with actual visible scenes; and connecting, linking the reading to their personal lives.

Also, Richards (1983) listed micro and macro skills of reading comprehension which is helpful for language instructors and test makers. Brown (2003) simplified this list. See Table 8. The micro and macro skills of listening and reading comprehension show both reading and listening comprehension involve cognitive processes, including lexical (word level, vocabulary) and syntactic (sentence level, grammar) processing, inference generation, and metacognitive strategies (activities directing the learning process such as selective attention and comprehension monitoring). These lists can help language instructors and test makers develop tests to assess their students' real comprehension abilities.

Additionally, Embertson and Wetzel (1987) compared two models: the text representation model by Kintsch and Van Dijk (1978) and the response decision model by Sternberg (1977) to examine the cognitive characteristics of paragraph comprehension items. They found both models can be a good representation of item difficulty. This Figure 6 of reading comprehension processing was used in the item difficulty analysis in this study. 
Table 8. Micro and Macro skills of reading comprehension (simplified list of Richards (Brown, 2003, p. 187.)

\section{Micro skills}

1. Discriminate among the distinctive graphemes and orthographic patterns of English.

2. Retain chunks of language of different lengths in short-term memory.

3. Process writing at an efficient rate of speed to suit the purpose.

4. Recognize a core of words and interpret word order patterns and their significance.

5. Recognize grammatical word classes (nouns, verbs, etc.), systems (e.g., tense, agreement, pluralization), patterns, rules and elliptical forms.

6. Recognize that a particular meaning may be expressed in different grammatical forms.

7. Recognize cohesive devices in written discourse and their role in signaling the relationship between and among clauses.

\section{Macro skills}

1. Recognize the rhetorical forms of written discourse and their significance for interpretation.

2. Recognize the communicative functions of written texts, according to form and purpose.

3. Infer context that is not explicit by using background knowledge.

4. From described events, ideas, etc., infer links and connections between events, deduce causes and effects, and detect such relations as main idea, supporting idea, new information, given information, generalization, and exemplification.

5. Distinguish between literal and implied meanings.

6. Detect culturally specific references and interpret them in a context of the appropriate cultural schemata.

7. Develop and use a battery of reading strategies, such as scanning and skimming, detecting discourse markers, guessing the meaning of words from context, and activating schemata for interpretation of texts.

Text representation

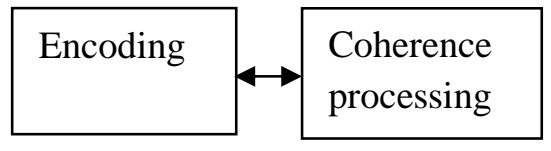

Response decision

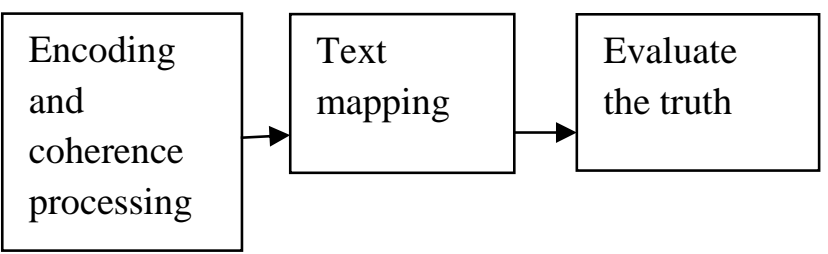

Figure 6. General processing model for multiple-choice paragraph comprehension items adopted from Embertson \& Wetzel, 1987, p. 177).

Hashmin et al (2014) used Bloom's Revised Taxonomy for test item analysis in Malay to recognize how it fits in with an English reading test. Based on their result, they suggested their item analysis can be used to measure specific cognitive abilities in reading comprehension tests. 
This model, in Table 9, was used for reading test item analysis and for examining reading skills in this study.

Eun and Junko (2014) mentioned that the recent investigations of first (L1) and second language (L2) reading abilities reflect the component-skills approach to reading. This approach views reading as comprised of multiple cognitive processes (e.g. decoding, vocabulary knowledge, syntactic processing, metacognition) and involves separate measurements of subskills of reading. Some researchers (e.g. Droop \&Verhoeven, 2003; Van-Gelderen et al., 2004; Jeon, 2011) showed this approach helps to identify key predictors of reading among L2 readers. The approach may help language teachers and testers identify areas of individual ability differences and design effective intervention programs and tests.

Table 9. Assessment of a Reading Comprehension Instrument as It Relates to Cognitive Abilities as Defined by Bloom's Revised Taxonomy

\begin{tabular}{|c|c|c|}
\hline $\begin{array}{c}\text { Reading Comprehension } \\
\text { Category }\end{array}$ & $\begin{array}{c}\text { Code } \\
\text { L1A, L1B, L1C }\end{array}$ & Reading Skills \\
\hline Literal (L) & $\begin{array}{l}\text { L2 } \\
\text { L3 } \\
\text { L4 } \\
\text { L5 } \\
\text { L6 }\end{array}$ & $\begin{array}{l}\text { identifying meaning of word/ } \\
\text { phrase/ sentence } \\
\text { identifying main idea } \\
\text { identifying important point } \\
\text { making comparison } \\
\text { identifying cause-effect } \\
\text { identifying sequence of } \\
\text { ideas/events }\end{array}$ \\
\hline Inferential $(\mathrm{F})$ & $\begin{array}{l}\text { F1 } \\
\text { F2 } \\
\text { F3 } \\
\text { F4 } \\
\text { F5 }\end{array}$ & $\begin{array}{l}\text { interpreting main idea } \\
\text { interpreting important point } \\
\text { interpreting comparison } \\
\text { interpreting cause-effect } \\
\text { making a conclusion }\end{array}$ \\
\hline Critical Creative (K) & $\begin{array}{l}\text { K1 } \\
\text { K2 } \\
\text { K3 } \\
\text { K4 }\end{array}$ & $\begin{array}{l}\text { evaluating } \\
\text { making a conclusion } \\
\text { internalizing } \\
\text { identifying the moral of the } \\
\text { story/lesson }\end{array}$ \\
\hline
\end{tabular}

Note: adopted from Hashmin, 2014, p. 3

\subsubsection{The educational practices of English language reading assessment}

In recent years, researchers have used meta-analysis to investigate issues regarding bilingual reading, such as cross-linguistic transfer across various language variables (MelbyLervag \& Lervag, 2011) or to explore the role of phonological skills in word reading ability 
among bilingual children (Melby-Lervag, Lyster, \& Hulme, 2012). These studies identified four strong or "high-evidence" reading correlates: (1) L2 decoding, (2) L2 vocabulary knowledge, (3) L2 grammar knowledge, and (4) L1 reading comprehension. Additional "low-evidence" correlates included L2 phonological awareness, L2 orthographic knowledge, L2 morphological knowledge, L2 listening comprehension, working memory, and metacognition. Csapó and Nikolov (2009) implemented projects among 6th- and 8th-graders in Hungary in order to find out how students' reading proficiency is compared to one another both in their native language and in English as a foreign language. They found strong relationships between L1 and L2 reading comprehension and other factors suggesting the learning process in early foreign language learning was complex.

As with listening skills, reading skills assessment benefits from computerized technology. Because reading a passage and then responding to multiple-choice, short-answer, or matching tasks are common task types for assessing English language reading; these types of assessments are good candidates for a computer-based assessment (CBA) approach. Garrett (1991) reported that converting these task types from paper-and-pencil tests to computer-delivered tests was a major goal of CBA. Carr (2006) stated these tasks are the most commonly used ones in CBA for assessing reading but required minor adaptations for computer delivery. Shabani (2012) tested the feasibility of a computerized version of dynamic assessment in the context of L2 reading comprehension. His results showed media effects such as scaffolding can improve students' reading comprehension by directing readers' attention to the important parts of the text and help them to understand better.

In summary, comprehending spoken and written texts requires two main processes: bottom-up, which involves decoding the word and sentence structures and top-down, which emphasizes the meaning of sentences and text based on background knowledge. Tobia et al. (2016) noted that both require working memory skills, but in most cases, it is possible to look back at the text in reading comprehension tasks, but this is not possible for orally presented texts. In my opinion, this may impact listening assessment. Also, Florit and Cain (2011) noted that reading and listening comprehension developed along different paths: Listening comprehension precedes and predicts reading comprehension, which can be developed only after formal education. Tobia et al. (2016) stated that reading and listening comprehension are significantly different from the productive domains of writing and speaking. 


\subsubsection{Computer-Based and Online Language Assessment}

Today, computer-based (CBA), computer-assisted (CALT), and web-based tests are widely used to assess language skills. Researchers agree that they save time and costs and they provide new ways to assess language skills especially for language listening and reading skills assessments. Earlier studies found computers to be useful in many ways. Brown (1997), for example, in his study summarized various advantages that researchers found related to computer-assisted language testing (CALT):

1. The use of computers allows students to work at their own pace.

2. CALTs generally take less time to finish than traditional paper-and-pencil tests and are therefore more efficient.

3. In CALTs, students should experience less frustration than on paper-and-pencil tests because they will be working on test items that are appropriate for their own ability levels.

4. Students may find that CALTs are less overwhelming (as compared to equivalent paper-and-pencil tests) because the questions are presented one at a time on the screen rather than in an intimidating test booklet with hundreds of test items.

5. Many students like computers and even enjoy the testing process.

(Brown, 1997, p. 41).

Thelwall (2000) stated that CBA is now used for exams and mid-unit tests and diagnostic assessments. He summarized how CBA is used in any different contexts and can perform different functions in formative and summative assessment. (see Table 10).

This table shows that computer-based assessment is not separate from the rest of the language learning process but situated in a learning environment. Ricketts and Wilks (2002) gave a formal evaluation by students at the end of the online examination. Their study results showed only a few students felt that online examinations were more stressful while the majority found the online examination format was less stressful than other exams. In their second phase, a change of interface (no scrolling) produced an improvement in performance. Similarly, Choi and Tinkler (2002) suggested that scrolling reading passages on computer screens seem to negatively affect the test-taking behaviors of younger students.

Studies on the computer-based testing have been increasing recently because the use of computer-based assessment has rapidly developed in the last decades. Kozma (2009) noted that there is a need to transform assessment from traditional methods because there is a significant gap between what happens in schools and what happens outside of schools. Computerized assessment can fill this gap. Today's technological word requires people to use subject knowledge and a variety of technological tools and resources to analyze and solve complex 
problems in their future career. He also noted that taking traditional exams without accessing other resources and applying simple procedures to pre-structured problems within a single school subject fails to prepare students for the demands of the 21 st century. Chapelle (2010) distinguished three main motives for using technology in language testing: (1) efficiency by utilizing automated writing evaluation or automated speech evaluation systems, (2) equivalence by making computerized tests equivalent to paper and pencil tests, and (3) innovation or the reconceptualization of the L2 ability construct. Terzis and Economides (2011) concluded that CBA must be playful, easy to use and useful based on careful design of the content, and they recommended that practitioners and educators have to promote CBA effectively in order to create an image acceptable by students.

Table 10. Taxonomy of the applications of CBA

\begin{tabular}{|c|c|c|}
\hline Area & Type & Description \\
\hline Summative & Exam & $\begin{array}{l}\text { An assessment solely for grading purposes such as an exam at the } \\
\text { end of a unit of study (Callear \& King, 1997; Zakrzewski \& Bull, } \\
\text { 1998). }\end{array}$ \\
\hline $\begin{array}{l}\text { Formative/ } \\
\text { Summative }\end{array}$ & Grading test & $\begin{array}{l}\text { An assessment for grading but which also provides feedback } \\
\text { intended to direct future studies. Includes a mid-unit small test, or } \\
\text { weekly problem sets (Callear \& King, 1997; Zakrzewski \& Bull, } \\
\text { 1998). }\end{array}$ \\
\hline Formative & Open access test & $\begin{array}{l}\text { A grading test that doubles as a set of exercises because students } \\
\text { are allowed to practice before sitting for the test (Thelwall, 1998). }\end{array}$ \\
\hline Formative & Self-test & $\begin{array}{l}\text { An assessment designed to give feedback to students on their } \\
\text { progress with a section of a unit of study (OR test, } \\
\text { http://www.cba.scit.wlv.ac.uk; Zakrzewski \& Bull, 1998). }\end{array}$ \\
\hline Formative & Exercises & $\begin{array}{l}\text { A problem set designed to consolidate learning on a section of a } \\
\text { unit of study (Whiting, 1985; Thoennessen \& Harrison, 1996). }\end{array}$ \\
\hline Formative & $\begin{array}{l}\text { Programmed } \\
\text { learning tool }\end{array}$ & $\begin{array}{l}\text { A linear CAL package based upon a question and answer session, } \\
\text { as pioneered by Skinner (1968). }\end{array}$ \\
\hline Formative & CAL quiz & $\begin{array}{l}\text { A marked exercise integrated into a CAL package, for example a } \\
\text { multiple-choice question presented after a slide containing new } \\
\text { information (Beilby, 1993; Kelly, Maunder \& Cheng, 1996). }\end{array}$ \\
\hline Formative & $\begin{array}{l}\text { Adaptive CAL } \\
\text { quiz }\end{array}$ & $\begin{array}{l}\text { A marked exercise integrated into a CAL package used to test the } \\
\text { student but also used to adapt the teaching of the package to } \\
\text { student weaknesses (Laurillard, 1993). }\end{array}$ \\
\hline Formative & Diagnostic test & $\begin{array}{l}\text { An assessment of prior learning taken before a unit of study } \\
\text { (Appleby et al., 1997). }\end{array}$ \\
\hline
\end{tabular}

Note. adopted from Thelwall (2000, p. 39). 
Suvorov and Hegelheimer (2013) noted that Computer-assisted language testing (CALT) is more suitable for evaluating second language learners' test performance because it utilizes multimedia and automatic response. . Ockey (2009) stated Computer-based testing (CBT) has gotten a large amount of attention in the field of second language assessment over the last two decades because of the use of computers to deliver, score and select test items. The increasing use of CBT has occurred on numerous assessments, from high-stakes, large-scale commercialized tests to low-stakes, small-scale assessments available for free on the Internet. However, Douglas and Hegelheimer (2007) found that software versions of high-stakes, largescale assessments that were delivered on CD-ROMs are now being replaced by Web-based testing systems.

Csapó, Molnár and Nagy, (2014) stated that in school practice the applicability of technology-based assessment is most efficient when it is used as early as possible and can be carried out anytime with very low cost and with no extra teacher time. They recommended that three dimensions need to be considered in using CBA: (1) making constructs currently assessed with traditional instruments measurable using computer technology, (2) enhancing the online assessment technology with functionalities that are already in use in other areas of information technology (e.g. speech recognition and detection of emotions), and (3) exploring ways of integrating frequent early assessment into educational processes. Additionally, Csapó, Molnár and Tóth (2009) found the test mode significantly affected students' achievement, and their results indicated that the scores on open-ended items requiring interacting with media were higher in paper and pencil mode than in computer-based mode. The students achieved higher scores in computer-based than in paper and pencil mode on the subtest containing multiplechoice items. Key factors relating to the test mode effect were information and computer technology expertise and familiarity, which differed between genders. Boys had more expertise in computer usage than girls.

Most language assessment developers, including those producing CBT systems, have designed tests to assess one or more of four skills (listening, speaking, reading, writing) independently. Recently, CBT which integrates one or more of the productive skills and one or more of the receptive skills, has become more widespread. Chapelle, Grabe and Berns (2000) noted that computerized language tests can be designed to assess a single language skill (i.e. reading, writing, speaking or listening) or a set of integrated skills (for instance, speaking and listening).

In this study, English language receptive skills (listening and reading) are the primary focus with a goal of a deeper understanding of the relationship between assessment, teaching 
and learning theory, and the current practice of these skills. As mentioned above, receptive skills are more appropriate for CBA than productive skills (speaking and writing) because receptive skills are assessed in more objective ways and are easier to score. Productive skills require more performance-based tasks which require more time and careful scoring. Ockey (2009) remarked that CBT has had a great impact on language assessment practices making it possible to score writing and speaking prompts and developing more authentic tasks than paperand-pencil tests, however, the challenges in developing effective CBT still exist but the advantages of using computers to assess language is always worth the effort.

\subsubsection{Testing listening skills online}

Computers are capable of delivering a larger variety and more authentic tasks for assessing listening than traditional paper-and-pencil assessments and can include context cues, which have not been in the paper-and-pencil tests. Traditional listening tests are designed to assess the ability to comprehend a classroom lecture delivered via cassette tape or other auralonly input devices. Ginther (2002) stated that computers make other listening tasks and contexts feasible, including visual context along with the aural input so that speakers can be observed communicating the intended message. Some test takers reported that using many cues help them comprehend the message when taking a listening test. Cues reported include lip movements, facial gestures, hand movements, and other body languages (Ockey, 2007).

On the other hand, others reported that visual input did not help them better understand the intended message, and some even say that visual input was distracting (Gruba, 1989; Wagner, 2007). However, the growing trend in language assessment to make tests as authentic as possible suggests that test-developers should use digital video as input for listening tests. Csapó, Ainley, Bennett, Latour and Law, (2012) stated that technology is not used the same way as other typical domains (mathematics) for listening comprehension in the computer-based assessment. Adding more videos of the speaker with the visual cues leads to better achievement in listening comprehension tests.

\subsubsection{Testing reading skills online}

Reading ability is commonly assessed by answering questions to assess students' understanding of written discourse. Reading a passage and then responding to multiple-choice, short-answer, or matching tasks are common task types that have been used in reading comprehension assessment (Alderson, 2000). Carr (2006) noted these tasks require only minor adaptations for computer delivery. Shabani (2012) stated that electronically delivered test with media scaffolding can enhance students' reading comprehension processes and can replace 
humans in raising readers' consciousness by directing their attention to the key sections of the text and assisting them to understand the text better. Choi, Kim and Boo (2003) found that because of the effects of significant multimedia for the computer-based language testing of reading comprehension, the grammar test showed the strongest comparability, and the reading comprehension tests the weakest comparability of the subjects' scores comparing the computerbased and paper-based language testing modes.

\subsection{Factors affecting Students' English Language Learning Achievement}

In this study, we will discuss teacher-related factors, consisting of teaching strategies, teaching materials, teachers' encouragement of out-of-class activities, and teachers' experience; student-related factors, consisting of learning strategies, students' attitude, study hours; schoolrelated factors consisting of school location, school technology supply; and demographic factors, consisting of students' socio-demographic background (age, gender and parents' education). These numerous factors can be organized into levels.

Bertolini, Stremmel and Thorngren (2012) explained that different levels of factors that impact on students' achievement can be shown on Bronfenbrenner's (1979) bio-ecological model. The model depicts different levels that surround a student and it shows personal factors as the most influential factor, interactions with others as the second most influential factor, and communities as the next most influential factor. See Figure 7.

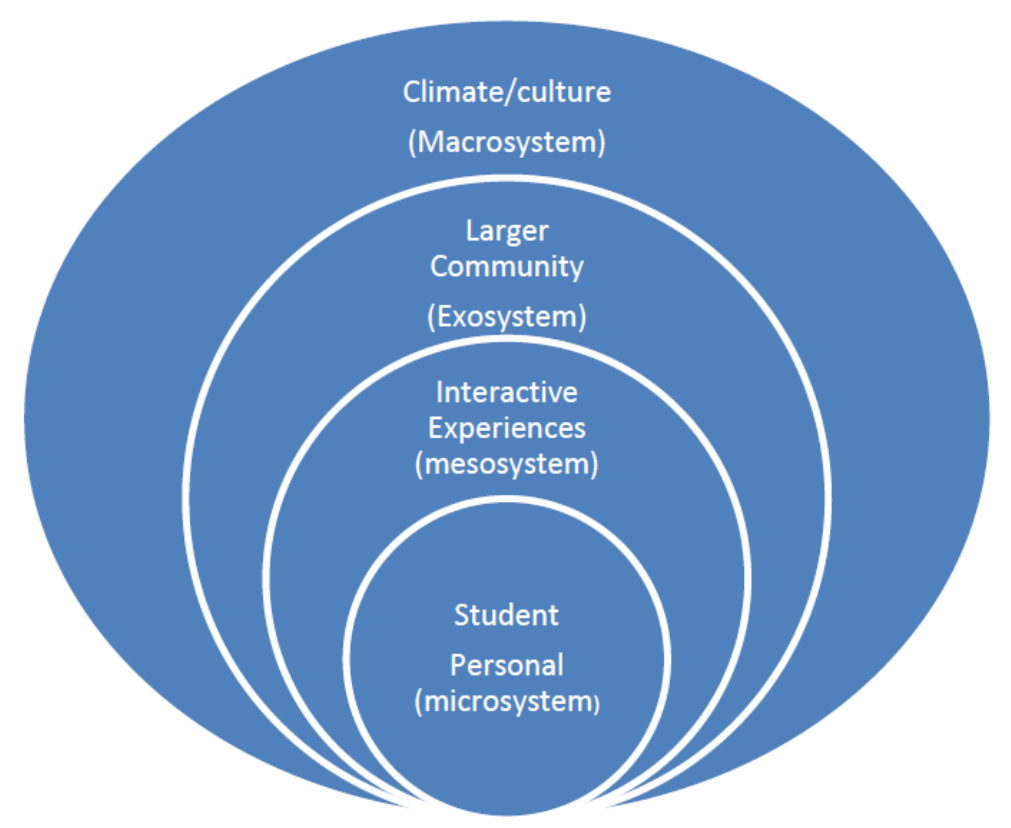

Figure 7. Bronfenbrenner's Bio-ecological Model (1979). 
Similarly, Széll (2013) identified several factors affecting student achievement. At the level of the student, he included gender, place of living, family background, attitudes to learning, motivation, and network of connections. For the level of schools, he included infrastructure, location, size of the school, atmosphere, and number and composition of students. Regarding teachers as another level, he included professional training, attitudes to teaching, motivation and cooperation. Santiago (2002) classified teaching technology as an important factor and defined it as the interaction between teachers and students and the materials and resources used in the classroom. Other relevant factors Santiago explored included curriculum content, methods for assessing student progress, class size and teaching loads. For the school environment, he included parental and community involvement, peer effects, an internal organization of schools, leadership, academic norms, safety and quality of facilities.

Crosnoe, Johnson and Elder (2004) termed factors as student factors, family factors, school factors and peer factors. Lightbown and Nina (2013), and Macaro (2010) identified two main factors: internal factors (age, personality, intrinsic motivation, experiences, cognition and native language) and external factors (curriculum, instruction, culture and status, extrinsic motivation and access to native speakers) that influence students' second language acquisition.

\subsubsection{Teacher-related factors}

The relationship between teachers' instructional techniques and student achievement is one of the most studied areas in elementary and secondary education. Numerous studies have investigated the influence of teaching-related factors on student learning achievement, not only for English language achievement but for other science subjects as well. Schroeder, Scot, Tolson, Huang and Lee (2007) identified the extant body of recent studies in science teaching to provide research-based evidence of effective teaching strategies. They found "Enhanced Context Strategies" and collaborative learning are related to students' previous experiences, and they involve activities such as group projects. Fidler (2002) examined which teaching strategies and techniques observed in the classroom were significant predictors of student achievement in case of 2nd- and 3rd-graders in a large US school system as measured by the spring 2000 SAT/9 scores on reading, mathematics, and language subjects. Fidler's results indicated that there were specific observed teaching techniques that impact student achievement in reading and language. The use of classroom management skills was also a significant predictor of reading achievement and language achievement. Their results also indicated that students who had experienced teachers scored significantly better in math and language. 
Quantitative research has suggested teacher quality and good classroom practices have a greater effect on students' achievement while qualitative literature has emphasized the value of individualizing instruction, teachers' professional development and authentic assessments (Wenglinsky, 2002). Klem and Connell (2004) reported that teachers' support of student engagement by creating a caring, well-structured learning environment has been shown to be a strong predictor of students successfully learning. Ganyaupfu (2013) stated a teacher-student interactive method followed by a student-centered method could be the most effective in developing students' academic performance. He added that in order to have such a good classroom practice, teachers need to have good professional development. Additionally, Hayes (2014) highlighted teachers' professional development needs to be supported by a good school policy trying to encourage teachers to incorporate new methods into classroom instruction.

\subsubsection{Student-related factors}

A positive relationship has also been found between participants' reading comprehension test performance and the use of learning strategies. Ghafournia and Afghari (2013) examined reader-related and text-related factors that significantly influenced students' reading comprehension passages. Bernaus and Gardner (2008) concluded that teachers' traditional strategies were not related to their students' English achievement, but attitude, students' motivation, language anxiety, and students' perceptions of learning strategies tended to be related to their language achievement.

Also, Nist and Simpson (1985) indicated that classroom instructors were responsible for teaching learning strategies to students actively and it was not enough just to realize a student's knowledge or awareness of a strategy. Teacher ingenuity, not necessarily published materials (e.g. workbooks, kits etc.), were found to be needed to assist students in learning how to apply and regulate new strategies for future tasks. Some studies showed students' language learning strategies can also affect students' learning achievement. Marefat and Barbari (2009) found students paid more attention to the use of linguistic forms and language responses. Additional they found students used more receptive skills than productive ones.

Zhang, Liu, Zhao and Xie (2006) studied Chinese EFL learners' test-taking strategy use and its effect on students' test performance. They found that significant correlations emerged between compensation and social strategies and students' test performance. They concluded that teachers should encourage EFL learners to use effective English test-taking strategies whenever possible, since English test-taking strategy could, indeed, affect students' test performance, at least for certain aspects of performance in English. Hulin and Yulian (2016) 
have shown that students' English learning beliefs were another strong predictor of English achievement. In their study, student personality also appeared to influence learning beliefs and learning achievement. Another researcher, Pesce (n.d.), mentioned five additional factors that may affect ESL students' test scores: self-study time (extra work at home), absenteeism, test anxiety, understanding the text structure, and focus on fluency. Wise, Barners, Harvey and Plake (2009) showed that feelings of anxiety toward computers and lack of experience using computers had a debilitating effect on student performance when a computer-based test was used. Also, they found student attitude towards time allocation for study per day were positively related to their performance.

\subsubsection{Socio-demographic factors}

Socio-economic status is frequently indicated as the main factor of students' quality of academic performance. Farooq, Chaudhry, Shafiq and Berhanu (2011) found socio-economic status and gender significantly affected students' achievement. Girls performed better on Math and English. Hijazi and Naqvi (2006) explored factors affecting college students' performance in Pakistan. Their result showed that the mother's education and age affected their children's performance. It is clear that a lot of factors have been shown to impact student performance. Some similar factors were chosen for this current study with results that were compatible with Farooq et al.’s (2011) and Hijazi and Naqvi’s (2006) study results.

Széll (2012) indicated that the socio-economic situation of the individual and the school, together with classroom processes, and the atmosphere of the school can all be included in the socio-economic context. EI-Omari (2016) was concerned about factors which the researcher believed to have a prominent relationship with learning English in Jordan. First, students whose parents were good at English reported greater achievement of language learning than students whose parents were not good at English. Second, students from small families reported better English language learning achievement than those living in big families. Third, students of high-income families reported achieving higher grades at learning English than those of lowincome families.

\subsubsection{School-related factors}

Lai, Sadoulet and Janvry (2009) included the teacher-student ratio, average class size, number of years the school has been in operation, school size, playground area, number of libraries, number of computer laboratories, and number of media facilities per 100 students in their school factors. Ariyarathne (2013) similarly mentioned that school factors include school structure, student-body composition and school climate. Students' educational outcomes and academic 
success were found to be greatly influenced by the type of school the students attend. His result indicated private schools tended to have both better funding and smaller class sizes than public schools. Ariyarathne (2013) found private schools have more opportunity to afford teaching and learning recourses which can raise academic achievement more than in public schools.

Schlesser (2004) examined how after-school activities may have encouraged students to excel in academics, and how teacher bias toward participating students' parents influence their children's participation. Students choose to participate in after-school activities because of their interests and a resulting achievement in academics directly contributed to student outcomes. Hasey (2014) said a curriculum is also one of the school factors that allows teachers and students to use meaningful language in new contexts. Ariyarathne (2013) added the average number of computers per classroom as a factor with a high impact on learning achievement.

\subsection{Summary}

The literature shows that assessment and testing practices in schools have followed a testing rather than a learning orientation. As a result of this, teachers and learners have been interested in the product of learning rather than the process of learning. Researchers are divided on whether high-stakes tests contribute to negative or positive effects in teaching practices. However, most researchers have found it affects teachers' instruction and test preparation strategies negatively and noted that teachers focus more on test practices than other active learning practices in the classroom. Also, there is little published research on how English language education is influenced by assessment and accountability policies. For test preparation strategies, teachers tend to pay more attention to subjects that are assessed with state-level assessments. Very little of the research regarding the teaching of listening and reading has reached English as foreign language teachers in Mongolia, compared to research-based vocabulary, speaking, and writing teaching practices, at least not in an effective way.

Researchers suggested different teaching materials improve students' language skills to match with their interests and out-of-class activities that can allow students to use the language in real situations to improve their learning outcomes and integrate these outside activities with classroom activities. However, most studies show that teachers mostly use textbooks and do not encourage students to do activities out of class. Using LLS and LLS training in the English language class not only encourages learners in their language learning but also helps teachers reflect on and improve their teaching. Students' attitude is also mentioned as one of the most important factors that impact on the improvement of language skills. From the literature, we 
can see that researchers mostly focused on exploring factors affecting students' general learning achievement and language learning, however very little is known about what factors may affect students' English language receptive skill learning achievement. Therefore, there is a need to find out how those relevant factors which are categorized into student-related factors consisting of learning strategies, students' attitude, study hours; school-related factors consisting of school location, school technology; teacher-related factors consisting of teaching strategies, teaching materials, teachers' encouragement of out-of-class activities, teachers' experience; and sociodemographic factors consisting of students' background (age, gender, parents' education) can affect students' learning achievement of English receptive skills. 


\section{CULTURAL BACKGROUND}

\subsection{Introduction}

National educational policy and the standards for each level of formal education are administered by the Ministry of Education Culture, Science and Sports (MECSS) in Mongolia. The education system consists of kindergarten, primary, lower secondary, upper secondary, high school, technical education or vocational training or higher education (all academic degrees from universities and colleges). State level exams are administered by the Educational Evaluation Center to place the level of implementing programs for the kindergarten, primary-, and complete secondary education, to analyze and assess the national quality of graduates in each grade, and to substantially assess students' knowledge and skills. Assessments are given in the 5th, 9th and 12th grades in Mathematics, Mongolian language, natural science, and foreign language (English or Russian) (EEC, 2016). Also, tests for specific subjects are given by local educational centers to examine students' standard level in each subject.

The purpose of the educational assessment in educational documents is stated precisely in Mongolia. In the educational evaluation standard, the following requirements are stated: (1) assessment content should be selected based on the right level of cognitive skill; (2) the tasks should be made to meet with the right skills of the course competence; (3) the methods of assessment should suit the assessed students' knowledge, ability and attitude; (4) students' selfassessment should be included to evaluate teaching and learning results and changes; (5) the assessment should have respectful, open and flexible versions. In the core curriculum the purpose of the assessment is defined as "to assess the students' learning process of knowledge, skills, and achievement and to improve the quality of education based on the assessment results" (MECS, 2015, p. 20). Regarding the regulation of secondary school students' and the evaluation of education quality, "The assessment of school achievement is the base for assessing and developing educational standards, curricula, textbooks, learning environment, the quality of training for pre-, in-service teachers, teachers' instructions, school activities and estimating the benefits of education" (MECS, 2013, p. 1). The following section discusses the state graduation exams that are taken at the elementary-, secondary- and high-secondary education levels to estimate the national quality of education. 


\subsection{Educational assessment and accountability in Mongolia}

International and national projects were conducted in recent years to examine the educational assessment in Mongolia. In one example, Mongolia was involved in the project of Monitoring Learning Achievement by UNESCO and UNICEF in 1999-2000 (Sed \& Nadmid, 2009). In this project, 2,545 4th grade students and 2,636 8th grade students were surveyed. The main result of this project was the big difference on test performance identified between urban and rural area students. The 8th-graders' average score on two tests was 54.0 and the age (6-7) of entering school was given as the main reason for the exam failure. Also, the report showed that directors', school managers', and parents' level of education influenced students' learning achievement.

Another big project was conducted to explore what skills and abilities were learned in mathematics and civic education by the 8th-graders. This project, surveying 4,729 8th-graders, was administered by the Ministry of Education, Culture and Science together with the Education and Evaluation Center under the support of the Soros foundation based on the Trends in International Mathematics and Science Study (TIMSS) assessment given in 2004-2005. The result showed that students achieved only $50.3 \%$ on the math test and $48.6 \%$ on the civil education test. Students who entered school at the age of 6-7 had better scores than those ones who entered at the age of 9-10. Students who live with their parents got better scores and their parent's education was one of the factors that influenced learning achievement. Also, it was found that large classroom size badly affected achievement as well.

From 1999-2008, five National Assessments of Learning Achievement, including the two mentioned above, were conducted in Mongolia. A project on primary education assessment of learning achievement was done in 2004 by MECS with the support of the UN Children's Foundation under the program of the assessment of learning achievement related to environments by the Asian Development Bank and UN. Another project on secondary education assessment of learning achievement was conducted on Math and Mongolian language in 2007 selecting 3,840 students from 6th and 9th grades, 576 teachers, 3,840 parents, and directors and school managers from 96 schools from the capital city, provinces and small villages. The results of these national assessments of learning achievement are used (1) to improve the quality of learning achievement and to give advice to teachers to change their instruction and, furthermore, to define the direction of the educational policy; (2) they are not used to rank the schools, teachers, and students; and (3) the results are introduced to policymakers, staff of educational institutes and parents to improve learning outcomes. 
Additionally, state level exams are administered by the Educational Evaluation Center to determine the level of implementing the programs at kindergarten, primary-, and lower- and upper-secondary education levels to make an appropriate effort to analyze the national quality of assessment at the graduate level and to substantially assess students' knowledge and skills. These assessments are taken at the 5th, 9th' and 12th grades in mathematics, Mongolian language, natural science and English language (EEC, 2018). The 5th-grade students are in their last grade of primary education, the 9th-grade students are in their last year of lower secondary education, and the 12th-grade students are in their last year of upper secondary education level. Therefore, the achievement test is administered to assess the level of students' knowledge and skills, the effectiveness of curricula implementation, and the quality of education at the time students are completing each level of education. See Table 11 for a list of grades and subjects.

Table 11. School achievement state-level tests in Mongolia.

\begin{tabular}{|c|c|c|}
\hline Education levels & Grades & Subjects \\
\hline \multirow[t]{3}{*}{ Elementary } & 5 & 1. Mongolian language \\
\hline & & 2. Mathematics \\
\hline & & 3. Science \\
\hline \multirow[t]{4}{*}{ Lower secondary } & 9 & 1. Mongolian Language \\
\hline & & 2. Mathematics \\
\hline & & 3. Science \\
\hline & & 4. Foreign language (English/Russian) \\
\hline \multirow[t]{4}{*}{ Upper secondary } & 12 & 1. Mongolian language and Literature \\
\hline & & 2. Mathematics \\
\hline & & 3. Elective (Science, Social science) \\
\hline & & 4. Foreign Language (English/Russian) \\
\hline
\end{tabular}

Note. From EEC (2018, 2019); http://www.eec.mn/ush

There are also different tests for specific purposes which are given by local educational centers to examine students' standard level for each subject (see Table 12).

Reflecting on the assessment system and different assessments in Mongolia, it appears teachers may have limited time for preparing and organizing effective classes to develop students' meaningful learning strategies. 
Table 12. Formal and informal assessments taken in schools for different purposes in Mongolia.

\begin{tabular}{|c|c|c|c|c|c|}
\hline № & Exams & Administered by & Purpose & Grades & Time \\
\hline 1 & $\begin{array}{l}\text { School } \\
\text { achievement tests }\end{array}$ & $\begin{array}{l}\text { Ministry of } \\
\text { Education }\end{array}$ & $\begin{array}{l}\text { To assess the completion of } \\
\text { Educational Standards for three } \\
\text { education levels }\end{array}$ & $\begin{array}{l}5 \text { th, } 9 \text { th, } \\
12 \text { th } \\
\text { grades }\end{array}$ & $\begin{array}{l}\text { End of } \\
\text { School year }\end{array}$ \\
\hline 2 & $\begin{array}{l}\text { Grade completion } \\
\text { exams }\end{array}$ & $\begin{array}{l}\text { Educational centers } \\
\text { in cities and } \\
\text { provinces }\end{array}$ & $\begin{array}{l}\text { To assess the completion of } \\
\text { Educational Standards for each } \\
\text { grade }\end{array}$ & All grades & $\begin{array}{l}\text { End of } \\
\text { School year }\end{array}$ \\
\hline 3 & $\begin{array}{l}\text { Specific subject } \\
\text { exams }\end{array}$ & $\begin{array}{l}\text { Educational centers } \\
\text { in cities and } \\
\text { provinces }\end{array}$ & $\begin{array}{l}\text { To assess the completion of } \\
\text { Educational Standards for each } \\
\text { subject }\end{array}$ & All grades & Spring \\
\hline 4 & $\begin{array}{l}\text { National } \\
\text { assessment of } \\
\text { School } \\
\text { achievement }\end{array}$ & $\begin{array}{l}\text { Educational } \\
\text { Evaluation Center }\end{array}$ & $\begin{array}{l}\text { To assess the completion of } \\
\text { Educational Standards for some } \\
\text { specific subjects and levels } \\
\text { (math, reading, foreign } \\
\text { language, science) }\end{array}$ & Random & Announced \\
\hline 6 & $\begin{array}{l}\text { University } \\
\text { Entrance exam }\end{array}$ & $\begin{array}{l}\text { Educational } \\
\text { Evaluation Center }\end{array}$ & $\begin{array}{l}\text { To assess the completion of } \\
\text { Educational Standards }\end{array}$ & $\begin{array}{l}\text { 12th } \\
\text { grade }\end{array}$ & June \\
\hline 7 & $\begin{array}{l}\text { Exams for } \\
\text { promoting } \\
\text { teachers' status }\end{array}$ & Educational centers & $\begin{array}{l}\text { To assess the effectiveness of } \\
\text { instruction }\end{array}$ & Random & Announced \\
\hline 8 & Term exams & $\begin{array}{l}\text { School } \\
\text { administrations }\end{array}$ & $\begin{array}{l}\text { To assess the process of teaching } \\
\text { and learning standard } \\
\text { completion }\end{array}$ & All grades & $\begin{array}{l}\text { End of each } \\
\text { semester }\end{array}$ \\
\hline 9 & Progress tests & $\begin{array}{l}\text { School } \\
\text { administrations }\end{array}$ & $\begin{array}{l}\text { To assess teaching and learning } \\
\text { progress }\end{array}$ & All grades & $\begin{array}{l}\text { During each } \\
\text { semester }\end{array}$ \\
\hline 10 & Lesson exams & Teachers & $\begin{array}{l}\text { To assess teaching and learning } \\
\text { progress on certain units in } \\
\text { textbooks }\end{array}$ & All grades & $\begin{array}{l}\text { After each } \\
\text { unit }\end{array}$ \\
\hline
\end{tabular}

Note. EEC, 2018; Dornod Educational Center, 2017.

\subsubsection{Mongolian English Language Education}

The U.S. Peace Corps and Voluntary Initiative Support Organization (VISO) have been cooperating with the Ministry of Education of Mongolia to train English language teachers and students since 1991. English language is taught as the main subject in schools and some programs such as the National Teacher Training Program (1996-2005), the Soros Foundation (2003-2008), the National English Program (2009-2020), and the "Education" National Program (2010-2021) were implemented for developing students' and teachers' English skills, for introducing international methodology practices, and for strengthening the language learning environment. The aim of the foreign language program in Mongolia (Russian and English) is to "develop citizens with the competence of a foreign language to express their views in social contexts and communicate in a foreign language" (SMNC, 2004, p. 11). Also, 
the educational department of each aimag (province) has a foreign language methodologist who helps teachers with their professional development.

Additionally, the Foreign Language Standard (2004) and the Core Curriculum (2015) introduced methodologies for English language teaching. The core curriculum emphasizes student-centeredness, group activities and hands-on learning. These characteristics of appropriate teaching styles were identified in the 2004 Standards booklet (MECS, 2004). Beside these documents, the Cambridge system (2011), a British international curriculum originating from the University of Cambridge, was piloted in 40 selected schools for six subject areas, including English, in Mongolia from 2011-2020. This effort aims to deliver reform by adopting the Cambridge system and provide support to national teams of experts and education methodologists. The long-term project goal of all these efforts is to build a world-class education system incorporating internationally recognized best practice and standards (Carrier \& Khalifa, 2014).

There is the English Language Teachers' Association in Mongolia (ELTAM) which organizes conferences, workshops and research projects for English language teachers to support their professional development. The ELTAM implements the following activities:

$>$ the National TEFL Conference

$>$ national curriculum development

$>$ national textbook development

$>$ implementation of the National Program on English Education

$>$ developing ELT in schools through rural branches

$>$ teacher training seminars and workshops on ELT methodology

$>$ the National English Olympics for secondary school students

$>$ ELTAM Newsletter production

$>$ services of the resource center

$>$ ELT materials production

$>$ test design for secondary school students

$>$ the survey among secondary school teachers

$>$ English Language program development for rural school drop-out children. (The main focus is made on helping secondary teachers from rural schools that do not have access to services and information.)

$>$ Feasibility study on the current situation of English Education p. 7).

(ELTAM, 2010,

\subsubsection{English language assessment and criteria in Mongolia}

Three major documents, the educational standard, the syllabus for each grade, and the structure of the academic year, are used in all types of schools in Mongolia. The Educational 
standard (2004) consists of 20 separate standards implemented at the primary-, secondary-, and high-secondary levels. Each course in each level of education has their own standards for teachers to follow including syllabus, teaching methods, and assessments to use in their teaching. The standards are guides for teachers for their teaching and evaluation. For example, the standard for English language teaching aims to give the students the opportunity to live in new situations by learning the competencies of socializing, self-learning, creating, and cognizing based on their needs. Each level is represented in the standards booklet for primary, basic-, and secondary levels with specific objectives identified. Within each of the four domains, reading, listening, speaking, and writing, specific competencies are detailed with their correlated objectives. According to the standard, teachers are encouraged to use communication and student-centered teaching methods and assess their students' learning achievement based on their competence in language skills and social-cultural skills. The standard aims to develop students learning progress, students learning environment, and to use teaching materials based on the appropriate age and characteristics of their thinking skills (SMNC, 2004).

The following is an extract of foreign language test criteria for different grade levels based on the Mongolian Foreign Language Standards handbook. The competencies are encoded as follows: $m \mathrm{GH} n: \mathrm{Ko}$ where $m$ is the grade level. $\mathrm{GH} n$ denotes one of four language skills and Kode notes competencies and testing criteria for receptive skills as follows translated by Ragchaa (in Campbell \& Ragchaa, 2013; see Tables 13, 14).

Table 13. Competence codes in Foreign Language Standard (2004).

\begin{tabular}{c|c|c|c}
\hline GH Code & Language Skill & K Code & Competency \\
\hline GH1 & Listening & K1 & Language comprehension \\
\hline GH2 & Speaking & K2 & Language usage \\
\hline GH3 & Reading & K3 & Functional ability \\
\hline GH4 & Writing & K4 & Interaction with others \\
\hline
\end{tabular}

Source: Foreign Language Standards for Elementary and Secondary Education, Standards and Measurements National Center, Ulaanbaatar, 2004 and Campbell \& Ragchaa (2013, p. 28). 
Table 14. The testing criteria of listening and reading skills for 6th and 8th grade students.

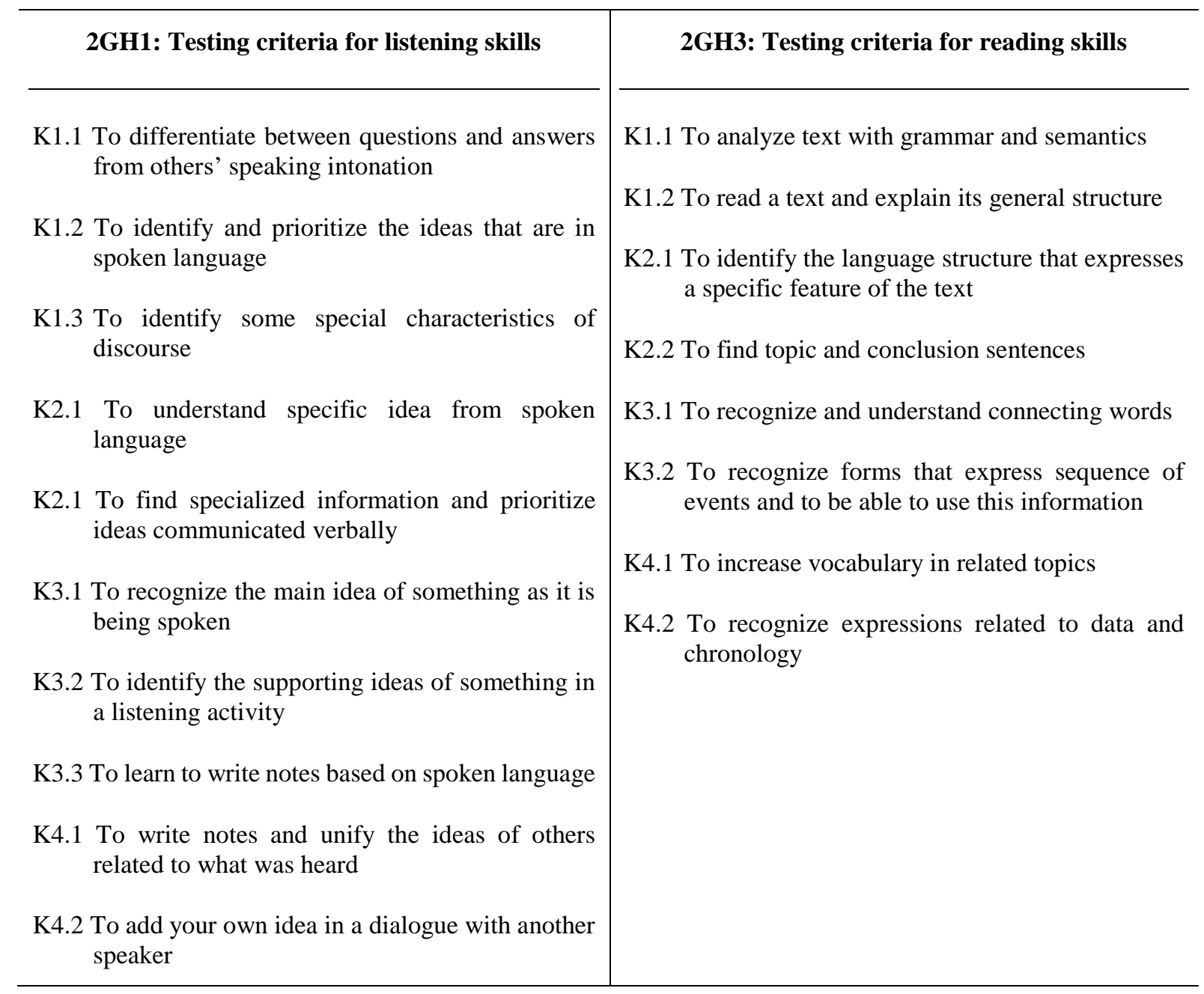

Source: Foreign Language Standards for Elementary and Secondary Education, Standards and Measurements National Center, Ulaanbaatar, 2004.Official publication document number MNS 5420-8:2004, Standard criteria for testing language skills and Campbell and Ragchaa (2013, p. 29).

Within this standards booklet, there are also details of the "methodology development for foreign language education" (p. 26) and principles for (1) selecting a content to learn, (2) teaching, (3) learning, and (4) evaluation and assessment. These principles are addressed with detailed expectations. For example, within teaching (2), the key concepts of the prescribed (teaching) methodology include communicative approach, pragmatic approach, functional approach, inductive approach and student-centered approach (p. 27). Another example, in assessment and evaluation (4), lists the following key points to be considered: focus on learners' development, student performance on different tasks, the quality of learning outcomes, and the learners' self-assessment of their own progress (p. 29). However, standards have been currently replaced with core curriculums. 
The core curricula for primary-, lower-, and upper secondary education are also important documents both for English language teachers and for guiding assessment efforts. These documents have been used as guidance on assessment methods and criteria for kindergarten, primary-, lower-secondary- and upper-secondary education since 2015. Each core curriculum has assessment methods and criteria for final and progress evaluations. Progress tests aim to support the student learning process, to make self-assessment possible, and to improve student learning efforts and styles by grading their participation and their improvement in learning. Final tests are used to assess students' knowledge and skills that should be acquired in each subject based on the educational evaluation standard. In the educational evaluation standard, the following requirements for the assessment are stated: (1) assessment content should be selected based on the right level of cognitive skill; (2) the tasks should be made to meet with the right skills of the course competence; (3) the methods of assessment should suit the students' knowledge, ability, and attitude; (4) the assessments should include students' self-assessment to evaluate teaching and learning results and improvement efforts; (5) the assessment should have respectful, open and flexible versions (SMNC, 2004).

As I mentioned in section 2.3, CEFR encourages a communicative approach to teaching but it isn't broken down by grade level, thus each country has to create lessons, textbooks and assessments based on the framework. Mongolia has created core curricula and identified which level corresponds to which grade and formulated its learning objectives, assessment criteria based on CEFR standards.

The core curriculum for lower secondary (MECS, 2015) includes grades 6-9 and provides guidance for each subject including syllabus, teaching methods and assessments. In this curriculum, English language students in grades 6-8 are required to meet the English language A1 to A2 levels of the Common European Framework of Reference for Languages (CEFR, 2001).

One can see how receptive skills are taught in Mongolia by examining the core curricula content and assessment criteria for English language listening and reading skills for the 6th and 8th grades as shown in Table 15 . 
Table 15. The Content and the assessment criteria of EL listening and reading skills for the 6th and 8th grades.

\begin{tabular}{cll}
\hline Grade & \multicolumn{1}{c}{ Content for listening skill } & \multicolumn{1}{c}{ Content for reading skill } \\
\hline \multirow{3}{*}{6} & $\begin{array}{l}\text { To learn proper pronunciation and the } \\
\text { structure of simple sentences by listening to } \\
\text { simple expressions, short dialogues and short } \\
\text { texts. }\end{array}$ & $\begin{array}{l}\text { To learn to make questions and answer } \\
\text { someone's questions after reading short } \\
\text { texts. }\end{array}$ \\
\hline \multirow{3}{*}{$\begin{array}{l}\text { To compare ideas and express own idea after } \\
\text { listening to simple conversations and short } \\
\text { passages }\end{array}$} & $\begin{array}{l}\text { To identify synonyms and antonyms and } \\
\text { find relations/reasons for something in the } \\
\text { text after analyzing a text. }\end{array}$ \\
\hline
\end{tabular}

\section{General assessment criteria for receptive skills}

- the ability to follow activity instructions

- the ability to understand personal information

- the ability to distinguish author's main and supporting idea

- the ability to guess the main idea/content of information

- the ability to recognize different types of texts

Note. National Core curriculum for lower secondary education of Mongolia (MECS, 2015, p. 129).

However, in an updated version, the levels are determined from low A1 to high A2 in $6^{\text {th }}$ and $8^{\text {th }}$ grades. The following tables 16,17 show how the learning objectives differ between the $6^{\text {th }}$ and $8^{\text {th }}$ grade levels of receptive skills as formulated in the English language course of core curriculum (updated, 2019). 
Table 16. Learning objectives of listening skill for 6th and 8th grades.

\begin{tabular}{|c|c|c|}
\hline & 6th grade (Low A1) & 8th grade (High A1) \\
\hline L1 & $\begin{array}{l}\text { Understand an increasing range of short, basic, } \\
\text { supported classroom instructions }\end{array}$ & $\begin{array}{l}\text { L1 Understand a sequence of supported } \\
\text { classroom instructions }\end{array}$ \\
\hline L2 & $\begin{array}{l}\text { Understand a limited range of unsupported } \\
\text { basic questions which ask for personal } \\
\text { information }\end{array}$ & $\begin{array}{l}\text { L2 Understand a growing range of } \\
\text { unsupported basic questions which ask for } \\
\text { personal information }\end{array}$ \\
\hline L3 & $\begin{array}{l}\text { Understand a limited range of unsupported } \\
\text { basic questions on general and curricular } \\
\text { topics }\end{array}$ & $\begin{array}{l}\text { L3 Understand a growing range of } \\
\text { unsupported basic questions on general and } \\
\text { curricular topics }\end{array}$ \\
\hline L4 & $\begin{array}{l}\text { Understand the main points of short supported } \\
\text { talk on an increasing range of general and } \\
\text { curricular topics }\end{array}$ & $\begin{array}{l}\text { L4 Understand the main points extended talk } \\
\text { on a range of general and curricular topics } \\
\text { with support }\end{array}$ \\
\hline L5 & $\begin{array}{l}\text { Understand some specific information and } \\
\text { detail of short, supported talk on an increasing } \\
\text { range of general and curricular topics }\end{array}$ & $\begin{array}{l}\text { L5 Understand most specific information and } \\
\text { detail of short, talk on a range of familiar } \\
\text { topics with support }\end{array}$ \\
\hline L6 & $\begin{array}{l}\text { Use contextual clues to predict content and } \\
\text { meaning in short, supported talk on an } \\
\text { increasing range of general and curricular } \\
\text { topics }\end{array}$ & $\begin{array}{l}\text { L6 Deduce meaning from context in short, } \\
\text { supported talk on a growing range of general } \\
\text { and curricular topics }\end{array}$ \\
\hline L7 & $\begin{array}{l}\text { Understand short, supported narratives on an } \\
\text { increasing range of general and curricular } \\
\text { topics }\end{array}$ & $\begin{array}{l}\text { L7 Understand supported narratives, } \\
\text { including some extended talk, on a range of } \\
\text { general and curricular topics }\end{array}$ \\
\hline L8 & $\begin{array}{l}\text { Recognize words that are spelled out on a } \\
\text { limited range of general and curricular topics }\end{array}$ & $\begin{array}{l}\text { L8 Recognize the opinion of the speaker(s) in } \\
\text { basic, supported talk on an increasing range } \\
\text { of general and curricular topics }\end{array}$ \\
\hline L9 & Understand short songs and rhythms & L9 Identify rhymes, and repetition \\
\hline
\end{tabular}


Table 17. Learning objectives of reading skills for 6th and 8th grades.

\begin{tabular}{|c|c|c|}
\hline & 6th grade (Low A1) & 8th grade (High A1) \\
\hline $\mathrm{R} 1$ & $\begin{array}{l}\text { Recognize, identify and sound a limited range } \\
\text { of language at text level with support. } \\
\text { Recognize the English alphabet in print }\end{array}$ & $\begin{array}{l}\text { R1 Recognize, identify and sound a range of } \\
\text { language at text level with some support }\end{array}$ \\
\hline $\mathrm{R} 2$ & $\begin{array}{l}\text { Read and follow familiar instructions for } \\
\text { classroom activities }\end{array}$ & $\begin{array}{l}\text { R2 Read and follow familiar instructions for } \\
\text { classroom activities with little support }\end{array}$ \\
\hline R3 & $\begin{array}{l}\text { Begin to read very short, simple, fiction and } \\
\text { non-fiction texts with confidence and } \\
\text { enjoyment, with support }\end{array}$ & $\begin{array}{l}\text { R3 Read short fiction and non-fiction texts on } \\
\text { an increasing range of general and curricular } \\
\text { topics with confidence and enjoyment, with } \\
\text { some support }\end{array}$ \\
\hline R4 & $\begin{array}{l}\text { Understand the main points of very short, } \\
\text { simple texts on a limited range of general and } \\
\text { curricular topics by using contextual clues }\end{array}$ & $\begin{array}{l}\text { R4 Understand the main points of short, } \\
\text { simple texts on an increasing range of general } \\
\text { and curricular topics by using contextual } \\
\text { clues }\end{array}$ \\
\hline R5 & $\begin{array}{l}\text { Understand some specific information and } \\
\text { detail in very short, simple texts on a limited } \\
\text { range of general and curricular topics with } \\
\text { support }\end{array}$ & $\begin{array}{l}\text { R5 Understand specific information and detail } \\
\text { in short, simple texts on a range of general } \\
\text { and curricular topics with little or without } \\
\text { support }\end{array}$ \\
\hline R6 & $\begin{array}{l}\text { Understand the meaning of very short, simple } \\
\text { texts on familiar general and curricular topics } \\
\text { by rereading them }\end{array}$ & $\begin{array}{l}\text { R6 Recognize the difference between fact and } \\
\text { opinion in short, simple texts on an increasing } \\
\text { range of general and curricular topics }\end{array}$ \\
\hline R7 & $\begin{array}{l}\text { Understand the meaning of simple short } \\
\text { sentences on familiar general and curricular } \\
\text { topics }\end{array}$ & $\begin{array}{l}\text { R7 Recognize the attitude or opinion of the } \\
\text { writer in short texts on an increasing range of } \\
\text { general and curricular topics }\end{array}$ \\
\hline $\mathrm{R} 8$ & $\begin{array}{l}\text { Use a simple picture dictionary with more } \\
\text { infrequent support }\end{array}$ & $\begin{array}{l}\text { R8 Use familiar paper and digital reference } \\
\text { resources to check meaning and extend } \\
\text { understanding with some support }\end{array}$ \\
\hline
\end{tabular}

Note. National Core Curriculum for lower secondary education of Mongolia (updated MECS, 2019, p. nd).

Table 16 and 17 above show 6th and 8th grade students are required to meet the levels of low A1 and high A1 in learning both English language listening and reading skills. According to the updated core curriculum, these learning objectives are also criteria for assessing students in these skills. 


\subsection{Summary}

The Mongolian government pays a lot of attention to English language education by implementing different programs, standards, curricula, and introducing international projects and international assessments. Despite being documented that English is a second language in Mongolia, it is not clear which term that should be used for describing this adoption: English as a second language or English as a foreign language. According to Richards et al. (1992), the ESL - English as a Second Language - refers to "the role of English for immigrant and other minority groups in English-speaking countries who use English at school and at work" (p. 124), and EFL - English as a Foreign Language - refers to "the role of English in countries where it is taught as a subject in schools but not used as the medium of instruction in education nor as a language of communication (e.g. government, business, industry) within the country." (pp.123124). In Mongolia, the English language is used as a Foreign Language and in order to use it as a second language, much more practice, time and reform in English language education would be needed.

Regardless of the term used, research is needed to find the reasons why English language education has developed slowly in Mongolia and why our students still cannot be fluent in speaking and writing or in the underlying listening and reading skills compared to other Asian countries, especially China, Japan and The Philippines. The reasons are hidden behind every aspect of education including assessment and associated accountability, teachers' instruction, school environment, students' learning strategies, and other socio-economic backgrounds. In order to develop English language education, research is needed to explore the hidden reasons behind the slow adoption of English language fundamental and comprehension skills (listening and reading), and the related assessment, instruction, and learning process of students. 


\section{METHODOLOGY}

\subsection{Introduction}

In this section, study samples, instruments, and data collection procedures of four main studies will be presented: (1) teachers' view of Educational assessment and accountability, (2) English teachers' teaching strategies of English receptive skills, (3) students' learning strategies and attitude towards English language learning receptive skills, and (4) assessment of students' English language receptive skills along with. Three sub studies will also be discussed: (5) English language teachers' view of assessment and accountability, (6) the relationship between teaching and learning strategies of ELRS, (7) factors affecting students' tests performance of English receptive skills.

The main purpose of these overall studies is to identify the issues and the reasons behind them in English language education by surveying teachers and students from selected schools to get different educational perspectives in Mongolia. In order to achieve the main purpose of this study, seven objectives were posed covering from broad to specific areas of research in order to identify (1) the teachers' view on the state-level exams and their reflection in their teaching practices due to the assessment and accountability system, (2) and more specifically, English language teachers' views and reflections in their teaching for further study of how (3) they teach English language receptive skills. Next this study attempts to identify (4) how students learn those fundamental skills and whether (5) teaching and learning these skills are related to each other to create meaningful learning, (6) how students learned these skills, and (7) what factors might have affected their test performance.

\subsection{Research questions}

Seven main research questions were addressed with their 32 sub-questions for deeper research according to the purpose and the objectives and the research gaps derived from the literature. 


\subsubsection{How is educational assessment and accountability used in the Mongolian}

Education system?

4.2.1.1 What are the primary and secondary teachers' beliefs about the usefulness and acceptance of large-scale assessments?

4.2.1.2 To what extent do teachers feel pressured by the different forms of achievement assessments?

4.2.1.3 How do teachers reflect on the shift in their teaching practices as informed by their assessments? How do they change their instruction?

4.2.1.4 What is the relationship between teachers' views on educational assessment and their instructions?

4.2.1.5 Which test preparation strategies do teachers mostly use?

4.2.1.6 Who puts pressure on primary and secondary school teachers in order to increase their pupils' learning achievement? To what extent does this happen?

\subsubsection{How do assessment and accountability influence English language instruction and} test taking strategies in Mongolia?

4.2.2.1 What beliefs do English language teachers have about the usefulness and acceptance of large-scale assessments?

4.2.2.2 How do English language teachers reflect on the shift in their teaching practices influenced by the assessments?

4.2.2.3 What is the relationship between English teachers'view on Educational assessment and their instructions in teaching English?

4.2.2.4 Which test preparation strategies do English language teachers mostly use?

\subsubsection{What are the English language teachers' perceptions of teaching ELRS?}

4.2.3.1 Which teaching English language listening strategies are mostly used?

4.2.3.2 Which teaching English language reading strategies are mostly used?

4.2.3.3 What teaching materials are used in teaching English language receptive skills?

4.2.3.4 How do teachers encourage their students to learn English language receptive skills out of class? 
4.2.3.5 What are the relationships between teaching strategies, teaching materials, and teachers' encouragement of out-of-class activities on English language receptive skills?

\subsubsection{How do students identify their strategies and attitudes towards ELRS?}

4.2.4.1 What strategies are frequently used for English language listening skills by 6th graders?

4.2.4.2 What strategies are frequently used for English language reading skills by 6th and 8th graders?

4.2.4.3 What are the students' attitudes towards English language receptive skills?

4.2.4.4 What is the relationship between English language learning strategies and attitudes?

\subsubsection{How are the teaching and learning strategies of English language receptive skills} related?

4.2.5.1 What is the relationship between teaching and learning strategies for English language listening skills?

4.2.5.2 What is the relationship between teaching and learning strategies for English language reading skills?

4.2.5.3 What is the relationship between teaching strategies and students' attitude towards ELRS?

4.2.5.4 What are the relationships between learning strategies of ELRS and teaching materials and teachers' encouragement of out-of-class activities?

\subsubsection{How did students perform on an online test developed for this study to assess their English language receptive skills?}

4.2.6.1 What is the 6th-graders' performance on the ELRS test?

4.2.6.2 What is the 8th-graders' performance on the ELRS test?

4.2.6.3 Which skill tasks are difficult for the 6th-grade students?

4.2.6.4 Which skill tasks are difficult for the 8th-grade students? 


\subsubsection{What are the factors affecting students' test performance?}

4.2.7.1 How do student-related factors affect students' test performance?

4.2.7.2 How do teacher-related factors affect students' test performance?

4.2.7.3 How do school-related factors affect students' test performance?

4.2.7.4 What is the difference between the students who have positive and negative attitudes performance on the ELRS test?

4.2.7.5 What is the difference between the students who have effective and ineffective use of learning strategies performance on the ELRS test?

\subsection{Hypotheses}

In Mongolia, elementary school teachers might feel more responsible for preparing their students for the school achievement test (SAT) than lower secondary teachers (see Table 3). As Table 3 shows, the 5th-grade SAT is where elementary competency knowledge and skills are assessed and only one teacher teaches all these subjects. Personal experience suggests these teachers spend more time working with students to help them master the elementary school competencies than time spent by lower secondary teachers. Secondary school teachers only teach one subject-area course and only if their course is included in the SAT and only if they teach 9th grade do they have to make a special effort to prepare their students for the SAT. From this situation, I formulated the following hypothesis: 
H1: Primary- and secondary school teachers' views on school achievement tests will be significantly different.

English language is one of the 9th-grade subjects included in the SAT; however, other subject teachers (math, Mongolian language, science) might also worry about their efforts to increase their students test scores. Therefore;

H2: English language teachers and other SAT subject teachers have the same reflections on their teaching practices.

H3: English language teachers and other SAT subject teachers use the same test preparation strategies for SATs in their teaching practices.

The teaching listening strategy questionnaire was developed based on strategies found in literature that were shown to be effective teaching strategies. Three strategies, students' discussion, developing students' metacognitive skill, and students' reflection emerged from a factor analysis of this teaching listening strategy questionnaire as being the most useful for English teachers.

H4: Three teaching strategies, students' discussion, developing students' metacognitive skill, and students' reflection should be used significantly more often than other teaching strategies to teach listening skills.

The literature shows that using specific reading strategies and activities and students' reflection tend to be useful and relevant teaching reading strategies. That means using different strategies to make students active and asking students to make inferences and discussing cultural points in the text are more effective strategies that can support students' metacognitive learning strategies.

H5: Specific reading strategies and activities, and students' reflection would be recognized by teachers as significantly different from other teaching reading strategies.

H6: There is no significant difference between 6th- and 8th-grade students' learning strategies for reading skills.

H7: There is no significant difference between 6th- and 8th-grade students' attitude towards learning reading skills. 
H8: Students' learning attitude is significantly correlated at $p<.05$ level with the four general types of learning strategies proposed in this study.

H9: There is a relationship between teaching strategies of receptive skills and students' attitude towards learning receptive skills.

H10: There is a relationship between teaching materials and students' learning strategies of receptive skills.

H11: There is a relationship between out-of-class activities and students' learning strategies of receptive skills.

H12: Teaching strategy will have positive effects on students' test performance.

According to the literature, using authentic materials and effective out-of-class activities support students' learning of listening and reading skills. So, skill acquisition should be positively correlated with each of these two dependent variables.

H13: Using virtual materials and out-of-class activities are significantly correlated at $p<.05$ level with skill acquisition.

H14: Parents' education has positive effect on their child's English language education.

H15: Students' positive attitudes will have positive effects on students' test performance and negative attitudes will have negative effects on students' test performance.

H16: Students' learning strategy will have positive effects on students' test performance. Also, there is not much chance for students to use the internet for studying at most schools or having much exposure to other authentic English language materials. Instead, students have to interact with their teacher and each students' own effort can impact their performance positively or negatively.

H17: A lack of computer supply and labs will have negative effects on online test performance.

H18: Internet connection has a positive effect on online test performance. 


\subsection{Methods}

\subsubsection{Study Site}

The place where the surveys were conducted was Dornod province in Mongolia. This is one of the biggest provinces and the central urban area for economic, social and educational status in the eastern part of Mongolia. The study site covers all the relevant characteristics of the Mongolian education system and may be considered as a culture-bearing unit fitting well to the purpose of this study. This study covered all public schools in the provincial capital and a representative sample of public schools in rural areas. These schools provide a good representation of the actual situation of how Mongolian teachers think about assessment and accountability and how the English language is taught in both urban and rural areas.

\subsubsection{Sampling}

Teachers from all subject areas were selected randomly and convenience from 12 schools (nine from the provincial center and three from rural areas). Additional English language teachers participated in the study. These teachers were drawn from 19 schools in Dornod province. Dornod province lies in the eastern part of Mongolia and includes a major city, Choibalsan. These 19 schools were in Choibalsan and in nearby villages (soums) in the surrounding metropolitan area. Sample selection was different in some cases because of special local situations, and these variations will be discussed in each of the following studies. The number of sample members participating in the English language learning strategy survey was a bit small because a reduction was done due to the limitation of internet connection, remote area, and teachers' and IT rooms' busy workload. However, the representation of sampling is reliable because studies covered all public schools in the center of the province and three rural areas.

The following sections describe the four main studies, each with different groups of participants, and three sub-studies related to three of the main studies. Each study involved different instruments and different participants starting from a broad view of educational assessment and accountability in general and then focusing more specifically on English language assessment, assessment of English language teaching and student learning styles, and finally an assessment of students' English language skills.

\subsubsection{Teachers involved in the study of educational assessment and accountability}

Participants in this study were 307 teachers from 12 schools; this covers approximately $35 \%$ of the teachers of the whole province (women: $n=259,87.5 \%$; men: $n=37,12.5 \%$ ), with 
$84 \%$ from Choibalsan and 16\% from rural schools. The mean age was 36.7 years $(\mathrm{SD}=8.3)$ and the mean teaching experience was 12.9 years ( $\mathrm{SD}=8.3)$. Additionally, 142 teachers $(46.2 \%)$ taught only at the primary level and 91 teachers (30.4\%) taught only at the secondary level while 70 teachers $(23.4 \%)$ taught at both primary and secondary levels. The degrees held by these teachers were professional (non-bachelor) certificates $(n=20,6.6 \%)$, bachelors $(n=224$, $74 \%)$, masters ( $\mathrm{n}=61,19.4 \%$ ), and no doctorates. Two sub-groups of primary- and secondary education level teachers were created to explore how many of the teachers taught the main subjects that are included in the national state exam. For the primary level, the Mongolian language was taught by 75 teachers $(100 \%)$ and mathematics was taught by 76 teachers $(100 \%)$. For the secondary education level, the Mongolian language was taught by 38 teachers $(16.5 \%)$, mathematics was taught by 50 teachers $(21.7 \%)$, and foreign language was taught by 36 teachers (15.6\%). After the overall teachers' data analysis exploring general ideas about assessment and accountability, 36 English teachers were identified and another analysis was made to explore specifically what English teachers think about assessment and how they change their instructions and test preparation strategies based on the impact of assessment and accountability.

\subsubsection{English language teachers involved in the study of teaching strategies}

Seventy-three English language teachers from 19 schools in Dornod province responded to this survey; $13.7 \%$ of them were men $(n=10)$ and $86.3 \%$ of them were women $(n=63)$. All English teachers from Dornod province were involved in this study: At the time of the study, there were 68 English language teachers and five English-Russian teachers teaching English language in the province covering all urban and rural schools according to the Local Education Center statistics (2017). These teachers had the following degrees: bachelors $(n=40) 54.8 \%$ and masters $(\mathrm{n}=31) 42.5 \%$. The average hours per week for teaching the English language were 20 hours and the average number of years of work experience was 10 years.

\subsubsection{Students involved in the study of learning strategies}

Participants in this study were 6th-grade students $(\mathrm{n}=100)$ and 8th-grade students $(\mathrm{n}=$ 115) ( $44.9 \%$ boys and $55.1 \%$ girls) from 12 schools. The 6th-grade students were in their first year of their secondary level and 8th-grade students were (now changed) in their last year of secondary level. Involving both groups allows us to see a picture of how English was taught during primary- and secondary levels and how well prepared each group appears to be for the next higher secondary education level. Seven to ten students from each of the 12 schools were selected conveniently by balancing gender and students' English proficiency levels from 
different English groups in both 6th and 8th grades. These reductions were due to the limitation of the Internet connection, a lack of devices, busy lab loads, and the size of the schools. There were usually 3-5 English classes with 25-35 students in each grade (e.g. 6a, 6b, 6c, .., and 8a, $8 \mathrm{~b}, 8 \mathrm{c}, \ldots)$ except in rural schools which had 7-15 students in each grade based on class sizes, and 1-2 teachers who divided the class into 1-2 groups (e.g. $6 \mathrm{a}^{1}, 6 \mathrm{a}^{2} ; 8 \mathrm{a}^{1}, 8 \mathrm{a}^{2}$ ) creating smaller size classes for rural schools. The sampling for this study covered overall 6th grades and 8th grades in all public schools in the center and the rural area of this province. The students' ages ranged from 10-14 years. The mean age was 12 years.

\subsubsection{Students involved in the assessment of language skills}

The same students $(n=100,6$ th-grade students and $n=115$ 8th-grade students from 12 schools) involved in the previous study of learning strategies also participated in the study of language skills. The breakdown by gender was $44.9 \%$ boys and $55.1 \%$ girls. Again, seven to ten students from 12 schools were selected conveniently by balancing gender and students' proficiency levels from different English groups in both 6th and 8th grades due to resource limits as described above.

\subsubsection{Participants in the sub-studies}

In the following Table 18, the subjects for the four main and three sub-studies are summarized. The three sub-studies include the following:

1. The English language teachers' instructional changes and test preparation strategies sub-study $(\mathrm{n}=36)$ was derived from the teachers' view of educational assessment and accountability study $(\mathrm{n}=307)$. The subjects were $100 \%$ women with a mean age of 33.8 years and a mean teaching experience of 9.4 years. $75 \%$ of them were Bachelor of Arts holders and 25\% of them were Master of Arts degree holders.

2. The relationship between teaching and learning strategies of English receptive skills sub-study $\left(\mathrm{n}_{\text {teachers }}=22, \mathrm{n}_{\text {students }}=215\right)$ was derived from the English teachers' teaching strategies $(n=73)$ and the students learning strategies $(n=215)$ studies. The 22 English teachers who taught English to those 6th- $(n=100)$ and 8th-grade $(n=$ 215) students in the students learning strategies study were also selected. Note that, in most cases, two teachers taught one grade by dividing them into 2 groups, except in the rural schools where one teacher taught both grades. Therefore, one teacher from each grade (6th and 8th) was selected in each school $(n=12)$ with her/his 7-15 students based on the class sizes by balancing students' gender and English proficiency levels from different groups. In this way, the 22 English teachers and 
their selected students can represent their schools' English language relationship between teaching strategies and receptive skills in these grades.

3. The factors affecting the test performance of English language receptive skills $\left(\mathrm{n}_{\text {English teachers }}=22, \mathrm{n}_{\text {IT teachers }}=12, \mathrm{n}_{\text {students }}=215\right)$ study was derived from the teaching strategy $(n=73)$, learning strategy $(n=215)$, and online assessment $(n=215)$ studies. In this study, a school infrastructure survey was included. The school infrastructure survey of IT teachers $(n=12)$ was conducted to examine the school's Internet connection and computer resources, to explore the school's ability to conduct online tests in these schools $(n=12)$.

The sub-studies will be discussed in more details in the results section.

Table 18. A summary of the subjects in the main studies and sub-studies

\begin{tabular}{|c|c|c|c|c|}
\hline \# & Main studies & Subjects & Sub-studies & Subjects \\
\hline 1 & $\begin{array}{l}\text { Teachers' view of Educational } \\
\text { assessment and accountability }\end{array}$ & 307 & $\begin{array}{l}\text { English language teachers' } \\
\text { instructional change and test } \\
\text { preparation strategies }\end{array}$ & 36 \\
\hline \multirow[t]{2}{*}{2} & \multirow{2}{*}{$\begin{array}{l}\text { English language teachers' } \\
\text { teaching strategies }\end{array}$} & \multirow[t]{2}{*}{73} & \multirow{3}{*}{$\begin{array}{l}\text { The relationship between } \\
\text { teaching and learning strategies }\end{array}$} & 22 \\
\hline & & & & \multirow[t]{2}{*}{215} \\
\hline 3 & Students' learning strategies & 215 & & \\
\hline \multirow[t]{5}{*}{4} & \multirow{2}{*}{$\begin{array}{l}\text { Assessing students' language } \\
\text { skills }\end{array}$} & \multirow[t]{5}{*}{215} & \multirow{5}{*}{$\begin{array}{l}\text { Factors affecting students' test } \\
\text { performance }\end{array}$} & 215 \\
\hline & & & & $\begin{array}{l}22 \text { (English language } \\
\text { teachers) }\end{array}$ \\
\hline & $\begin{array}{l}\text { English language } \\
\text { teachers' teaching } \\
\text { strategies }\end{array}$ & & & 12 (IT teachers) \\
\hline & $\begin{array}{l}\text { Students' learning } \\
\text { strategies }\end{array}$ & & & \\
\hline & $>$ School infrastructure & & & \\
\hline
\end{tabular}

\subsubsection{Instruments}

\subsubsection{Teachers' view on Educational assessment and accountability}

The teachers' view on educational assessment and accountability questionnaire was created based on numerous international questionnaires (Hamilton, Berend \& Stecher, 2005; Moore \& Waltman, 2007). This is the questionnaire of the IPEA (International Project for the Study of Educational Accountability Systems) project. Tóth (2014) adapted this questionnaire to fit into the Hungarian context in her $\mathrm{PhD}$ dissertation. In adapting this version into Mongolian context, some questions related to International assessment were discarded because Mongolia 
is not included in some International studies such as PISA and TIMMS. The questionnaire consisted of seven blocks of questions (61 items). Each block represented a particular assessment or accountability procedure: (1) Teachers' background questions consisting of five items, (2) views on large-scale assessments consisting of 10 items, (3) test preparation strategies consisting of nine items, (4) perceived pressure for different types of assessment consisting of seven items, (5) amount of test practice consisting of three categorical items, (6) changes in instructional practice including 20 statements, and (7) perceived pressure from different stakeholders consisting of seven items. Teachers' opinions were assessed on a four-point Likert scale $(1=$ disagree; $4=$ agree); see the questionnaire in Appendix A. In the following table 19, the reliability of 4 block questions are summarized except the background questions and amount of test practice which were responded with open and selective categories. The test preparation strategies, which had low (Cronbach $\alpha=.57$ ) reliability, was also excluded.

Table 19. The reliability of the questionnaire

\begin{tabular}{l|c|c}
\hline \multicolumn{1}{c|}{ Parts of the questionnaire } & No. of items & $\begin{array}{c}\text { Cronbach's } \\
\text { alpha }\end{array}$ \\
\hline View on large-scale assessments & 10 & .88 \\
\hline Perceived pressure for different type of measurements/assessments & 7 & .87 \\
\hline Changes in instruction due to large scale assessments & 20 & .722 \\
\hline Perceived pressure by different stakeholders & 7 & .860 \\
\hline Total & 44 & .817 \\
\hline
\end{tabular}

\subsubsection{English language teachers' teaching strategies of English receptive skills}

The teaching strategy questionnaire included four blocks of 78 items: six for background, nine for pre-listening, 10 for while-listening, 10 for post-listening, nine for pre-reading, and nine for while-reading, seven for post-reading, 10 for teaching material, and 8 for encouragement of out-of-class activities. The questionnaire was developed based on Baker and Westrup (2000); Lindsay's (2000) and Voronina's (2009) teaching receptive skill stages and strategies. All items which were related to teaching strategies and teachers' encouragement of out-of-class activities were assessed on a five-point Likert scale $(1=$ Never or almost never true of me; 5 = Always or almost always true of me). The section on teaching materials was assessed with a different Likert scale ( $1=$ never to $5=$ always $)$, and the teachers' background questions were assessed with multiple choices and open-ended responses (see Appendix B). 
Exploratory Factor Analysis (EFA) was used to examine the construct validity of this study's instruments using principal components extraction with varimax rotation. Four instruments, teaching listening strategies $\left(\mathrm{KMO}=.81, \chi^{2}=898.712, \mathrm{df}=210, p<.001\right)$, teaching reading strategies $\left(\mathrm{KMO}=.82, \chi^{2}=579.184, \mathrm{df}=136, p<.001\right)$, teaching materials $\left(\mathrm{KMO}=.81, \chi^{2}=265.496, \mathrm{df}=36, p<.001\right)$, and out-of-class activities $\left(\mathrm{KMO}=.87, \chi^{2}=\right.$ 393.582, df $=28, p<.001$ ), were loaded and 13 factors were extracted from 59 items: (1) students' discussion before listening, (2) preparing students for the listening, (3) developing students' cognitive skill, (4) developing students' metacognitive skill, (5) students' reflection after listening, (6) checking comprehension after listening, (7) activating pre-existing knowledge before reading, (8) using general reading scales, (9) specific reading strategies and activities, (10) students' reflection after reading, (11) using virtual recourses, (12) using traditional materials, and (13) after-class activities. In tables20, 21, 22 rotation matrices of factors are displayed. Also, the EFA results are consistent with the fact that the questionnaire was created based on the theory of three-stages teaching strategies.

Table 20. Factor loadings for teaching listening strategies

\begin{tabular}{|c|c|c|c|}
\hline Stages & Teaching listening items & $\begin{array}{l}\text { Students' } \\
\text { discussion }\end{array}$ & $\begin{array}{c}\text { Teachers' } \\
\text { preparation }\end{array}$ \\
\hline \multirow{10}{*}{ 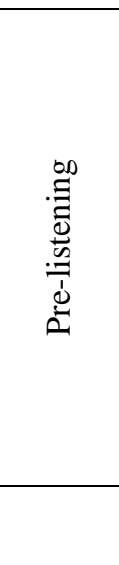 } & I ask students to discuss their opinion on the topic & .857 & \\
\hline & I use brainstorming on topics or vocabulary & .797 & \\
\hline & I ask students to discuss charts, graphs, maps, or statistics & .768 & \\
\hline & I ask students to discuss pictures, photos, or cartoons & .755 & \\
\hline & I ask students to discuss their personal experiences & .731 & \\
\hline & $\begin{array}{l}\text { I ask students to predict what the text will be about (from title, } \\
\text { pictures etc) }\end{array}$ & & .560 \\
\hline & I pre-teach vocabulary and grammar using various ways & & 617 \\
\hline & I read a short text related to the topic & & .857 \\
\hline & I give written exercises related to the text to come & & .763 \\
\hline & $\begin{array}{cc}\begin{array}{c}\text { Developing } \\
\text { cognitive }\end{array} & \text { Developing } \\
\text { metacog. skill }\end{array}$ & & \\
\hline \multirow{10}{*}{ 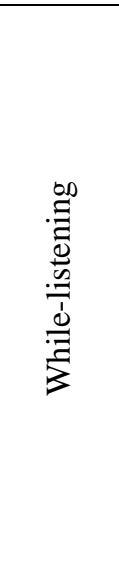 } & $\begin{array}{l}\text { I ask students to check topics, events, or pictures discussed } \\
\text { before }\end{array}$ & .866 & \\
\hline & I ask students to complete charts or diagrams & .596 & \\
\hline & I ask students to complete a gap fill & .499 & \\
\hline & I ask students to follow a route on a map & .654 & \\
\hline & I ask students to identify errors in a script & .721 & \\
\hline & I ask students to predict vocabulary from the context & 639 & \\
\hline & I ask students to answer multiple choice questions & .557 & \\
\hline & $\begin{array}{l}\text { I ask students to number topics, events, or pictures in correct } \\
\text { order }\end{array}$ & & .750 \\
\hline & I ask students to form questions and give short answers & & .848 \\
\hline & I ask students to take notes & & .807 \\
\hline
\end{tabular}




\begin{tabular}{llc}
\hline & \multicolumn{1}{c}{$\begin{array}{c}\text { Students } \\
\text { reflection }\end{array}$} & $\begin{array}{c}\text { Checking } \\
\text { comprehension }\end{array}$ \\
\hline & $\begin{array}{l}\text { I ask students to discuss ideas or cultural points in the text } \\
\text { I ask students to discuss interpretations and opinions }\end{array}$ & .851 \\
\cline { 2 - 3 } & $\begin{array}{l}\text { I ask students to learn new functional language taken from the } \\
\text { listening }\end{array}$ & .851 \\
\hline
\end{tabular}

Table 21. Factor loadings for teaching reading strategies

\begin{tabular}{|c|c|c|c|}
\hline Stages & Teaching reading items & Pre-reading & \\
\hline \multirow{5}{*}{ 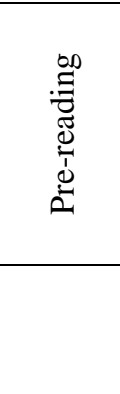 } & $\begin{array}{l}\text { I ask students to think about the subject of the reading they're } \\
\text { about to do }\end{array}$ & .795 & \\
\hline & I activate their pre-existing knowledge & .867 & \\
\hline & I use brainstorming on a topic & .788 & \\
\hline & I assign a short passage related to the topic & .523 & \\
\hline & & $\begin{array}{l}\text { General } \\
\text { reading scales }\end{array}$ & $\begin{array}{c}\text { Specific } \\
\text { reading } \\
\text { strategies and } \\
\end{array}$ \\
\hline \multirow{9}{*}{ 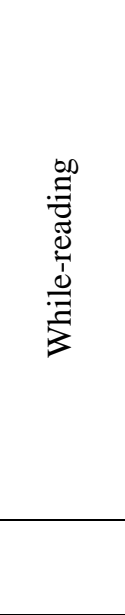 } & I ask students to read for general understanding (skimming) & .484 & \\
\hline & I ask students to read for specific information (scanning) & .869 & \\
\hline & I ask students to read for detail & .871 & \\
\hline & $\begin{array}{l}\text { I use different activities to motivate students (e.g. jigsaw } \\
\text { reading, jumbled texts, etc.) }\end{array}$ & & .790 \\
\hline & I check comprehension while reading & & .862 \\
\hline & I ask students to guess the meaning of words from the context & & .654 \\
\hline & I relate the reading to other skills (listening, speaking, writing) & & .566 \\
\hline & $\begin{array}{l}\text { I give written exercises related to the text content, vocabulary or } \\
\text { grammar }\end{array}$ & & .682 \\
\hline & & $\begin{array}{l}\text { Students' } \\
\text { reflection }\end{array}$ & \\
\hline \multirow{3}{*}{ 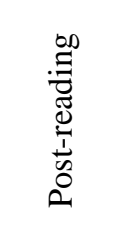 } & $\begin{array}{l}\text { I ask students to interpret or make inferences about implied } \\
\text { information }\end{array}$ & .534 & \\
\hline & I ask students to discuss the main idea & .700 & \\
\hline & I use different activities to motivate students & .748 & \\
\hline
\end{tabular}


Table 22. Factor loadings for teaching materials

\begin{tabular}{lcc}
\hline \multicolumn{1}{c}{ Teaching material item } & Virtual recourses & Traditional materials \\
\hline Songs and music & .719 \\
\hline TV show or interview & .753 \\
\hline Radio broadcasting & .538 \\
\hline Videos or movies & .896 \\
\hline News & .617 \\
\hline A textbook listening material & \\
\hline A textbook reading material & & .910 \\
\hline A newspaper or journal article & & .712 \\
\hline Additional short passages and stories & & .872 \\
\hline Books & & .801 \\
\hline \multicolumn{1}{c}{ Out-of-class item } & .875 \\
\hline I ask students to learn new English songs & .861 \\
\hline $\begin{array}{l}\text { I ask students to watch TV news and interviews for } \\
\text { homework and report it in the class }\end{array}$ & .740 \\
\hline I ask students to speak to native speakers & .690 \\
\hline $\begin{array}{l}\text { I ask students to listen to the information from the } \\
\text { Internet and report it in the class }\end{array}$ & .861 \\
\hline $\begin{array}{l}\text { I ask students to read short stories at home and talk or } \\
\text { write about it. }\end{array}$ & .907 \\
\hline $\begin{array}{l}\text { I ask students to read newspapers or articles for } \\
\text { homework. }\end{array}$ & \\
\hline $\begin{array}{l}\text { I ask students to work in group projects to gather } \\
\text { information from the Internet. }\end{array}$ & \\
\hline I ask students to recite poems & \\
\hline
\end{tabular}

Eleven items were discarded because of low factor loadings and two items with loadings higher than .700 belonging to factors with less than three members were also discarded (see Table 23 below). 
Table 23. Eliminated items from teaching strategy questionnaire

\begin{tabular}{|c|c|c|}
\hline Categories & Items & Factor loadings \\
\hline \multirow{3}{*}{ Post-listening } & $\begin{array}{l}\text { I review pre-listening vocabulary and teach new } \\
\text { vocabulary }\end{array}$ & .480 \\
\hline & I set-up out-of-class research or interview projects & .432 \\
\hline & I ask students to translate what they understood & -.795 \\
\hline \multirow{5}{*}{ Pre-reading } & I use quotations related to the topic & .406 \\
\hline & I pre-teach key words & .406 \\
\hline & I assign tasks related to the topic & .426 \\
\hline & I read the text aloud & .453 \\
\hline & I explain and translate what the text is about & .849 \\
\hline While-reading & I ask students to use a dictionary while reading & .666 \\
\hline \multirow{4}{*}{ Post-reading } & $\begin{array}{l}\text { I ask students to figure out relationships such as cause } \\
\text { and effect }\end{array}$ & .636 \\
\hline & $\begin{array}{l}\text { I check comprehension by asking questions or true } \\
\text { false statements }\end{array}$ & .527 \\
\hline & I ask students to translate what they understood & .412 \\
\hline & I give written exercises related to the text & .834 \\
\hline
\end{tabular}

In addition to establishing construct validity, a Cronbach's alpha test for reliability was calculated for each of the 13 teaching strategy factors. The results show high reliability for all factors on the teaching strategy questionnaire. See Table 24.

Table 24. Reliability of teaching strategy questionnaire

\begin{tabular}{l|c|c}
\multicolumn{1}{c|}{ Teaching strategy factors } & No. of items & Cronbach's Alpha \\
\hline Students' discussion & 5 & .889 \\
\hline Teachers' preparation & 4 & .877 \\
\hline Developing cognitive skill & 7 & .874 \\
\hline Developing metacognitive skill & 3 & .879 \\
\hline Students' reflection & 4 & .878 \\
\hline Checking comprehension & 3 & .873 \\
\hline Activating pre-existing knowledge & 4 & .895 \\
\hline General reading scales & 3 & .874 \\
\hline Specific reading strategies and activities & 5 & .890 \\
\hline Students' reflection & 3 & .882 \\
\hline Virtual recourses & 5 & .878 \\
\hline Traditional materials & 4 & .880 \\
\hline After class activities & 8 & .889 \\
\hline Total & 58 & \\
\hline
\end{tabular}




\subsubsection{Students' learning strategies of English receptive skills}

Two questionnaires, one for 6th-graders and one for 8th-graders, were created based on numerous international questionnaires (Huseynova, 2007; Leppänen, 2007; PISA, 2015; Oxford, 1997) with a few extra items added to account for Mongolian-specific differences in the education system. The 6th-grade questionnaire included both listening and reading learning strategy and attitude questions; the 8th-grade questionnaire included only learning strategies and attitudes for reading. The questionnaires consisted of 13 blocks of questions where listening attitude and strategy for listening skill items were different for the 6th-grade survey based on an online test of English language receptive skills content which was taken before the survey questionnaire (see Appendix C).

The 6th-grade questionnaire had 37 items including background (5), listening (7) and reading attitude (9), and listening (7) and reading strategies (9). The 8th-grade questionnaire had 23 items including background (5), reading attitude (9), and reading strategies (9). Listening strategies were analyzed separately for 6th-grade data while reading strategies' analyses were done on both grades. Both questionnaires are reliable (Cronbach's alpha $=.68$ for grade 6 and .76 for grade 8 ). Two items for listening and three items for reading strategies were assessed with categorical responses, and five items for listening and six items for reading strategies were assessed on a five-point Likert scale $(1=$ strongly agree; $5=$ strongly disagree $)$. For the final analysis, these scales were recoded into $1=$ strongly disagree to $5=$ strongly agree. Test items were created based on Oxford's (1990) Language Learning Strategy Classification. See Table 25 .

With the help of exploratory factor analysis using principal component method with varimax rotation grouping by strategies $\left(\mathrm{KMO}=.72, \chi^{2}=85.8, \mathrm{df}=21, p<.001,2\right.$ factors, 7 items $)$, reading attitudes (KMO $=.60, \chi^{2}=99.6, \mathrm{df}=15, p<.001,2$ factors, 6 items; $)$, and

listening attitudes $\left(\mathrm{KMO}=.64, \chi^{2}=58.1, \mathrm{df}=15, p<.001,2\right.$ factors, 6 items $)$, six factors were identified: (1) positive reading attitude, (2) negative reading attitude, (3) awareness of improving listening skill, (4) understanding the speaker and listening for fun, (5) listening strategies, and (6) reading strategies. Every scale contained three statements, except listening strategies which included four items. See Tables 26, 27 and 28. 
Table 25. Questionnaire classifications of learning strategies based on Oxford (1990).

\begin{tabular}{|c|c|c|}
\hline Learning strategies & Strategy definitions & Classifications \\
\hline I listen English songs and TV news to improve my listening skill & \multirow{6}{*}{$\begin{array}{l}\text { Involve planning, } \\
\text { thinking about the } \\
\text { learning process as it is } \\
\text { taking place, and } \\
\text { monitoring, and } \\
\text { evaluating one's } \\
\text { progress. }\end{array}$} & \multirow{6}{*}{ Metacognitive } \\
\hline I spend particular time on listening tasks for practice per day & & \\
\hline I take notes while I listen & & \\
\hline I sometimes read books & & \\
\hline I read short stories and tales at home & & \\
\hline I spend particular time on reading tasks for practice per day & & \\
\hline I understand the content though speaker's voice/talking & \multirow{4}{*}{$\begin{array}{l}\text { Understand or produce } \\
\text { messages in the target } \\
\text { language despite } \\
\text { limitations of } \\
\text { knowledge. }\end{array}$} & \multirow{4}{*}{ Compensation } \\
\hline I do mind mapping while listening & & \\
\hline I guess vocabulary from the context & & \\
\hline $\begin{array}{l}\text { I predict the main idea of the whole passage from its title or } \\
\text { sub-titles }\end{array}$ & & \\
\hline I ask questions to clarify anything that I don't fully understand & \multirow{2}{*}{$\begin{array}{l}\text { Learn through } \\
\text { interaction with others. }\end{array}$} & \multirow{2}{*}{ Social } \\
\hline I participate more in reading activities in the classroom & & \\
\hline I choose key words while listening & \multirow{4}{*}{$\begin{array}{l}\text { Involve more direct } \\
\text { manipulation of the } \\
\text { learning material itself. }\end{array}$} & \multirow{4}{*}{ Cognitive } \\
\hline I read the story quickly and choose key words & & \\
\hline If the story is long, I divide it into several parts & & \\
\hline I ask questions myself before I read the story & & \\
\hline
\end{tabular}

\section{Table 26. Factor loadings for listening attitude}

\begin{tabular}{lcc}
\multicolumn{1}{c}{ Listening attitude item } & $\begin{array}{c}\text { Awareness of improving } \\
\text { listening skill }\end{array}$ & $\begin{array}{c}\text { understanding speakers } \\
\text { and listening for fun }\end{array}$ \\
\hline $\begin{array}{l}\text { I like to listen to English songs during } \\
\text { classes }\end{array}$ & .720 & \\
\hline I like to fill in gaps listening to the topic & .683 & .706 \\
\hline I like to improve my English listening skill & .625 & .823 \\
\hline I like to understand the speaker & & .655 \\
\hline I like to listen to speaker's voice/accent & & \\
\hline Listening in English is fun for me & & \\
\hline
\end{tabular}

Table 27. Factor loadings for reading attitude

\begin{tabular}{lcc}
\hline \multicolumn{1}{c}{ Reading attitude item } & $\begin{array}{c}\text { Positive reading } \\
\text { attitude }\end{array}$ & $\begin{array}{c}\text { Negative reading } \\
\text { attitude }\end{array}$ \\
\hline I like talking about English books with others & .720 & \\
\hline I like to exchange English books with my friends & .648 & .827 \\
\hline Reading English books is fun for me & .749 & .647 \\
\hline I read in English only if I have to & & .773 \\
\hline For me, reading in English is a waste of time & & \\
\hline I read in English only to get information that I need & & \\
\hline
\end{tabular}


Table 28. Factor loadings for learning strategies

\begin{tabular}{lcc}
\hline \multicolumn{1}{c}{ Learning strategies item } & Listening strategies & Reading strategies \\
\hline I understand the content through the speaker's voice/talking & .614 & .825 \\
\hline I choose key words listening to the topic & .769 & .802 \\
\hline I take notes while listening to the story & .640 & .762 \\
\hline I picture the scenario in mind while listening & .554 \\
\hline I guess new vocabulary when I read books in English. & & \\
\hline I read the story quickly and choose key words. & & \\
\hline If the story is long, I divide it into small parts. & & \\
\hline
\end{tabular}

Six items were discarded because of low factor loadings and two items with loadings higher than 700 belonging to factors with less than three members were also discarded (see table 29). I expected learning strategies would be extracted as language learning classifications; however, factor analysis revealed different factors and I lost some important items. Therefore, I prefer to use the items created based on both theory and factors derived from exploratory factor analysis to get more and meaningful results due to the specifications of the analyses in the final analyses in the results section. The methods of the analyses will be explained before each analysis.

The reason of low reliability of the learning strategy and attitude questionnaire might be affected by the online environment which may have confused the students, or the students tried hard. They might have been in a hurry to leave (because it was after school and on weekends) and so they could just fill it in quickly by guessing (see Table 30.).

Table 29. Discarded items from learning strategy questionnaire.

\begin{tabular}{llc}
\hline \multicolumn{1}{c}{ Categories } & \multicolumn{1}{c}{ Items } & Factor loadings \\
\hline Listening attitude & Listening improves my knowledge and speaking & .784 \\
\hline \multirow{2}{*}{ Reading attitude } & Reading develops my knowledge and speaking & .770 \\
\cline { 2 - 3 } & I like to improve my reading skill & .840 \\
\cline { 2 - 3 } Listening strategy & I like to enlarge my vocabulary & .867 \\
\hline \multirow{2}{*}{ Reading strategy } & I ask questions to clarify anything that I don’t fully & .535 \\
\cline { 2 - 3 } & I ask questions myself before I read the story & .518 \\
\cline { 2 - 3 } & I participate in reading activities in the classroom & .645 \\
\hline
\end{tabular}


Table 30. Reliability of the learning strategy and attitude questionnaire

\begin{tabular}{l|c|c}
\hline \multicolumn{1}{c|}{ Factors } & No. of items & A \\
\hline Positive reading attitude & 3 & .705 \\
Negative reading attitude & 3 & .628 \\
Awareness of improving listening skill & 3 & .685 \\
Understanding speakers and listening for fun & 3 & .628 \\
Listening strategies & 4 & .681 \\
Reading strategies & 3 & .647 \\
Total & 19 & .662 \\
\hline
\end{tabular}

\subsubsection{Assessing students' language skills}

The English language test used in this study was developed by Csapó and Nikolov (2001) for assessing Hungarian students' English language receptive skills. There were 40 items including four tasks (two listening and two reading) in the 6th-grade test and 50 items including five tasks (all reading) in the 8th-grade test (see Appendix D and E). The reliability coefficients (Cronbach a) of the version of tests used in the study can be found in Table 31.

Table 31. Reliability of tests used in the study

\begin{tabular}{|c|c|c|c|c|}
\hline Grades & Skills & Tests & No. of items & a \\
\hline \multirow{5}{*}{6} & \multirow{2}{*}{ Listening } & Finding places & 10 & .87 \\
\hline & & Finding titles & 10 & .79 \\
\hline & \multirow{2}{*}{ Reading } & Matching titles & 10 & .65 \\
\hline & & Filling gaps & 10 & .60 \\
\hline & All tests & & 40 & .86 \\
\hline \multirow{6}{*}{8} & \multirow{5}{*}{ Reading } & Matching definitions & 10 & .88 \\
\hline & & Finding notices & 9 & .87 \\
\hline & & Matching interview questions & 9 & .84 \\
\hline & & Finding answers for quiz & 8 & .76 \\
\hline & & Finding missing information in ads & 9 & .79 \\
\hline & All tests & & 45 & .82 \\
\hline
\end{tabular}

\subsubsection{School infrastructure questionnaire}

The school infrastructure questionnaire included 49 items and items were assessed with 15 selective categorical and five open responses (See Table 32.). The questionnaire can be found in Appendix F. The questionnaire was adapted from The Hungarian Educational Longitudinal Program (HELP) which was launched in the 2003/2004 academic year in Hungary and was translated into Mongolian language for this study. 
Table 32. The structure of school infrastructure questionnaire

\begin{tabular}{lcc}
\hline Parts of the questionnaire & No. of items & Scales \\
\hline School area & 3 & \\
\cline { 1 - 2 } Supply of computers & 29 & \\
\cline { 1 - 2 } Classroom equipment & 17 & \\
\hline Total & 49 & \\
\hline
\end{tabular}

\subsubsection{Procedures}

Survey procedures are summarized here in Table 33 by the order of the dates when they were conducted. All surveys were conducted through the online eDia.hu (2009) platform. Before conducting each survey, I visited all schools and took permission from school principals, managers and the foreign language specialist in the local education department and talked to teachers and students in person.

Table 33. The summary of data collection procedure

\begin{tabular}{|c|c|c|c|c|}
\hline Studies & Respondents & A platform & Time & Place \\
\hline School infrastructure & 12 IT teachers & \multirow{5}{*}{$\begin{array}{l}\text { eDia } \\
\text { system.hu } \\
(2009)\end{array}$} & $\begin{array}{c}\text { Feb, 2016-Sep, } \\
2016\end{array}$ & \multirow{5}{*}{$\begin{array}{l}\text { Dornod } \\
\text { province, } \\
\text { Mongolia }\end{array}$} \\
\hline $\begin{array}{c}\text { Teachers' view of } \\
\text { Educational assessment } \\
\text { and accountability }\end{array}$ & $\begin{array}{l}307 \text { primary and } \\
\text { secondary school } \\
\text { teachers }\end{array}$ & & $\begin{array}{l}\text { January - } \\
\text { September in } \\
2016\end{array}$ & \\
\hline $\begin{array}{c}\text { English teachers' teaching } \\
\text { strategies }\end{array}$ & $\begin{array}{c}73 \text { English language } \\
\text { teachers }\end{array}$ & & May -July in 2017 & \\
\hline $\begin{array}{l}\text { Students' learning } \\
\text { strategies }\end{array}$ & $\begin{array}{l}215 \text { 6th- and 8th- } \\
\text { grade students }\end{array}$ & & $\begin{array}{c}\text { January - March } \\
\text { in } 2017\end{array}$ & \\
\hline $\begin{array}{l}\text { Assessing students' } \\
\text { language skills }\end{array}$ & $\begin{array}{l}215 \text { 6th- and 8th- } \\
\text { grade students }\end{array}$ & & $\begin{array}{l}\text { October/2016- } \\
\text { January/2017 }\end{array}$ & \\
\hline
\end{tabular}

Two self-developed surveys, teaching English language receptive skills and learning strategies of English language receptive skills were developed with the help of Prof. Benő Csapó, MTA-SZTE Research Group on the Development of Competences, University of Szeged; Dr. John David Campbell, Ed.D in Educational Leadership, Northern Arizona University, USA and ReaAan Dietlin, Arizona University, MA in Asian studies, specialised in Teaching English to Foreigners, USA. Survey content was based on numerous studies.

After developing and reviewing English versions of the questionnaires on teachers' view on assessment and accountability, school infrastructure, and student learning strategies were translated into Mongolian with the help of the following expert group, Dr. Odmandah Myagmarsuren, Mongolian Language and Literature Department in Mongolian University of Education, and Dr. Enkhjargal Sukhbaatar, Department of Mongolian Language and Literature, 
Dornod University. The translations were reviewed by the group and the author for appropriate Mongolian language stylistics and appropriate word choice. The teaching strategy questionnaire and the online assessment were not translated into Mongolian. Before conducting these surveys, I talked to English language teachers and students in person and asked them to fill out the questionnaire online. School IT teachers and English language teachers administered the process of testing and filling out the online questionnaires and tests. Students' responses for both the reading and listening assessments and the student Language Learning Strategy questionnaire (see Appendix C) were collected online in school computer labs, after school, due to the busy schedule of labs.

\subsubsection{Data analysis}

All data was analyzed using the SPSS 24 software for quantitative analyses. The research questions, the focus of analysis, and the methods of analysis are summarized in Table 34.

Table 34. Research Questions, Data Source, Focus of Analysis, and Methods of Analysis of the study

\begin{tabular}{|c|c|c|}
\hline Research question & Focus of Analysis & Methods of Analysis \\
\hline $\begin{array}{l}\text { How is educational assessment } \\
\text { and accountability used in the } \\
\text { Mongolian Education system? }\end{array}$ & $\begin{array}{l}\text { Educational accountability and } \\
\text { teachers' view on large-scale } \\
\text { assessment }\end{array}$ & $\begin{array}{l}\text { Independent sample t-test, } \\
\text { descriptive analysis and } \\
\text { correlation analysis }\end{array}$ \\
\hline $\begin{array}{l}\text { How do assessment and } \\
\text { accountability influence English } \\
\text { language instruction and test- } \\
\text { taking strategies in Mongolia? }\end{array}$ & $\begin{array}{l}\text { English language teachers' view } \\
\text { on assessment and its reflection on } \\
\text { instruction }\end{array}$ & $\begin{array}{l}\text { Independent sample t-test and } \\
\text { correlation analysis }\end{array}$ \\
\hline $\begin{array}{l}\text { What are English language } \\
\text { teachers' perceptions of teaching } \\
\text { ELRS? }\end{array}$ & $\begin{array}{l}\text { Teaching strategies of English } \\
\text { language receptive skills }\end{array}$ & $\begin{array}{l}\text { Paired-sample t-test, descriptive } \\
\text { analysis and correlation analysis }\end{array}$ \\
\hline $\begin{array}{l}\text { How do students identify their } \\
\text { strategies and attitudes towards } \\
\text { ELRS? }\end{array}$ & $\begin{array}{l}\text { Learning strategies of English } \\
\text { language receptive skills }\end{array}$ & $\begin{array}{l}\text { Paired-sample t-test, descriptive } \\
\text { analysis and correlation analysis }\end{array}$ \\
\hline $\begin{array}{l}\text { How are teaching and learning } \\
\text { English language receptive skills } \\
\text { related? }\end{array}$ & $\begin{array}{l}\text { Relationship between teaching and } \\
\text { learning strategies }\end{array}$ & $\begin{array}{l}\text { Descriptive analysis (indirect } \\
\text { comparison and correlation) }\end{array}$ \\
\hline $\begin{array}{l}\text { How did students perform on an } \\
\text { online test developed for this study } \\
\text { to assess their English language } \\
\text { receptive skills? }\end{array}$ & Students' test performance & $\begin{array}{l}\text { IRT, descriptive and content } \\
\text { analysis (cognitive operations) }\end{array}$ \\
\hline $\begin{array}{l}\text { What are the factors affecting } \\
\text { students' test performance? }\end{array}$ & $\begin{array}{l}\text { Factors influencing test } \\
\text { performance }\end{array}$ & $\begin{array}{l}\text { A multiple linear regression } \\
\text { analysis }\end{array}$ \\
\hline
\end{tabular}




\section{RESULTS}

\subsection{Study 1: How are Educational assessment and accountability used in the Mongolian Education system?}

\subsubsection{Introduction}

Recent international studies (Darling-Hammond et al, 2014; Scott \& Paul, 2015; Marion $\&$ Leather, 2015) have focused on educational assessment and its effect on educational quality. However, in Mongolia, teachers' attitudes towards large-scale assessments have been a largely uncovered area of research. Therefore, the aim of this study was to examine the general views of primary and secondary school teachers' about state-level assessments also known in this document as school achievement tests (SATs). Note that primary school teachers prepare 5thgrade students for SATs and secondary school teachers prepare 9thand 12th-grade students for these tests. Also, the pressure on teachers resulting from the different forms of achievement assessments, teachers' reflection on teaching practices, the effect of stakeholders who pressure teachers to increase their pupils' achievement, and the connection between pressures and changes in teaching practices due to large-scale assessments will be discussed and compared to Tóth's (2014) study in Hungary. In addition, this study created a baseline survey for a deeper understanding of English language teachers' views and their everyday instruction changes due to the SAT large-scale assessments and resulting accountability impacts. As mentioned in the section describing the developing of the instrument, this questionnaire was adapted and fitted to the Mongolian context.

\subsubsection{What are the primary and secondary school teachers' beliefs about the usefulness} and acceptance of large-scale assessments?

An independent-sample t-test was used to identify differences in how primary and secondary school teachers think about the acceptance of the large-scale assessments (school achievement tests). The results showed overall good support for both primary and secondary school teachers for school achievement tests to be conducted on a regular basis $(\mathrm{M}=3.7-3.6$, $\mathrm{SD}=.56-.62$ ). Both groups generally felt such assessments were important for work in schools $(\mathrm{M}=3.4-3.3, \mathrm{SD}=.70-.84)$, and that assessments contribute to an increased effort in schools $(\mathrm{M}=3.6-3.3, \mathrm{SD}=.07-.06)$. However, both groups of teachers somewhat disagreed that school achievement tests provide a basis for discussion among colleagues $(\mathrm{M}=2.5-2.7$, $\mathrm{SD}=1.0-1.1)$ and that they support the debate about the concept of competence $(\mathrm{M}=2.4$, 
$\mathrm{SD}=.96$ - 1.0). Finally, two statements, that school achievement tests contribute to an increased effort in schools $(\mathrm{t}=3.05, p<.05)$ and they provide an objective basis to evaluate schools $(\mathrm{t}=3.71, p<.05)$ were found to be significantly different between primary and secondary school teachers suggesting primary school teachers were more accepting of school achievement tests than secondary school teachers. See Table 35. Also, the table below shows that teachers' views were different for only two of the 10 opinions reported on the Teachers' view of Educational assessment and accountability questionnaire. Thus, H1 was rejected. Perhaps primary school teachers think SATs contribute to an increased effort by schools and provide a more objective basis to evaluate schools compared to 9th-grade teachers who might feel pressure from this assessment as their 5-year work is assessed.

Table 35. Teachers' view on school achievement tests (SAT).

\begin{tabular}{|c|c|c|c|c|c|c|c|}
\hline Items (School achievement tests........) & $\mathbf{N}$ & $\begin{array}{c}\text { Prim } \\
(1) \\
\operatorname{Sec}(2) \\
\end{array}$ & $\mathbf{M}$ & SD & SE & $\mathbf{t}$ & $\mathbf{P}$ \\
\hline \multirow{2}{*}{ should be conducted on a regular basis. } & 73 & 1 & 3.7 & .56 & .06 & \multirow{2}{*}{.65} & \multirow{2}{*}{ n.s. } \\
\hline & 211 & 2 & 3.6 & .62 & .04 & & \\
\hline \multirow{2}{*}{ are important for work in schools. } & 73 & 1 & 3.4 & .70 & .08 & \multirow{2}{*}{.39} & \multirow{2}{*}{ n.s } \\
\hline & 204 & 2 & 3.4 & .84 & .05 & & \\
\hline \multirow{2}{*}{ only cause trouble in schools. } & 74 & 1 & 1.9 & .98 & .11 & \multirow{2}{*}{-.83} & \multirow{2}{*}{ n.s } \\
\hline & 203 & 2 & 2.0 & 1.0 & .07 & & \\
\hline \multirow{2}{*}{ create more problems than solutions. } & 76 & 1 & 2.9 & .84 & .09 & \multirow{2}{*}{1.52} & \multirow{2}{*}{ n.s } \\
\hline & 204 & 2 & 2.8 & .95 & .06 & & \\
\hline \multirow{2}{*}{ contribute to an increased effort in schools. } & 72 & 1 & 3.6 & .61 & .07 & \multirow{2}{*}{3.05} & \multirow{2}{*}{$p<.05$} \\
\hline & 203 & 2 & 3.3 & .91 & .06 & & \\
\hline \multirow{2}{*}{ provide an objective basis to evaluate schools. } & 76 & 1 & 3.3 & .81 & .09 & \multirow{2}{*}{3.71} & \multirow{2}{*}{$p<.05$} \\
\hline & 204 & 2 & 2.9 & 1.0 & .07 & & \\
\hline \multirow{2}{*}{ are not useful for my job as a teacher. } & 74 & 1 & 1.9 & 1.0 & .12 & \multirow{2}{*}{1.14} & \multirow{2}{*}{ n.s } \\
\hline & 207 & 2 & 1.7 & .99 & .06 & & \\
\hline \multirow{2}{*}{ provide a basis for discussion among colleagues. } & 74 & 1 & 2.5 & 1.0 & .12 & \multirow{2}{*}{$\begin{array}{c} \\
1.35 \\
\end{array}$} & \multirow{2}{*}{ n.s } \\
\hline & 200 & 2 & 2.7 & 1.1 & .08 & & \\
\hline \multirow{2}{*}{$\begin{array}{l}\text { are barely applicable for individual student } \\
\text { evaluations. }\end{array}$} & 76 & 1 & 2.7 & 1.0 & .12 & \multirow{2}{*}{1.60} & \multirow{2}{*}{ n.s } \\
\hline & 203 & 2 & 2.4 & 1.0 & .07 & & \\
\hline \multirow{2}{*}{$\begin{array}{l}\text { support the debate about the concept of } \\
\text { competence. }\end{array}$} & 74 & 1 & 2.4 & .96 & .11 & \multirow{2}{*}{.12} & \multirow{2}{*}{ n.s } \\
\hline & 204 & 2 & 2.4 & 1.0 & .07 & & \\
\hline
\end{tabular}

\subsubsection{To what extent do teachers feel pressured by the different forms of achievement assessments?}

Another questionnaire examined to what extent teachers felt pressured by the different types of tests with a scale from $1=$ not at all, $2=$ barely, $3=$ somewhat to $4=$ a lot. The four exams are (1) standardized tests on a state level which are graded externally, (2) standardized tests on a state level which are graded by the teachers themselves, (3) standardized tests using 
selected samples from each school to assess educational standards across provinces, and (4) centralized final exams (see Table 36.).

A 95\% confidence interval around each of the means was constructed by pooling the two levels together (primary and secondary). The result shows that all these means overlap at the 0.05 significance level. In other words, the means are not far enough apart to claim any significant difference between the four types of assessments at the 0.05 confidence level.

Table 36. The extent of teachers' pressure from different forms of assessments.

\begin{tabular}{l|c|c|c|c|c|c|c}
\hline \multicolumn{1}{c|}{ Exams } & Level & Mean & SD & SE & N & 95\%LB & 95\% UB \\
\hline State graded external & $1+2$ & 2.9 & .85 & .05 & 277 & 2.7 & 2.9 \\
\hline State graded internal & $1+2$ & 2.9 & .86 & .05 & 229 & 2.7 & 3.0 \\
\hline Selected samples & $1+2$ & 2.7 & .90 & .05 & 234 & 2.5 & 2.8 \\
\hline Centralized & $1+2$ & 2.7 & .94 & .05 & 259 & 2.5 & 2.8 \\
\hline
\end{tabular}

\subsubsection{How do teachers reflect on the shift in their teaching practices influenced by the assessments?}

Part five of the questionnaire was designed to examine how teachers change their instruction in their teaching practice due to the assessment. The items were assessed with scale from 1 (disagree) to 4 (agree). Since the questionnaire was adapted, confirmatory factor analysis was also used to identify factors of changes in teachers' instructional practice as a result of system-level assessments $\left(\chi^{2}=1.47, p=.002 ; \mathrm{CFI}=.943 ; \mathrm{TLI}=.927 ; \mathrm{RMSEA}=.032,95 \%\right.$ $(\mathrm{CI}=.029-.042)$ ). Five factors were identified from the dataset: (1) giving homework (I assign more homework and I assign more difficult homework), (2) teaching methods (I search for more effective teaching methods, I focus more strongly on educational standards, I focus more strongly on the competencies that are assessed as part of the educational concept in SATs, and I focus more strongly on overarching competencies), (3) content of instruction (I reduce instructional content, I take less liberties in how I design my lesson, I have narrowed down the curricular content of my instruction, and my instruction focuses more strongly on competencies rather than on content, (4) testing strategy (I spend more time teaching general test-taking strategies, I focus more strongly on multiple-choice tests, and I focus more strongly on tests with open-ended questions), and (5) teachers' attention to special students (I focus more strongly on low achievers, I focus more strongly on high achievers, and I offer more assistance outside of classroom instruction). (see table 37). Grouping the questions into these factors and then doing a 95\% confidence interval with simple descriptive statistics to compare against the overall mean yielded the confidence intervals around each of the means for these factors. Table 
37 shows the means in increasing order and indicates that teachers focused more on their instructional content $(\mathrm{M}=3.5, \mathrm{SD}=.44)$ and teaching methods $(\mathrm{M}=3.4, \mathrm{SD}=.42)$. However, they did less change on testing strategies $(\mathrm{M}=2.9, \mathrm{SD}=.64)$, paying attention to special students $(\mathrm{M}=2.5, \mathrm{SD}=.62)$, and giving homework $(\mathrm{M}=2.2, \mathrm{SD}=.77)$.

Table 37. Changes in teachers' instructional practice

\begin{tabular}{lccccc}
\hline \multicolumn{1}{c}{ Instructions } & $\mathbf{N}$ & $\mathbf{M}$ & $\mathbf{S D}$ & $\mathbf{9 5 \%} \mathbf{L B}$ & $\mathbf{9 5 \%}$ UB \\
\hline Content of instruction & 289 & 3.5 & .44 & 3.3 & 3.4 \\
\hline Teaching methods & 290 & 3.4 & .42 & 3.3 & 3.4 \\
\hline Testing strategies & 287 & 2.9 & .64 & 2.8 & 3.0 \\
\hline Attention to special students & 288 & 2.5 & .62 & 2.4 & 2.5 \\
\hline Giving homework & 292 & 2.2 & .77 & 2.1 & 2.3 \\
\hline
\end{tabular}

\subsubsection{What is the relationship between teachers' view on educational assessment and their instructional practices?}

As the result of the correlation analysis, very low significant correlations were found between teachers' perception of school achievement assessments and their instructional content $(\mathrm{r}=.19, p<.01)$, testing strategies $(\mathrm{r}=.19, p<.01)$, and teaching methods $(\mathrm{r}=.17, p<.01)$ that were used in the classroom. For the correlation among instructional changes, teaching methods have significant and stronger correlations with the content of instruction $(\mathrm{r}=.37, p<$ $.01)$, and testing strategy $(\mathrm{r}=.42, p<.01)$. A weaker, but significant correlation between teaching methods and attention to special students are also observed $(\mathrm{r}=.13, p<.05)$. The content of instruction is significantly related to testing strategy $(\mathrm{r}=.38, p<.01)$ and attention to special students $(\mathrm{r}=.30, p<.01)$. The testing strategy was also significantly correlated with attention to special students $(\mathrm{r}=.27, p<.01)$. See Table 38 .

Table 38. The relationships between teachers' view on large-scale assessments and teachers' instructional changes.

\begin{tabular}{l|c|c|c|c|c}
\hline & $\mathbf{1}$ & $\mathbf{2}$ & $\mathbf{3}$ & $\mathbf{4}$ & $\mathbf{5}$ \\
\hline View on assessment & & & & & \\
Giving homework & .10 & & & & \\
Teaching methods & $.17^{* *}$ & -.05 & & & \\
Content of instruction & $.19^{* *}$ & .06 & $.37^{* *}$ & & \\
Testing strategy & $.19^{* *}$ & $.13^{*}$ & $.42^{* *}$ & $.38^{* *}$ & \\
Attention to special students & .07 & $.18^{* *}$ & $.13^{*}$ & $.30^{* *}$ & $.27^{* *}$ \\
\hline
\end{tabular}

Note: $* p<.05, * * p<.01$. 


\subsubsection{Which test preparation strategies do teachers mostly use?}

Teachers' test preparation strategies were assessed with a scale of 4 from (1) disagree to (4) agree. The descriptive statistics suggest that generally ( $M=3.5$ cut off value) teachers more often use tasks in regular instruction that are similar to those in SATs $(\mathrm{M}=3.6, \mathrm{SD}=.62)$ and practice test formats that are used in the SAT $(\mathrm{M}=3.6, \mathrm{SD}=.64)$, and discuss general tasktaking strategies with students $(\mathrm{M}=3.5, \mathrm{SD}=.79)$. Also, an independent sample t-test was used to show the difference between primary and secondary school teachers' view on test preparation strategies. The results showed that primary school teachers tend to see the coherence between instructional content and the tasks of the State exam increased $(\mathrm{Mp}=3.7, \mathrm{SDp}=.57 ; \mathrm{Ms}=3.4$, SDs $=.84)$, they seek to improve students' motivation to do well on the state exam $(\mathrm{Mp}=3.6$, $\mathrm{SDp}=.59 ; \mathrm{Ms}=3.4, \mathrm{SDs}=.75)$, and they try to improve students' test-taking skills (e.g. practice on public release tasks) that are used in the State exam $(\mathrm{Mp}=3.6, \mathrm{SDp}=.72 ; \mathrm{Ms}=3.3$, SDs $=.87$ ) more than secondary school teachers (see Table 39.).

Table 39. Test preparation strategies

\begin{tabular}{|c|c|c|c|c|c|c|c|}
\hline Items & $\mathbf{N}$ & $\begin{array}{c}\text { Prim } \\
\text { (1) } \\
\text { Sec (2) }\end{array}$ & Mean & SD & SE & $\mathbf{T}$ & $\mathbf{P}$ \\
\hline \multirow{2}{*}{$\begin{array}{l}\text { try to improve students' test-taking skills (e.g. } \\
\text { practice on public release tasks) that are used in the } \\
\text { State exam }\end{array}$} & 75 & 1 & 3.5 & .72 & .08 & \multirow{2}{*}{2.42} & \multirow{2}{*}{$p<.05$} \\
\hline & 207 & 2 & 3.3 & .87 & .06 & & \\
\hline \multirow{2}{*}{$\begin{array}{l}\text { seek to improve students' motivation to do well on } \\
\text { the state exam }\end{array}$} & 76 & 1 & 3.6 & .59 & .06 & \multirow{2}{*}{2.25} & \multirow{2}{*}{$p<.05$} \\
\hline & 206 & 2 & 3.4 & .75 & .05 & & \\
\hline \multirow{2}{*}{$\begin{array}{l}\text { see to it that the coherence between instructional } \\
\text { content and the tasks of the State exam is increased. }\end{array}$} & 74 & 1 & 3.6 & .57 & .06 & \multirow[t]{2}{*}{3.13} & \multirow[t]{2}{*}{$p<.05$} \\
\hline & 200 & 2 & 3.4 & .84 & .05 & & \\
\hline \multirow{2}{*}{$\begin{array}{l}\text { practice test formats that are used in the State exam } \\
\text { (e.g. multiple-choice tasks). }\end{array}$} & 75 & 1 & 3.7 & .55 & .06 & \multirow{2}{*}{1.75} & \multirow{2}{*}{ n.s } \\
\hline & 202 & 2 & 3.5 & .67 & .04 & & \\
\hline \multirow{2}{*}{$\begin{array}{l}\text { use tasks in regular instruction that are similar to } \\
\text { those in the State exam more often }\end{array}$} & 77 & 1 & 3.7 & .46 & .05 & \multirow[t]{2}{*}{1.88} & \multirow[t]{2}{*}{ n.s } \\
\hline & 197 & 2 & 3.6 & .67 & .04 & & \\
\hline \multirow{2}{*}{$\begin{array}{l}\text { set aside or put less emphasis, in regular instruction, } \\
\text { on content that will not be tested. }\end{array}$} & 77 & 1 & 2.3 & 1.0 & .11 & \multirow[t]{2}{*}{.131} & \multirow[t]{2}{*}{ n.s } \\
\hline & 204 & 2 & 2.2 & .99 & .07 & & \\
\hline \multirow{2}{*}{ discuss general task-taking strategies with students. } & 74 & 1 & 3.5 & .70 & .08 & \multirow{2}{*}{.148} & \multirow{2}{*}{ n.s } \\
\hline & 204 & 2 & 3.5 & .82 & .05 & & \\
\hline
\end{tabular}




\subsubsection{Who puts pressure on primary and secondary school teachers in order to increase their pupils' achievement? To what extent does this happen?}

This questionnaire is intended to identify who puts pressure on teachers to increase students' test scores. For the extent of perceived pressure on teachers by different stakeholders two factors were identified from the dataset $\left(\chi^{2}=2.49, p<.001\right.$, TLI $=.91, \mathrm{CFI}=.92$, RMSEA $=.052,95 \%(\mathrm{CI}=.048-.056)):$ (1) Professional, for example: colleagues, central administration, school board, and (2) Non-professional, for example: parents, public. Table 40 shows the primary and secondary school teachers' pressure from the stakeholders. The results indicate that there is no significant difference between primary and secondary school teachers' answers for the two factors $\left(\mathrm{M}_{\mathrm{P}}=2.7, \mathrm{SD}_{\mathrm{P}}=.83 ; \mathrm{M}_{\mathrm{S}}=2.8, \mathrm{SD}_{\mathrm{S}}=.74, \mathrm{t}=-.74, p=.45\right)$ and $\left(\mathrm{M}_{\mathrm{P}}=1.9, \mathrm{SD}_{\mathrm{P}}=.89 ; \mathrm{M}_{\mathrm{S}}=2.1, \mathrm{SD}_{\mathrm{S}}=.82, \mathrm{t}=-1.01, p=.31\right)$. A $95 \%$ confidence interval around each of the means was constructed by pooling the two levels together (primary and secondary). The result shows that professional stakeholders $\left(\mathrm{N}_{\text {prof }}=284, \mathrm{M}_{\mathrm{prof}}=2.8, \mathrm{SD}_{\text {prof }}=.76\right.$ and $\left.\mathrm{N}_{\text {non }}=257, \mathrm{M}_{\text {non }}=2.0, \mathrm{SD}_{\mathrm{non}}=.84\right)$ put significantly more pressure on teachers to increase learning achievement. See Table 41.

Table 40. The difference between the two levels of teachers' perceived pressure by different stakeholders

\begin{tabular}{c|c|c|c|c|c|c|c}
\hline & $\begin{array}{c}\text { Prim (1) } \\
\text { Sec (2) }\end{array}$ & N & Mean & SD & SE & t & P \\
\hline \multirow{2}{*}{$\begin{array}{c}\text { Professional (P) } \\
\text { /colleagues, CA, SB, Ministry/ }\end{array}$} & 1 & 76 & 2.7 & .83 & .09 & \multirow{2}{*}{-.74} & .45 \\
\cline { 1 - 7 } $\begin{array}{c}\text { Non-professional (NP) } \\
\text { /Parents and public/ }\end{array}$ & 1 & 76 & 1.9 & .89 & & \multirow{2}{*}{-1.01} & \multirow{2}{*}{.31} \\
\cline { 1 - 7 } & 2 & 198 & 2.1 & .82 & & & \\
\hline
\end{tabular}

Table 41. Overall teachers' perceived pressure by different stakeholders

\begin{tabular}{lccccc}
\hline \multicolumn{1}{c}{ Stakeholders } & N & M & SD & 95\% LB & 95\% UB \\
\hline Professional & 284 & 2.8 & .76 & 2.6 & 2.8 \\
\hline Non-professional & 284 & 2.0 & .84 & 1.9 & 2.1 \\
\hline
\end{tabular}

\subsubsection{Summary}

Study 1 presented the case of the Mongolian National Educational Assessment System in an attempt to understand and model teachers' beliefs about acceptance of state-level 
assessments, the relation between teachers' views on state-level assessments and the teaching process, and to understand the underlying mechanisms between teachers' perceived pressure induced by different stakeholders in primary and secondary schools. The results revealed that teachers generally felt such assessments were important for work and found them useful. This aligns with Tóth's (2014) result on required assessments in the Hungarian school system. However, compared to her results, secondary school teachers in Mongolia appear to feel more pressure from large-stake assessments, while in Hungary primary school teachers feel more pressure., In this study, there was no significant difference in teachers' perception of pressure on state-level standardized tests or standardized tests using selected samples to assess educational standards across provinces and centralized final exams in Mongolia. Pressure experienced by both primary and secondary school teachers in Mongolia was closely related to the stakes of the assessment on schools and on students and the state-level tests administered by the government and those externally graded by teachers are significant sources of pressure in schools.

Generally, teachers are less willing to narrow the curriculum due to the national assessment system; they focus more on students with poor results on the state assessments. Also, they pay more attention to test-taking strategies and multiple-choice tests in classroom instruction.

There is no difference in primary and secondary school teachers' answers on perceived pressure by different stakeholders. However, in general, they feel more pressured by professional stakeholders than by non-professional ones as Tóth's (2014) study result shows. There is a significant correlation between teachers' view on large scale assessments and reallocation of teaching methods, test-taking strategies, and the content of the assessment. In brief, these three factors are really connected such that teachers put more emphasis on giving better instructions in order to improve their students' performance on large scale tests because of pressure from professional stakeholders. This is similar to Tóth's result in that assessments have a major effect on the teaching methods and assessments highlight the necessity of supporting and developing poor performers so, as a consequence, teachers pay more attention to these students. The results of this study will be used as the empirical basis exploring the issues related to current assessment practices and their effect on the Mongolian education system. 


\subsection{Study 2: How do assessment and accountability influence English language instruction and test preparation strategies in Mongolia?}

\subsubsection{Introduction}

Thirty-six foreign language teachers participated in this secondary and primary school teachers' study. Foreign language teachers include both English and Russian language teachers, and Russian language teachers teach both Russian and English language. Therefore, these selected 36 foreign language teachers can be considered as English language teachers. Study 2 aims to specify and understand more deeply about what English language teachers think of state-level assessments and their usefulness, and how English language teachers' instructions and test preparation strategies are changed due to their perceptions of state-level assessments based on Study 1 data.

\subsubsection{What beliefs do English language teachers have about the usefulness and acceptance of large-scale assessments?}

An independent sample t-test was used based on the acceptance of the large-scale assessments to compare the means of the selected 36 English teachers' opinions with other teachers' opinions. Table 42 shows that English language teachers in Dornod province have similar ideas compared to other teachers. Specifically, they think that school achievement tests should be conducted on a regular basis $(\mathrm{M}=3.6, \mathrm{SD}=.60)$, that tests contribute to an increased effort in schools $(\mathrm{M}=3.4, \mathrm{SD}=.93)$, that tests provide an objective basis to evaluate schools $(\mathrm{M}=3.3, \mathrm{SD}=.79)$, and that these tests are important for work in schools $(\mathrm{M}=3.2, \mathrm{SD}=.98)$. They also, like teachers of other subjects, somewhat disagree with the view that school achievement tests support the debate about the concept of competence $(\mathrm{M}=2.2, \mathrm{SD}=.96)$, and they provide a basis for discussion among colleagues $(\mathrm{M}=2.3, \mathrm{SD}=.96)$. Other teachers, however, had different opinions about the statements "School achievement tests are important for work in schools" $(\mathrm{t}=-1.16, p<.05)$ and "School achievement tests are not useful for my job as a teacher" $(\mathrm{t}=-1.46, p<.05)$. See Table 42. 
Table 42. English language teachers' view on school achievement tests.

\begin{tabular}{|c|c|c|c|c|c|c|c|}
\hline & School achievement tests & Groups & $\mathbf{N}$ & $\mathbf{M}$ & SD & $\mathbf{T}$ & $\mathbf{P}$ \\
\hline \multirow{2}{*}{1} & \multirow{2}{*}{ Should be conducted on a regular basis } & ENG & 36 & 3.6 & .60 & \multirow{2}{*}{-.60} & \multirow{2}{*}{ n.s } \\
\hline & & Other & 262 & 3.6 & .65 & & \\
\hline \multirow{2}{*}{2} & \multirow{2}{*}{ Contribute to an increased effort in schools } & ENG & 34 & 3.4 & .93 & \multirow{2}{*}{.24} & \multirow{2}{*}{ n.s } \\
\hline & & Other & 253 & 3.3 & .85 & & \\
\hline \multirow[b]{2}{*}{3} & \multirow{2}{*}{ Provide an objective basis to evaluate schools } & ENG & 35 & 3.3 & .79 & \multirow{2}{*}{1.70} & \multirow{2}{*}{ n.s } \\
\hline & & Other & 257 & 3.0 & 1.0 & & \\
\hline \multirow{2}{*}{4} & \multirow{2}{*}{ Are important for work in schools } & ENG & 36 & 3.2 & .98 & \multirow{2}{*}{-1.16} & \multirow{2}{*}{$p<.05$} \\
\hline & & Other & 255 & 3.3 & .79 & & \\
\hline \multirow{2}{*}{5} & \multirow{2}{*}{ Create more problems than solutions } & ENG & 35 & 2.7 & .93 & \multirow{2}{*}{-.82} & \multirow{2}{*}{ n.s } \\
\hline & & Other & 257 & 2.8 & .92 & & \\
\hline \multirow{2}{*}{6} & \multirow{2}{*}{ Provide a basis for discussion among colleagues } & ENG & 34 & 2.3 & 1.0 & \multirow{2}{*}{-1.79} & \multirow{2}{*}{ n.s } \\
\hline & & Other & 252 & 2.6 & 1.1 & & \\
\hline \multirow{2}{*}{7} & \multirow{2}{*}{ Support the debate about the concept of competence } & ENG & 36 & 2.2 & .96 & \multirow{2}{*}{-.69} & \multirow{2}{*}{ n.s } \\
\hline & & Other & 253 & 2.4 & 1.0 & & \\
\hline \multirow{2}{*}{8} & \multirow{2}{*}{$\begin{array}{l}\text { Are barely applicable for individual student } \\
\text { evaluations }\end{array}$} & ENG & 34 & 2.1 & 1.1 & \multirow{2}{*}{-.29} & \multirow{2}{*}{ n.s } \\
\hline & & Other & 257 & 2.6 & 1.0 & & \\
\hline \multirow{2}{*}{9} & \multirow{2}{*}{ Only cause trouble in schools } & ENG & 36 & 2.0 & .96 & \multirow{2}{*}{5.50} & \\
\hline & & Other & 253 & 2.0 & 1.0 & & n.s \\
\hline 10 & Aropt ucoful for mu ish os torbor & ENG & 36 & 1.5 & .80 & 1.46 & $0<05$ \\
\hline 10 & Are not userur ror my joo as a teacner & Other & 257 & 1.8 & 1.0 & -1.40 & $p<.00$ \\
\hline
\end{tabular}

\subsubsection{How do English language teachers reflect on the shift in their teaching practices}

\section{influenced by the assessments?}

An independent sample t-test was also used to explore which instructional changes were mostly made by English teachers in teaching English in comparison to other teachers. The results in Table 43 below show that English language teachers and other subjects' teachers usually search for more effective teaching methods $(\mathrm{M}=3.8, \mathrm{SD}=.35)$, take less liberty on how they design their lessons $(\mathrm{M}=3.7, \mathrm{SD}=.62)$, reduce instructional content $(\mathrm{M}=3.6$, $\mathrm{SD}=.60)$, and focus more on educational standards $(\mathrm{M}=3.5, \mathrm{SD}=.56)$. English teachers have different opinions on the statement "I search for more effective teaching methods" $(\mathrm{t}=1.32$, $p<.05)$ and "I have narrowed down the curricular content of my instruction" $(\mathrm{t}=-2.02, p<.05)$ compared to teachers of other subjects in general. The results suggest that English language teachers are less willing to narrow down their curricular content than teachers in other fields, and that they spend more effort searching for effective teaching methods. Table 43 below shows 
that English language teachers' reflections were mostly in line with those of other teachers reflecting on their instructional efforts. The results show $\mathrm{H} 2$ was accepted with a significant difference for only two of the 8 opinions. English language teachers appear to search for more effective teaching methods than other teachers, and they appear to be less willing to narrow down the curricular content of their instruction than others. This might be connected with their effort to improve students' preparation for the English language section of the SAT.

Table 43. English language teachers' instructional changes

\begin{tabular}{|c|c|c|c|c|c|c|c|}
\hline & Instructions & Groups & $\mathbf{N}$ & $\mathbf{M}$ & SD & $\mathbf{t}$ & $\mathbf{P}$ \\
\hline \multirow{2}{*}{1} & \multirow{2}{*}{ I search for more effective teaching methods } & ENG & 35 & 3.8 & .35 & \multirow{2}{*}{1.32} & \multirow{2}{*}{$p<.05$} \\
\hline & & Other & 246 & 3.7 & .47 & & \\
\hline \multirow{2}{*}{2} & \multirow{2}{*}{ I take less liberties in how I design my lessons } & ENG & 36 & 3.6 & .62 & \multirow{2}{*}{.33} & \multirow{2}{*}{ n.s } \\
\hline & & Other & 244 & 3.6 & .57 & & \\
\hline \multirow{2}{*}{3} & \multirow{2}{*}{ I reduce instructional content } & ENG & 36 & 3.5 & .60 & \multirow{2}{*}{1.34} & \multirow{2}{*}{ n.s } \\
\hline & & Other & 244 & 3.3 & .74 & & \\
\hline \multirow{2}{*}{4} & \multirow{2}{*}{ I focus more on Educational standards } & ENG & 36 & 3.5 & .56 & \multirow{2}{*}{.11} & \multirow{2}{*}{ n.s } \\
\hline & & Other & 247 & 3.5 & 67 & & \\
\hline \multirow{2}{*}{5} & \multirow{2}{*}{$\begin{array}{l}\text { My instruction focuses more strongly on } \\
\text { competences rather than content }\end{array}$} & ENG & 35 & 3.5 & .78 & \multirow{2}{*}{1.61} & \multirow{2}{*}{ n.s } \\
\hline & & Other & 247 & 3.5 & .62 & & \\
\hline \multirow{2}{*}{6} & \multirow{2}{*}{ I focus more strongly on multiple choice tests } & ENG & 36 & 3.4 & .69 & \multirow{2}{*}{1.69} & \multirow{2}{*}{ n.s } \\
\hline & & Other & 246 & 3.1 & .83 & & \\
\hline \multirow{2}{*}{7} & \multirow{2}{*}{$\begin{array}{l}\text { I focus more strongly on overarching competences } \\
\text { (writing and reading in mathematics instruction) }\end{array}$} & ENG & 36 & 3.3 & .75 & \multirow{2}{*}{-1.22} & \multirow{2}{*}{ n.s } \\
\hline & & Other & 239 & 3.4 & .70 & & \\
\hline \multirow{2}{*}{8} & \multirow{2}{*}{$\begin{array}{l}\text { I have narrowed down the curricular content of my } \\
\text { instruction }\end{array}$} & ENG & 36 & 3.0 & .58 & \multirow{2}{*}{-2.02} & \multirow{2}{*}{$p<.05$} \\
\hline & & Other & 245 & 3.2 & .72 & & \\
\hline
\end{tabular}

\subsubsection{What is the relationship between English language teachers' view on Educational}

\section{assessment and their instructional practice in teaching English?}

Based on confirmatory factor analysis, the following factors of changes in teachers' instructional practice were identified: (1) giving homework, (2) teaching methods, (3) content of the instruction, (4) testing strategy, and (5) teachers' attention to special students. A correlation analysis was done to identify how English teachers' view on school achievement tests (SATs) are related to their teaching practices. As a result, English language teachers' assessment view was found to be significantly related to the content of instruction $(r=.35$, $p<.05)$. The analysis also shows that teaching methods and testing strategy are correlated $(\mathrm{r}=.35, p<.05)$, and the content of the instruction is correlated with testing strategy $(\mathrm{r}=.33$, $p<.05)$ and attention to special students $(\mathrm{r}=.47, p<.01)$. These results are presented in Table 44 which follows. 
Table 44. The relationship between assessment attitude and teachers' instructional changes

\begin{tabular}{l|c|c|c|c|c}
\hline & $\mathbf{1}$ & $\mathbf{2}$ & $\mathbf{3}$ & $\mathbf{4}$ & $\mathbf{5}$ \\
\hline View on assessments & & & & & \\
Giving homework & .02 & & & & \\
Teaching methods & .13 & -.13 & & & \\
Content of instruction & $.35^{*}$ & .05 & .25 & & \\
Testing strategy & .03 & -.07 & $.35^{*}$ & $.33^{*}$ & \\
Attention to special students & .18 & .03 & .17 & $.47^{* *}$ & -.00 \\
\hline
\end{tabular}

Note. $* p<.05, * * p<.01$.

\subsubsection{Which test preparation strategies do English language teachers mostly use?}

English language teachers often use tasks in regular instruction that are similar to those in school achievement tests $(\mathrm{M}=3.6, \mathrm{SD}=.47)$, discuss general task-taking strategies with students $(\mathrm{M}=3.6, \mathrm{SD}=.58)$, have students practice test formats that are used in school achievement tests $(\mathrm{M}=3.5, \mathrm{SD}=.66)$, and seek to improve students' motivation to do well on SATs $(\mathrm{M}=3.4, \mathrm{SD}=.73)$. One significantly different statement compared to other teachers' answers was "I discuss general task-taking strategies with students" $(\mathrm{t}=1.49, p<.05)$. Other teachers, however, see more coherence between instructional content and tasks in SATs $(\mathrm{t}=-1.40, p<.05)$ and try to improve students' test taking skills (practice on public release tasks that are used in SATs $)(t=-.90, p<.05)$ as summarized in Table 45 below. Also, the table below shows H3 was partially accepted in that English language teachers' test preparation strategies were actually significantly different for three of the 7 test preparation strategy items. English language teachers seem to use more general task-taking strategies than other teachers, however, they seem less concerned trying to achieve coherence between instructional content and the tasks of the SAT and less convinced that trying to improve students' test taking skills is as useful as other non-English language teachers. 
Table 45. English language teachers' test preparation strategies

\begin{tabular}{|c|c|c|c|c|c|c|c|}
\hline & Test preparation strategies & Groups & $\mathbf{N}$ & $\mathbf{M}$ & SD & $\mathbf{t}$ & $\mathbf{P}$ \\
\hline \multirow{2}{*}{1} & \multirow{2}{*}{$\begin{array}{l}\text { I more often use tasks in regular instruction } \\
\text { that are similar to those in school } \\
\text { achievement test }\end{array}$} & ENG & 34 & 3.6 & .47 & \multirow{2}{*}{.21} & \multirow{2}{*}{ n.s } \\
\hline & & Other & 253 & 3.6 & .64 & & \\
\hline \multirow{2}{*}{2} & \multirow{2}{*}{$\begin{array}{l}\text { I discuss general task-taking strategies with } \\
\text { students }\end{array}$} & ENG & 34 & 3.6 & .58 & \multirow{2}{*}{1.49} & \multirow{2}{*}{$p<.05$} \\
\hline & & Other & 256 & 3.5 & .81 & & \\
\hline \multirow{2}{*}{3} & \multirow{2}{*}{$\begin{array}{l}\text { I practice test formats that are used in } \\
\text { school achievement test }\end{array}$} & ENG & 35 & 3.5 & .66 & \multirow{2}{*}{-.55} & \multirow{2}{*}{ n.s } \\
\hline & & Other & 255 & 3.5 & .64 & & \\
\hline \multirow{2}{*}{4} & \multirow{2}{*}{$\begin{array}{l}\text { I seek to improve students' motivation to do } \\
\text { well on SATs }\end{array}$} & ENG & 36 & 3.3 & .72 & \multirow{2}{*}{-.52} & \multirow{2}{*}{ n.s } \\
\hline & & Other & 258 & 3.4 & .73 & & \\
\hline \multirow{2}{*}{5} & \multirow{2}{*}{$\begin{array}{l}\text { I see to it that coherence between } \\
\text { instructional content and the tasks of the } \\
\text { SAT is increased }\end{array}$} & ENG & 35 & 3.2 & 1.0 & \multirow{2}{*}{-1.40} & \multirow{2}{*}{$p<.05$} \\
\hline & & Other & 252 & 3.5 & .74 & & \\
\hline \multirow{2}{*}{6} & \multirow{2}{*}{$\begin{array}{l}\text { I try to improve students' test taking skills } \\
\text { (practice on public release tasks that are } \\
\text { used in SATs) }\end{array}$} & ENG & 35 & 3.2 & 1.1 & \multirow{2}{*}{-.90} & \multirow{2}{*}{$p<.05$} \\
\hline & & Other & 260 & 3.4 & .79 & & \\
\hline \multirow{2}{*}{7} & \multirow{2}{*}{$\begin{array}{l}\text { I set aside or put less emphasis, in regular } \\
\text { instruction, on content that will not be } \\
\text { tested }\end{array}$} & ENG & 35 & 2.1 & 1.0 & \multirow{2}{*}{-1.15} & \multirow{2}{*}{$\mathrm{n} . \mathrm{s}$} \\
\hline & & Other & 259 & 2.3 & 1.0 & & \\
\hline
\end{tabular}

\subsubsection{Summary}

Since English language is an important subject included in school achievement tests, it is important that English language teachers should believe that state-level assessments are important for their work and that the results of the assessment are linked with the school and teachers' efforts. The state-level assessments cause English teachers to focus more on the assessment content and influence their design of progress and final exams. English teachers also prefer to prepare students for the assessments by practicing test items during class that are similar to the school achievement test items. The results of this study will help to give insights into the issues behind the teaching and learning process of English language education in Mongolia. It is important to explore the reasons behind ineffective teaching and learning strategies and their effect on learning achievement, and how English language instruction has been changing due to the educational assessment and accountability system in Mongolia. 


\subsection{Study 3: What are English language teachers' perceptions of teaching English language receptive skills?}

\subsubsection{Introduction}

Many EFL experts suggest that receptive skills should be taught based on communicative language teaching (CLT) including pre-, while-, and post stages; therefore, the strategies in this questionnaire are categorized into these stages. On the other hand, researchers have shown that receptive skills are often taught based on terminology and forms, not on active ways of using real life communication. Hence, Study 3 aims to explore how receptive skills are currently taught in Mongolia.

English language teachers were asked to tell which teaching strategies, teaching materials, and encouragement of out-of-class activities they use to develop students' English language receptive skills. Teaching strategies of receptive skills were categorized mostly based on the theory of Baker and Westrup (2000) and Lindsay's (2000) three-stage (pre-, while-, post-) teaching methodologies which were discussed in the theoretical framework of this document. A five-point Likert scale was used in this questionnaire with the following categories: (1) never or almost never true of me, (2) usually not true of me, (3) somewhat true of me, (4) usually true of me, and (5) always or almost always true of me.

\subsubsection{Which teaching English language listening strategies are mostly used?}

The five most frequently used listening strategies in each teaching stage were identified. From the results, it was found that teachers (1) usually check comprehension after listening $(\mathrm{M}=4.2, \mathrm{SD}=.98),(2)$ ask students to discuss pictures, photos before listening $(\mathrm{M}=4.1$, $\mathrm{SD}=1.36)$, (3) ask students to answer multiple choice questions ( $\mathrm{M}=3.9, \mathrm{SD}=1.11)$, (4) ask students to discuss their opinions on the topic $(\mathrm{M}=3.9, \mathrm{SD}=1.1),(5)$ ask students to do tasks related to grammar, vocabulary, and pronunciation $(\mathrm{M}=3.9, \mathrm{SD}=1.0$; see Table 46$)$. A pairedsample t-test showed two strategies that were significantly more widely adopted by all English teachers in the study: "I ask students to discuss pictures, photos or cartoons" $(\mathrm{t}=5.50, p<.01)$ and "I check comprehension of listening (asking questions, true-false statements, etc.)" $(\mathrm{t}=2.91, p<.05)$. See Table 46 . H4 was rejected because only one of the three theoretically most useful strategies was found to be significantly different from other strategies. The strategy of having students discuss pictures, photos and cartoons before listening was found to be a common best practice among the English teachers surveyed. The two other predicted strategies, developing metacognitive skill and students' reflection, were not found to be significantly 
different. Another significantly used strategy was checking on the comprehension of listening in the post-listening phase of the lesson.

Table 46. Five most frequently used teaching listening strategies in each stage of teaching listening.

\begin{tabular}{|c|c|c|c|c|c|c|}
\hline & & Strategies & $\mathbf{M}$ & SD & $\mathbf{T}$ & $\mathbf{P}$ \\
\hline \multirow{5}{*}{ 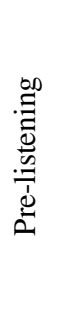 } & 1 & I ask students to discuss pictures, photos or cartoons & 4.1 & 1.3 & 5.50 & $p<.01$ \\
\hline & 2 & I ask students to discuss their opinion on the topic & 3.9 & 1.1 & 1.00 & n.s \\
\hline & 3 & I pre-teach vocabulary and grammar using various ways & 3.8 & 1.1 & -.10 & n.s \\
\hline & 4 & I ask students to discuss charts, graphs, maps or statistics & 3.8 & 1.0 & -.66 & n.s \\
\hline & 5 & I use brainstorming on topics or vocabulary & 3.7 & 1.1 & - & - \\
\hline \multirow{5}{*}{ 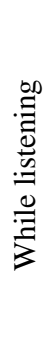 } & 1 & I ask students to answer multiple choice questions & 3.9 & 1.1 & .83 & n.s \\
\hline & 2 & I ask students to take notes & 3.8 & 1.1 & -.13 & n.s \\
\hline & 3 & I ask students to form questions and give short answers & 3.8 & 1.0 & -1.51 & n.s \\
\hline & 4 & I ask students to complete a gap fill & 3.6 & 1.0 & .50 & n.s \\
\hline & 5 & $\begin{array}{l}\text { I ask students to number topics, events or pictures in } \\
\text { correct order }\end{array}$ & 3.6 & 1.1 & - & - \\
\hline \multirow{5}{*}{ 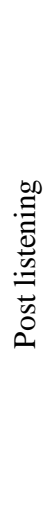 } & 1 & $\begin{array}{l}\text { I check comprehension of listening (asking questions, } \\
\text { true false statements, etc.) }\end{array}$ & 4.2 & 0.9 & 2.91 & $p<.05$ \\
\hline & 2 & $\begin{array}{l}\text { I ask students to do tasks related to vocabulary, } \\
\text { grammar, pronunciation }\end{array}$ & 3.9 & 1.0 & -1.33 & n.s \\
\hline & 3 & $\begin{array}{l}\text { I set up awareness-raising activities for grammar, } \\
\text { vocabulary, or pronunciation }\end{array}$ & 3.7 & 1.2 & -.89 & n.s \\
\hline & 4 & $\begin{array}{l}\text { I review pre-listening vocabulary and teach new } \\
\text { vocabulary }\end{array}$ & 3.7 & 1.0 & -1.04 & n.s \\
\hline & 5 & $\begin{array}{l}\text { I ask students to link listening with another skill } \\
\text { (speaking, reading, writing) }\end{array}$ & 3.6 & .99 & - & - \\
\hline
\end{tabular}

\subsubsection{Which teaching English language reading strategies are mostly used?}

From the survey results, the five most frequently used teaching reading strategies in each stage are shown in Table 47. The most commonly used strategies include: teachers usually check comprehension by asking questions or true-false statements $(\mathrm{M}=4.2, \mathrm{SD}=.99)$ after reading, give written exercises related to the text content, work on vocabulary or pronunciation $(\mathrm{M}=4.1, \mathrm{SD}=1.10$ ), and use different activities to motivate students (jigsaw reading, jumbled texts etc. $)(\mathrm{M}=4.0, \mathrm{SD}=1.07)$ while reading. The results show that teachers mostly use whilereading strategies more than other stages in teaching reading. Also, strategies of assigning tasks related to the topic $(\mathrm{M}=3.4, \mathrm{t}=2.36, p<.05)$ and checking comprehension by asking questions or true-false statements $(\mathrm{M}=4.2, \mathrm{t}=2.33, p<.05)$ were found significantly different from other strategies. This suggests that fewer teachers assign tasks related to the topic compared to other 
strategies, but most teachers do follow up with questions to check comprehension. See Table 47.

H5 was rejected because there is no significant difference in the strategies between using specific reading activities and students' reflection in teaching reading skills recognized by the teachers in this study. The most common pre-reading strategy appears to be assigning tasks related to the topic. Teachers also significantly utilize the strategy of checking comprehension by asking questions or making true-false statements in post reading activities. However, there are no other clear favorites among the strategies presented, suggesting that teachers believe they are using all these strategies on a fairly equal basis.

Table 47. The five most frequently used teaching reading strategies

\begin{tabular}{|c|c|c|c|c|c|c|}
\hline & & Strategies & $\mathbf{M}$ & SD & $\mathbf{T}$ & $\mathbf{P}$ \\
\hline \multirow{5}{*}{ ف } & 1 & I pre-teach key words & 3.9 & 1.0 & -.23 & n.s \\
\hline & 2 & I use brainstorming on a topic & 3.8 & 1.0 & & \\
\hline & 3 & $\begin{array}{l}\text { I ask students to think about the subject of the } \\
\text { reading they are about to do }\end{array}$ & 3.7 & 1.0 & -1.27 & n.s \\
\hline & 4 & I activate their pre-existing knowledge & 3.7 & 1.0 & .37 & n.s \\
\hline & 5 & I assign tasks related to the topic & 3.4 & 1.1 & 2.36 & $p<.05$ \\
\hline \multirow{5}{*}{$\frac{d}{3}$} & 1 & $\begin{array}{l}\text { I give written exercises related to the text } \\
\text { content, vocabulary or pronunciation }\end{array}$ & 4.1 & 1.1 & -.14 & n.s \\
\hline & 2 & $\begin{array}{l}\text { I use different activities to motivate students } \\
\text { (jigsaw reading, jumbled texts etc.) }\end{array}$ & 4.0 & 1.0 & .66 & n.s \\
\hline & 3 & $\begin{array}{l}\text { I ask students to guess the meaning of words } \\
\text { from the context }\end{array}$ & 4.0 & 1.0 & -.15 & n.s \\
\hline & 4 & I check comprehension while reading & 4.0 & 1.0 & 1.24 & n.s \\
\hline & 5 & $\begin{array}{l}\text { I relate the reading to other skills (listening, } \\
\text { speaking, writing) }\end{array}$ & 3.8 & 1.0 & - & - \\
\hline \multirow{4}{*}{$\begin{array}{l}1 \\
\frac{1}{2} \\
0 \\
0\end{array}$} & 1 & $\begin{array}{l}\text { I check comprehension by asking questions or } \\
\text { true-false statements }\end{array}$ & 4.2 & .99 & 2.33 & $p<.05$ \\
\hline & 2 & $\begin{array}{l}\text { I give written exercises related to the text } \\
\text { content, vocabulary or grammar }\end{array}$ & 4.0 & .94 & -1.43 & n.s \\
\hline & 3 & I ask students to discuss the main idea & 3.8 & 1.1 & .24 & n.s \\
\hline & 4 & $\begin{array}{l}\text { I use different activities to motivate students } \\
\text { (making posters, group report etc.) }\end{array}$ & 3.8 & 1.0 & - & - \\
\hline
\end{tabular}

Besides showing the most frequently used teaching strategies, I also wanted to examine the instructional strategies along the factors emerging from the analysis. Before doing descriptive analysis, the five-point Likert scale - (1) never or almost never true of me, (2) usually not true of me, (3) somewhat true of me, (4) usually true of me, and (5) always or almost always true of me - was computed into (1) efficient and (2) inefficient strategies. Students' discussion $(\mathrm{M}=1.0, \mathrm{SD}=.02)$, developing students' metacognitive skills $(\mathrm{M}=1.0, \mathrm{SD}=.04)$, 
and using general reading scales $(\mathrm{M}=1.0, \mathrm{SD}=.04)$ were indicated as the most efficient teaching strategies. See Table 48.

Table 48. The efficiency of instructional strategies along the factors emerging from the factor analysis.

\begin{tabular}{cccc}
\hline Factors & $\mathbf{N}$ & Mean & Std. Deviation \\
\hline Discussion & 72 & 1.0 & .02 \\
Preparation & 71 & .98 & .06 \\
Cognitive & 71 & .98 & .07 \\
Metacognition & 70 & 1.0 & .04 \\
Reflection & 71 & .98 & .12 \\
Checking & 71 & .99 & .06 \\
Pre-reading & 71 & .99 & .05 \\
General reading & 71 & 1.0 & .04 \\
Specific & 71 & .99 & .03 \\
Reflection & 70 & .99 & .04 \\
\hline
\end{tabular}

Table 49, below shows less used but important teaching strategies to teach ELRS. Especially, making inferences and discussing opinions/cultural points, and finding out cause and effects are important strategies to develop students' strategic skills and to give students a chance to use the language in real situations. However, they are not often used. For listening, setting up out-of-class research and interview projects $(\mathrm{M}=2.9, \mathrm{SD}=1.0)$ is barely used, and asking students to discuss interpretations and opinions $(\mathrm{M}=3.1, \mathrm{SD}=1.0)$, asking students to discuss ideas or cultural points in the text $(\mathrm{M}=3.1, \mathrm{SD}=.99)$ are used somewhat while asking students to figure out relations such as cause and effect $(\mathrm{M}=3.0, \mathrm{SD}=1.0)$ and asking students to interpret or make inferences about implied information $(\mathrm{M}=3.1, \mathrm{SD}=1.1)$ are also not frequently used compared to other strategies in teaching reading. See Table 49.

Table 49. Less used teaching strategies in each skill.

\begin{tabular}{l|c|c|l|c|c}
\hline Teaching listening strategies & M & SD & Teaching reading strategies & M & SD \\
\hline $\begin{array}{l}\text { Ask students to identify errors in a } \\
\text { script while listening }\end{array}$ & 2.9 & 1.0 & $\begin{array}{l}\text { Ask students to figure out relations such } \\
\text { as cause and effect after reading }\end{array}$ & 3.0 & 1.0 \\
\hline $\begin{array}{l}\text { Set up out-of-class research and } \\
\text { interview projects }\end{array}$ & 2.9 & 1.0 & $\begin{array}{l}\text { Ask students to interpret or make } \\
\text { inferences about implied information } \\
\text { after reading }\end{array}$ & 3.1 & 1.1 \\
\hline $\begin{array}{l}\text { Ask students to discuss } \\
\text { interpretations and opinions after } \\
\text { listening }\end{array}$ & 3.1 & 1.0 & Reading for detail while reading & 3.4 & 1.0 \\
\hline $\begin{array}{l}\text { Ask students to discuss ideas or } \\
\text { cultural points in the text after } \\
\text { listening }\end{array}$ & 3.1 & .99 & $\begin{array}{l}\text { Scanning (read for specific information) } \\
\text { while reading }\end{array}$ & 3.5 & .98 \\
\hline
\end{tabular}




\subsubsection{What teaching materials are frequently used in teaching English receptive skills?}

For asking about teaching materials, a five-point Likert scale $(1=$ never, $2=$ seldom, $3=$ sometimes, 4 = often, $5=$ always) was used for responses. Paired sample t-test was done to find out what teaching materials are mostly used. In Table 50 we can see the three most used teaching materials in each skill from six listening and four reading materials. For developing students' listening skill, teachers often use textbooks $(\mathrm{M}=4.0, \mathrm{SD}=1.1)$ and sometimes use songs and music $(\mathrm{M}=3.4, \mathrm{SD}=1.1)$, but using $\mathrm{TV}$ show or interview is rarely applied $(\mathrm{M}=2.7$, $\mathrm{SD}=1.1)$. For reading, additional short passages $(\mathrm{M}=3.4, \mathrm{SD}=1.1)$, textbooks $(\mathrm{M}=3.1$, $\mathrm{SD}=1.2)$ and newspapers and journals $(\mathrm{M}=3.1, \mathrm{SD}=1.2)$ are sometimes used for teaching receptive skills. Those frequently used materials are significantly different from the other materials in the survey. See Table 50.

Table 50. Three most frequently used teaching materials for teaching receptive skills

\begin{tabular}{|c|c|c|c|c|c|c|}
\hline & & Materials & $\mathbf{M}$ & SD & $\mathbf{t}$ & $\mathbf{P}$ \\
\hline \multirow{3}{*}{ 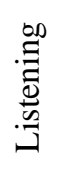 } & 1 & Textbook & 4.0 & 1.1 & 3.37 & $p<.05$ \\
\hline & 2 & Songs and music & 3.4 & 1.1 & 6.61 & $p<.01$ \\
\hline & 3 & TV show or interview & 2.7 & 1.1 & -8.04 & $p<.01$ \\
\hline \multirow{3}{*}{$\begin{array}{l}\stackrel{00}{\Xi} \\
\stackrel{\Xi}{\Xi} \\
\simeq\end{array}$} & 1 & Textbook & 3.1 & 1.2 & 6.88 & $p<.01$ \\
\hline & 2 & Additional short passages or stories & 3.4 & 1.1 & -2.87 & $p<.05$ \\
\hline & 3 & A newspaper or journal article & 3.1 & 1.2 & - & - \\
\hline
\end{tabular}

\subsubsection{How do teachers encourage their students to learn English receptive skills out of class?}

The result of this survey indicated that teachers usually asked students to learn new English songs $(\mathrm{M}=3.8, \mathrm{SD}=1.0)$, sometimes asked students to speak to native speakers $(\mathrm{M}=3.2, \mathrm{SD}=1.2)$, and sometimes asked them to watch TV news for homework $(\mathrm{M}=3.0$, $\mathrm{SD}=1.0$ ) for improving listening skills. For improving reading skills, teachers asked students to read short stories at home and talk/write about them $(\mathrm{M}=3.8, \mathrm{SD}=1.2)$, asked students to read newspapers or articles for homework $(\mathrm{M}=3.2, \mathrm{SD}=1.1)$, and asked students to gather information in group work from the Internet sources $(\mathrm{M}=3.1, \mathrm{SD}=1.0)$. A paired sample $\mathrm{t}$ test showed that asking students to learn new English songs $(\mathrm{M}=3.8, \mathrm{t}=5.18, p<.01)$ and asking students to read short stories at home and talk/write about it $(\mathrm{M}=3.8, \mathrm{t}=6.28, p<.01)$ were found to be significantly different from other strategies, suggesting these were the most popular strategies used by the largest number of English teachers. See Table 51. 
Table 51. Teachers' encouragement of out-of-class activities.

\begin{tabular}{|c|c|c|c|c|c|c|}
\hline & & Activities & $\mathbf{M}$ & SD & $\mathbf{t}$ & $\mathbf{P}$ \\
\hline \multirow{4}{*}{ 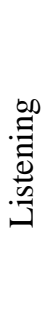 } & 1 & I ask students to learn new English songs & 3.8 & 1.0 & 5.18 & $p<.01$ \\
\hline & 2 & I ask students to speak to native speakers & 3.2 & 1.2 & .55 & n.s \\
\hline & 3 & $\begin{array}{l}\text { I ask students to listen to any information from the internet } \\
\text { and report it in the class }\end{array}$ & 3.0 & 1.1 & -.25 & n.s \\
\hline & 4 & $\begin{array}{l}\text { I ask students to watch TV news and interviews for } \\
\text { homework and report it in the class }\end{array}$ & 3.0 & 1.0 & - & - \\
\hline \multirow{3}{*}{ 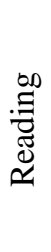 } & 1 & $\begin{array}{l}\text { I ask students to read short stories at home and talk/write } \\
\text { about it }\end{array}$ & 3.8 & 1.2 & 6.28 & $p<.01$ \\
\hline & 2 & I ask students to read newspapers or articles for homework & 3.2 & 1.1 & 1.05 & n.s \\
\hline & 3 & $\begin{array}{l}\text { I ask students to work in group projects to gather information } \\
\text { from the internet }\end{array}$ & 3.1 & 1.0 & - & - \\
\hline
\end{tabular}

\subsubsection{What are the relationships between teaching strategies and teaching materials and teachers' encouragement of out-of-class activities?}

The most frequently used teaching strategies in each teaching stage, teaching materials, and teachers' encouragement of out-of-class activities of receptive skills were each combined into one variable in order to do a correlation analysis comparing teaching materials and teachers' encouragement efforts to listening and reading skills. In table 52, all correlations are significant at .01 level. Four of the stronger correlations are listed here. Teaching strategies of receptive skills were correlated with teaching materials and teachers' encouragement of out-ofclass activities. Next, listening activities had strong correlations with teaching materials for listening skills $(\mathrm{r}=.63, p<.01)$. Next, reading activities were also strongly correlated with teachers' encouragement of out-of-class reading activities $(\mathrm{r}=.55, p<.01)$. Pre-teaching reading activities had a strong correlation with teaching materials used for listening activities $(\mathrm{r}=.53, p<.01)$, and the activities that teachers use during listening were also strongly correlated with teachers' encouragement of out-of-class listening activities $(\mathrm{r}=.52, p<.01)$.

Table 52. The relationship among teaching strategies and teaching materials and teachers' encouragement of out-of-class activities

\begin{tabular}{l|l|c|c|c|c|c|c}
\hline \multirow{2}{*}{$\begin{array}{c}\text { Language } \\
\text { skills }\end{array}$} & \multicolumn{2}{|c|}{ Teaching listening skill } & \multicolumn{3}{c}{ Teaching reading skill } \\
\cline { 3 - 8 } & & Pre- & While- & Post- & Pre- & While- & Post- \\
\hline \multirow{2}{*}{ Teaching materials } & Listening & .38 & .38 & .63 & .53 & .47 & .49 \\
\cline { 2 - 8 } & Reading & .25 & .47 & .46 & .49 & .39 & .38 \\
\hline \multirow{2}{*}{$\begin{array}{l}\text { Teachers' encouragement } \\
\text { of out-of-class activities }\end{array}$} & Listening & .31 & .42 & .48 & .37 & .40 & .50 \\
\cline { 2 - 8 } & Reading & .40 & .52 & .48 & .51 & .48 & .55 \\
\hline
\end{tabular}

Note: all correlations are significant, $p<.01$ 
A look at the 13 exploratory factor analyses grouping of teaching-related factors, derived from the teaching strategy questionnaire, resulted in the correlations shown in Table 53. Most of the factors were significantly correlated with each other. Some of the most highly correlated factors are worth mentioning. For example, preparing students for listening tasks using students' pre-existing knowledge was highly correlated with discussions before listening $(\mathrm{r}=.60, p<.01)$. Developing students' cognitive skill was correlated with preparing students for listening $(\mathrm{r}=.63, p<.01)$. Developing cognitive and metacognitive skills during listening had strong correlations $(\mathrm{r}=.61, p<.01)$. Using pre-reading activities before reading was correlated with developing cognitive skill $(\mathrm{r}=.61, p<.01)$ and with using specific reading scales $(\mathrm{r}=.61, \mathrm{p}<.01)$. Finally, using traditional materials in a classroom was significantly correlated with after class activities $(\mathrm{r}=.63, p<.01)$.

Table 53. Correlations among overall teaching-related factors.

\begin{tabular}{lllllllllllll}
\hline & 1 & 2 & 3 & 4 & 5 & 6 & 7 & 8 & 9 & 10 & 11 & 12 \\
\hline Discussion & & & & & & & & & & & & \\
Preparation & $.60^{* *}$ & & & & & & & & & & & \\
Cognitive & $.54^{* *}$ & $.63^{* *}$ & & & & & & & & & & \\
Metacog & $.33^{* *}$ & $.51^{* *}$ & $.61^{* *}$ & & & & & & & & & \\
Reflection & $.32^{* *}$ & $.47^{* *}$ & $.50^{* *}$ & $.44^{* *}$ & & & & & & & & \\
Checking & .09 & $.31^{* *}$ & $.45^{* *}$ & $.43^{* *}$ & $.41^{* *}$ & & & & & & & \\
Pre-reading & $.51^{* *}$ & $.59^{* *}$ & $.61^{* *}$ & $.51^{* *}$ & $.53^{* *}$ & $.39^{* *}$ & & & & & & \\
General reading & -.17 & .05 & .09 & .16 & $.26^{*}$ & $.40^{* *}$ & $.39^{* *}$ & & & & & \\
Specific & $.58^{* *}$ & $.47^{* *}$ & $.60^{* *}$ & $.53^{* *}$ & $.36^{* *}$ & $.50^{* *}$ & $.61^{* *}$ & $.34^{* *}$ & & & & \\
Reflection & $.40^{* *}$ & $.40^{* *}$ & $.37^{* *}$ & $.33^{* *}$ & $.41^{* *}$ & $.35^{* *}$ & $.45^{* *}$ & $.35^{* *}$ & $.58^{* *}$ & & & \\
Virtual & -.00 & .20 & $.28^{*}$ & .11 & $.43^{* *}$ & $.25^{*}$ & $.25^{*}$ & $.27^{*}$ & .11 & $.31^{* *}$ & & \\
Traditional & .08 & $.32^{* *}$ & $.38^{* *}$ & $.43^{* *}$ & $.51^{* *}$ & $.35^{* *}$ & $.41^{* *}$ & $.31^{* *}$ & $.27^{*}$ & $.31^{* *}$ & $.52^{* *}$ & \\
After class & $.31^{* *}$ & $.47^{* *}$ & $.50^{* *}$ & $.50^{* *}$ & $.50^{* *}$ & $.33^{* *}$ & $.42^{* *}$ & .14 & $.45^{* *}$ & $.56^{* *}$ & $.41^{* *}$ & $.63^{* *}$ \\
\hline
\end{tabular}

Note: $* p<.05, * * p<.01$.

\subsubsection{Summary}

The data result shows that teachers do not seem to use active strategies (e.g. checking comprehension by asking questions, giving written exercises, asking multiple choice questions) that are appropriate for developing students' creative and critical thinking skills (making inferences, interpreting implied information, finding cause and effects, or identifying cultural points). Also, textbooks were found to be the main resource and English teachers didn't often use additional and authentic materials for teaching receptive skills. For out-of-class activities, group projects and collecting information for presenting were related to real life. However, they 
were not used often enough to really improve students' communicative competence. These results of teachers' perceptions about their teaching practice of the English language will be used in the study to explore how teachers' perceptions are matched with their students' perceptions of learning strategies and test performance.

\subsection{Study 4: How do students identify their learning strategies and attitudes towards English language receptive skills?}

\subsubsection{Introduction}

This study starts to meet the need for identifying learning strategies used for English language receptive skills by exploring how attitudes towards those language skills can be correlated with LLSs. Learning strategies and students' attitudes towards learning receptive skills were asked from 6th- and 8th-graders in each skill. Using an online test assessment, 6thgraders were asked both listening and reading skill strategies and attitudes and 8th-graders were asked reading skill strategies and attitudes related to only the reading skill.

\subsubsection{What learning strategies are frequently used for English listening skill by 6th- graders?}

Paired sample t-test was used to find the most frequently and commonly used listening strategies by 6th-graders. A five-point Likert scale was used in the questionnaire ranging from (1) strongly agree, to (5) strongly disagree. In this report, to make it more accessible, values were recoded into 4-5 for agree and strongly agree, 3 for neither disagree nor agree, and 1-2 for strongly disagree and disagree. In Table 54, the most common listening skill strategies were to choose key words while listening $(\mathrm{M}=4.5, \mathrm{SD}=.74)$, to mostly ask questions when they didn't fully understand $(\mathrm{M}=4.4, \mathrm{SD}=.97)$, and to do mind mapping while listening $(\mathrm{M}=4.2$, $\mathrm{SD}=.89)$. For the two categorical questions, the highest results showed $44.8 \%$ of the students spent 5-10 minutes on listening tasks every day and 41.7\% of them listened to English songs to improve their listening skills. Understanding the content through speaker's intonation $(\mathrm{t}=3.54$, $p<.05)$ and taking notes while listening $(\mathrm{t}=-3.44, p<.05)$ were significantly different from the other listening strategies suggesting these strategies were not widely adopted (see Table 54). 
Table 54. The frequencies of listening skill strategies by 6th-graders.

\begin{tabular}{|c|c|c|c|c|c|}
\hline Strategies & $\mathbf{N}$ & $\mathbf{M}$ & SD & $\mathbf{T}$ & $\mathbf{P}$ \\
\hline I choose key words while listening & 76 & 4.5 & .74 & 1.03 & n.s \\
\hline $\begin{array}{l}\text { I ask questions to clarify anything that I don't fully } \\
\text { understand }\end{array}$ & 77 & 4.4 & .97 & .26 & n.s \\
\hline I do mind mapping while listening & 77 & 4.2 & .89 & - & - \\
\hline $\begin{array}{l}\text { I understand the content through speaker's } \\
\text { intonation }\end{array}$ & 76 & 3.6 & 1.0 & 3.54 & $p<.05$ \\
\hline I take notes while listening & 77 & 2.8 & 1.2 & -3.44 & $p<.05$ \\
\hline
\end{tabular}

\subsubsection{What learning strategies are frequently used for reading skills by 6th- and 8th- graders?}

Reading strategies with matched items were asked from both grades. Scales were recoded same way as mentioned in section 5.4.2. Table 55 shows the results of independent sample ttests to identify when there was a significant difference between both grades' reading strategies. H6 was accepted because a statistically significant difference was found for only one strategy "If the story is long, I divide it into small parts" between two grades $\left(\mathrm{M}_{6}=4.0, \mathrm{SD}_{6}=1.1\right.$; $\left.\mathrm{M}_{8}=3.3, \mathrm{SD}_{8}=1.3\right)$. In both grades, students mostly guessed new words from the context $\left(\mathrm{M}_{6}=4.1, \mathrm{SD}_{6}=-.88, \mathrm{M}_{8}=4.1, \mathrm{SD}_{8}=.92\right)$ and predicted the main idea from its title $\left(\mathrm{M}_{6}=4.0\right.$, $\left.\mathrm{SD}_{6}=.99 ; \mathrm{M}_{8}=3.8, \mathrm{SD}_{8}=1.0\right)$. The 6th-graders also mostly divided the long story into small parts $(\mathrm{M}=4.0, \mathrm{SD}=1.1)$ and the 8 th-graders participated more in reading activities in a class $(\mathrm{M}=4.0, \mathrm{SD}=.94)$. For the non-Likert categorical questions, the highest percentages were $53.7 \%$ of 6 th-grade students reading tales and $45.1 \%$ of them spending 5-10 minutes on reading tasks every day. While for 8 th-grade students, $49.1 \%$ read a long story and $41.4 \%$ of them spent 5-10 minutes on reading tasks every day.

Table 55. Reading strategies used by both graders.

\begin{tabular}{|c|c|c|c|c|c|c|}
\hline Strategies & Grades & $\mathbf{N}$ & $\mathbf{M}$ & SD & $\mathbf{T}$ & $\mathbf{P}$ \\
\hline \multirow{2}{*}{$\begin{array}{l}\text { I guess the meaning of new words from the } \\
\text { context }\end{array}$} & 6 & 78 & 4.1 & .88 & \multirow{2}{*}{-1.70} & \multirow{2}{*}{ n.s } \\
\hline & 8 & 100 & 4.1 & .92 & & \\
\hline \multirow{2}{*}{ I ask questions before I read the story } & 6 & 76 & 2.5 & 1.3 & \multirow{2}{*}{-1.69} & \multirow{2}{*}{ n.s } \\
\hline & 8 & 98 & 1.9 & 1.2 & & \\
\hline \multirow{2}{*}{$\begin{array}{l}\text { I participate more in reading activities in the } \\
\text { classroom }\end{array}$} & 6 & 76 & 3.6 & 1.0 & \multirow{2}{*}{-1.00} & \multirow{2}{*}{ n.s } \\
\hline & 8 & 94 & 4.0 & .94 & & \\
\hline \multirow{2}{*}{ I read the story and choose key words } & 6 & 74 & 3.5 & 1.1 & \multirow{2}{*}{.27} & \multirow{2}{*}{ n.s } \\
\hline & 8 & 100 & 3.5 & 1.2 & & \\
\hline \multirow{2}{*}{ If the story is long, I divide it into small parts } & 6 & 72 & 4.0 & 1.1 & \multirow{2}{*}{-2.13} & \multirow{2}{*}{.035} \\
\hline & 8 & 99 & 3.3 & 1.3 & & \\
\hline \multirow{2}{*}{$\begin{array}{l}\text { I predict the main idea of the whole passage } \\
\text { from its titles }\end{array}$} & 6 & 69 & 4.0 & .99 & \multirow{2}{*}{-1.20} & \multirow{2}{*}{ n.s } \\
\hline & 8 & 96 & 3.8 & 1.0 & & \\
\hline
\end{tabular}

Note: Significant at $p<.05$. 


\subsubsection{What are the students' attitudes towards learning English language receptive}

skills?

Using an online assessment developed for this study, 6th-grade students were assessed on both listening and reading skills attitudes, while 8th-graders were assessed only on reading. The attitude towards learning listening skills for 6th-graders was analyzed separately while attitudes for reading were analyzed together. In each case, opinion values were $1=$ strongly agree to $5=$ strongly disagree and recoded into $1=$ agree and $2=$ uncertain and disagree .

As a result of descriptive statistics for 6th-grade listening attitudes, students liked to improve listening skills (97.4\%) and believed that listening improved their knowledge and speaking skill (92.4\%). Also, they liked to listen to English songs (85.4\%) and trying to understand the speaker $(82.9 \%)$. See Figure 8.

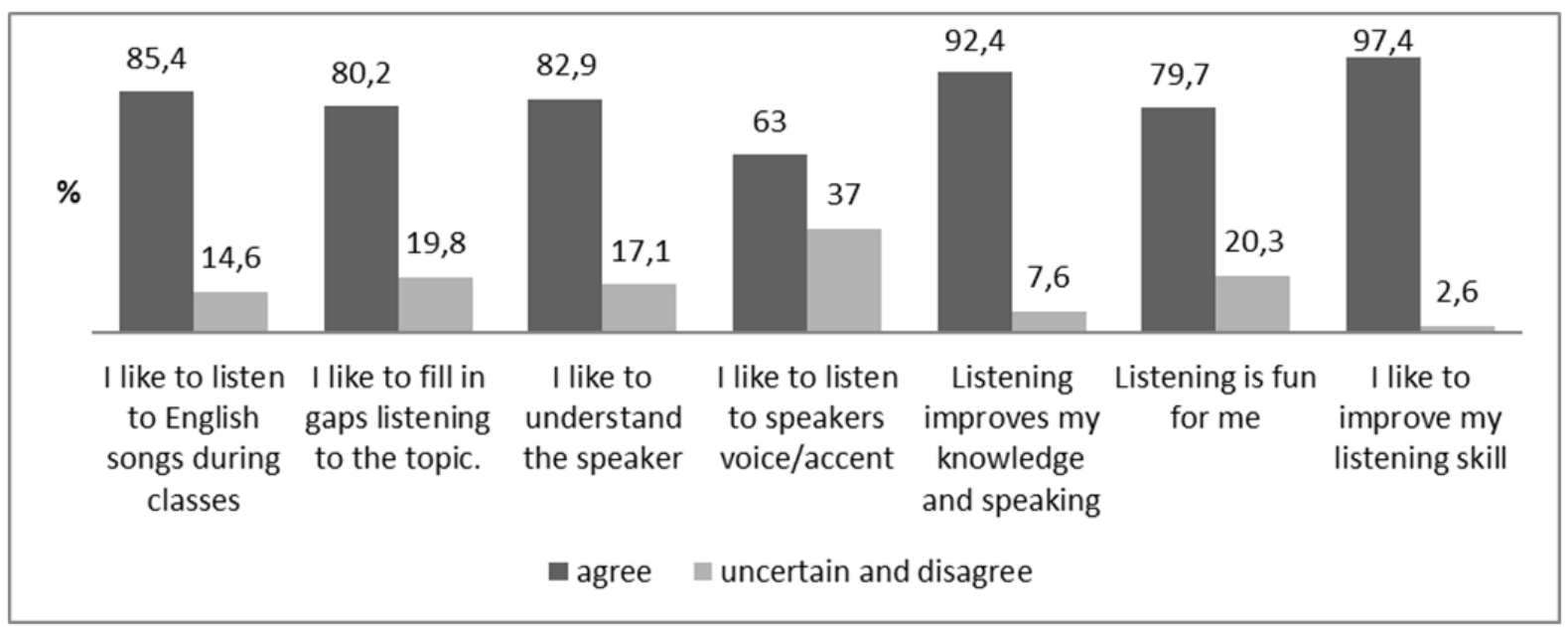

Figure 8. 6th-grade students' attitude towards learning listening skill

Both 6th- and 8th-grade students were assessed with the same reading skill tests. Again, values were recoded from a five-point Likert scale into agree, uncertain, and disagree categories. Here, only values from the agreeing category were selected to compare the two grades' reading attitudes. The results of the descriptive study showed that all students tend to like to enlarge their vocabulary, improve their reading skills, and believe reading develops their knowledge and speaking skill. A comparison of their overall response percentages showed 6thgrade students have more positive attitudes towards learning reading skills than 8th-graders. See Figure 9. To support this statement, significant differences are shown in table 56. H7 was partially accepted because only two significant differences were found: More 8th-grade students think reading in English is a waste of time $(\mathrm{N}=96, \mathrm{M}=4.3, \mathrm{SD}=1.1, \mathrm{t}=-1.9, p<.01)$ 
and more 6th-grade students like to exchange books with others $(\mathrm{N}=73, \mathrm{M}=2.2, \mathrm{SD}=1.3$, $\mathrm{t}=.86, p<.05)$.

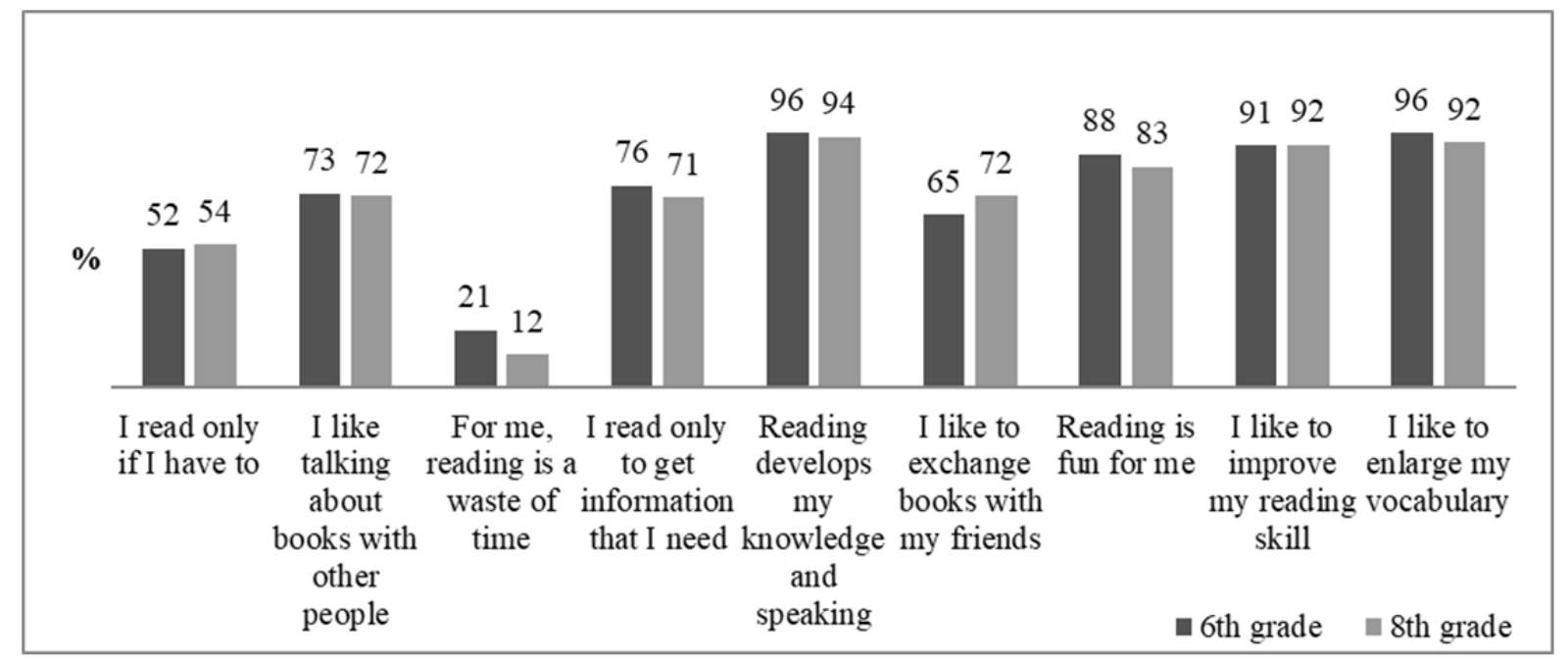

Figure 9. 6th- and 8th-grade students' attitude towards learning reading skill

Table 56. The difference between 6th-and 8th-grades' reading attitude

\begin{tabular}{|c|c|c|c|c|c|c|c|}
\hline Reading attitude & Grades & $\mathbf{N}$ & $\mathbf{M}$ & SD & SE & $\mathbf{t}$ & $\mathbf{P}$ \\
\hline \multirow{2}{*}{ I read only if I have to } & 6 & 73 & 2.7 & 1.5 & .18 & \multirow{2}{*}{.58} & \multirow{2}{*}{.24} \\
\hline & 8 & 100 & 2.6 & 1.5 & .15 & & \\
\hline \multirow{2}{*}{$\begin{array}{l}\text { I like talking about } \\
\text { books with other } \\
\text { people }\end{array}$} & 6 & 73 & 1.9 & 1.1 & .13 & \multirow{2}{*}{-.55} & \multirow{2}{*}{.85} \\
\hline & 8 & 98 & 2.0 & 1.0 & .10 & & \\
\hline \multirow{2}{*}{$\begin{array}{l}\text { For me, reading is a } \\
\text { waste of time }\end{array}$} & 6 & 72 & 3.9 & 1.5 & .18 & \multirow{2}{*}{-1.91} & \multirow{2}{*}{$p<.01$} \\
\hline & 8 & 96 & 4.3 & 1.1 & .11 & & \\
\hline \multirow{2}{*}{$\begin{array}{l}\text { I read only to get } \\
\text { information that I need }\end{array}$} & 6 & 74 & 2.0 & 1.4 & .16 & \multirow{2}{*}{-.198} & \multirow{2}{*}{.58} \\
\hline & 8 & 96 & 2.0 & 1.3 & .13 & & \\
\hline \multirow{2}{*}{$\begin{array}{l}\text { Reading develops my } \\
\text { knowledge and } \\
\text { speaking }\end{array}$} & 6 & 75 & 1.2 & .52 & .06 & \multirow{2}{*}{.196} & \multirow{2}{*}{.91} \\
\hline & 8 & 96 & 1.2 & .58 & .05 & & \\
\hline \multirow{2}{*}{$\begin{array}{l}\text { I like to exchange } \\
\text { books with my friends }\end{array}$} & 6 & 73 & 2.2 & 1.3 & .16 & \multirow{2}{*}{.86} & \multirow{2}{*}{$p<.05$} \\
\hline & 8 & 95 & 2.0 & 1.0 & .10 & & \\
\hline \multirow{2}{*}{ Reading is fun for me } & 6 & 77 & 1.5 & .80 & .09 & \multirow{2}{*}{-1.35} & \multirow{2}{*}{.48} \\
\hline & 8 & 97 & 1.7 & .93 & .09 & & \\
\hline \multirow{2}{*}{$\begin{array}{l}\text { I like to improve my } \\
\text { reading skill }\end{array}$} & 6 & 77 & 1.3 & .73 & .08 & \multirow{2}{*}{.113} & \multirow{2}{*}{.91} \\
\hline & 8 & 97 & 1.3 & .75 & .07 & & \\
\hline \multirow{2}{*}{$\begin{array}{l}\text { I like to enlarge my } \\
\text { vocabulary }\end{array}$} & 6 & 77 & 1.1 & .50 & .05 & \multirow{2}{*}{-.83} & \multirow{2}{*}{.09} \\
\hline & 8 & 95 & 1.2 & .71 & .07 & & \\
\hline
\end{tabular}




\subsubsection{What is the relationship between students' learning strategies and attitudes towards ELRS?}

The most frequently used learning strategies of receptive skills were indexed into one variable according to the language learning strategy classification of Oxford (1990), and also, both grades' attitudes' means were computed into a single variable in each receptive skill before the correlation analysis. A correlation analysis was used to identify if there was any relationship between attitude towards language learning and language learning strategies of English receptive skills for both grades. In Table 57, we can see that 6th-grade students' attitude towards English language receptive skills had stronger correlations with language learning strategies than 8th-grade students. Especially, reading compensation strategies and attitude towards listening had a strong correlation $(\mathrm{r}=.74, p<.01)$ and social reading strategies and reading attitude also had a strong correlation $(\mathrm{r}=.71, p<.01)$. Listening compensation strategies were significantly correlated with listening $(\mathrm{r}=.55, p<.01)$ and reading attitudes $(\mathrm{r}=.72, p<.01)$ for 6th-graders. For 8th-graders, reading cognitive strategies had a moderate significant correlation with reading attitude $(\mathrm{r}=.43, p<.01)$. The results suggest that younger students were more willing to learn English language than older students, and their attitude and learning strategies strongly correlated with each other. For H8, more younger students' attitude and learning strategies were significantly correlated at the $p<.05$ level with their learning strategies than with those of older students. Perhaps as the work gets harder the older students lost faith in these strategies and some began to feel they were no longer doing as well as they thought at mastering the skills.

Table 57. Correlation between students' attitude towards language skills and language learning strategies

\begin{tabular}{l|l|c|c|c}
\hline \multirow{2}{*}{$\begin{array}{l}\text { Language } \\
\text { skills }\end{array}$} & \multirow{2}{*}{$\begin{array}{l}\text { Learning } \\
\text { strategies }\end{array}$} & \multicolumn{2}{|c|}{ 6th-grade } & 8th-grade \\
\cline { 3 - 5 } & $\begin{array}{c}\text { Attitude towards } \\
\text { learning listening }\end{array}$ & $\begin{array}{c}\text { Attitude towards } \\
\text { learning reading }\end{array}$ & $\begin{array}{c}\text { Attitude towards } \\
\text { learning reading }\end{array}$ \\
\hline \multirow{4}{*}{ Reading } & Metacognitive & $.52^{* *}$ & $.64^{* *}$ & $-.28^{* *}$ \\
& Compensation & $.74^{* *}$ & $.70^{* *}$ & $.27^{* *}$ \\
& Social & $.68^{* *}$ & $.71^{* *}$ & n.s \\
& Cognitive & $.53^{* *}$ & $.59^{* *}$ & $.43^{* *}$ \\
\hline \multirow{4}{*}{ Listening } & Metacognitive & $.59^{* *}$ & $.72^{* *}$ & \\
& Compensation & $.68^{* *}$ & $.72^{* *}$ & \\
& Social & $.55^{* *}$ & $.43^{* *}$ & \\
& Cognitive & $.62^{* *}$ & $.64^{* *}$ & \\
\hline
\end{tabular}

Note. $* * p<.01$ 
Additionally, to help the reader and the English language teachers better understand which learning strategies and attitudes may be related to one another, six factors derived from the language learning strategy questionnaire were run in second correlation analysis (see Table 58). The results showed that most of the variables are significantly correlated with one another. It seems useful to highlight the higher correlations here. For example, students' attitude towards reading had significant correlations with attitude towards improving listening skill $(r=.48$, $p<.01)$, the attitude towards understanding the speaker $(\mathrm{r}=.49, p<.01)$, and learning listening strategies $(\mathrm{r}=.52, p<.01)$. Learning listening strategies had also significant correlations with the attitude towards understanding the speaker $(\mathrm{r}=.42, p<.01)$ and learning reading strategies $(\mathrm{r}=.37, p<.01)$.

Table 58. Correlations among six learning-related factors.

\begin{tabular}{l|ccccc}
\hline & 1 & 2 & 3 & 4 & 5 \\
\hline Positive reading attitude & & & & & \\
Negative reading attitude & $-.15^{*}$ & & & & \\
Improving listening skill & .02 & $.48^{* *}$ & & & \\
Understanding the speaker & -.06 & $.49^{* *}$ & $.23^{*}$ & $.42^{* *}$ & $.37^{* *}$ \\
Listening strategies & .12 & $.52^{* *}$ & $.26^{*}$ & .16 & $.31^{* *}$ \\
Reading strategies & $.24^{* *}$ & $.16^{*}$ & & &
\end{tabular}

Note. $* p<.05, * * p<.01$

\subsubsection{Summary}

Based on the results, it is noticed that the 6th-grade students have a more positive attitude towards learning English receptive skills and they tend to be active users of learning strategies. Also, 6th-grade students use mostly cognitive and compensation strategies for listening skills. Both 6th- and 8th-grade students tend to use cognitive strategies for reading skills to practice reading, to analyze the text, and to try to find the reasons and effects of textual content. There is not much difference between the two grades' usage of learning reading strategies. Sixthgraders use strategies a little bit more than 8th-graders and divide long stories up more often to understand them better. Eight-graders participate more in reading activities than the 6thgraders. Sixth-graders appeared to have a more positive attitude towards learning English language receptive skills than 8th-graders, and attitudes were significantly related to their learning strategies. This study showed what students think about their usage of learning strategies and attitude towards learning English, and later these results will be used to show how their opinions matched with their real ability (test performance) and with their teachers' perceptions about teaching strategies. 


\subsection{Study 5: How are teaching and learning strategies of English language receptive skills related?}

\subsubsection{Introduction}

It is important that teachers know their students' learning strategies and interests so that they can improve their students' skills using appropriate methods matched with students' attitudes and interests based on their learning strategies. English language teaching and learning strategies in Mongolia have not been well researched yet. For this study, 22 English teachers out of 73 teachers who teach English were selected along with their 215 students to probe for a deeper understanding about the actual and everyday interaction between teachers and students, and the relationship between teaching and learning strategies of English receptive skills in everyday class. We cannot do direct comparison of teaching and learning strategies with correlation analysis because of the disproportionate representation of strategies in the questionnaires. Thus, we characterized them and compared them indirectly using descriptive analysis with most frequently used teaching and learning strategies.

\subsubsection{What is the relationship between teaching and learning strategies in English listening class?}

The teaching and learning strategies of English listening skill with the highest means from 6th-grade are compared in table 59 to show the actual usage of teaching and learning strategies in everyday listening classes of all 73 English language teachers. The table shows that teachers usually tend to check students' comprehension by asking questions and true-false statements during and after a listening activity $(\mathrm{M}=4.2, \mathrm{SD}=.98)$, teachers also discuss the pictures or photos related to the listening activity $(\mathrm{M}=4.1, \mathrm{SD}=1.3)$, and teachers ask students to answer multiple choice questions $(\mathrm{M}=4.0, \mathrm{SD}=1.1)$ and to do the tasks related to the listening passage $(\mathrm{M}=3.9, \mathrm{SD}=1.0)$. Meanwhile, students want to work on keywords while listening $(\mathrm{M}=4.5$, $\mathrm{SD}=.74)$, ask questions to clarify meaning $(\mathrm{M}=4.4, \mathrm{SD}=.97)$, and do mind mapping about the main idea while listening $(\mathrm{M}=4.2, \mathrm{SD}=.89)$. 
Table 59. A comparison table for the most frequently used teaching and learning strategies of English listening skills.

\begin{tabular}{l|c|c|c|l|c|c|c}
\hline \multicolumn{1}{c|}{ Teaching listening skill } & N & M & SD & Learning listening skill & N & M & SD \\
\hline $\begin{array}{l}\text { I check comprehension of listening } \\
\text { (asking questions, true false } \\
\text { statements etc.) }\end{array}$ & 73 & 4.2 & .98 & $\begin{array}{l}\text { I choose key words while } \\
\text { listening }\end{array}$ & 76 & 4.5 & .74 \\
\hline $\begin{array}{l}\text { I ask students to discuss pictures, } \\
\text { photos or cartoons }\end{array}$ & 73 & 4.1 & 1.3 & $\begin{array}{l}\text { I ask questions to clarify } \\
\text { anything that I don't fully } \\
\text { understand }\end{array}$ & 77 & 4.4 & .97 \\
\hline $\begin{array}{l}\text { I ask students to answer multiple } \\
\text { choice questions }\end{array}$ & 73 & 4.0 & 1.1 & $\begin{array}{l}\text { I do mind mapping while } \\
\text { listening }\end{array}$ & 77 & 4.2 & .89 \\
\hline $\begin{array}{l}\text { I ask students to do tasks related to } \\
\text { vocabulary, grammar, pronunciation }\end{array}$ & 73 & 3.9 & 1.0 & $\begin{array}{l}\text { I understand the content } \\
\text { through speaker's intonation }\end{array}$ & 76 & 3.6 & 1.0 \\
\hline $\begin{array}{l}\text { I ask students to discuss their opinion } \\
\text { on the topic }\end{array}$ & 73 & 3.9 & 1.1 & I take notes while listening & 77 & 2.8 & 1.2 \\
\hline I ask students to take notes & 73 & 3.8 & 1.2 & & & & \\
\hline
\end{tabular}

\subsubsection{What is the relationship between teaching and learning strategies in English reading class?}

Similarly, a descriptive analysis of reading skills showing the most frequently used teaching and learning strategies of English reading skill by 73 English language teachers are summarized in Table 60. The table shows how everyday English reading classes are integrated with both instruction and learning. Before doing these descriptive statistics and correlations, the 6th- and 8th-grade language learning strategies' results were combined, and the most frequently used strategies were computed into general strategies used by both grades of students. The top two teaching strategies found were asking questions or true-false statements after reading $(\mathrm{M}=4.2, \mathrm{SD}=.99)$ and giving written exercises related to the text content, vocabulary or pronunciation while reading $(\mathrm{M}=4.1, \mathrm{SD}=1.1)$. Students usually guess the meaning of words from the context $(\mathrm{M}=4.1, \mathrm{SD}=.88)$, participate more in reading activities $(\mathrm{M}=4.0, \mathrm{SD}=.94)$, divide the long text into smaller parts $(\mathrm{M}=4.0, \mathrm{SD}=1.1)$, and predict the main idea from the title $(\mathrm{M}=4.0, \mathrm{SD}=.99)$. As with listening, the results showed reading was also mostly taught based on asking multiple choice questions or giving written exercises. 
Table 60. The comparison table for the most frequently used teaching and learning strategies of English reading skill.

\begin{tabular}{l|c|c|c|l|c|c|c}
\hline \multicolumn{1}{c|}{ Teaching reading skill } & $\mathbf{N}$ & $\mathbf{M}$ & $\mathbf{S D}$ & Learning reading skill & $\mathbf{N}$ & $\mathbf{M}$ & SD \\
\hline $\begin{array}{l}\text { I check comprehension by asking } \\
\text { questions or true-false statements } \\
\text { after reading }\end{array}$ & 73 & 4.2 & .99 & $\begin{array}{l}\text { I guess the meaning of } \\
\text { new words from the } \\
\text { context }\end{array}$ & 180 & 4.1 & .88 \\
\hline $\begin{array}{l}\text { I give written exercises related to the } \\
\text { text content, vocabulary or } \\
\text { pronunciation while reading }\end{array}$ & 73 & 4.1 & 1.1 & $\begin{array}{l}\text { I participate more in } \\
\text { reading activities in the } \\
\text { classroom }\end{array}$ & 172 & 4.0 & .94 \\
\hline $\begin{array}{l}\text { I use different activities to motivate } \\
\text { students (jigsaw reading, jumbled } \\
\text { texts etc.) }\end{array}$ & 73 & 4.0 & 1.0 & $\begin{array}{l}\text { If the story is long, I } \\
\text { divide it into small parts }\end{array}$ & 177 & 4.0 & 1.1 \\
\hline $\begin{array}{l}\text { I give written exercises related to the } \\
\text { text content, vocabulary or grammar } \\
\text { after listening }\end{array}$ & 73 & 4.0 & .94 & $\begin{array}{l}\text { I predict the main idea } \\
\text { of the whole passage } \\
\text { from its titles }\end{array}$ & 168 & 4.0 & .99 \\
\hline $\begin{array}{l}\text { I ask students to guess the meaning of } \\
\text { words from the context }\end{array}$ & 73 & 4.0 & 1.0 & $\begin{array}{l}\text { I read the story and } \\
\text { choose key words }\end{array}$ & 177 & 3.5 & 1.2 \\
\hline $\begin{array}{l}\text { I check comprehension while reading } \\
\text { I pre-teach key words }\end{array}$ & 73 & 4.0 & 1.0 & $\begin{array}{l}\text { I read tales and short } \\
\text { stories at home }\end{array}$ & 180 & 3.1 & .96 \\
\hline \begin{tabular}{l} 
I use brainstorming on a topic \\
\hline
\end{tabular} & 73 & 3.8 & 1.0 & 1.0 & & & \\
\hline
\end{tabular}

\subsubsection{What is the relationship between teaching strategies and students' attitude towards ELRS?}

A correlation analysis was also used for exploring whether there were any significant correlations between teaching strategies and students' attitude towards learning English receptive skills (see Table 61 for listening skills and Table 62 for reading skills). Learning listening strategies and attitudes towards learning listening skill were asked from 6th-graders on their online assessment. The teaching strategy "asking students to answer multiple choice questions during listening" has some moderate significant correlations with the students' beliefs that listening improves their knowledge and speaking $(\mathrm{r}=.31, p<.01)$, with like to fill in gaps $(\mathrm{r}=.24, \mathrm{p}<.05)$, with like to listen to speakers' voice and accent $(\mathrm{r}=.24, p<.05)$, and with listening is fun for them $(\mathrm{r}=.23, p<.05)$. Also, teachers ask students to do tasks related to the text was moderately correlated with students' attitude to fill in gaps while listening $(r=.32$, $p<.01)$. 
Table 61. The relationships between teaching listening strategies and students' attitude towards learning listening skill.

\begin{tabular}{|c|c|c|c|c|c|c|}
\hline \multirow{2}{*}{$\begin{array}{l}\text { Students' attitude } \\
\text { towards learning } \\
\text { listening skill }\end{array}$} & \multicolumn{6}{|c|}{ Teaching listening strategies } \\
\hline & $\begin{array}{l}\text { Discuss } \\
\text { their } \\
\text { opinion }\end{array}$ & $\begin{array}{c}\text { Discuss } \\
\text { pictures, } \\
\text { photos }\end{array}$ & $\begin{array}{l}\text { Answer multiple } \\
\text { choice questions }\end{array}$ & $\begin{array}{l}\text { Take } \\
\text { notes }\end{array}$ & $\begin{array}{c}\text { Check } \\
\text { comprehension }\end{array}$ & $\begin{array}{l}\text { Do tasks } \\
\text { related to } \\
\text { the text }\end{array}$ \\
\hline $\begin{array}{l}\text { Listen to English songs } \\
\text { during classes }\end{array}$ & $-.29^{* *}$ & .02 & -.10 & .09 & -.12 & -.09 \\
\hline $\begin{array}{l}\text { Fill in gaps listening to } \\
\text { the topic. }\end{array}$ & .16 & -.18 & $.24^{*}$ & -.05 & .21 & $.32^{* *}$ \\
\hline Understand the speaker & .15 & .07 & .14 & .01 & .00 & .07 \\
\hline $\begin{array}{l}\text { Listen to speakers' } \\
\text { voice/accent }\end{array}$ & -.05 & -.10 & $.24^{*}$ & .03 & .01 & .11 \\
\hline $\begin{array}{l}\text { Listening improves my } \\
\text { knowledge and } \\
\text { speaking }\end{array}$ & .10 & -.16 & $.31^{* *}$ & .07 & .08 & .15 \\
\hline Listening is fun for me & .09 & -.06 & $.23^{*}$ & .12 & .11 & .21 \\
\hline $\begin{array}{l}\text { Like to improve my } \\
\text { listening skill }\end{array}$ & -.05 & -.02 & -.00 & .02 & -.17 & -.16 \\
\hline
\end{tabular}

Note. $* p<.05, * * p<.01$.

Teaching reading strategies and students' attitude towards learning reading skill were assessed by both grades and a correlation analysis was done on the most frequently used general teaching reading strategies and attitudes used by both grades. Here, only one weak correlation was found between the teaching strategy of giving exercises related to the text after reading and students' attitude of exchanging books with their friends $(\mathrm{r}=.17, p<.05)$. Also, students' attitude of reading in English only to get the information when they need it had negative correlations with teaching strategies of pre-teaching keywords $(\mathrm{r}=-.20, p<.01)$ and with checking comprehension after reading $(\mathrm{r}=-.15, p<.05)$. H9 was rejected because there were no highly significant correlations found at the $p<.05$ level between teaching strategies of receptive skills and students' attitudes towards learning receptive skills. 
Table 62. The relationship between teaching reading strategies and students' attitude towards learning reading skills.

\begin{tabular}{l|c|c|c|c|c|c|c|c}
\hline \multirow{2}{*}{$\begin{array}{l}\text { Attitude } \\
\text { towards } \\
\begin{array}{l}\text { learning } \\
\text { reading skill }\end{array}\end{array}$} & $\begin{array}{c}\text { Use } \\
\text { brainstorming }\end{array}$ & $\begin{array}{c}\text { Pre- } \\
\text { teach } \\
\text { words }\end{array}$ & $\begin{array}{c}\text { Use diff. } \\
\text { activities }\end{array}$ & $\begin{array}{c}\text { Guess } \\
\text { the } \\
\text { voc. }\end{array}$ & $\begin{array}{c}\text { Check } \\
\text { comprehension } \\
\text { while }\end{array}$ & $\begin{array}{c}\text { Give } \\
\text { exercises } \\
\text { while }\end{array}$ & $\begin{array}{c}\text { Check } \\
\text { comprehension } \\
\text { after }\end{array}$ & $\begin{array}{c}\text { Give } \\
\text { exercises } \\
\text { after }\end{array}$ \\
\hline $\begin{array}{l}\text { Talking } \\
\text { about books } \\
\text { with other } \\
\text { people }\end{array}$ & .09 & -.05 & .09 & .00 & .07 & .05 & -.00 & .11 \\
\hline $\begin{array}{l}\text { Read only to } \\
\text { get } \\
\text { information } \\
\text { that I need }\end{array}$ & -.05 & $-.20^{* *}$ & -.10 & .05 & -.04 & -.06 & $-.15^{*}$ & -.06 \\
\hline $\begin{array}{l}\text { Reading } \\
\text { develops my } \\
\text { knowledge } \\
\text { and speaking }\end{array}$ & .11 & .00 & .09 & .06 & .11 & .11 & .05 & .12 \\
\hline $\begin{array}{l}\text { Exchange } \\
\text { books with } \\
\text { my friends }\end{array}$ & .06 & .01 & .04 & -.02 & -.06 & .02 & .07 & $.17^{*}$ \\
\hline $\begin{array}{l}\text { Improve my } \\
\text { reading skill }\end{array}$ & .11 & -.03 & .06 & .05 & .13 & .083 & .01 & .08 \\
\hline $\begin{array}{l}\text { Enlarge my } \\
\text { vocabulary }\end{array}$ & .08 & -.01 & .09 & .01 & .11 & .02 & .06 & .03 \\
\hline
\end{tabular}

Note. $* p<.05, * * p<.01$.

\subsubsection{What is the relationship between learning strategies and teaching materials and}

\section{teachers' encouragement of out-of-class activities?}

Both 6th- and 8th-grade students' frequently using learning strategies of English receptive skills were computed into categories based on Oxford's classifications. The most frequently used teaching materials and out-of-class activities were indexed into one variable in each skill. A correlation analysis was used to explore how teaching materials and teachers' encouragement of out-of-class activities were related to students' learning strategies of English receptive skills. The result indicated that cognitive learning strategies of receptive skills are moderately correlated with teaching materials used for reading $(\mathrm{r}=.27, p<.05)$ and listening $(\mathrm{r}=.26$, $p<.05)$ and with out-of-class activities of reading skill $(\mathrm{r}=.28, p<.05)$. H10 and H11 were also rejected because there were no highly significant correlations found at the $p<.05$ level among teaching materials of receptive skills, out-of-class activities, and students' learning strategies of receptive skills (see Table 63). 
Table 63. The relationship among learning strategies, teaching materials and out-of-class activities.

\begin{tabular}{|c|c|c|c|c|c|}
\hline \multirow{2}{*}{$\begin{array}{l}\text { Language } \\
\text { skills }\end{array}$} & \multirow{2}{*}{ Learning strategies } & \multicolumn{2}{|c|}{ Teaching materials } & \multicolumn{2}{|c|}{$\begin{array}{l}\text { Teachers' encouragement of } \\
\text { out-of-class activities }\end{array}$} \\
\hline & & Listening & Reading & Listening & Reading \\
\hline \multirow{4}{*}{ 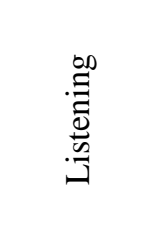 } & Metacognitive & .07 & .17 & .07 & .24 \\
\hline & Compensation & .14 & .11 & -.13 & .00 \\
\hline & Social & .05 & -.00 & -.00 & -.03 \\
\hline & Cognitive & .14 & $.27^{*}$ & .05 & .12 \\
\hline \multirow{4}{*}{ 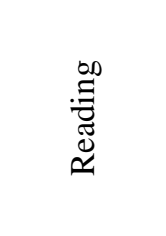 } & Metacognitive & .12 & .23 & .15 & .09 \\
\hline & Compensation & -.06 & -.18 & -.11 & -.22 \\
\hline & Social & .05 & -.07 & -.08 & -.06 \\
\hline & Cognitive & $.26^{*}$ & .18 & .10 & $.28^{*}$ \\
\hline
\end{tabular}

Note. $* p<.05$.

\subsubsection{Summary}

Generally, it is visible that the strategies which can improve students' communicative competence and critical thinking skill based on communicative language teaching and collaborative learning are not often used in English language teaching in Mongolia. Using common classroom tasks (asking questions, filling gaps, using multiple choice questions, and written exercises) appeared to lower students' attitude toward learning English. Reading outof-class material was not effectively used in teaching and learning for the 8th-grade. Based on Koch's (2016) research, when pre-, while-, post-teaching strategies and students' learning strategies match one another, the learning outcome should be more successful. Additionally, there were no high significant correlations found among teaching strategies and learning strategies. This suggests everyday instructions evidently do not coincide with learning strategies to improve students' English language skills.

To help students be more successful in their receptive skills, language instructors need to incorporate LLSs into their teaching and train students to apply appropriate language learning strategies. For example, teachers need to ask students to stay focused more on reading and listening activities since the students answered they sometimes read books and spend only 510 minutes on reading and listening tasks per practice at home. This result showed that students don't study with much concentration on understanding the text deeply. Students want more active learning, but teachers focus more on checking comprehension and written exercises during listening class. In study 6 and 7, I explore how these relationships of teaching and learning strategies influence students' learning outcome. 


\subsection{Study 6: How did students perform on an online test assessing their English language receptive skills?}

\subsubsection{Introduction}

Cognitive tasks (including test items) are described as requiring multiple processing stages, strategies, and knowledge stored. Embretson and Wetzel (1987) noted that the cognitive test construction should follow some explicit principles such as: linking the meaning of test scores to the underlying cognitive process, assuring, item parameters represent the sources of cognitive complexity in a test item and linking abilities to processes that underlie task difficulty. Therefore, in this study, cognitive operations were used for examining whether test items and tasks were matched with students' cognitive skills, which level of cognitive skills of those targeted students needed further improvement, and how the test items can be improved for the Mongolian context in a further study with a larger sample. The 6th-grade online test included both reading and listening tasks but the 8th-grade test had only reading tasks. These tests were both used in assessing Hungarian students' receptive skills in 2011. Therefore, I used the same provided tests and the 8th-grade Hungarian test did not have a listening component.

\subsubsection{What are the 6th- and 8th'graders' performances in the ELRS test?}

Generally, Item Response Theory (IRT) was used to identify whether test items were matched with students' ability levels. The results are shown respectively in Figure 10 and 11. From the maps, it is evident that 6th-grade students had more difficulties with the test. This is seen by observing that most items are above -1 , which means test item difficulty level was above the students' average level in the 6th-grade map. Thus, the reliability of the 6th-grade reading test was low. I would explain the reason of that as students in Mongolia have to learn a second alphabet to read English and, possibly, younger Mongolian children are more oral than visual learners based on the strong oral traditions that could be different between the Mongolian and the Hungarian cultures. So, perhaps, a test developed for Hungarian 6th-graders might not be appropriate in Mongolia as students could learn listening skills much faster than reading skills.

For the 8th-grade students', items are normally distributed between +1 and -1 of the students' average level. The 6th-grade test included both listening and reading tasks while the 8th-grade test included only reading tasks. 


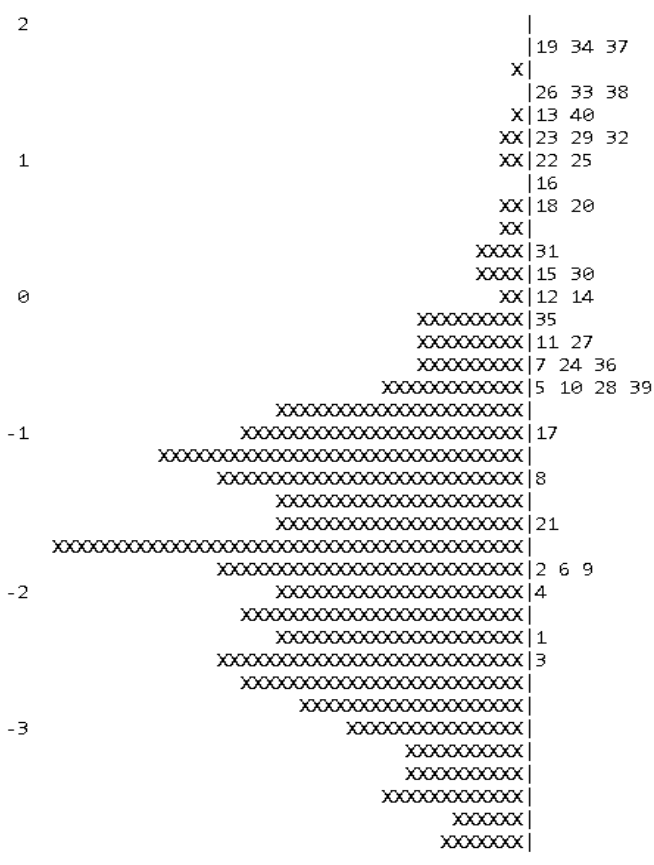

Figure 10. Item difficulty map for 6th-grade test

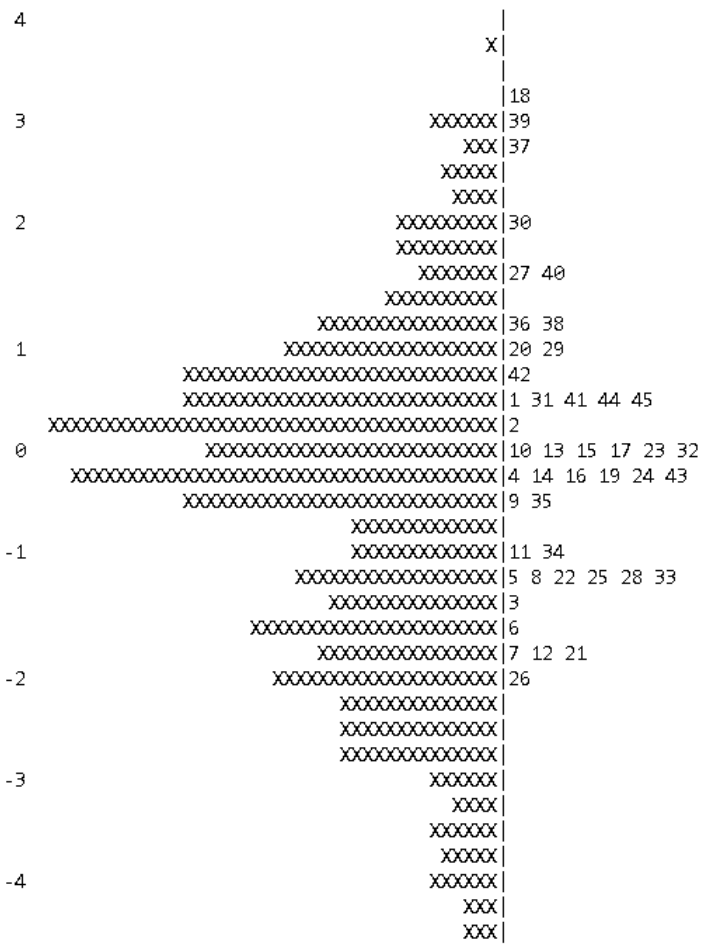

Figure 11.8th-grade test item difficulty map

Additionally, based on IRT, descriptive analysis was used to explore how each grade performed in each task. The correct answer maximum score should be 1 in both grades' tests. The results showed that 6th-grade students performed well on listening to the conversation and 
finding places $(\mathrm{M}=.42, \mathrm{SD}=.28)$. However, they had more difficulty with reading tasks than with listening, especially, filling in the gaps with missing parts in a text $(\mathrm{M}=.14, \mathrm{SD}=.16)$, and listening to film trailers and identifying the titles $(\mathrm{M}=.14, \mathrm{SD}=.21) .8$ th-grade students performed better on matching definitions with the words $(\mathrm{M}=.53, \mathrm{SD}=.33)$ and matching questions with the answers $(\mathrm{M}=.54, \mathrm{SD}=.28)$. However, they had problems with matching quiz questions with the right answers $(\mathrm{M}=.40, \mathrm{SD}=.27)$ and finding missing parts in advertisements $(\mathrm{M}=.28, \mathrm{SD}=.25)$. See Table 64. Also, independent t-test results indicated that there was no significant difference between gender performances in both grade tests (6th-grade, $\left.\mathrm{M}_{\text {male }}=.22, \mathrm{SD}_{\text {male }}=.10 ; \mathrm{M}_{\text {female }}=.23, \mathrm{SD}_{\text {female }}=.23, \mathrm{~F}=4.21, \mathrm{t}=-.03, p>.05\right)$; $\left(8\right.$ th-grade, $\left.\mathrm{M}_{\text {male }}=.50, \mathrm{SD}_{\text {male }}=.24 ; \mathrm{M}_{\text {female }}=.42, \mathrm{SD}_{\text {female }}=.24, \mathrm{~F}=.096, \mathrm{t}=1.61, p>.05\right)$.

Table 64. Descriptive statistics of test performance

\begin{tabular}{|c|c|c|c|c|c|c|c|}
\hline \multirow{2}{*}{ Skills } & \multicolumn{3}{|l|}{ 6th grade } & \multirow{2}{*}{ Skills } & \multicolumn{3}{|l|}{ 8th grade } \\
\hline & Tasks & $M$ & $S D$ & & Tasks & $M$ & $S D$ \\
\hline \multirow{2}{*}{ 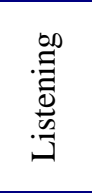 } & Identifying the places & .42 & .28 & \multirow{6}{*}{ 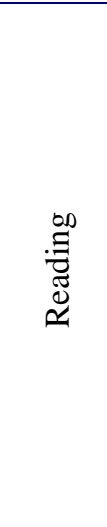 } & $\begin{array}{l}\text { Matching definitions with the } \\
\text { words }\end{array}$ & .53 & .33 \\
\hline & $\begin{array}{l}\text { Identifying the titles for the } \\
\text { films }\end{array}$ & .14 & .21 & & $\begin{array}{l}\text { Matching meanings of the } \\
\text { notices }\end{array}$ & .45 & .32 \\
\hline \multirow{4}{*}{$\stackrel{\infty}{\Xi}$} & $\begin{array}{l}\text { Identifying the titles for the } \\
\text { book descriptions }\end{array}$ & .18 & .17 & & $\begin{array}{l}\text { Matching questions with the } \\
\text { corresponding answers }\end{array}$ & .54 & .28 \\
\hline & Filling the gaps in a text. & .14 & .90 & & $\begin{array}{l}\text { Matching quiz questions with } \\
\text { the right answer }\end{array}$ & .40 & .27 \\
\hline & \multirow[t]{2}{*}{ Total } & \multirow{2}{*}{.22} & \multirow[t]{2}{*}{.16} & & $\begin{array}{l}\text { Finding the missing parts of the } \\
\text { advertisements }\end{array}$ & .28 & .25 \\
\hline & & & & & Total & .44 & .26 \\
\hline
\end{tabular}

\subsubsection{Which tasks and skills are difficult for the 6th-graders?}

Based on item response theory (IRT) maps and descriptive analysis of test performances, items and tasks were analyzed theoretically to identify which tasks and skills were difficult for 6th-graders and which cognitive process and cognitive skills were actually assessed with these tests. For a deeper analysis of the items in the listening and reading tests ability to assess students' cognitive skills, it was necessary to explore which cognitive process and skills were difficult for students. Both grade tests were analyzed mainly based on Mayer's (1984) and Sternberg's (1985) cognitive processes of meaningful learning. The listening task items were analyzed based on Anderson's (1985) three-phase listening comprehension model and a framework for describing listening ability (Buck, 2001) mentioned in the theoretical section. Items 1 - 10 asked students to listen to people talking and decide where they are located. According to the model and the framework, these items are related to perceptual processing and 
discourse knowledge. The results are shown more detailed in Table 65. Items 11 - 20 asked students to listen to ten short film trailers and choose a title for each film. These items assessed the utilization process and pragmatic knowledge.

Reading task items were analyzed based on Embretson and Wetzel's (1987) cognitive processing model of reading comprehension, which was also discussed in the theoretical part, in Chapter 2. As noted earlier, the online test items are designed to assess cognitive processes and skills such as finding relevant information, understanding text, making referential connections, and evaluating content. With this design, the attributes used in this study related to cognitive operations. Also, cognitive abilities, as defined by Bloom's Revised Taxonomy (2001) as used in Hashmin et al. (2014), were used as a theoretical basis for reading item analysis. Items 21 - 30 asked students to read the descriptions of books and find the title of each book. According to the model and ability framework, these items assess text mapping processes and the ability to identify important points in a text. Items 31 - 40 asked students to fill in the missing parts in the text and assess coherence processes demonstrating the ability to identify meanings of words, phrases, sentences, and connecting a text meaning with their prior knowledge. See Table 65.

Table 65. Item and task analysis of the 6th-grade test.

\begin{tabular}{|c|c|c|c|c|c|}
\hline $\begin{array}{l}\text { Difficulty } \\
\text { levels }\end{array}$ & $\begin{array}{l}\text { Items } \\
\text { on a } \\
\text { map }\end{array}$ & Type of tasks & Skills & Cognitive process & Cognitive skills \\
\hline \multirow{3}{*}{ Difficult } & $\begin{array}{l}31,34 \\
37,33 \\
40,32 \\
38\end{array}$ & $\begin{array}{l}\text { Filling gaps } \\
\text { with missing } \\
\text { parts of } \\
\text { sentences }\end{array}$ & \multirow{2}{*}{ : } & $\begin{array}{l}\text { Encoding and coherence } \\
\text { processes of retrieving } \\
\text { relevant information and } \\
\text { connecting word meanings } \\
\text { and propositions into a } \\
\text { meaningful representation of } \\
\text { the text }\end{array}$ & $\begin{array}{l}\text { Identifying meaning of } \\
\text { words, phrases and } \\
\text { sentences and the logical } \\
\text { connections between the } \\
\text { phrases to make } \\
\text { meaningful content. }\end{array}$ \\
\hline & $\begin{array}{l}26,23 \\
29,22 \\
25\end{array}$ & $\begin{array}{l}\text { Matching titles } \\
\text { with book } \\
\text { descriptions }\end{array}$ & & $\begin{array}{l}\text { Text mapping process of } \\
\text { relating the propositions in } \\
\text { the question and response } \\
\text { alternatives to the } \\
\text { information retrieved from } \\
\text { the passage }\end{array}$ & $\begin{array}{l}\text { Identifying important } \\
\text { points in a text and } \\
\text { making inferences to find } \\
\text { an appropriate title. }\end{array}$ \\
\hline & $\begin{array}{c}19,13 \\
16,18 \\
20 \\
\end{array}$ & $\begin{array}{l}\text { Finding titles } \\
\text { for film trailers }\end{array}$ & \multirow{3}{*}{ 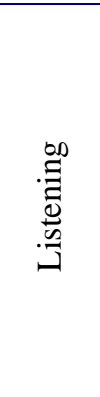 } & \multirow{2}{*}{$\begin{array}{l}\text { Utilization process (relating } \\
\text { a mental representation of } \\
\text { the text meaning to existing } \\
\text { knowledge }\end{array}$} & \multirow{2}{*}{$\begin{array}{l}\text { Understanding the } \\
\text { function or the } \\
\text { illocutionary force of an } \\
\text { utterance or a longer text } \\
\text { and connecting to existing } \\
\text { knowledge }\end{array}$} \\
\hline Medium & $\begin{array}{c}11,12 \\
14,15 \\
17 \\
\end{array}$ & $\begin{array}{l}\text { Finding titles } \\
\text { for film trailers }\end{array}$ & & & \\
\hline Easy & $\begin{array}{l}7,2,6 \\
9,4,1 \\
\quad 3\end{array}$ & $\begin{array}{l}\text { Finding places } \\
\text { for } \\
\text { conversations }\end{array}$ & & $\begin{array}{l}\text { Parsing processes of } \\
\text { identifying the parts of } \\
\text { speech, syntactic relations }\end{array}$ & $\begin{array}{l}\text { Understanding shorter } \\
\text { utterances or interactive } \\
\text { discourse between two or } \\
\text { more speakers }\end{array}$ \\
\hline
\end{tabular}




\subsubsection{Which tasks and skills are difficult for the 8th-graders?}

For 8th-grade students, there were five reading tasks including 50 items. For these tasks, finding missing information in advertisements and matching quiz questions with answers were more difficult than matching definitions with words and matching interview questions with the answers. The 8th-grade test included only reading tasks and the items were analyzed based mainly on Mayer's (1984) and Sternberg's (1985) cognitive processes of meaningful learning and Embretson and Wetzel's (1987) cognitive processing model of reading comprehension and cognitive abilities as defined by Bloom's Revised Taxonomy (2001) as used in Hashmin et al. (2014). Items 1 - 10 asked students to pair words with their definitions. According to the model and ability framework, these items assessed students' encoding and internal coherence processes and the ability to identify the meaning of words, phrases, and sentences. Items 11 20 asked students to read notices and find the meanings of these notices, and also to assess the truth status of content, to confirm alternative responses, and to demonstrate the inferential ability to interpret important points, which is constructing coherent external connections by connecting with their existing knowledge.

Items 21 - 30 asked students to read short interviews and match the questions with the answers. These items assessed the text mapping process by relating the propositions in the question and response alternatives to the information in the reading and the ability to identify sequences of ideas or events. Items 31 - 40 asked students to read quiz questions and find the right answers. These items assessed evaluating truth status, confirming response alternatives, and demonstrating the inferential ability to interpret cause-effect and make a conclusion.

Items 41 - 50 asked students to read advertisements and find the missing information for each gap in the advertisements, and to assess text mapping processes by relating the propositions in the question and response alternatives to the information as well as demonstrating the inferential ability to interpret important points and interpret comparisons which is also making external connections. See Table 66. 
Table 66. Item and task analysis of the 8th-grade test.

\begin{tabular}{|c|c|c|c|c|c|}
\hline $\begin{array}{l}\text { Difficulty } \\
\text { levels }\end{array}$ & $\begin{array}{l}\text { Items } \\
\text { on a } \\
\text { map }\end{array}$ & Type of tasks & Skills & Cognitive process & Cognitive skills \\
\hline \multirow[b]{2}{*}{ Difficult } & $\begin{array}{l}39,37, \\
40,38, \\
42,41, \\
44,45\end{array}$ & $\begin{array}{l}\text { Finding missing } \\
\text { info in } \\
\text { advertisements }\end{array}$ & \multirow{5}{*}{ 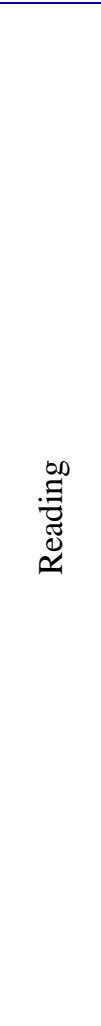 } & $\begin{array}{l}\text { Evaluating truth status process of } \\
\text { falsification and confirmation of } \\
\text { response alternatives }\end{array}$ & $\begin{array}{l}\text { Interpreting cause- } \\
\text { effect and making } \\
\text { inference } \\
\text { identifying cultural } \\
\text { points }\end{array}$ \\
\hline & $\begin{array}{l}30,36 \\
29,31\end{array}$ & $\begin{array}{l}\text { Finding the } \\
\text { answers for quiz } \\
\text { questions }\end{array}$ & & $\begin{array}{l}\text { Text mapping process of relating } \\
\text { the propositions in the question } \\
\text { and response alternatives to the } \\
\text { information retrieved from the } \\
\text { passage }\end{array}$ & $\begin{array}{l}\text { Identifying } \\
\text { sequence of } \\
\text { ideas/events and } \\
\text { main points, usage } \\
\text { of factual } \\
\text { knowledge } \\
\end{array}$ \\
\hline Medium & $\begin{array}{l}13,15 \\
17,14 \\
16,19\end{array}$ & $\begin{array}{l}\text { Finding the } \\
\text { meanings for the } \\
\text { notices }\end{array}$ & & $\begin{array}{l}\text { Evaluating truth status process of } \\
\text { falsification and confirmation of } \\
\text { response alternatives }\end{array}$ & $\begin{array}{l}\text { Interpreting } \\
\text { important point }\end{array}$ \\
\hline \multirow[t]{2}{*}{ Easy } & $\begin{array}{l}5,8,3 \\
6,7,9\end{array}$ & $\begin{array}{l}\text { Matching } \\
\text { definitions with } \\
\text { words }\end{array}$ & & $\begin{array}{l}\text { Encoding and coherence are } \\
\text { processes of retrieving relevant } \\
\text { information and connecting word } \\
\text { meanings and propositions into a } \\
\text { meaningful representation of the } \\
\text { text }\end{array}$ & $\begin{array}{l}\text { Identifying meaning } \\
\text { of word/ phrase/ } \\
\text { sentence }\end{array}$ \\
\hline & $\begin{array}{l}22,25 \\
28,21 \\
26\end{array}$ & $\begin{array}{l}\text { Matching } \\
\text { interview } \\
\text { questions with the } \\
\text { answers }\end{array}$ & & & \\
\hline
\end{tabular}

\subsubsection{Summary}

Based on IRT maps of item difficulty, descriptive and content analysis, it can be concluded that 6th-grade students had more difficulties in English receptive skills than 8thgrade students. Specifically, 6th-grade students had problems especially with finding missing parts of a sentence and matching titles with book descriptions. The results showed they did better on listening tasks than on reading tasks. For 8th-graders, they had difficulties with certain types of reading tasks such as finding missing information in advertisements and matching quiz questions with answers.

The content analysis was based on the cognitive theories of the listening and reading processes. The result shows that the 6th-grade test items may be characterized as testing the ability of identifying and understanding the main points in a text. The main difficulty for these students was using grammatical knowledge to make meaning from text by connecting parts of sentences which generally means they had the difficulty with constructing internal and external connections with the text. For the 8th-graders, test items assessed the ability of looking for information on the main theme of the text, making text-based inferences, and adding in separate pieces of information. The main difficulty for 8th-graders was making inferences and 
identifying the main points and cultural points that means to build external connections with the text.

Knowledge about cognitive structures can help test developers and educators to construct test items with desirable measurement and cognitive characteristics, operate constructs, and satisfactorily understand the cognitive processes of thinking and performance. Finding the difficulties that students face in learning English may help teachers find better teaching methods and pay more attention to individual development. The results of this study will be used in my further study to explore the issues behind these test performances.

\subsection{Study 7: What are the factors affecting students' test performance?}

\subsubsection{Introduction}

This study aimed to examine which student-, teacher-, and school-related factors may influence students' English language receptive skills' achievement in urban and rural settings in Mongolia. The factors discussed in this study are student-related factors, teacher-related factors, and school-related factors. The lists below show each group's factors.

Teacher-related factors:

$>$ teachers' education level

$>$ work experience

$>$ teaching hours per week

$>$ teaching strategies

$>$ teaching materials

$>$ teachers' encouragement of after class activity

Student-related factors:

$>$ students' gender

$>$ students' age

$>$ parental education

$>$ students' attitude

$>$ learning strategies

School-related factors:

> school location

$>$ computer supply

$>$ Internet connection

$>$ devices (microphone and headsets) 
In this study, 22 English language teachers who teach English to 8th-grade $(\mathrm{n}=115)$ students, and 12 information technology teachers' who responded to a questionnaire about their schools' $(n=12)$ infrastructure were selected to explore factors that may influence students' test scores. The 6th-grade $(n=100)$ student data was not run in the analysis due to the low reliability of tests. Analyses were done based on the factors that were derived from the exploratory factor analysis and items (statements) in each factor were made into composite indexes before the analyses.

\subsubsection{How do teacher-related factors affect students' test performance?}

For teacher-related factors, teachers' education level, work experience, and teaching hours were coded as teachers' background variables in a linear regression analysis $\left(\mathrm{R}^{2}=13 \%\right.$, $\mathrm{F}=5.31, p<.01)$. English teachers' background responses indicated 54.8\% of English teachers had a bachelor's degree and $42.5 \%$ had a master's degree. These 22 teachers (27.4\%) taught 19 hours on average per week. The mean of teachers' work experience was 10 years $(M=9.9)$. Teachers' education level was the significant predictor of test performance $(\beta=.37, p<.01)$. Teaching strategies, teachers' encouragement of after class activities and teaching materials were also grouped as another set of variables $\left(\mathrm{R}^{2}=35 \%, \mathrm{~F}=5.42, p<.01\right)$. Teaching strategies were recoded into a scale with two values $(1=$ inefficient, $2=$ efficient $)$ before doing the regression analysis. Teachers' encouragement of out-of-class activities and teaching materials were made composite indexes based on factor analysis before doing the regression analysis. Teachers' preparation for listening activity $(\beta=-.27, p<.05)$ and developing students' cognitive skills during listening $(\beta=-1.01, p<.01)$ significantly affected 8th-grade test performance to a negative direction. See Table 67.

Table 67. Teachers' background and teaching listening strategies affecting test performance.

\begin{tabular}{c|l|c|c}
\hline \multicolumn{2}{c}{ Independent variables } & \multicolumn{2}{c}{ 8th grade } \\
\cline { 2 - 3 } & Teachers' education level & $r \beta(\%)$ & $p<.01$ \\
\hline \multirow{3}{*}{ Background } & Teachers' work experience & 11.8 & n.s \\
\cline { 2 - 4 } & Teaching hours per week & -.32 & n.s \\
\hline \multirow{2}{*}{ Pre-listening } & Students' discussion & -.70 & n.s \\
\cline { 2 - 4 } & Preparation for the text & 1.6 & $p<.05$ \\
\hline \multirow{3}{*}{ While-listening } & Developing cognitive skills & -28.5 & $p<.05$ \\
\cline { 2 - 4 } & Developing metacognitive skill & -13.2 & n.s \\
\hline \multirow{2}{*}{ Post-listening } & Students' reflection & -28.4 & n.s \\
\cline { 2 - 4 } & Checking comprehension & -10.4 & n.s \\
\hline
\end{tabular}

Note. Dependent variables: Mean scores of 8th-grade test performance. 
For teaching reading strategies, using specific reading strategies $(\beta=-.93, p<.01)$ negatively affected the test performance. See Table 68.

As stated previously, $\mathrm{H} 12$ was expected to show that specific reading teaching strategies would have a positive impact on students' test performance. However, this hypothesis was rejected because three teaching strategies from 13 factors emerging from the questionnaire were found to predict the test performance negatively and no positive effects were found.

Table 68. Teaching reading strategies affecting test performance.

\begin{tabular}{c|l|c|c}
\hline \multicolumn{2}{c}{ Independent variables } & \multicolumn{2}{c}{ 8th grade } \\
\cline { 3 - 4 } Pre-listening & Pre-reading & $r \beta(\%)$ & n.s \\
\cline { 2 - 4 } & Using general reading scales & 2.4 & n.s \\
\hline \multirow{3}{*}{ While-listening } & $\begin{array}{l}\text { Specific reading strategies and } \\
\text { activities }\end{array}$ & 2.9 & \multicolumn{2}{c}{$p<.01$} \\
\cline { 2 - 4 } & Students' reflection & -13.0 & n.s \\
\hline \multirow{2}{*}{ Post-listening } & Pre-reading & 1.01 & n.s \\
\cline { 2 - 4 } & Using general reading scales & 2.4 & n.s \\
\hline
\end{tabular}

Note. Dependent variables: Mean scores of 8th-grade test performance.

No significant explained variance was found in teaching materials and after-class activities on 8th-grade test performance. Note, I expected (H13) that virtual materials and afterclass activities would be the best indicators of students' test performance since these are very important for developing receptive skills. However, no effects were found for these factors (see Table 69).

Table 69. Teaching materials and out-of-class activities affecting test performance.

\begin{tabular}{c|l|c|c}
\hline \multirow{2}{*}{\multicolumn{2}{c}{ Independent variables }} & \multicolumn{2}{c}{ 8th grade } \\
\cline { 3 - 4 } & Virtual materials & $r \beta(\%)$ & n.s \\
\cline { 2 - 4 } TM & Traditional materials & -7.1 & n.s \\
\hline \multirow{2}{*}{ ENC } & After class activities & -3.0 & n.s \\
\hline
\end{tabular}

Note. Dependent variables: Mean scores of 8 th-grade test performance.

\subsubsection{How do student-related factors affect students' test performance?}

Students' gender, parents education and students' age were students' background variables $\left(\mathrm{R}^{2}=14.1, \mathrm{~F}=5.35, \mathrm{p}<.01\right)$, and students' attitudes $\left(\mathrm{R}^{2}=22.8, \mathrm{~F}=2.43, p<.05\right)$, learning strategies were used as other variables $\left(\mathrm{R}^{2}=.08, \mathrm{~F}=1.24, p>.05\right)$ for student-related factors in a linear regression analysis to explore links between these factors and test 
performance. Regarding students' background factors, their fathers mostly $(60.9 \%)$ had a secondary education level and only $21.8 \%$ of fathers had a higher education level and mothers (54.6\%) had a secondary education level and $36.2 \%$ of them had a higher education level. Students' ages ranged from $11-14$ years and $37 \%$ of them were boys and $63 \%$ of them were girls. Students' self-reported study hours showed that $45 \%$ of them studied 5 - 10 minutes, $20.7 \%$ studied 10 - 15 minutes, and $15.9 \%$ studied more than 15 minutes on listening tasks and $43.1 \%$ studied 5 - 10 minutes, $21 \% 10$ - 15 minutes, and $17.7 \%$ studied more than 15 minutes on reading task for practice per day. Most of the students studied only 5 - 10 minutes on receptive skill tasks per day and only a few of them spent more than 15 minutes.

The results in Table 70 show that parents education had a significant impact on the 8thgrade students' test performance $(\beta=.31, p<.01)$. Therefore, $\mathrm{H} 14$ was accepted, that parental education has an effect on their children's English language education, specifically, for older students. Nine statements of students' attitude in our questionnaire were ran in regression analysis as independent variables shown in Table 70. I included only two significant predictors of students' attitude on their test performance in this table. It is not surprising that students' positive attitude (I like to improve my reading skill, $\beta=.52, p<.01$ ) positively affected, and a negative attitude (reading is a waste of time, $\beta=-.37, p<.01$ ) negatively affected their test performance. Therefore, H15 was accepted indicating that students' positive attitude affects their test performance positively and negative attitude affects it negatively. However, there was no significant impact found from six of the students' learning strategies on their test performance, therefore leading me to reject H16.

Table 70. Student-related factors affecting test performance

\begin{tabular}{c|l|c|c}
\hline \multicolumn{2}{c}{ Independent variables } & \multicolumn{2}{c}{ 8th grade } \\
\cline { 3 - 4 } & Gender & $r \beta(\%)$ & $p$ \\
\cline { 2 - 4 } Background & Parental education & -30.9 & $p<.01$ \\
\cline { 2 - 4 } & Age & 10.7 & n.s \\
\hline \multirow{2}{*}{ Attitudes } & For me, reading is a waste of time & -20.5 & $p<.01$ \\
\cline { 2 - 4 } & I like to improve my reading skill & -71.9 & $p<.01$ \\
\hline
\end{tabular}

Note. Dependent variables: Mean scores of 8 th-grade test performance.

\subsubsection{How do school-related factors affect students' test performance?}

School location, the number of computers, labs, Internet connection, and the number of devices (headphones and microphones) were considered as school-related factors in this study. 
Twelve information technology (IT) teachers from 12 schools responded to a questionnaire about school infrastructure. Three of the schools were in a rural area in some distance from the center of the city. The schools usually have 15 - 20 computers in one or two labs except for the schools in rural areas which had only 7 - 10 computers in one lab. Table 71 shows the number of computers and labs in each school.

Table 71. Computers and labs in each school.

\begin{tabular}{c|c|c|c|c|c}
\hline Schools & $\begin{array}{c}\text { The number of } \\
\text { students }\end{array}$ & $\begin{array}{c}\text { The number of } \\
\text { student groups }\end{array}$ & $\begin{array}{c}\text { The number of } \\
\text { computers in } \\
\text { schools }\end{array}$ & $\begin{array}{c}\text { The number of } \\
\text { classes equipped } \\
\text { with computers }\end{array}$ & $\begin{array}{c}\text { The number of } \\
\text { computers in } \\
\text { each ICT room }\end{array}$ \\
\hline 1 & 1600 & 52 & $50-$ & 2 & 20,20 \\
\hline 2 & 292 & 11 & $10-20$ & 1 & 20 \\
\hline 5 & 1567 & 51 & $50-$ & 2 & 17,16 \\
\hline 6 & 520 & 23 & $10-20$ & 1 & 20 \\
\hline 8 & 955 & 32 & $30-40$ & 2 & 19,19 \\
\hline 11 & 386 & 18 & $20-30$ & 1 & 18 \\
\hline 12 & 953 & 41 & $30-40$ & 1 & 30 \\
\hline Khan-uul & 1414 & 48 & $30-40$ & 2 & 15,10 \\
\hline Shine-hogjil & 1260 & 45 & $20-30$ & 2 & 11,20 \\
\hline Bayan-uul & 844 & 25 & $10-20$ & 1 & 18 \\
\hline Bulgan & 135 & 9 & $10-20$ & 1 & 10 \\
\hline Bayantumen & 110 & 9 & $1-10$ & 1 & 10 \\
\hline
\end{tabular}

For the Internet connection and useful devices such as microphone and headsets, only eight schools $(66 \%)$ out of the 12 were connected to the Internet. Informal discussions with teachers indicated that the Internet was used only in administrators' and teachers' rooms, and in some special cases, they could use it in labs for limited time because paying for the Internet was one of the problems faced by these schools. Also, most schools had only $1-5$ headphones and 1 - 5 microphones, and they said they received such devices as part of some national and international projects, but they were easily broken. Figure 12 shows the percentage of schools with an Internet connection and the percentage with the limited number of devices in schools.

Regression analysis was done to explore how these school infrastructure factors affect students' online test performance. I hypothesized that the small number of computers and labs in Mongolian schools may negatively affect students' online test performance; however, this hypothesis, H17, was not shown to be a significant predictor. However, the results showed that 
access to the Internet impacted 8th-graders' online test performance. Therefore, H18 was accepted suggesting schools with more Internet access have higher scores (see Table 72).

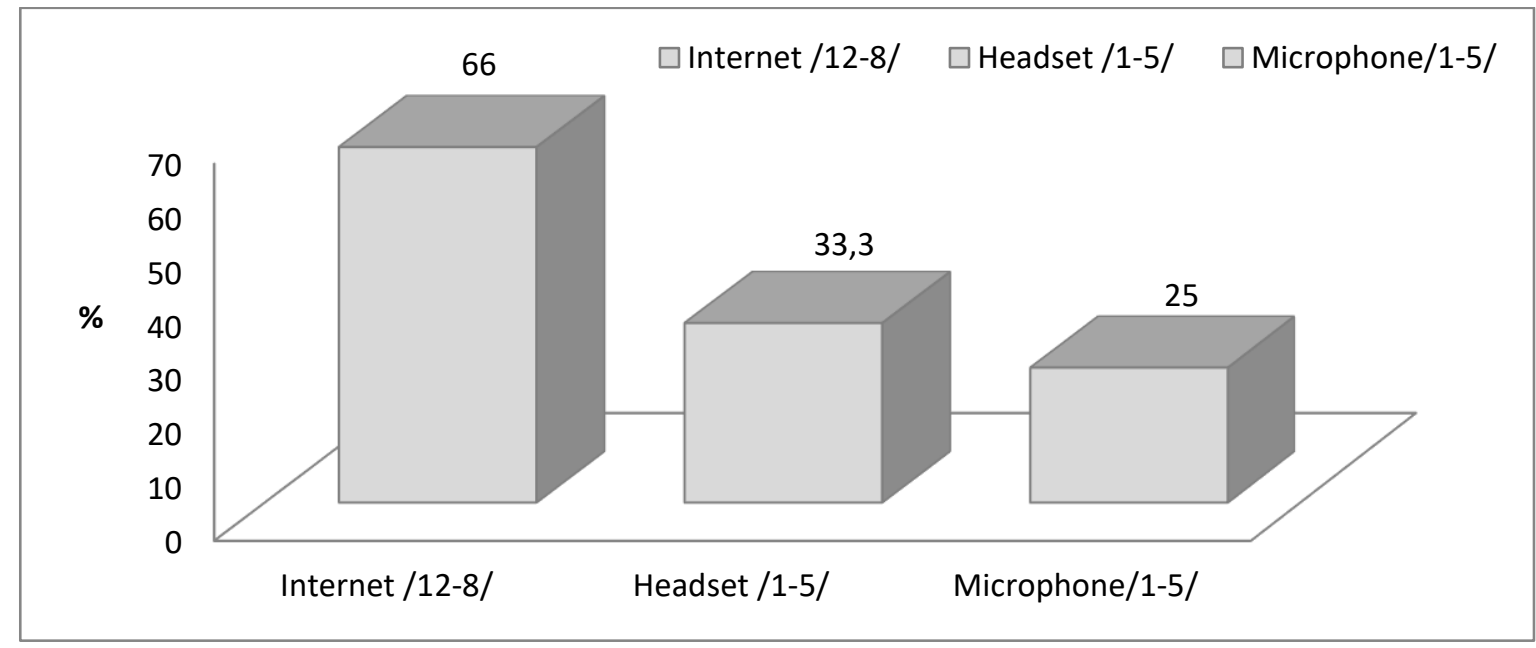

Note: 12 - 8 (8 schools have the Internet access), 1 - 5 (only 1 - 5 pieces of device).

Figure 12. Internet connections and devices in schools.

Table 72. School-related factors affecting students' test performance.

\begin{tabular}{llcc}
\hline Factors & Independent variables & \multicolumn{2}{c}{ 8th grade } \\
& & $r \beta(\%)$ & $p$ \\
\hline School-related & School location & -.039 & n.s \\
& Computer supply & -.584 & n.s \\
& Labs & -.940 & $p<.05$ \\
& Internet connection & .801 & n.s \\
\hline
\end{tabular}

Note. Dependent variables: Mean scores of 8 th-grade test performance.

\subsubsection{What is the difference between students who have positive and those who have negative attitude test performances of ELRSs?}

It is important to know how students' attitudes towards learning are matched with their test performance. In order to find it out, I divided students into two groups: those who have positive attitudes and those with negative attitudes, recoding scales into $1-2=$ positive attitude and $3-5=$ negative attitude. I then identified their differences in their test performances using an independent sample t-test. Table 73 shows that students who have positive attitudes performed better than students who have negative attitudes in both grades' test performance. 
Table 73. Difference between two groups of attitudes' test performance of ELRSs in each grade.

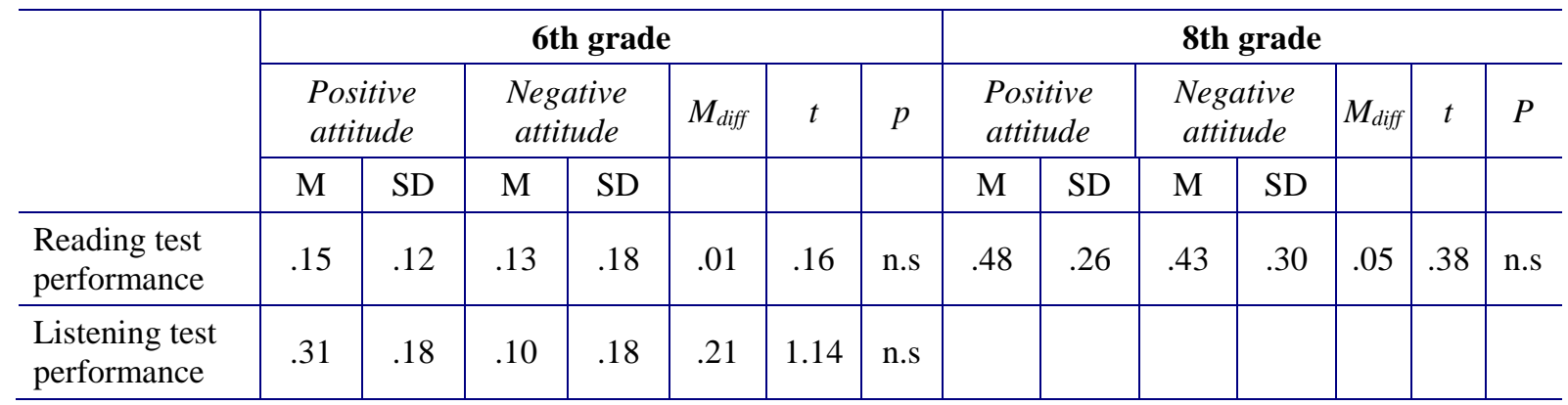

\subsubsection{What is the difference between the students who have effective and those who have ineffective use of learning strategies' test performance of ELRSs?}

Similarly, it is also important to know how students' usages of learning strategies are matched with their test performances. In order to find it out, I divided students into two groups: those who use learning strategies effectively and those who use learning strategies ineffectively, recoding scales into $1-2=$ effective and $3-5=$ ineffective. I then identified their differences in their test performances using independent sample t-test. Table 74 shows, that students who use effective learning strategies performed well in reading tests in both grades, however, the 6th-grade students who use ineffective listening strategies performed better than students who use effective strategies $\left(\mathrm{M}_{\mathrm{eff}}=.29, \mathrm{SD}_{\mathrm{eff}}=.15 ; \mathrm{M}_{\text {ineff }}=.36, \mathrm{SD}_{\text {ineff }}=.24\right)$ on listening tests $($ see table 74). I would explain this result by suggesting that the strategies students think ineffective can still influence the improvement of their listening skill.

Table 74. Difference between two groups of use of learning strategies' test performance of ELRSs in each grade.

\begin{tabular}{|c|c|c|c|c|c|c|c|c|c|c|c|c|c|c|}
\hline & \multicolumn{7}{|c|}{ 6th grade } & \multicolumn{7}{|c|}{ 8th grade } \\
\hline & \multicolumn{2}{|c|}{ effective } & \multicolumn{2}{|c|}{ ineffective } & \multirow[t]{2}{*}{$M_{\text {diff }}$} & \multirow[t]{2}{*}{$T$} & \multirow[t]{2}{*}{$P$} & \multicolumn{2}{|c|}{ effective } & \multicolumn{2}{|c|}{ ineffective } & \multirow[t]{2}{*}{$M_{\text {diff }}$} & \multirow[t]{2}{*}{$T$} & \multirow[t]{2}{*}{$P$} \\
\hline & $\mathrm{M}$ & SD & $\mathrm{M}$ & SD & & & & $M$ & SD & $\mathrm{M}$ & SD & & & \\
\hline $\begin{array}{l}\text { Reading test } \\
\text { performance }\end{array}$ & .17 & .13 & .05 & .04 & .05 & 4.58 & $p<.05$ & .48 & .25 & .43 & .29 & .04 & .66 & n.s \\
\hline $\begin{array}{l}\text { Listening test } \\
\text { performance }\end{array}$ & .29 & .15 & .36 & .24 & -.07 & n.s & & & & & & & & \\
\hline
\end{tabular}

\subsubsection{Summary}

8th-graders appeared to have problems with tasks related to real life on the reading test. Therefore, teachers need to consider providing more practice related to real life situations in their reading classes. However, 8th-grade students also have a relatively low attitude towards 
learning reading. This kind of attitude likely affects their reading achievement. Teachers think they prepare their students for reading, develop their students' cognitive skills effectively, and use different reading activities, however, these strategies seem to be the negative indicators of 8th-grade reading performance.

Family characteristics like parental education were significant predictors for 8th-grade students' performance. Internet connection also influenced students' test performance, however, computer labs alone appeared to have no effect on test performance. This might also have affected student performance in this study because teachers in this study don't often use computer-based tests.. I observed that English teachers' opportunity to use computer labs in their teaching was very limited because of the busy scheduled time for other information technology classes. This study will be used as a basis for exploring some other important factors that influence English language achievement in Mongolia using larger samples (from other provinces) in future studies.

\subsection{Chapter summary}

From the results of all studies mentioned above, it appears that most teachers focus on testing materials which are tested in state-level assessment because of pressure from the accountability system based on the test results. The teachers also appear to be worried more about the scores on these tests than about the students' learning outcome. Therefore, this view of assessment may influence teachers' everyday classroom instructions. Since the English language is included in state-level assessments, this impact on instruction also affected English language Education in Mongolia. In other words, English language teachers paid more attention to testing than learning outcomes. Their instruction and the students' learning process was not focused on using the language in real life and did not effectively develop students' communicative skills. This may be one of the reasons why progress in Mongolian English language education is slow. However, a larger sample from some other provinces is needed to explore these important findings contributing to the development of Mongolian English language education. 


\section{CONCLUSIONS AND DISCUSSIONS}

\subsection{Introduction}

In this chapter, the general research purpose, objectives, methods used for obtaining results, main findings, more detailed recommendations, limitations, and future research will be discussed. The purpose of the dissertation was to identify the issues and the reasons behind the instruction, learning, and assessment of English language receptive skills (ELRSs) in Mongolian primary and secondary education and to recommend some important considerations for English language teachers and school administrators to improve English language education. These topics were discussed under the categories of assessment and accountability systems, teachers' instruction, students' learning strategies, and investigations into factors of language learning achievement according to the seven main research questions or studies given below. This research is unique in that it examined the issues of English language education in a Mongolian setting from different educational aspects to gain a clear understanding about the reasons behind the problems for Educational policy makers and teachers, and to make recommendations about some important considerations to improve the quality of English language education in Mongolia.

\subsection{Study 1: How is Educational assessment and accountability used in the Mongolian Education system?}

This study explored perceptions of teachers in all disciplines about state-level exams and school achievement tests. The results helped to better understand the accountability effect of these exams on the quality of Education in Mongolia. In order to identify relevant issues, six research questions were addressed mainly asking about teachers' views on assessment and accountability, the tests and stakeholders that put pressure on teachers, and the impact of the assessments on teachers' instruction and test preparation. A t-test was used to explore the differences between primary and secondary school teachers' perceptions. The main findings from the results reveal that state-level tests administered by the government and externally graded by teachers and professional stakeholders (school administrators, colleagues, central administration body) are the main sources of pressure in any school type leading to expectations to increase students' scores on tests. Due to teachers' views on Educational assessment and accountability and the pressure felt from the tests and stakeholders, there have been some 
changes made in the teaching practices. Primary school teachers, especially, reported experiencing more changes on their instructions than secondary school teachers. Generally, however, teachers typically refuse to narrow the curriculum due to the national assessment system; they focus more on students with poor results to try to improve their state exam scores. Teachers also reported paying more attention to test-taking strategies and multiple-choice tests in classroom instruction.

In brief, teachers' views on assessment, pressures from exams and stakeholders, and changes in teaching practices are really connected in ways that lead teachers to put more emphasis on giving better instructions in order to improve their students' performance on largescale tests.

These results may have implications for teacher education research and practice. Recent studies (e.g. Hadley, 2010; Ngang et al., 2014; Darling-Hammond, 2016) suggest that aspects of teacher education and career experience are positively associated with teachers' curricular knowledge and implementation of standards. Future research should probe more precisely on the specific ways that teacher education programs influence teachers' understanding and use of standards documents in diverse classrooms. This study formed the empirical basis for the next study, discussed below, about English language teachers' view on assessment and accountability.

\subsection{Study 2: How do assessment and accountability influence English language instruction and test taking strategies in Mongolia?}

This study aimed to identify English language teachers' belief about the usefulness of state-level assessments (school achievement tests) and how English language instruction has been changing due to the educational assessment and accountability system in Mongolia. An independent sample t-test was used for exploring the frequencies and differences between the perceptions of assessment and accountability, and their instructional changes. The main results indicated that English language teachers think state-level assessments are important for improving the quality of language education since English language is included in school achievement tests. They also think it is better to conduct these assessments regularly.

However, they believe that these assessments are aimed only at evaluating schools, not for developing individuals' learning outcomes. English language teachers try to use more effective teaching methodologies even though they already do not have enough time to prepare their lessons due to their workload and the different types of assessments. Therefore, they 
reduce their instructional content and focus more on preparing students for exams. In addition, their view on the importance of large-scale assessments influences the content of the assessment that they design for progress and final tests in their classes. Thus, this may be the reason why English teachers prefer to ask students to practice on the test formats that are used in the school achievement tests during class. Therefore, English language teachers focus more on test practice that are tested in school achievement tests and other government/school administered tests.

These results led to the next study to explore what English language teachers think about their teaching and whether there are any similar thoughts about teaching English by focusing more on testing rather than improving individuals' skills or using more active strategies to develop students' learning achievements.

\subsection{Study 3: What are teachers' perceptions of teaching ELRSs?}

The purpose of this study was to find out which teaching strategies were frequently, and which were less used, and what teaching materials and after-class activities are mainly used for developing students' English language receptive skills. A t-test was used to find the frequencies and differences in teaching strategies and teaching materials. The common method for teaching English language receptive skills was using students' pre-existing knowledge to help students understand what they would listen to or read before listening or reading a text, then asking students to do some written exercises related to the text during a lesson, and finally ask students to answer some multiple choice questions or true-false statements to check their comprehension about the texts. I expected those language teachers would use more active learning strategies based on communication language teaching methods and give students opportunities to use the language in real life situations, but these strategies were not very often used.

Based on the questionnaire data, active teaching strategies such as after class research projects, asking students to make interpretations on implied information, finding out the causes or effects of something in the text, and identifying cultural points in the text did not receive more responses. These strategies are very important for students to develop their creative and critical thinking skills and can give students a chance to use the language in real life situations to develop useful English language receptive skills. Instead, English teachers in this study usually used traditional materials (textbooks, additional passages, newspapers/journals) and not the virtual materials which have been shown to be important to improve students' receptive skills. Asking students to learn English songs and read short stories at home were the most frequently used after-class activities but other effective activities like group research projects 
were not used at all. From the theories of teaching English skills, receptive skills can be best developed by using real and authentic materials and communicative activities. The results of this study showed there is little adoption of these best practices and English language teachers don't use more active and communicative activities during classes.

These results clearly show that English language teachers need to change their instructions focusing more on individuals' development. Also, educational quality is not only due to teachers' instruction but also to students' learning attitudes and good use of strategies.

This observation led to the need to find out what students think about their attitudes and learning strategies and whether teachers' and students' perceptions of teaching and learning strategies are similar or different.

\subsection{Study 4: How do students identify their strategies and attitudes towards ELRSs?}

The aim of this study was to identify what students think about their attitude towards learning English language receptive skills and their use of learning strategies. A t-test was used to identify the frequencies and the differences of strategies and a descriptive analysis was used to explore what kind of attitudes students mostly have in learning ELRSs. Sixth grade students were given a questionnaire covering both listening and reading ELRS while 8th-graders were given a questionnaire covering only reading. The results showed that the 6th-grade students use mostly cognitive and compensation strategies for listening skills and both 6th- and 8th-grade students tend to use cognitive strategies for reading skill.

There was not much difference between the two grades' usage of learning reading strategies. Sixth-graders used learning strategies a bit more than 8th-graders and they tended to use more effective strategies independently. However, 8th-graders tended to participate more in reading activities than the 6th-graders in class. For attitudes, younger students had more positive attitudes towards learning English than older students. Students' attitude towards language learning and language learning strategies were strongly related to each other. Compared to teaching strategies, students tended to use active strategies and they tried to do tasks on their own by guessing the meaning, choosing the key words and dividing the story to improve their understanding of the content. Students had developed useful strategies, but it doesn't say anything about attitude toward learning. Students might be very negative toward their language class and still have learned good strategies. 
To explore linkages between student and teacher strategies, the next study will discuss how teaching and learning strategies are related to each other.

\subsection{Study 5: How are teaching and learning English language receptive skills related?}

This study aimed to identify whether teachers' and students' perceptions of teaching and learning English language receptive skills are related to each other or not. The study focused on the specific situation of the Mongolian English language education and learning system. Especially, the study reviewed national criteria for receptive skills and collected data on teachers' and students' self-reported assessment of their use of teaching and learning strategies and what teachers and students felt were the most helpful strategies. The method used for finding results was descriptive analysis with frequently used strategies and correlation analysis of attitudes and teaching materials. Due to the disproportion of teaching and learning strategy questionnaires, direct comparison of strategies with correlation analysis was not possible to be done. Based on the results it is evident that there is not much good relationship found between teaching and learning strategies. Teachers teach more by focusing on testing and written tasks in the classroom while students try to use more active strategies. There is a mismatch between teaching and learning in English language Education in Mongolia in this study area.

Also, it appears that commonly used teaching strategies and related classroom tasks (asking questions, asking students to fill gaps in a text, asking multiple choice questions to check comprehension, and giving written exercises related to the text) seem to lower students' language learning attitude, especially for 8th-grade students. Students' time spent on reading and listening practice per day was also not enough and they did not concentrate on understanding a text more deeply. According to Koch (2016) when pre-, while-, and postteaching strategies and students' learning strategies match each other, the learning outcome can be more successful. However, this study found no relationship between teaching and learning strategies for English language receptive skills.

Based on the questionnaire data, active learning might happen, but teachers are not as consciously aware of how their lesson activities relate to the strategies as I described them in the questionnaire.

Therefore, if language instructors were to incorporate LLSs into their teaching and train students to apply appropriate language learning strategies they should be more successful in their receptive skills teaching efforts. 


\subsection{Study 6: How did students perform on an online test assessing their English language receptive skills?}

This study aimed to explore whether test items and tasks were matched with students' ability level, how they performed in each task of each skill, what cognitive processes were asked to perform the tasks, and what cognitive skills caused students the most difficulties. Item Response Theory, descriptive analysis, and cognitive operations were used to analyze the results. From this analysis, I found that 6 th-grade students had more difficulties with reading tasks than listening, and 8th-grade students had problems with more extensive reading tasks which require students to make references and find out cultural points in the text. The tasks in the 6th-grade reading test asked students to use the cognitive process of encoding and coherence by retrieving relevant information, to connect word meaning and propositions into a meaningful representation of the text, and to map the process of relating propositions in questions and responses to the information in the text. These cognitive processes require such skills to identify the meaning of words, phrases and sentences; and to find important points in a text, and to make inferences.

Generally, teachers who teach 6th-graders should pay attention to developing students with the above-mentioned cognitive skills. For 8th-graders, those reading tasks which were difficult were the ones that required students to use the cognitive process of reading to evaluate truth status by falsification in order to confirm responses and to relate the propositions in the questions to the responses. To do these tasks well, students need to interpret causes and effects, make inferences, identify cultural points, identify sequences of ideas and events, and use both cultural and factual knowledge to understand the topic. According to the Mongolian government English language core curricula for the 6th- and 8th-level students, they should be expected to perform well on the online test based on the CEFR A1-A2 level that was used in this study. However, 6th-grade test performance was not good.

Therefore, in the last study, study 7 , I tried to find out the factors affecting only 8th-grade test performance. This study's results will also be useful for improving test items for later research with larger samples and for teachers and students to understand which cognitive skills students need to improve to solve such tasks in their future learning. 


\subsection{Study 7: What are the factors affecting students' test performance?}

This study aimed to identify how some of the factors related to teaching, learning and school influence student's test scores on an English online test; and how students' attitude and views on learning strategy matched with their real actions. Multiple linear regression and independent sample t-tests were used for exploring the findings.

The findings showed not much effect found between language learning strategies and test performance, suggesting that learning reading strategies should be taught more to improve test performance. On the other hand, some effects were found due to teaching strategies of listening and reading skills.

Support should be given to help teachers try to involve students more actively in the classroom and in after-class activities as research shows this may positively influence students' learning achievement. The findings suggest that using the Internet was also shown to positively affect students' online test performance.

As mentioned in Wise et al. (2009), feelings of anxiety toward computers and lack of experience in using computers have a debilitative effect on examinee performance. This type of anxiety might have affected student performance in this study because teachers in this study do not often use computer-based tests. This researcher observed that English teachers' opportunity to use computer labs in their teaching was very limited because of the busy scheduled time of other information technology classes.

Considering all the task difficulties, strategies, test performance issues, and influencing factors, it takes a lot of resources and time for an educator to identify all the significant factors and then plan classroom activities and teaching and learning strategies based on these factors. Further research is needed to explore this problem with a large sample from more scattered geographical regions (in other provinces). Additionally, other factors, including more student factors, family factors, school factors, and peer factors, need to be considered. Understanding the factors that may contribute to the academic success of students' English achievement remains an important area of research.

\subsection{Educational implication}

To sum up the main findings, most teachers in this study think that school achievement tests are important to improve the quality of education. However, they feel pressured by these state-level exams because of the accountability impact on their career based on the test results. Thus, teachers focus more on testing to increase their students' test scores. This situation 
influences all subject teachers, but especially English language teachers who end up spending most of their class time on practicing the test formats that are used in school achievement tests and other end of term assessments. Since the English language is included in school achievement tests, these assessments are considered high-stake tests by these teachers. As a result, teachers and students tend to use ineffective strategies in and out of the classroom. These problems affect students' language learning achievement. Based on the statistical analysis of the questionnaires, primary and secondary school teachers have similar views on assessment as being important for improving the quality of education. However, the assessment system is used to evaluate schools and is expected to increase efforts made by teachers, but it doesn't effectively support students' competence in learning English. The current assessment implementation may lead to teachers teaching and test taking practices for the sole purpose of increasing students' test score. English language is one of the subjects that included in the SAT, therefore, the results show English language teachers might reduce their instructional content and tend not to use effective teaching strategies so that their students' learning strategies may not be developed. Thus, English teachers everyday practice might mismatch because of no significant correlations between teaching and learning strategies in the classroom and the different factors which might be the assessment accountability system and its influence in teaching, students' lack of learning strategy usage, older students' attitude, and parents' low education level of English language, school online and computer availability for students' learning.

\subsection{Recommendations}

I would like to give some recommendations based on the results and conclusions just presented to educational policymakers and teachers to help them understand that there are some possibilities for improving English language education in Mongolia. It is clear to me that there are some important changes needed in our educational field. These suggested changes should be started through changing policymakers', teachers', students', and parents' view on educational goals to develop individuals' skills to use knowledge in real life, not to focus on assessing and evaluating.

For policymakers and school administrators:

It is important to provide a discussion or to conduct surveys among teachers to find out how the assessment content can be improved for developing individuals' competencies. 
The accountability system is another tool for encouraging teachers and students and improving the quality of education. Very careful attention should be paid to the activities (evaluating schools, ranking schools' teachers) that are made based on the assessment results and more national and international studies are needed to improve the accountability system in Mongolia.

$>$ It is important to reduce the different types of assessments that are mentioned in section 3.2 and focus more on learning outcomes.

$>$ Primary school teachers are important for building fundamental learning skills and knowledge in students. However, it seems these teachers worry too much about the test results, not about their students' learning achievement. One suggestion to help this situation is for teacher education programs to influence teachers' understanding and use of educational standards in diverse classrooms instead of focusing on high-stake test results.

$>$ In recent years, teachers are increasingly busy with more paperwork (writing lesson plans, syllabus, curricula, and different types of surveys etc.) than actual instructions in classrooms. Teachers in this study responded they have not enough time to prepare effective lessons. This might be one of the reasons that the English language is in a slow process of adoption as an official second language. It seems important, therefore, to try to reduce teacher's paperwork and workloads.

Policymakers and school administrators should also increase the opportunities for teachers and students to use the Internet more in their classes and assess their students with online tests.

For teachers:

Tests and assessments can be used as another teaching method to encourage students' learning process by including more effective and interesting tasks to develop students' thinking and creative skills and changing task types to ones that are more related to reallife situations.

Using common tasks as currently practiced by most English teachers may lower students' attitude and motivation to study. It is better to use active and communicative activities in the classroom.

B Based on a good understanding of spoken and written language, people can respond (talk and write) appropriately. Teaching English language receptive skills through three stages of pre-, while-, and post- can give students a chance to understand the spoken and written texts better. 
Using more virtual materials and effective after-class activities can give students the opportunity to listen to real conversation and search for information on their own, and expressing their idea with their own words helps to develop stronger English language receptive skills.

Relating the teachers' instruction to the students' learning strategies produces more effective outcomes. Teachers should strive to train their students to use effective learning strategies through their instructions and encourage students to be excited about learning English.

By implementing online testing to assess students' receptive skills, teachers can give students a chance to use modern information technology. Access to online computers and computer-based lessons allows students to use the Internet to enlarge their knowledge and skills.

\subsection{Limitations}

There were some shortcomings in conducting the studies discussed in this report, especially regarding the specialties of the targeted places and the population. The following are examples of the challenges faced in researching Mongolian English language teaching and learning:

There is little published research about educational assessment and accountability in Mongolia.

Little is known about English language education in Mongolia except for the published state standards and curricula.

$>$ Only one province and a few rural schools were included in this survey due to the difficulties in traveling to remote areas in Mongolia.

Many schools still have limited Internet access.

$>$ The sample size for some of the studies was limited due to a lack of devices, limited Internet connections, and a lack of experience by both teachers and students in using online testing.

\subsection{Future research}

In the future, more samples from different cities or provinces should be included in a follow-up study to get more confidence in these findings. Interviews with teachers and classroom observations should be used to get more information about real situations in 
classroom language teaching. Furthermore, to get a whole picture of English language education in Mongolia, the other two skills (speaking and writing) should be included with receptive skills.

\subsection{Summary}

The overall goal of this dissertation was to identify the issues in English language education in Mongolia looking through the different aspects of assessment and its accountability involved in teaching, learning and assessing the students' skills. Teachers' instructional practices have been changing due to their view on high-stake educational assessment and accountability. They are focusing more on testing rather than developing students' learning outcome. These pressures negatively influence teaching and learning strategies in Mongolian English language education. Furthermore, they drive students into ineffective instruction and learning environments resulting in the observed students' low achievement in the English language. 


\section{ACKNOWLEDGEMENT}

Foremost, I would like to express my most sincere appreciation to my advisor Professor Benő Csapó who has guided and supported me throughout my academic journey and in writing this thesis. Besides my advisor, I would like to thank Dr. John David Campbell, who worked together with me in Dornod University, for his encouragement, insightful comments for improving research, and help with language issues.

My sincere thanks also goes to my professors: Prof. Dr. Tibor Vidákovich, Dr. Edit Katalin Molnár, Prof. Dr. Gyöngyvér Molnár, Dr. József Fejes Balázs, Dr. Edit Tóth, and Prof. Dr. Csaba Csíkos, for guiding and supporting me through my studies and helping me live comfortably in Szeged. I am also very grateful to my examiners for my internal defense, Dr. Anita Habók and Tibor Vígh. Without their time, their expertise, and their feedback on my proposal and dissertation, I would not have been able to complete my work.

Also, I express my thanks to Dr. Odmandakh Myagmarsuren and Enkhjargal Sukhbaatar for translating questionnaires appropriately into the Mongolian language. I thank Mrs. Raeann Dietlin and Erica Iman, who were US Peace Corps volunteers in Dornod province, also for their advice on English language editing in questionnaires.

I thank my fellow classmates in the Doctoral School of Education: Yunjun Kong, Linus Kambeyo, Hao Wu, Sansarmaa Khurelbaatar, Davaajav Purevjav, and Thongsay Phonphanit for the stimulating discussions, for working together before deadlines, and for all the fun we have had in the last four years.

Last, but not least, I would like to thank my family: my sister, my husband, and my parents-in-law, for taking care of my children during my study time in Hungary and for supporting me spiritually throughout my life. 


\section{REFERENCES}

Abidin, M, J. Z. (2012). EFL students' attitudes towards learning English language. International Journal of Scientific and Research Publications, 3(9), 1-2.

Ableeva, R. (2008). Listening comprehension in foreign language instruction [PDF file]. (CALPER professional development document 08110), University Park, Pennsylvania: The Pennsylvania State University, Center for Advanced Language Proficiency Education and Research. Retrieved from http://calper.la.psu.edu/sites/default/files/pubfiles/CPDD0810_Listening_Comprehens ion.

Abrams, L. M. (2004). Teachers' views on high-stakes testing: Implications for the classroom [PDF file]. Arizona State University Education Policy Studies Laboratory, Working Paper EPSL0401-104-EPRU. Retrieved from https://pdfs.semanticscholar.org/33fa/5985b23ea4ef2c289e09ea9bbb839a6d3cf9.pdf.

Abrams, L. M., Pedulla, J. J., \& Madaus, G. F. (2003). Views from the classroom: Teachers' opinions of statewide testing programs. Theory into Practice, 42(1), 8-29.

Afflerbach, P., Pearson, P. D., \& Paris, S. G. (2008). Clarifying differences between reading skills and reading strategies. The Reading Teacher, 61(5), 364-373.

Aguilera, L. C., \& Filologia, L. (2012). Receptive language skills learning and teaching: listening and reading. Publications of Didactic, 32, 153-371.

Ahmed, S. (2015). Attitudes towards English language learning among EFL learners at UMSKAL. Journal of Education and Practice, 6(18), 6-16.

Alderson, J. C. (2000). Assessing reading. Cambridge: Cambridge University Press.

Alderson, J. C., \& Bachman, L. (2001). “Series editors' preface.” In G. Buck, Assessing listening (pp. X-xi). Cambridge, England: Cambridge University Press.

Ali, Z., Mukundan, J., Baki, R., \& Ayub, A. F. M. (2012). Second language learners ${ }^{\text {ee }}$ attitudes towards the methods of learning vocabulary. English Language Teaching, 5 (4), 24-36.

Alkaff, A. A. (2013). Students' attitudes and perceptions towards learning English. Arab World English Journal, 4, 106-121.

Alqarni, F. (2015). Collaborative strategic reading to enhance learners' reading comprehension in English as a foreign language. Academic Journal of Interdisciplinary Studies, 4(1), 161-166. 
Alqarni, F. (2015). Collaborative Strategic Reading to Enhance Learners' Reading Comprehension in English as a Foreign Language. Academic Journal of Interdisciplinary Studies, 4 (1), 161-166.

Anckar, J. (2011). Assessing foreign language listening comprehension by means of the multiple-choice format: Processes and products [Ph.D. dissertation]. Jyväskylä Studies in Humanities, 159. Retrieved from https://jyx.jyu.fi/bitstream/handle/123456789/40911/978-951-39-4410-0_2011.pdf

Anderson, J. A. (2005). Education Policy Series: Accountability in Education. Paris:

UNESCO-IEP. Retrieved from https://unesdoc.unesco.org/ark:/48223/pf0000140986.

Anderson, J. R. (1985). Cognitive psychology and its implications (2nd Ed.). New York, NY: W. H. Freeman and Company.

Ariryarathne, A. H. (2013). Factors affecting on students' test scores: Data analysis and report writing. Retrieved from https://www.academia.edu/9187281/factors_affecting_on_students_test_scores_st306data_analysis_and_report_writing_acknowledgement.

Bachman, L. F. (1990). Fundamental considerations in language testing. Oxford, England: Oxford University Press.

Bachman, L. F. (2007). What is the construct? The dialectic of abilities and contexts in defining constructs in language assessments. In J. Fox, M. Wesche, D. Bayliss, L. Cheng, C. E. Turner \& C. Doe (Eds.), Language testing reconsidered (pp. 41-71). Ottawa, Canada: Ottawa University Press.

Bachman, L. F., \& Palmer, A. S. (1996). Language testing in practice: Designing and developing useful language tests. Oxford, England: Oxford University Press.

Bacsa, E., \& Csikos, C. (2016). The role of individual differences in the development of listening comprehension in the early stages of language learning. In M. Nikolov (Ed.), Assessing young learners of English: Global and local perspectives (pp. 263-289). New York: Springer.

Bailey, A. L., \& Butler, F. A. (2003). An evidentiary framework for operationalizing academic language for broad application to K-12 education: A design document [PDF File]. Retrieved from https://cresst.org/wp-content/uploads/R611.pdf

Baker, J., \& Westrup, H. (2000). The English language teacher's handbook: How to teach large classes with few resources. London: Continuum.

Bamanger, E. M., \& Gashan, A. K. (2014). In-service EFL teachers' beliefs about teaching Reading Strategies. English Language Teaching, 7(8), 14-22. 
Bandpay, B. A. (2016). Adult's learning strategies for receptive skills self-managing or teacher- managing. International Journal of Research in English Education, 1, 16-21.

Barnes, N., Fives, H., \& Dacey, Ch. M. (2014). Teachers' beliefs about assessment: Perceptions of Assessment, chapter 16, 284-300.

Barnes, N., Fives, H., \& Dacey, Ch. M. (2017). U.S. teachers' conceptions of the purposes of assessment. Teaching and Teacher Education, 65 (2017), 107-116.

Bernaus, M., \& Gardner, R. C. (2008). Teacher motivation strategies, student perceptions, student's motivation, and English achievement. The Modern language Journal, 92(3), $387-401$.

Bernhardt, E. B. (2011). Understanding advanced second-language reading. New York: Routledge.

Bertolini, K., Stremmel, A., \& Thorngren, J. (2012). Student achievement factors. Retrieved from https://eric.ed.gov/?id=ED568687

Betebenner, D. W., \& Linn, R. L. (2009, December). Growth in student achievement: Issues of measurement, longitudinal data analysis and accountability, Presented at Exploratory Seminar, National Center for the Improvement of Educational Assessment, Dover, New Hampshire. Retrieved from http://www.ets.org/Media/Research/pdf/BetebennerandLinnPresenterSession1.pdf

Bloom, B. (1956). Taxonomy of Educational Objectives: Handbook I, Cognitive Domain. New York: Davis Press.

Bors, L., Lugossy, R., \&Nikolov, M. (2001). A comparative evaluation study of the teaching of English in Pecs primary schools. Iskola kultura, 11(4), 73-88.

Boyd, D., Grossman, P., Hammerness, K., Lankford, H., Loeb, S., McDonald, M., Reininger, M., Ronfeldt, M., \& Wyckoff, J. (2008). Surveying the landscape of teacher education in New York city: Constrained variation and the challenge of innovation. Education Evaluation and Policy Analysis, 30(4), 319-343.

Braun, H. (2012, September). Using student work for educator accountability: The road from authenticity to validity [PDF powerpoint]. Presentation at the Reidy Interactive Lecture Series September 13, 2012. Retrieved from https://www.nciea.org/sites/default/files/inline-files/RILS-2012_Braun.pdf

Bronfenbrenner, U. (1979). Beyond the deficit model in child and family policy. Teachers College Record, 81(1), 95-104.

Brown, G. (2015). Leading school-based assessment for educational improvement: Rethinking accountability. Rassegna Italiana di Valutaziono, 19, 61. 
Brown, G. T. L. (2004). Teachers' conceptions of Assessment: Implications for policy, 11(3), 301-318

Brown, G. T. L., \& Gao, L. (2015). Chinese teachers' conceptions of assessment for and of learning: Six competing and complementary purposes. Cogent Education, 2(1), DOI: 10.1080/2331186X.2014.993836.

Brown, H.D. (2007). Teaching by principles an interactive approach to language pedagogy. London: Pearson, Longman.

Brown, J, D. (1997). Computers in language testing: Present research and some future directions. Language Learning \& Technology, 1(1), 44-59.

Brown, J. D., \& Hudson, T. (1998). The alternatives in language assessment. TESOL Quarterly, 32(4), 653-675.

Buck, G. (2001). Assessing listening. Cambridge: Cambridge University Press.

Butler, Y, Someya, Y., \& Fukuhara, E. (2014). Online games for YLs' foreign language learning. English Language Teaching Journal, 68(3), 265-275. doi: 10.1093/elt/ccu008.

Butler, Y. G. (2016). Self-assessment of and for young learners' foreign language learning. In M. Nikolov (Ed.), Assessing young learners of English: Global and local perspectives (pp. 291-315). New York: Springer.

Campbell, J, D., \& Ragchaa, J. (2013). English teaching methodology handbook for $2^{\text {nd }}$ semester. Dornod, Mongolia: Dornod Institute.

Canale, M. L., \& Swain, M. (1980). Theoretical bases of communicative approaches to second language teaching and testing. Applied Linguistics, 1, 1-47.

Carnoy, M., \& Loeb, S. (2002). Does external accountability affect student outcomes? A cross-state analysis. Educational Evaluation and Policy Analysis, 24(4), 305-331.

Carr, N. T. (2006). Computer-based testing: Prospects for innovative assessment. In L. Ducate $\&$ N. Arnold (Eds.), Calling on CALL: From theory and research to new directions in foreign language teaching (CALICO monograph series, 5, (pp. 289-312). San Marcos, Texas: CALICO. 12

Carrel, P. L. (1998). Can reading strategies be successfully taught?. Australian Review of Applied Liguistics. 21(1), 1-20.

Carrier, M., \& Khalifa, H. (2014). Cambridge English case studies. Cambridge, England: University of Cambridge.

Chalhoub-Deville, M. (2003). Second language interaction: Current perspectives and future trends. Language Testing, 20, 369-383. 
Chapelle, C. (2010). The relationship between second language learning. Language teaching, 43(1), 66-74.

Chapelle, C. A. (1998). Construct definition and validity inquiry in SLA research. In L. F. Bachman \& A. D. Cohen (Eds.), Second language acquisition and language testing interfaces (pp. 32-70). Cambridge, England: Cambridge University Press.

Chapelle, C. A., \& Douglas, D. (2006). Assessing language through computer technology. Cambridge, England: Cambridge University Press.

Chapelle, C., Grabe, W., \& Berns, M. (2000). Communicative language proficiency: Definition and implications for TOEFL 2000. TOEFL monograph series 10. Princeton, NJ: Educational Testing Service.

Choi, I., Kim, K. S., \& Boo, J. (2003). Comparability of a paper-based language test and a computer-based language test. Language Testing, 20, 295. doi: 10.1191/02655322031t258oa.

Choi. S, W., \& Tinkler. T. (2002, April). Evaluating comparability of paper-and-pencil and computer-based assessment in a K-12 setting. Paper presented at the annual meeting of the National Council on Measurement in Education, New Orleans, LA. Retrieved from https://www.researchgate.net/publication/274713232_Evaluating_comparability_of_p aper-and-pencil_and_computer-based_assessment_in_a_K-12_setting_1 classes with few resources. London: Continuum.

Clerehan, R. (1995). Taking it down: Note taking practices of L1 and L2 students. English for Specific Purposes, 14, 137-155.

Cohen, A. D. (1998). Strategies and processes in test taking and SLA. In L.F. Bachman \& A.D. Cohen (Eds.), Interfaces between second language acquisition and language testing research (pp. 90-111). New York: Cambridge University Press.

Cohen, A. D. (2010). Focus on the language learner: Styles, strategies and motivation. In N. Schmitt (Ed.), An introduction to applied linguistics (2nd ed., pp. 161-179). London: Hodder Education.

Common European Framework of Reference for languages CEFR: learning, teaching, assessment. (2001). Cambridge, England: Council of Europe Cambridge University Press.

Conley, D. T. (2015). A new era for educational assessment. Education Policy Analysis Archives, 23(8). doi: https://doi.org/10.14507/epaa.v23.1983 
Crosnoe, R., Johnson, M. K., \& Elder, G. H. (2004). School size and the interpersonal side of education: An examination of race/ethnicity and organizational context. Social Science Quarterly, 85(5), 1259-1274.

Csapó, B., Molnár, G., \& Nagy, J. (2014). Computer-based assessment of school readiness and early reasoning. Journal of Educational Psychology. doi: 10.1037/a0035756

Csapó, B., \& Nikolov, M. (2001). Hungarian students' performances on English and German tests. Paper presented at the European Language Testing in a Global Context Conference. Barcelona, Spain: Universitat Pompeu Fabra.

Csapo, B., \& Nikolov, M. (2009). The cognitive contribution to the development of proficiency in a foreign language. Learning and Individual Differences, 19, 203-218.

Csapó, B., Ainley, J., Bennett, R., Latour, T., \& Law, N. (2012). Technological issues of computer-based assessment of 21 st century skills. In B. McGaw, P. Griffin \& E. Care (Eds.), Assessment and teaching of $21^{\text {st }}$ century skills (pp. 143-230). New York, NY: Springer. doi:10.1007/978-94-007-2324-5_4

Csapó, B., Molnár, Gy., \& Tóth, K. (2009). Comparing paper-and-pencil and online assessment of reasoning skills. A pilot study for introducing electronic testing in largescale assessment in Hungary. In: Scheuermann, F. and Björnsson, J. (n.d.): The transition to computer-based assessment. New approaches to skills assessment and implications for large-scale testing (pp. 120-125). Luxembourg: Office for Official Publications of the European Communities, Luxemburg.

Darling-Hammond, L., Wilhoit, G., \& Pittenger, L. (2014). Accountability for college and career readiness: Developing a new paradigm. Educational Policy Analysis Archives, 22(86), 1-25. DC: National Academies Press.

Dornod Educational Center. (2017). Exam schedule for different subjects [Paper version]. Dornod, Mongolia: Dornod Institute

Doró, K., \& Habók, A. (2013). Language learning strategies in elementary school: The effect of age and gender in an EFL context. Journal of Linguistics and Language Teaching, 4(2), 25-37.

Douglas, D., \& Hegelheimer, V. (2007). Assessing language using computer technology. Annual Review of Applied Linguistics, 27, 115-32.

Droop, M., \& Verhoeven, L. (2003). Language proficiency and reading ability in first- and second-language learners. Reading Research Quarterly, 38, 78-103.

Earl, L., \& Katz, S. (2006). Leading schools in a data-rich world: Harnessing data for school improvement. Thousand Oaks: Corwin. 
eDia. (2009). Developing Diagnostic Assessments: Szeged, Hungary: The Center for Research on Learning and Instruction, University of Szeged.

Education Evaluation Center. (2018). State level exams. Retrieved from http://eec.mn/ush, Accessed March 17, 2018.

Education Evaluation Center. (2019). State level exams. Retrieved from http://eec.mn/ush.

El-Omari, A. H. (2016). Factors affecting students' achievement in English language learning. Journal of Educational and Social Research, 6(2), 9-18.

ELTAM. (2010). Reflective learning, Reflective teaching [the $4^{\text {th }}$ National TEFL conference book]. Ulaanbaatar, Mongolia: ELTAM. Retrieved from http://resource3.sodonvision.com/eltam/file/2012/9/7570iyj4923y7z7ddqwnmm85z/20 10\%20TEFL\%20Conference\%20Program.pdf

Embretson, S. E., \& Wetzel, C. D. (1987). Component latent trait models for paragraph comprehension tests. Applied Psychological Measurement, 11(2), 175-193.

Enever, J. (2011). ElliE: Early language learning in Europe. London: The British Council.

Enever, J., Moon, J., \& Raman, U. (2009). Young learner English language policy and implementation: International perspectives. Reading, England: Garnet Education Publishing Ltd.

English language teachers' association of Mongolia (ELTAM). (2014). Activities and events, www.mongoliatesol.mn

Erbaggio, P. (2012). Enhancing student engagement through online authentic materials. The International Association for Language Learning Technology, 42(2), 27-51.

Eshghinejad, S. (2016). EFL students' attitudes toward learning English language: The case study of Kashan University students. Cogent Education, 3(1), 1236434.

Eslami-Rasekh, Z., \& Valizadeh, K. (2008). Teachers' sense of self-efficacy, English proficiency, and instructional strategies: A study of nonnative EFL teachers in Iran. TESL EJ, 11(4), 1-19. Retrieved from http://tesl-ej.org/ej44/a1.pdf.

Eun, H. J., \& Junko Y. (2014). L2 reading comprehension and its correlates: A metaAnalysis. A Journal of research in language studies, 160-168.

Farooq, M. S., Chaudhry, A. H., Shafiq, M., \& Berhanu, G. (2011). Factors affecting students' quality of academic performance: A case of secondary school level. Journal of Quality and Technology Management, 7(2), 1-14.

Ferris, D., \& Tagg, T. (1996). Academic oral communication needs of EAP learners: What subject-matter instructors actually require. TESOL Quarterly, 30, 31-58. 
Fidler, P. (2002). The relationship between teacher instructional techniques and characteristics and student achievement in reduced size classes. Retrieved from https://eric.ed.gov/?id=ED473460

Field, J. (2008). Listening in the language classroom. Cambridge, UK: Cambridge University Press.

Florit, E., \& Cain, K. (2011). The simple view of reading: Is it valid for different types of alphabetic orthographies? Educational Psychology Review, 23, 553-576. doi: 10.1007/s10648-011-9175-6.

Flowerdew, J., \& L. Miller (2005). Second language listening: Theory and practice. New York: Cambridge University Press.

Flowerdew, J., \& Miller, J. (1997). The teaching of academic listening comprehension and the question of authenticity. English for Specific Purposes, 16, 27-46.

Fox, J., Wesche, M., Bayliss, D., Cheng, L., Turner, C.E., \& Doe, C. (2007). Language testing reconsidered, University of Ottawa Press, Ottawa.

Fulcher, G., \& Davidson, F. (2007). Language testing and assessment. Abingdon, England: Routledge Applied Linguistics.

Fuller, S. C., \& Ladd, H. F. (2012). School based accountability and the distribution of teacher quality among grades in elementary schools. Panel Session for the Association for Education Finance and Policy, Boston, MA.

Gajalakshmi, V. (2013). High school students' attitude towards learning English language. International Journal of Scientific and Research Publications, 3(9), 1-2.

Ganyaupfu, E. M. (2013). Teaching Methods and Students' Academic Performance. International Journal of Humanities and Social Science Invention, 2(9), 29-35.

Gao, X. (2009). 'The English corner' as an out-of-class learning activity. ELT Journal, 63(1), 60-67.

Gao, Y. (2009). On the practice teaching of English reading. English language teaching, 2(3), 140-143.

Garcia Mayo, M. P., \& Garcia Lecumberri, M. L. (2003). Age and the acquisition of English as a foreign language. Clevedon, England: Avon/Multilingual Matters LTD.

Retrieved from http://www.laslab.org/wpcontent/uploads/maturational_constraints_on_foreignlanguage_written_production.pdf

Garcia, G. E., McKoon, G., \& August, D. (2006). Synthesis: Language and literacy assessment. In D. August \& T. Shanahan (Eds.), Developing literacy in second- 
language learners: Report of the National Literacy Panel on language minority children and youth (pp. 269-318). Mahwah, New Jersey: Lawrence Erlbaum.

Gardiner, L. F. (2000). Re-designing higher education: Producing dramatic gains in student learning. Higher Education Report, 23(7), 109.

Gardner, R. C. (1968). Attitudes and motivation: Their role in second language acquisition. TESOL Quarterly, 2(3), pp. 141-150.

Garrett, N. (1991). Technology in the service of language learning: Trends and issues. Modern Language Journal, 75, 74-101.

Garrison, C., \& Ehringhaus, M. (2010). Formative and summative assessments in the classroom. Retrieved [18.06.2018] from: http://www.amle.org/BrowsebyTopic/WhatsNew/WNDet.aspx?ArtMID=888\&Article $\mathrm{ID}=286$

Gersten, R., Fuchs, L.S., Williams, J. P., \& Baker, S. (2001). Teaching reading comprehension strategies to students with learning disabilities: A review of research. Review of Educational Research, 71, 279-320.

Ghafournia, N., \& Afghari, A. (2013). Exploring the relationship between learning strategies, Academic Disciplines, and Reading comprehension test performance. Iranian Journal of Applied Linguistics, 16 (2), 21-51.

Ghanbari, F., \& Hashemian, M. (2014). The effects of English songs on young learners' listening comprehension and pronunciation. International Journal of Language Learning and Applied Linguistics World, 6(3), 337-345.

Gilakjani, A. P. (2011). A study of factors affecting EFL learners' English listening comprehension and strategies for improvement. Journal of Language Teaching and Research, 2(5), 977-988.

Ginther, A. (2002). Context and content visuals and performance on listening comprehension stimuli. Language Testing, 19(2), 133-67.

Goh, C. (2008). Metacognitive instruction for second language listening development: Theory, practice and research implications. RELC Journal, 39, 188-213. doi: $10.1177 / 0033688208092184$.

Goh, C. C. (1998). How ESL learners with different listening abilities use comprehension strategies and tactics. Language Teaching Research, 2(2), 124-147.

Gough, P. B., \& Tunmer, W. E. (1986). Decoding, reading, and reading disability. Remedial and Special Education, 7(1), 6-10. 
Grabe, W. (2009). Reading in a second language: Moving from theory to practice. New York: Cambridge University Press.

Grabe, W., \& Stoller, F. L. (2011). Teaching and researching reading (2nd Ed.). New York: Routledge.

Graesser, A. C. (2007). An introduction to strategic reading comprehension. In D. McNamara (Ed), Reading comprehension strategies: Theories, interviews, and technologies (pp. 3-26). Mahwah, New Jersey: Lawrence Erlbaum Associates, Inc.

Graham, S. (2017). Research into practice: Listening strategies in an instructed classroom setting. Language teaching, 50(1), 107-119.

Graham, S., \& Macaro, E. (2008) Strategy instruction in listening for lower-intermediate learners of French. Language Learning, 58(4), 747-783.

Griffiths, C., \& Cansiz, G. (2015). Language learning strategies: A holistic view. Studies in Second Language Learning and Teaching, 5(3), 473-493.

Grow, L., \& Leblanc. L. (2015). Teaching receptive language skills: Recommendations for instructors. Behavior Analysis in Practice, 6(1), 56-57.

Gruba, P. (1989). A comparison study of audio and video presentation modes in tests of ESL listening comprehension (Unpublished master's thesis). University of California, Los Angeles.

Hadley, R. J. (2010). Principals' Opinions on the Impact of High-Stakes Testing on Teaching and Learning in the Public Elementary Schools in the State of Utah, PhD Dissertations, Department of Educational Leadership and Foundation, Brigham Young University, December 2010.

Hakuta, K., \& Beatty, A. (2000). Testing English-language learners in U.S. schools. Washington, DC: National Academies Press.

Hamilton, L, S., Stecher, B. M., \& Klein, S. P. (2002). Making Sense of Test-Based Accountability in Education. Rand Corporation, Santa Monica.

Hamilton, L. S., Berends, M., \& Stecher, B. (2005). Teachers' Responses to Standards-Based Accountability. Working paper. Rand Corporation, Santa Monica.

Hargreaves, A., \& Braun, H. (2013). Data-driven improvement and accountability. Boulder, CO: National Education Policy Center. Retrieved from http://nepc.colorado.edu/publication/data-driven-improvement-accountability/.

Harley, A. (2008). Cognitive development: Overview, Retrieved from https://resources.saylor.org/wwwresources/archived/site/wp content/uploads/2011/07/psych406-5.3.pdf. 
Hashim, N. H, Dagostino, L., Carifio, J., Bauer, J. D., \& Zhao, Q. (2014). Assessment of a reading comprehension instrument as it relates to cognitive abilities as defined by Bloom's revised taxonomy. Current Issues in Education, 17(1). Retrieved from http://cie.asu.edu/ojs/index.php/cieatasu/article/view/1281.

Hayes, D. (2014). Factors influencing success in teaching English in state primary schools. British Counsil/E324.

Hemmatia, F., \& Ghaderi, E. (2014). The Effect of four formats of multiple-choice questions on the listening comprehension of EFL learners. Procedia-Social and Behavioral Sciences, 98, 637- 644.

Herman, J., \& Golan, S. (1991). Effects of standardized testing on teachers and learninganother look. Los Angeles, CA: National Center for Research on Evaluation, Standards and Student Testing, UCLA.

Hijazi, S. T., \& Naqvi, S. M. R. (2006). Factors affecting students' performance. Bangladesh e-Journal of Sociology, Vol. 3(1), pp. 65-99.

Hild, G., \& Nikolov, M. (2011). Teachers' views on tasks that work with primary school EFL learners. In M. Lehmann, R. Lugossy \& J. Horvath (Eds.) UPRT 2010: Empirical studies in English applied linguistics (pp. 47-62). Pecs: Lingua Franca Csoport. Retrieved from htt://mek.oszk.hu/10100/10158.

Hodge, M., \& Welch, J. (2016). An implementation perspective: Relevant lessons from No Child Left Behind for the implementation of the Every Student Succeeds Act. JEEL, 3(9), 1-17.

Holbein, J. B., \& Ladd, H. F. (2017). Accountability pressure: Regression discontinuity estimates of how No Child Left Behind influenced student behavior. Economics of Education Review, 58, 55-57.

Hong, Y. (2008). On teaching strategies in second language acquisition. US-China Education Review, 5 (1), 61-67.

Hoover, W. A., \& Gough, P. B. (1990). The simple view of reading. Reading and Writing. An Interdisciplinary Journal, 2, 127-160.

Hulin, R., \& Yulian, B. (2016). A study of the relationship between learning belief and English achievement of Chinese English major college students. Journal of Education and Practice, 7(14), 99-103.

Hung, Y. J., Samuelson, B. L., \& Chen, S. C. (2016). The relationships between peer and selfassessment and teacher assessment of young EFL learners' oral presentations. In. M. Nikolov (Eds.), Assessing young learners of English: Global and local perspectives (pp. 317-338). New York: Springer. 
Huseynova, F. (2007). Assessing students' listening and reading skills questionnaires on listening and reading skills. Lincoln University, Nebraska.

Hyland, F. (2004). Learning Autonomously: Contextualizing out-of-class English language learning. Language Awareness, 13(3), 180-202.

Jacob, B. A. (2005). Accountability incentives and behavior: The impact of high stakes testing in the Chicago public schools. Journal of Public Economics, 89(5-6), 297-327.

Jeon, E. (2011). Contribution of morphological awareness to second-language reading Comprehension. Modern Language Journal, 95, 217-235.

Jeon, E. H., \& Yamashita, J. (2014). L2 reading comprehension and its correlates: A metaAnalysis. A Journal of research in language studies, 160-168.

Johnstone, R. (2009). An early start: What are the key conditions for generalized success? In Koda, K. (1996). L2 word recognition research: A critical review. Modern Language Journal, 80, 14, 450-460.

Joseph, L. (2004). Reading —encourage positive attitudes: strategies for parents and teachers. National Association of School Psychologists.

Khalil, A. (2005). Assessment of language learning strategies used by Palestinian EFL learners. Foreign Language Annals, 38(1), 108-119.

Khamkhien, A. (2010). Factors affecting language learning strategy reported usage by Thai and Vietnamese EFL learners. Foreign language teaching, 7(1), 66-85.

Klem, A. M., \& Connel, J. P. (2004). Relationships matter: Linking teacher support to student engagement and achievement. Journal of School Health, 74(7), 262-273.

Koch, Sh. (2016). Focus on the 4 basic language skills: Receptive. TESOL English language bulletin, Retrieved from http://exclusive.multibriefs.com/content/focus-on-the-4-basiclanguage-skills.

Koda, K. (2005). Insights into second language reading: A cross-linguistic approach. New York: Cambridge University Press.

Koda, K. (2007). Reading and language learning: Cross linguistic constraints on second language reading development. Language Learning, 57, 1-44.

Kolić-Vehovec, S., \& Bajšanski, I. (2006b). Metacognitive strategies and reading comprehension in elementary school students. European Journal of Psychology of Education, 21, 439-451.

Kolić-Vehovec, S., Bajšanski, I., \& Zubkovic, B, R. (2011). The role of reading strategies in scientific text comprehension and academic achievement of university students. Review of Psychology, 18(2), 1-90. 
Kolodziej, Th. (2011). The Benefits and Detriments of the No Child Left behind Act, ESSAI 9 (21). Retrieved from http://dc.cod.edu/essai/vol9/iss 1/21.

Koretz, D., Mccaffrey, D., \& Hamilton, L. (2001). Toward a framework for validating gains under high-stakes conditions. CSE Technical Report. No. 551. Los Angeles, CA: Center for the Study of Evaluation, University of California.

Koshbakht, F., \& Gorjian, B. (2017). Using authentic materials in teaching reading comprehension to EFL learners. Journal of Applied Linguistics and Language Learning, 3(2), 48-54.

Kozma, R. (2009). Transforming education: Assessing and teaching 21st century skills: Assessment call to action. In (Eds). Scheuermann., F \& Björnsson, J. (2009), The Transition to computer-based assessment: New approaches to skills assessment and implications for large-scale testing. Luxembourg: Office for official publications of the European Communities.

Lado, R. (1961). Language testing: The construction and use of foreign language tests. London: Longman.

Lai, C., Zhu, Wh., \& Gong, G. (2014). Understanding the quality of out-of-class English learning. TESOL Quarterly. Retrieved from: http://hdl-handle.net/10722/200986.

Lai, F., Sadoulet, E., \& Janvry, A. (2007). The effect of school and teacher quality on student performance: Using a natural experiment from the middle school reforms in Beijing,

Lakshmi, N., \& Reddy, D. S. (2015). The effect of computer assisted language learning (call) on Listening skills. Journal of English language and literature, 2. pp (nd).

Leppänen, S. (2007). Study on English. Retrieved from: https://www.jyu.fi/hytk/fi/. University of Jyväskylä Department of Languages. Centre of excellence for the study of variation, contacts and change in English, Finland.

Levine, T. H., Howard, E., \& Moss, D. (2014). Preparing classroom teachers to succeed with second language learners. New York, NY: Routledge.

Liao, S. (n.d). Listening strategies and applications in EFL classroom. Retrieved from http:// english.tyhs.edu.tw/xoops/html/tyhs/teach/.

Lightbown, P. M., \& Nina, S. (2013). How Languages Are Learned. Oxford: Oxford University Press Print.

Lindsay, P. (2000). Teaching English worldwide: A new practical guide to teaching English. Provo, Utah: Alta Book Company.

Linn, R. L., \& Dunbar, S. B. (1990). The Nation's report card goes home: Good news and bad about trends in achievement. Phi Delta Kappan, 72 (2), 127-133. 
Macaro, E. (2010). Continuum Companion to Second Language Acquisition. London: Continuum Print.

Majid, A. N. (2011). The use of information technology in teaching English: An attempt to develop student-centered learning at Telkom Polytechnic. Journals Telkom University, 402-407.

Marefat, F., \& Barbari, F. (2009). The relationship between out-of-class language learning strategy use and reading comprehension ability. Porta Linguarum, 12, 91-106.

Maroin, S., \& Leather, P. (2015). Assessment and accountability to support meaningful learning. Education Policy-Analysis Archives, 23 (9).

Mayer, R. E. (2008). Learning and Instruction. Upper Saddle River, N.J: Pearson Merrill Prentice Hall.

Mayer, R. E. (1 984). Aids to prose comprehension. Educational Psychologist, 1 9, 30-42.

McNamara, T., \& Roever, C. (2006). Language Testing: The Social Dimension. International Journal of Applied Linguistics, 16 (2), 242 - 258.

Meijer, J. (2004). Learning potential, personality characteristics, and test performance. In Hamers, J. H. M., Sijtsma, K., \& Ruijssenaars, A. J. J. M. (Eds.) Learning potential assessment: Theoretical, methodological, and practical issues. (pp.341 - 360). Steenwijk, Netherlands.

Melby-Lervªg, M., \& Lervªg, A. (2011). Cross-linguistic transfer of oral language, decoding, phonological awareness and reading comprehension: A meta-analysis of the correlational evidence. Journal of Research in Reading, 34, 114-135.

Melby-Lervªg, M., Lyster, S. H., \& Hulme, C. (2012). Phonological skills and their role in learning to read: A meta-analytic review. Psychological Bulletin, 138, 322-352.

Mihaljevic Djigunovic, J. M. (2016). Individual differences and young learners' performance on L2 speaking tests. In M. Nikolov (Ed.), Assessing young learners of English: Global and local perspectives. New York: Springer.

Ming, T. S., Ling, T. S., \& Jafaar, N. M. (2011). Attitudes and motivation of Malaysian secondary students towards learning English as a second Language: A case study. The Southeast Asian Journal of English Language Studies, 17, 40-54.

Ministry of Education, Culture and Science (MECS). (2015). Суурь боловсрольын ияөм хөтөлбөр [National core curriculum for basic education]. Ulaanbaatar, Mongolia.

Ministry of Education, Culture, and Science (MECS). (2014). Бага боловсролын сургалтын цөм хөтөлбөр [National core curriculum for primary education]. Ulaanbaatar, Mongolia: 
Ministry of Education, Culture, and Science. (2013). Ерөнхий боловсрольнн сургуулийн суралиагчийн болон боловсрольн чанарын үнэлгээний журам [The regulation on secondary school students and the evaluation on Educational quality]. Retrieved from http://www.legalinfo.mn/annex/details/5459?lawid=7723 Accessed June 15, 2018.

Moore, J. L., \& Waltman, K. (2007). Pressure to increase test scores in reaction to NCLB: An investigation of related factors, Annual meeting for the American Educational Research and Evaluation Association.

Munoz, C. (Ed.). (2006). Age and the rate of foreign language learning. Clevedon: Avon/Multilingual Matters.

Murray, G., \& Kojima, M. (2007). Out-of-class language learning: One learner's story, Learner Autonomy, Academia.edu.

Nation, I. S. P. (2008). Teaching ESL/EFL reading and writing. New York: Routledge.

Nation, I. S. P., \& Newton, J. (2009). Teaching ESL/EFL listening and speaking. New York: Routledge.

Nation, I. S. P. (2013). Learning vocabulary strategies in another language. (Second edition). Cambridge: Cambridge University Press.

National Center of Standards and Measurement (NCSM). (2014). Primary and complete secondary education standards: Retrieved from http:// teacher.sur.mn/, Ulaanbaatar, Mongolia.

National Reading Panel. (2000). Teaching children to read. Retrieved from: http:/www.nichd.nih.gov/publications/nrp/smallbook.htm.

National Research Council. 2001. Knowing what students know: The science and design of educational assessment. Committee on the Foundations of Assessment. Pelligrino, J., Chudowsky, N., \& Glaser, R., eds. Board on testing and assessment, center for education. Division of behavioral and social sciences and education. Washington, DC: National Academy Press.

NBETPP report. (2003). Perceived effects of state-mandated testing programs on teaching and learning, Joseph J. Pedulla, Lisa M. Abrams, George F. Madaus, Michael K. Russell, Miguel A. Ramos \& Jing Miao Lynch, School of Education, Boston College.

NCLRC. (n.d). The essential of language teaching, Teaching listening, Retrieved from: http://www.nclrc.org/essential/listening/stratlisten.htm.

Nejabati, N. (2015). The effects of teaching self-regulated learning strategies on EFL students' reading comprehension. Journal of Language Teaching and Research, 6 (6), 1343-1348. 
Newton, P. E. (2007). Clarifying the purposes of educational assessment. Assessment in Education, 14(2), 149-170.

Ngang, T. K., Hong, C. S., \& Chanya, A. (2014). Collective work of novice teachers in changing teaching practices. Procedia-Social and Behavioral Sciences, 116 (21), 536540 .

Nichols, S., Glass, G., \& Berliner, D. (2012). High-stakes testing and student achievement: Updated analyses with NAEP data. Education Policy Analysis Archives, 20 (20), 1-35.

Nikolov, M. (2009a). The age factor and early language learning. Berlin/New York: Mouton de Gruyter. Reviewed by Ingrid Pufahl, Center for Applied Linguistics, 2011. Retrieved from https://journals.linguisticsociety.org/booknotices/?p=1580.

Nikolov, M. (2009b). Early learning of modern foreign languages: Processes and outcomes. Clevedon, UK: Multilingual matters.

Nikolov, M. (2016). A framework for young EFL learners' diagnostic assessment: Can do statements and task types. In M. Nikolov (Ed.), Assessing young learners of English: Global and local perspectives (pp. 65-92). New York: Springer. 15

Nikolov, M., \& Csapó, B. (2010). The relationship between reading skills in early English as a foreign language and Hungarian as a first language. International Journal of Bilingualism, 14 (3), 315-329.

Nikolov, M., \& Jozsa, K. (2006). Relationships between language achievements in English and German and classroom related variables. In M. Nikolov \& J. Horvath (Eds.), UPRT 2006: Empirical studies in English applied linguistics (pp. 197-224). Pecs: Lingua Franca Csoport, PTE.

Nist, S. L., \& Simpson, M. L. (1985). The relationship between the use of study strategies and test performance. Journal of Reading Behavior, 17(1), 15-26.

Nor, H. (2014). The techniques in teaching listening skill. Journal on English as a Foreign Language, 4(1), 41-51.

Nunan, D., \& Carter, R. (2001). The Cambridge guide to teaching English to speakers of other languages, Cambridge University Press.

Ockey, G. J. (2007). Construct implications of including still image or video in computerbased listening tests. Language Testing, 24, 517-537.

Ockey, G. J. (2009). Developments and challenges in the use of computer-based testing for assessing second language ability. The Modern Language Journal, 93, 836-47.

Olsen, L., \& Huckin, T. N. (1990). Point-driven understanding in engineering lecture Comprehension. English for Specific Purposes, 9, 33-47. 
Omid, A., \& Azam, R. (2016). Using authentic materials in the foreign language classrooms: Teachers' perspectives in EFL classes. International Journal of Research Studies in Education, 5 (2), 105-116.

Omuna, M. O., Onchera, P. O., \& Kimutai, Ch, K. (2016). Availability and use of instructional resources for teaching and learning of English reading skills in secondary schools in Teso North Sub Country, Kenya. Educational Research, 7(1), 1-9.

Önalan, O., \& Karagül, A. E. (2018). A study on Turkish EFL teachers' beliefs about assessment and its different uses in teaching English. Journal of Language and Linguistic Studies, 14(3), 190-201.

Oxford, R. L. (1990). Language learning strategies: What every teacher should know, New York: Newbury House Press.

Oxford, R. L. (2011). Teaching and researching: Language learning strategies (applied linguistics in action). Pearson ESL, England.

Oxford, R. L. (2003). Language learning styles and strategies: An overview. Proceedings of GALA (Generative Approaches to Language Acquisition) conference, 1-25. Retrieved from http://web.ntpu.edu.tw/-language/workshop/read2.pdf.

Padwick, A. (2010). Attitudes towards English and varieties of English in globalizing, India. University of Groningen. Newcastle, England.

Palmer, R. (2014). Listening strategies that develop active listeners. TESOL connections. Retrieved from http://newsmanager.commpartners.com/tesolc/issues/2014-0601/3.html.

Papaefthymiou-Lytra, S. (2012). Foreign language testing and assessment in Greece: An overview and appraisal. Research Papers in Language Teaching and Learning, 3(1), 22-32. Retrieved from http://rpltl.eap.gr.

Pavičič, T. V. (2008). Vocabulary learning strategies and foreign language acquisition. Clevedon: Maltilinqual Matters.

Pellegrino, J. M., Chudowsky, N., \& Glaser, R. (2001). Knowing what students know: The science and design of educational assessment, Board on Testing and Assessment Center for Education, National Research Council.

Peng,J., \& Zheng, S. (2016). A longitudinal study of a school's assessment projects in Chongqing, China. In M. Nikolov (Ed.), Assessing young learners of English: Global and local perspectives (pp. 213-241). New York: Springer.

Pesce, C. (n.d). Five surprising factors that may affect your ESL students' test scores. Retrieved from: http//www.busyteacher.org/14472. 
PISA (2015). Draft Questionnaire Framework. Retrieved from: http://www.oecd.org/.../PISA-2015-draft-questionnaire-framework.pdf.

Powers, D. E. (2010). The case for a comprehensive, four skills assessment of English language proficiency. TOEIC Compendium study, 12, 2-11.

Prasad, B. N. (2013). Communicative language teaching in 21st century ESL classroom. English for Specific Purposes World, 40 (14), pp. 1-8.

Remesal, A. (2011). Primary and secondary teachers' conceptions of assessment: A qualitative study. Journal of Teaching and Teacher Education, 27(2), 472-482.

Renandya, W. A., \& Hu, G. (2018).Introduction to teaching listening. The TESOL Encyclopedia of English Language Teaching, First Edition, John Wiley \& Sons, Inc.

Renukadevi, D. (2014). The role of listening in language acquisition; the challenges \& strategies in teaching listening. International Journal of Education and Information Studies, 4 (1), 59-63.

Richards, J. (2005). Curriculum development in language teaching. New York: Cambridge University Press.

Richards, J. C. (1983). Listening comprehension: Approach, design, procedure. TESOL Quarterly, 17(2), 219-240.

Richards, J. C., Platt, J., \& Platt, H. (1992). Dictionary of language teaching and applied linguistics. London: Longman.

Richards, J. C., 1943-. (2002). Longman dictionary of language teaching and applied linguistics. London; New York: Longman,

Ricketts, C., \& Wilks, S. J. (2002). Improving student performance through computer-based assessment: Insights from recent research. Assessment \& Evaluation in Higher Education, 27 (5), 475-479.

Rixon, S. (2013). British Council Survey of policy and practice in primary English language teaching worldwide. London: British Council.

Rixon, S. (2016). Do developments in assessment represent the 'coming of age' of young learners' English language teaching initiatives? The international picture. In M. Nikolov (Ed.), Assessing young learners of English: Global and local perspectives (pp. 19-41). New York: Springer.

Riyanto, S. (2015). The Role of attitude in language learning in reading comprehension. University of Lampung (unpublished script). Bandar Lampung.

Rose, J. (2006). Independent review of the teaching of early reading: Final report. London, England: Department for Education and Skills. 
Sadiku, L. M. (2015). The importance of four skills reading, speaking, writing, listening in a lesson hour. European Journal of language and literature studies, 1(1), pp. 29-31.

Sanqvist, P. (2009). Extramural English matters: out-of-school English and impact on Swedish ninth graders' oral proficiency and vocabulary. PhD dissertation, Faculty of Arts and Education, Karlstad University.

Santiago, P. (2002). Teacher demand and supply: Improving teaching quality and addressing teacher shortages, OECD Education Working Paper No. 1.

Sayer, P., \& Ban, R. (2014). Young EFL students' engagements with English outside the classroom. ELT Journal, 68(3), 321-329. doi: 10.1093/elt/ccu013.

Schlesser, C. E. (2004). The correlation between extracurricular activities and grade point average of middle school students. A research paper, the graduate school, University of Wisconsin-Stout.

Schmidt, R., \& Watanabe, Y. (2001). Motivation, strategy use, and pedagogical preferences in foreign language learning. In Z. Dörnyei \& R. Schmidt (Eds.), Motivation and second language acquisition (Technical Report \#23, pp. 313-359). Honolulu: University of Hawai, Second Language Teaching and Curriculum Center.

Schueler, A. (1980). An exploratory study of Egan's four stages of educational development and their application to curriculum design in physical education, Master's thesis, The University of British Columbia.

Scott, M., \& Paul, L. (2015). Assessment and accountability to support meaningful Learning. Education Policy Analysis Archives, 23 (9).

Sed, S., \& Nadmid, В. (2009). Боловсрольнн Үндэсний Үнэлгээ ба суралцагчдын сурлагын Үнэлгээний залгамж холбоо [Bolovsroliin unelgee ba suraltsagchdiin surlagiin unelgeenii zalgamj holboo]:(Project Report. 2007-2008), The Institute of Education, Ulaanbaatar, Mongolia.

Shabani, K. (2012). Dynamic assessment of L2 learners' reading comprehension processes: A 16 Vygotskian perspective. Procedia - Social and Behavioral Sciences, 32, 321-328.

Shabani, K. (2014). Dynamic assessment of L2 listening comprehension in transcendence tasks. Procedia - Social and Behavioral Sciences, 98, 1729-1737.

Singhal, M. (2001). Reading proficiency, reading strategies, metacognitive awareness and L2 readers. The Reading Matrix, 1(1), pp. n.d.

Snowling, M., Cain, K., Nation, K., \& Oakhill, J. (2009). Reading comprehension: nature, assessment and teaching, Universities of York, Oxford, Lancaster and Sussex. 
Standards and Measurements National Center (SMNC). (2004). Foreign Language Standards for Elementary and Secondary Education, Ulaanbaatar, Soyombo printing.

Sternberg. R. J. (1985). Beyond IQ: A triarchic theory of human intelligence. Cambridge, England: Cambridge University Press.

Stoller, L., Anderson, N. J., Grabe, W., \& Komiyama, R. (2013). Instructional enhancements to improve students' English. Teaching Forum, 1, 2-33.

Suvorov, R., \& Hegelheimer, V. (2013). Computer-assisted language testing. In A. J. Kunnan (Ed.), The companion to language assessment (pp. 594-613). Hoboken, NJ: John Wiley \& Sons.

Széll, K. (2013). Factors determining student achievement. Hungarian Educational Research Journal, 3, 55-66.

Säälik, Ü. (2015). Learning strategies explaining boys' and girls' reading performance in schools with different language. Social and Behavioral Sciences, 180, 1649-1655.

Taylor, L., \& Geranpayeh, A. (2011). Assessing listening for academic purposes: Defining and operationalizing the test construct. Journal of English for Academic Purposes, 10, 89-101.

Terenzini, P. T. (1989). Assessment with open eyes: Pitfalls in studying student outcomes. Journal of Higher Education, 60, 644.

Terhart, E. (2013). Teacher resistance against school reform: reflecting an inconvenient truth. School leadership management, 33(5), 486-500.

Terzis, V., \& Economides, A, A. (2011). The acceptance and use of computer based assessment. Computers \& Education 56, 1032-1044.

Thelwall, M. (2000). Computer-based assessment: a versatile educational tool. Computers \& Education, 34, 37-49.

Thomson, N. (2012). Techniques used to support students learning in a language other than their mother tongue, Executive summary.

Thèkes, I. (2016). Assessing young Hungarian EFL learners' vocabulary and learning strategies. Ph.D dissertation. Szeged: University of Szeged.

Tobia, V., Ciancaleoni, M., \& Bonifacci, P. (2016). Theoretical models of comprehension skills tested through a comprehension assessment battery primary school for children. Language Testing, 1-17.

Tomlinson, B. (2011). Materials developed in language teaching, $2^{\text {nd }}$ edition, Cambridge University Press. 
Tóth, E. (2014). Teachers' beliefs on system level assessments and their impact on the teaching and learning process, $P h D$ dissertation summary, Szeged: University of Szeged, Hungary.

Tóth, E., \& Csapó, B. (2011). Comparing primary and high-school teachers' attitudes towards testing and accountability. Paper presented at the 14th European Conference for the Research on Learning and Instruction. Exeter, United Kingdom, August 30September 3, 2011. 57.

Tran, T, H. (2012). Second Language Assessment for Classroom Teachers, Paper presented at MIDTESOL-2012, Ames, Iowa Rolla, Missouri, USA

Urquhart, S., \& Weir, C. J. (1998). Reading in a second language: Process, product and practice. New York: Routledge.

Van Gelderen, A., Schoonen, R., de Glopper, K., Hulstijn, J., Simis, A., \& Snellings, P. (2004). Linguistic knowledge, processing speed, and metacognitive knowledge in first- and second-language reading comprehension: A componential analysis. Journal of Educational Psychology, 96, 19-30.

Vandergrift, L., \& Goh, C. M. (2012). Teaching and learning second language listening. New York: Routledge.

Vavla, L., \& Gokaj, R. (2013). Learner's perceptions of Assessment and Testing in EFL classrooms in Albania. Mediterranean Journal of Social Sciences, 4(11), 509-515.

Voronina, A. (2009). Always learning: Developing receptive skills, Pearson. Retrieved from: https://docplayer.net/23978264-Developing-receptive-skills-anna-voronina-pearsonteacher-trainer.html.

Wagner, E. (2007). Are they watching? Test-taker viewing behavior during an L2 video listening test. Language Learning \& Technology, 11(1), 67-86.

Warschauer, M \& Healey, D. (1998). Computers and language learning: An overview. Language Teaching, 31, 57-71.

Weng, P. L. P., Yunus, M. Md., \& Embi, M. A. B. (2016). Successful language learning strategies used by successful year 5 English as a second language (ESL) learners. Proceeding of ICECRS, 1, 1-11.

Wenglinsky, H. (2002). How schools matter: The link between teacher classroom practices and student academic performance. Education Policy Analysis Archives, 10(12). Retrieved from http://epaa.asu.edu/epaa/v10n12/.

West, R., \& D. Tsagari (2004). Testing and Assessment in Language Learning. (Vol. 3). Hellenic Open University: Patras. 
Wilden, E., \& Porsch, R. (2016). Learning EFL from year 1 or year 3? A comparative study on children's EFL listening and reading comprehension at the end of primary education. In M. Nikolov (Ed.), Assessing young learners of English: Global and local perspectives (pp. 191-212). New York: Springer.

Wise, S. L., Barners, L. B., Harvey, A. L., \& Plake, B. S. (2009). Effects of computer anxiety and computer experience on the computer based achievement test performance of college students. Applied Measurement in Education, 2(3), 235-241.

World Language standards. (2010), Second edition, USA

Xiao, L. (2006). English Teaching Methodology. Beijing: Foreign Language Teaching and Research Press.

Zare, P. (2012). Language learning strategies among EFL/ESL learners: A review of literature. International Journal of Humanities and Social Science, 2, 162-169.

Zare, P., \& Nooreen, N. (2011). The Relationship between language learning strategy use and reading comprehension achievement among Iranian undergraduate EFL learners. World Applied Sciences Journal, 13(8), 1870-1877.

Zhang, W., Liu, M., Zhao, Sh., \& Xie, Q. (2006). English test-taking strategy use and students' test performance. Asian EFL Journal, 13(2), pp. nd. 


\section{APPENDIX A \\ Teachers' opinion about educational assessment and accountability questionnaire}

\section{How do you judge the following statements?}

School achievement tests (SATs)

\begin{tabular}{lcccc}
\hline & Disagree & $\begin{array}{c}\text { Somewhat } \\
\text { disagree }\end{array}$ & $\begin{array}{c}\text { Somewhat } \\
\text { agree }\end{array}$ & Agree \\
\hline should be conducted on a regular basis. & $\square$ & $\square$ & $\square$ & $\square$ \\
are important for work in schools. & $\square$ & $\square$ & $\square$ & $\square$ \\
only cause trouble in schools. & $\square$ & $\square$ & $\square$ & $\square$ \\
create more problems than solutions. & $\square$ & $\square$ & $\square$ & $\square$ \\
contribute to an increased effort in schools. & $\square$ & $\square$ & $\square$ & $\square$ \\
provide an objective basis to evaluate schools. & $\square$ & $\square$ & $\square$ & $\square$ \\
are not useful for my job as a teacher. & $\square$ & $\square$ & $\square$ & $\square$ \\
provide a basis for discussion among colleagues. & $\square$ & $\square$ & $\square$ & $\square$ \\
are barely applicable for individual student evaluations. & $\square$ & $\square$ & $\square$ & $\square$ \\
support the debate about the concept of competence. & $\square$ & $\square$ & $\square$ & $\square$ \\
\hline
\end{tabular}

\section{Test Preparation Strategies}

Which of the following strategies are used, in your opinion, by colleagues of your school, or other schools, in preparation for and during the SATs.

\begin{tabular}{|c|c|c|c|c|}
\hline & Disagree & $\begin{array}{c}\text { Somewhat } \\
\text { disagree }\end{array}$ & $\begin{array}{l}\text { Somewhat } \\
\text { agree }\end{array}$ & Agree \\
\hline $\begin{array}{l}\text { try to improve students' test-taking skills (e.g. practice on } \\
\text { public release tasks) that are used in the SATs). }\end{array}$ & $\square$ & $\square$ & $\square$ & $\square$ \\
\hline $\begin{array}{l}\text { seek to improve students' motivation to do well on the } \\
\text { SATs. }\end{array}$ & $\square$ & $\square$ & $\square$ & $\square$ \\
\hline $\begin{array}{l}\text { see to it that the coherence between instructional content } \\
\text { and the tasks of the SATs is increased. }\end{array}$ & $\square$ & $\square$ & $\square$ & $\square$ \\
\hline $\begin{array}{l}\text { practice test formats that are used in the SATs (e.g. } \\
\text { multiple-choice tasks). }\end{array}$ & $\square$ & $\square$ & $\square$ & $\square$ \\
\hline $\begin{array}{l}\text { more often use tasks in regular instruction that are similar } \\
\text { to those in the SATs. }\end{array}$ & $\square$ & $\square$ & $\square$ & $\square$ \\
\hline $\begin{array}{l}\text { set aside or put less emphasis, in regular instruction, on } \\
\text { content that will not be tested. }\end{array}$ & $\square$ & $\square$ & $\square$ & $\square$ \\
\hline discuss general task-taking strategies with students. & $\square$ & $\square$ & $\square$ & $\square$ \\
\hline $\begin{array}{l}\text { exclude individual, mainly underachieving students from } \\
\text { the test. }\end{array}$ & $\square$ & $\square$ & $\square$ & $\square$ \\
\hline use the following alternative strategy: & $\square$ & $\square$ & $\square$ & $\square$ \\
\hline
\end{tabular}




\section{Perceived Pressure for Different Types of Tests}

Please indicate if you feel pressured by any of the following types of achievement assessments, even if you have not had any experience with it. Please also indicate if you have already administered any of these assessments.

\begin{tabular}{|c|c|c|c|c|c|c|}
\hline & \multicolumn{4}{|c|}{ Feel pressured } & \multicolumn{2}{|c|}{$\begin{array}{c}\text { Have } \\
\text { administered }\end{array}$} \\
\hline & $\begin{array}{c}\text { Not at } \\
\text { all }\end{array}$ & Barely & $\begin{array}{l}\text { Some- } \\
\text { what }\end{array}$ & A lot & No & Yes \\
\hline $\begin{array}{l}\text { Standardized tests on a state level which are } \\
\text { administered as census and are graded externally }\end{array}$ & $\square$ & $\square$ & $\square$ & $\square$ & $\square$ & $\square$ \\
\hline $\begin{array}{l}\text { Standardized tests on a state level which are } \\
\text { administered as census and are graded by the teachers } \\
\text { themselves }\end{array}$ & $\square$ & $\square$ & $\square$ & $\square$ & $\square$ & $\square$ \\
\hline $\begin{array}{l}\text { Standardized tests using samples to assess educational } \\
\text { standards across states }\end{array}$ & $\square$ & $\square$ & $\square$ & $\square$ & $\square$ & $\square$ \\
\hline Centralized final exams & $\square$ & $\square$ & $\square$ & $\square$ & $\square$ & $\square$ \\
\hline $\begin{array}{l}\text { Across-school comparative tests (e.g., by cooperation } \\
\text { with neighbouring schools) }\end{array}$ & $\square$ & $\square$ & $\square$ & $\square$ & $\square$ & $\square$ \\
\hline Within-school comparative tests & $\square$ & $\square$ & $\square$ & $\square$ & $\square$ & $\square$ \\
\hline Classroom tests & $\square$ & $\square$ & $\square$ & $\square$ & & \\
\hline
\end{tabular}




\section{Amount of Test Practice}

Did you practice with your students for the SATs?

\begin{tabular}{|c|c|c|c|c|}
\hline No & \multicolumn{4}{|l|}{ Yes } \\
\hline \multirow[t]{6}{*}{$\square$} & $\square$ & & & \\
\hline & \multicolumn{4}{|c|}{ If yes, when did you start practicing with your students? } \\
\hline & $\begin{array}{c}\text { Several months } \\
\text { before the test }\end{array}$ & $\begin{array}{c}\text { In the month before } \\
\text { the test }\end{array}$ & $\begin{array}{l}\text { In the two weeks } \\
\text { before the test }\end{array}$ & $\begin{array}{c}\text { Some days before } \\
\text { the test }\end{array}$ \\
\hline & $\square$ & $\square$ & $\square$ & $\square$ \\
\hline & \multicolumn{4}{|c|}{ In this case, how much total classroom time did you spend on practicing? } \\
\hline & __ hours & __ minutes & & \\
\hline
\end{tabular}

\section{Change of Instructional Practice}

The increased use of achievement assessments created a debate about possible positive and negative consequences of the assessments on instruction. Did your instruction change due to this discussion? To what extent do the following statements apply to you?

\begin{tabular}{lcccc}
\hline & Disagree & $\begin{array}{c}\text { Somewhat } \\
\text { disagree }\end{array}$ & $\begin{array}{c}\text { Somewhat } \\
\text { agree }\end{array}$ & Agree \\
\hline I assign more homework. & $\square$ & $\square$ & $\square$ & $\square$ \\
I assign more difficult homework. & $\square$ & $\square$ & $\square$ & $\square$ \\
I search for more effective teaching methods. & $\square$ & $\square$ & $\square$ & $\square$ \\
I focus more strongly on educational standards. & $\square$ & $\square$ & $\square$ & $\square$ \\
$\begin{array}{l}\text { I focus more strongly on the competences that are assessed as } \\
\text { part of the educational concept in the SATs. }\end{array}$ & $\square$ & $\square$ & $\square$ & $\square$ \\
I spend more time teaching general test-taking strategies. & $\square$ & $\square$ & $\square$ & $\square$ \\
I focus more strongly on low achievers. & $\square$ & $\square$ & $\square$ & $\square$ \\
I focus more strongly on high achievers. & $\square$ & $\square$ & $\square$ & $\square$ \\
I offer more assistance outside of classroom instruction. & $\square$ & $\square$ & $\square$ & $\square$ \\
I focus more strongly on multiple-choice tests. & $\square$ & $\square$ & $\square$ & $\square$ \\
I focus more strongly on tests with open-ended questions (e.g., & $\square$ & $\square$ & $\square$ & $\square$ \\
essays, portfolios). & & & $\square$ \\
\hline
\end{tabular}




\begin{tabular}{lcccc}
\hline & Disagree & $\begin{array}{c}\text { Somewhat } \\
\text { disagree }\end{array}$ & $\begin{array}{c}\text { Somewhat } \\
\text { agree }\end{array}$ & Agree \\
\hline I reduce instructional content. & $\square$ & $\square$ & $\square$ & $\square$ \\
I take less liberties in how I design my lessons. & $\square$ & $\square$ & $\square$ & $\square$ \\
I set aside or spend less time on content which will not be tested. & $\square$ & $\square$ & $\square$ & $\square$ \\
$\begin{array}{l}\text { I focus more strongly on overarching competencies (e.g., writing } \\
\text { and reading in mathematics instruction). }\end{array}$ & $\square$ & $\square$ & $\square$ & $\square$ \\
$\begin{array}{l}\text { I have narrowed down the curricular content of my instruction. } \\
\text { My instruction focuses more strongly on competencies rather }\end{array}$ & $\square$ & $\square$ & $\square$ & $\square$ \\
than content. & $\square$ & $\square$ & $\square$ & $\square$ \\
$\begin{array}{l}\text { I think it is inappropriate to change my instructional practices } \\
\text { because of achievement assessments. }\end{array}$ & $\square$ & $\square$ & $\square$ & $\square$ \\
$\begin{array}{l}\text { Results from my instructional practices are good, so I don't see } \\
\text { why I should change them. }\end{array}$ & $\square$ & $\square$ & $\square$ & $\square$ \\
$\begin{array}{l}\text { My instructional practices have changed in the following } \\
\text { alternative way: }\end{array}$ & $\square$ & $\square$ & $\square$ & $\square$ \\
\hline
\end{tabular}

\section{Perceived Pressure by Different Stake Holders}

To what extent do you feel pressured by each of the following sources to increase your students' performance on the SATs?

\begin{tabular}{llcccc}
\hline & & Not at all & Barely & Somewhat & A lot \\
\hline a) Yourself & $\square$ & $\square$ & $\square$ & $\square$ \\
b) Colleagues & $\square$ & $\square$ & $\square$ & $\square$ \\
c) Central Administration & $\square$ & $\square$ & $\square$ & $\square$ \\
d) School Board & $\square$ & $\square$ & $\square$ & $\square$ \\
e) Parents & $\square$ & $\square$ & $\square$ & $\square$ \\
f) Public & $\square$ & $\square$ & $\square$ & $\square$ \\
g) Government & $\square$ & $\square$ & $\square$ & $\square$ \\
\hline
\end{tabular}




\section{APPENDIX B \\ Questionnaire for teaching strategies of English language receptive skills}

\section{Background information}

1. What is your age? (Please write here.) years.

2. What is your gender?
A. Male
B. Female

3. What kind of university did you graduate at?
A. Government
B. Non-governmental
C. University with foreign investment
D. Foreign university

4. What is your education degree?
A. Diploma (vocational degree, not bachelor)
B. Bachelor's
C. Master's
D. Doctorate degree or higher

5. How many years have you been teaching English? (Please write here.) years.

6. How many hours do you teach English in a week? (Please write here.) hours.

\section{Teaching strategies for listening skills}

How true or not true of you are these statements about your teaching PRE-LISTENING strategies?

\begin{tabular}{|c|l|c|c|c|c|c|}
\hline & \multicolumn{1}{|c|}{ Strategies } & $\begin{array}{c}\text { Never or } \\
\text { almost } \\
\text { never true } \\
\text { of me }\end{array}$ & $\begin{array}{c}\text { Usually } \\
\text { not true of } \\
\text { me }\end{array}$ & $\begin{array}{c}\text { Somewhat } \\
\text { true of me }\end{array}$ & $\begin{array}{c}\text { Usually } \\
\text { true of me }\end{array}$ & $\begin{array}{c}\text { Always or } \\
\text { almost } \\
\text { always } \\
\text { true of me }\end{array}$ \\
\hline 1 & $\begin{array}{l}\text { I ask students to discuss their } \\
\text { opinion on the topic }\end{array}$ & A & B & C & D & D \\
\hline 2 & $\begin{array}{l}\text { I use brainstorming on topics } \\
\text { or vocabulary }\end{array}$ & A & B & C & D & E \\
\hline 3 & $\begin{array}{l}\text { I ask students to discuss } \\
\text { charts, graphs, maps, or } \\
\text { statistics }\end{array}$ & A & B & C & D & E \\
\hline 5 & $\begin{array}{l}\text { I ask students to discuss } \\
\text { pictures, photos, or cartoons }\end{array}$ & $\begin{array}{l}\text { I ask students to discuss their } \\
\text { personal experiences }\end{array}$ & A & B & C & D \\
\hline
\end{tabular}




\begin{tabular}{|c|l|c|c|c|c|c|}
\hline & \multicolumn{1}{|c|}{ Strategies } & $\begin{array}{c}\text { Never or } \\
\text { almost } \\
\text { never true } \\
\text { of me }\end{array}$ & $\begin{array}{c}\text { Usually } \\
\text { not true of } \\
\text { me }\end{array}$ & $\begin{array}{c}\text { Somewhat } \\
\text { true of me }\end{array}$ & $\begin{array}{c}\text { Usually } \\
\text { true of me }\end{array}$ & $\begin{array}{c}\text { Always or } \\
\text { almost } \\
\text { always } \\
\text { true of me }\end{array}$ \\
\hline 6 & $\begin{array}{l}\text { I ask students to predict what } \\
\text { the text will be about (from } \\
\text { title, pictures etc) }\end{array}$ & A & B & C & D & E \\
\hline 7 & $\begin{array}{l}\text { I pre-teach vocabulary and } \\
\text { grammar using various ways }\end{array}$ & A & B & C & D & E \\
\hline 8 & $\begin{array}{l}\text { I read a short text related to } \\
\text { the topic }\end{array}$ & A & B & C & D & E \\
\hline 9 & $\begin{array}{l}\text { I give written exercises related } \\
\text { to the text to come }\end{array}$ & A & B & C & D & E \\
\hline
\end{tabular}

How true or not true of you are these statements about your teaching WHILE-LISTENING strategies?

\begin{tabular}{|c|c|c|c|c|c|c|}
\hline & Strategies & $\begin{array}{c}\text { Never or } \\
\text { almost } \\
\text { never true } \\
\text { of me }\end{array}$ & $\begin{array}{l}\text { Usually } \\
\text { not true of } \\
\text { me }\end{array}$ & $\begin{array}{l}\text { Somewhat } \\
\text { true of me }\end{array}$ & $\begin{array}{l}\text { Usually } \\
\text { true of me }\end{array}$ & $\begin{array}{c}\text { Always or } \\
\text { almost } \\
\text { always } \\
\text { true of me }\end{array}$ \\
\hline 1 & $\begin{array}{l}\text { I ask students to check } \\
\text { topics, events, or pictures } \\
\text { discussed before }\end{array}$ & A & B & $\mathrm{C}$ & $\mathrm{D}$ & $\mathrm{E}$ \\
\hline 2 & $\begin{array}{l}\text { I ask students to complete } \\
\text { charts or diagrams }\end{array}$ & A & B & $\mathrm{C}$ & $\mathrm{D}$ & $\mathrm{E}$ \\
\hline 3 & $\begin{array}{l}\text { I ask students to complete a } \\
\text { gap fill }\end{array}$ & A & B & $\mathrm{C}$ & $\mathrm{D}$ & $\mathrm{E}$ \\
\hline 4 & $\begin{array}{l}\text { I ask students to follow a } \\
\text { route on a map }\end{array}$ & A & B & $\mathrm{C}$ & $\mathrm{D}$ & $\mathrm{E}$ \\
\hline 5 & $\begin{array}{l}\text { I ask students to identify } \\
\text { errors in a script }\end{array}$ & A & B & $\mathrm{C}$ & $\mathrm{D}$ & $\mathrm{E}$ \\
\hline 6 & $\begin{array}{l}\text { I ask students to predict } \\
\text { vocabulary from the context }\end{array}$ & A & B & $\mathrm{C}$ & $\mathrm{D}$ & $\mathrm{E}$ \\
\hline 7 & $\begin{array}{l}\text { I ask students to answer } \\
\text { multiple choice questions }\end{array}$ & A & B & $\mathrm{C}$ & $\mathrm{D}$ & $\mathrm{E}$ \\
\hline 8 & $\begin{array}{l}\text { I ask students to number } \\
\text { topics, events, or pictures in } \\
\text { correct order }\end{array}$ & A & B & $\mathrm{C}$ & $\mathrm{D}$ & $\mathrm{E}$ \\
\hline 9 & $\begin{array}{l}\text { I ask students to form } \\
\text { questions and give short } \\
\text { answers }\end{array}$ & A & B & $\mathrm{C}$ & $\mathrm{D}$ & $\mathrm{E}$ \\
\hline 10 & I ask students to take notes & A & B & $\mathrm{C}$ & $\mathrm{D}$ & $\mathrm{E}$ \\
\hline
\end{tabular}

How true or not true are these statements about your teaching POST-LISTENING strategies?

\begin{tabular}{|c|c|c|c|c|c|c|}
\hline & Strategies & $\begin{array}{c}\text { Never or } \\
\text { almost } \\
\text { never true } \\
\text { of me }\end{array}$ & $\begin{array}{l}\text { Usually } \\
\text { not true of } \\
\text { me }\end{array}$ & $\begin{array}{l}\text { Somewhat } \\
\text { true of me }\end{array}$ & $\begin{array}{l}\text { Usually } \\
\text { true of me }\end{array}$ & $\begin{array}{c}\text { Always or } \\
\text { almost } \\
\text { always } \\
\text { true of me }\end{array}$ \\
\hline 1 & $\begin{array}{l}\text { I ask students to discuss } \\
\text { ideas or cultural points in } \\
\text { the text }\end{array}$ & A & B & $\mathrm{C}$ & D & E \\
\hline 2 & $\begin{array}{l}\text { I ask students to discuss } \\
\text { interpretations and opinions }\end{array}$ & A & B & $\mathrm{C}$ & D & E \\
\hline
\end{tabular}




\begin{tabular}{|c|l|c|c|c|c|c|}
\hline & \multicolumn{1}{|c|}{ Strategies } & $\begin{array}{c}\text { Never or } \\
\text { almost } \\
\text { never true } \\
\text { of me }\end{array}$ & $\begin{array}{c}\text { Usually } \\
\text { not true of } \\
\text { me }\end{array}$ & $\begin{array}{c}\text { Somewhat } \\
\text { true of me }\end{array}$ & $\begin{array}{c}\text { Usually } \\
\text { true of me }\end{array}$ & $\begin{array}{c}\text { Always or } \\
\text { almost } \\
\text { always } \\
\text { true of me }\end{array}$ \\
\hline 3 & $\begin{array}{l}\text { I ask students to learn new } \\
\text { functional language taken } \\
\text { from the listening }\end{array}$ & A & B & C & D & E \\
\hline 4 & $\begin{array}{l}\text { I ask students to link } \\
\text { listening with another skill } \\
\text { (speaking, reading, writing) }\end{array}$ & A & B & C & D & E \\
\hline 5 & $\begin{array}{l}\text { I review pre-listening } \\
\text { vocabulary and teach new } \\
\text { vocabulary }\end{array}$ & A & B & C & D & E \\
\hline 6 & $\begin{array}{l}\text { I set up awareness-raising } \\
\text { activities for grammar, } \\
\text { vocabulary or pronunciation }\end{array}$ & A & B & C & D & E \\
\hline 7 & $\begin{array}{l}\text { I set up out-of-class research } \\
\text { or interview projects }\end{array}$ & A & B & C & D & E \\
\hline 8 & $\begin{array}{l}\text { I check comprehension of } \\
\text { reading (e.g. asking } \\
\text { questions, true false } \\
\text { statements etc.) }\end{array}$ & A & B & C & D & E \\
\hline 9 & $\begin{array}{l}\text { I ask students to do tasks } \\
\text { related to vocabulary, } \\
\text { grammar or pronunciation }\end{array}$ & A & B & C & D & E \\
\hline 10 & $\begin{array}{l}\text { I ask students to translate } \\
\text { what they understood }\end{array}$ & A & B & C & D & E \\
\hline
\end{tabular}

\section{Teaching strategies for reading skills}

How true or not true are these statements about your teaching PRE-READING strategies?

\begin{tabular}{|c|c|c|c|c|c|c|}
\hline & Strategies & $\begin{array}{l}\text { Never or } \\
\text { almost } \\
\text { never true } \\
\text { of me }\end{array}$ & $\begin{array}{l}\text { Usually } \\
\text { not true of } \\
\text { me }\end{array}$ & $\begin{array}{l}\text { Somewhat } \\
\text { true of me }\end{array}$ & $\begin{array}{l}\text { Usually } \\
\text { true of me }\end{array}$ & $\begin{array}{c}\text { Always or } \\
\text { almost } \\
\text { always } \\
\text { true of me }\end{array}$ \\
\hline 1 & $\begin{array}{l}\text { I ask students to think about } \\
\text { the subject of the reading } \\
\text { they're about to do }\end{array}$ & $\mathrm{A}$ & B & $\mathrm{C}$ & $\mathrm{D}$ & $\mathrm{E}$ \\
\hline 2 & $\begin{array}{l}\text { I activate their pre-existing } \\
\text { knowledge }\end{array}$ & $\mathrm{A}$ & B & $\mathrm{C}$ & $\mathrm{D}$ & $\mathrm{E}$ \\
\hline 3 & I use brainstorming on a topic & $\mathrm{A}$ & B & $\mathrm{C}$ & $\mathrm{D}$ & E \\
\hline 4 & $\begin{array}{l}\text { I assign a short passage } \\
\text { related to the topic }\end{array}$ & $\mathrm{A}$ & B & $\mathrm{C}$ & $\mathrm{D}$ & $\mathrm{E}$ \\
\hline 5 & $\begin{array}{l}\text { I use quotations related to the } \\
\text { topic }\end{array}$ & $\mathrm{A}$ & B & $\mathrm{C}$ & $\mathrm{D}$ & $\mathrm{E}$ \\
\hline 6 & I pre-teach key words & A & B & $\mathrm{C}$ & $\mathrm{D}$ & $\mathrm{E}$ \\
\hline 7 & $\begin{array}{l}\text { I assign tasks related to the } \\
\text { topic }\end{array}$ & $\mathrm{A}$ & B & $\mathrm{C}$ & $\mathrm{D}$ & $\mathrm{E}$ \\
\hline 8 & I read the text aloud & $\mathrm{A}$ & B & $\mathrm{C}$ & $\mathrm{D}$ & $\mathrm{E}$ \\
\hline 9 & $\begin{array}{l}\text { I explain and translate what } \\
\text { the text is about }\end{array}$ & $\mathrm{A}$ & B & $\mathrm{C}$ & $\mathrm{D}$ & $\mathrm{E}$ \\
\hline
\end{tabular}


How true or not true are these statements about your teaching WHILE-READING strategies?

\begin{tabular}{|c|c|c|c|c|c|c|}
\hline & Strategies & $\begin{array}{c}\text { Never or } \\
\text { almost } \\
\text { never } \\
\text { true of } \\
\text { me }\end{array}$ & $\begin{array}{l}\text { Usually } \\
\text { not true of } \\
\text { me }\end{array}$ & $\begin{array}{l}\text { Somewhat } \\
\text { true of me }\end{array}$ & $\begin{array}{l}\text { Usually } \\
\text { true of me }\end{array}$ & $\begin{array}{c}\text { Always or } \\
\text { almost } \\
\text { always } \\
\text { true of me }\end{array}$ \\
\hline 1 & $\begin{array}{l}\text { I ask students to read for general } \\
\text { understanding (skimming) }\end{array}$ & A & B & $\mathrm{C}$ & $\mathrm{D}$ & E \\
\hline 2 & $\begin{array}{l}\text { I ask students to read for specific } \\
\text { information (scanning) }\end{array}$ & A & B & $\mathrm{C}$ & $\mathrm{D}$ & E \\
\hline 3 & I ask students to read for detail & A & B & $\mathrm{C}$ & $\mathrm{D}$ & E \\
\hline 4 & $\begin{array}{l}\text { I use different activities to } \\
\text { motivate students (e.g. jigsaw } \\
\text { reading, jumbled texts etc.) }\end{array}$ & A & B & $\mathrm{C}$ & $\mathrm{D}$ & E \\
\hline 5 & $\begin{array}{l}\text { I check comprehension while } \\
\text { reading }\end{array}$ & A & B & $\mathrm{C}$ & $\mathrm{D}$ & E \\
\hline 6 & $\begin{array}{l}\text { I ask students to guess the } \\
\text { meaning of words from the } \\
\text { context }\end{array}$ & A & B & $\mathrm{C}$ & $\mathrm{D}$ & E \\
\hline 7 & $\begin{array}{l}\text { I relate the reading to other skills } \\
\text { (listening, speaking, writing) }\end{array}$ & A & B & $\mathrm{C}$ & $\mathrm{D}$ & E \\
\hline 8 & $\begin{array}{l}\text { I give written exercises related to } \\
\text { the text content, vocabulary or } \\
\text { grammar }\end{array}$ & A & B & $\mathrm{C}$ & $\mathrm{D}$ & E \\
\hline 9 & $\begin{array}{l}\text { I ask students to use a dictionary } \\
\text { while reading }\end{array}$ & A & B & $\mathrm{C}$ & $\mathrm{D}$ & E \\
\hline
\end{tabular}

How true or not true are these statements about your teaching POST-READING strategies?

\begin{tabular}{|c|l|c|c|c|c|c|}
\hline \multicolumn{1}{|c|}{ Strategies } & $\begin{array}{c}\text { Never or } \\
\text { almost } \\
\text { never true } \\
\text { of me }\end{array}$ & $\begin{array}{c}\text { Usually } \\
\text { not true } \\
\text { of me }\end{array}$ & $\begin{array}{c}\text { Somewhat } \\
\text { true of me }\end{array}$ & $\begin{array}{c}\text { Usually } \\
\text { true of me }\end{array}$ & $\begin{array}{c}\text { Always or } \\
\text { almost } \\
\text { always } \\
\text { true of me }\end{array}$ \\
\hline 1 & $\begin{array}{l}\text { I ask students to interpret or make } \\
\text { inferences about implied } \\
\text { information }\end{array}$ & A & B & D & E \\
\hline 2 & $\begin{array}{l}\text { I ask students to discuss the main } \\
\text { idea }\end{array}$ & A & B & C & D & E \\
\hline 3 & $\begin{array}{l}\text { I ask students to figure out } \\
\text { relationships such as cause and } \\
\text { effect }\end{array}$ & A & B & C & D & E \\
\hline 4 & $\begin{array}{l}\text { I use different activities to } \\
\text { motivate students (e.g. making } \\
\text { posters, group report etc.) }\end{array}$ & A & B & C & D & E \\
\hline 5 & $\begin{array}{l}\text { I check comprehension by asking } \\
\text { questions or true false statements }\end{array}$ & A & B & C & D & E \\
\hline 6 & $\begin{array}{l}\text { I ask students to translate what } \\
\text { they understood }\end{array}$ & A & B & C & D & E \\
\hline 7 & $\begin{array}{l}\text { I give written exercises related to } \\
\text { the text content, vocabulary or } \\
\text { grammar }\end{array}$ & A & B & C & D & E \\
\hline
\end{tabular}




\section{Lesson materials used for teaching receptive skills}

How often do you use the following teaching materials for LISTENING SKILLS?

\begin{tabular}{|c|l|c|c|c|c|c|}
\hline & \multicolumn{1}{|c|}{ Materials } & Never & Seldom & Sometimes & Often & Always \\
\hline 1 & A textbook material & A & B & C & D & E \\
\hline 2 & Songs and music & A & B & C & D & E \\
\hline 3 & TV show or interview & A & B & C & D \\
\hline 4 & Radio broadcasting & A & B & C & D \\
\hline 5 & Videos or movies & A & B & C & D & E \\
\hline 6 & News & A & B & C & D & E \\
\hline
\end{tabular}

How often do you use the following teaching materials for READING SKILLS?

\begin{tabular}{|c|l|c|c|c|c|c|}
\hline \multicolumn{1}{|c|}{ Materials } & Never & Seldom & Sometimes & Often & Always \\
\hline 1 & A textbook material & A & B & C & D & E \\
\hline 2 & $\begin{array}{l}\text { A newspaper or journal } \\
\text { article }\end{array}$ & A & B & C & D & E \\
\hline 3 & $\begin{array}{l}\text { Additional short passages } \\
\text { and stories }\end{array}$ & A & B & C & D \\
\hline 4 & Books & A & B & C & D & E \\
\hline
\end{tabular}

\section{Encouragement for out-of-class activities for receptive skills}

How true or not true are these statements about your encouragement of using LISTENING strategies out-of-the class?

\begin{tabular}{|c|c|c|c|c|c|c|}
\hline & Questions & $\begin{array}{l}\text { Never or } \\
\text { almost } \\
\text { never true } \\
\text { of me }\end{array}$ & $\begin{array}{l}\text { Usually } \\
\text { not true of } \\
\text { me }\end{array}$ & $\begin{array}{l}\text { Somewhat } \\
\text { true of me }\end{array}$ & $\begin{array}{l}\text { Usually } \\
\text { true of me }\end{array}$ & $\begin{array}{l}\text { Always or } \\
\text { almost } \\
\text { always } \\
\text { true of me }\end{array}$ \\
\hline 1 & $\begin{array}{l}\text { I ask students to learn new } \\
\text { English songs }\end{array}$ & A & B & $\mathrm{C}$ & $\mathrm{D}$ & $\mathrm{E}$ \\
\hline 2 & $\begin{array}{l}\text { I ask students to watch TV } \\
\text { news and interviews for } \\
\text { homework and report it in } \\
\text { the class. }\end{array}$ & A & B & $\mathrm{C}$ & $\mathrm{D}$ & $\mathrm{E}$ \\
\hline 3 & $\begin{array}{l}\text { I ask students to speak to } \\
\text { native speakers }\end{array}$ & A & B & $\mathrm{C}$ & D & $\mathrm{E}$ \\
\hline 4 & $\begin{array}{l}\text { I ask students to listen to } \\
\text { any information from the } \\
\text { Internet and report it in the } \\
\text { class }\end{array}$ & A & B & $\mathrm{C}$ & $\mathrm{D}$ & $\mathrm{E}$ \\
\hline
\end{tabular}


How true or not true are these statements about your encouragement of using READING strategies out-of- the class?

\begin{tabular}{|c|c|c|c|c|c|c|}
\hline & Questions & $\begin{array}{l}\text { Never or } \\
\text { almost } \\
\text { never true } \\
\text { of me }\end{array}$ & $\begin{array}{l}\text { Usually } \\
\text { not true of } \\
\text { me }\end{array}$ & $\begin{array}{l}\text { Somewhat } \\
\text { true of me }\end{array}$ & $\begin{array}{l}\text { Usually } \\
\text { true of me }\end{array}$ & $\begin{array}{l}\text { Always or } \\
\text { almost } \\
\text { always } \\
\text { true of me }\end{array}$ \\
\hline 1 & $\begin{array}{l}\text { I ask students to read short } \\
\text { stories at home and talk or } \\
\text { write about it. }\end{array}$ & A & B & $\mathrm{C}$ & D & $\mathrm{E}$ \\
\hline 2 & $\begin{array}{l}\text { I ask students to read } \\
\text { newspapers or articles for } \\
\text { homework. }\end{array}$ & A & B & $\mathrm{C}$ & $\mathrm{D}$ & $\mathrm{E}$ \\
\hline 3 & $\begin{array}{l}\text { I ask students to work in } \\
\text { group projects to gather } \\
\text { information from the } \\
\text { Internet. }\end{array}$ & A & B & $\mathrm{C}$ & D & $\mathrm{E}$ \\
\hline 4 & $\begin{array}{l}\text { I ask students to recite } \\
\text { poems }\end{array}$ & A & B & $\mathrm{C}$ & D & $\mathrm{E}$ \\
\hline
\end{tabular}




\section{APPENDIX C \\ Language learning strategy questionnaire}

\section{Background}

1. Are you a girl or a boy?
a. Girl
b. Boy

2. What is your grade?
a. 6
b. 8

3. What is your age?
a. 10
b. 11
c. 12
d. 13
e. 14

4. What is the highest level of education completed by your father <or stepfather or male guardian $>$ ?
a. Did not go to school
b. Primary school
c. Lower secondary
d. Secondary education
e. Higher education (bachelor or master) or more

5. What is the highest level of education completed by your mother <or stepmother or female guardian>?
a. Did not go to school
b. Primary school
c. Lower secondary
d. Secondary education
e. Higher education (bachelor or master) or more

II. Attitude and learning strategy for English language listening and reading skills

To what extent do you agree or disagree with these statements about your English listening attitude?

\begin{tabular}{|c|l|c|c|c|c|c|}
\hline \multicolumn{1}{|c|}{ Questions } & $\begin{array}{c}\text { strongly } \\
\text { agree }\end{array}$ & agree & $\begin{array}{c}\text { neither agree } \\
\text { nor disagree }\end{array}$ & disagree & $\begin{array}{c}\text { strongly } \\
\text { disagree }\end{array}$ \\
\hline 1 & $\begin{array}{l}\text { I like to listen to English songs } \\
\text { during classes }\end{array}$ & A & B & C & D & E \\
\hline 2 & $\begin{array}{l}\text { I like to fill in gaps listening to } \\
\text { the topic. }\end{array}$ & A & B & C & D \\
\hline 3 & I like to understand the speaker & A & B & C & D & E \\
\hline 4 & $\begin{array}{l}\text { I like to listen to speakers } \\
\text { voice/accent }\end{array}$ & A & B & C & E \\
\hline 5 & $\begin{array}{l}\text { Listening improves my } \\
\text { knowledge and speaking }\end{array}$ & A & B & C & D \\
\hline 6 & Listening is fun for me & A & B & C & D & E \\
\hline 7 & I like to improve my listening skill & A & B & C & D & E \\
\hline
\end{tabular}


To what extent do you agree or disagree with these statements about your English reading attitude?

\begin{tabular}{|c|l|c|c|c|c|c|}
\hline \multicolumn{1}{|c|}{ Questions } & $\begin{array}{l}\text { strongly } \\
\text { agree }\end{array}$ & agree & $\begin{array}{l}\text { neither } \\
\text { agree nor } \\
\text { disagree }\end{array}$ & disagree & $\begin{array}{l}\text { strongly } \\
\text { disagree }\end{array}$ \\
\hline 1 & I read only if I have to & A & B & C & D & E \\
\hline 2 & $\begin{array}{l}\text { I like talking about books with other } \\
\text { people }\end{array}$ & A & B & C & D & E \\
\hline 3 & For me, reading is a waste of time & A & B & C & D \\
\hline 4 & I read only to get information that I need & A & B & C & D & E \\
\hline 5 & $\begin{array}{l}\text { Reading develops my knowledge and } \\
\text { speaking }\end{array}$ & A & B & C & D & E \\
\hline 6 & $\begin{array}{l}\text { I like to exchange books with my } \\
\text { friends }\end{array}$ & A & B & C & D & E \\
\hline 7 & Reading is fun for me & A & B & C & D & E \\
\hline 8 & I like to improve my reading skill & A & B & C & D & E \\
\hline 9 & I like to enlarge my vocabulary & A & B & C & D & E \\
\hline
\end{tabular}

\section{Learning strategy for English listening skill}

1. What do you listen to from any of the following in English in your daily life? You can choose more than one.
a) Music and songs
b) Radio Programs
c) News
d) Movies
e) Lectures
f) Listen to the same task which was used in a class
g) Foreigners speaking

2. How much time do you spend on each listening task for practice per day?
a) Under 5 Min.
b) 5 - 10 Min.
c) 10-15 Min.
d) More than 15 Min 
3. To what extent do you agree or disagree with the following referring toyour English listening strategy?

\begin{tabular}{|c|l|c|c|c|c|c|}
\hline \multicolumn{1}{|c|}{ Questions } & $\begin{array}{c}\text { strongly } \\
\text { agree }\end{array}$ & agree & $\begin{array}{c}\text { neither } \\
\text { agree nor } \\
\text { disagree }\end{array}$ & disagree & $\begin{array}{c}\text { strongly } \\
\text { disagree }\end{array}$ \\
\hline 1 & $\begin{array}{l}\text { I understand the content through } \\
\text { the speaker's voice/talking }\end{array}$ & A & B & C & D & E \\
\hline 2 & $\begin{array}{l}\text { I ask questions to clarify } \\
\text { anything that I don't fully } \\
\text { understand }\end{array}$ & A & B & C & D & E \\
\hline 3 & $\begin{array}{l}\text { I choose key words listening to } \\
\text { the topic }\end{array}$ & A & B & C & D & E \\
\hline 5 & $\begin{array}{l}\text { I take notes while listening to the } \\
\text { story }\end{array}$ & A & B & C & D & E \\
\hline
\end{tabular}

\section{Learning strategy for English reading skill}

1. How often do you read a book in English?
a) never
b) seldom
c) sometimes
d) often
e) very often

2. What do you like to read?
a) a short story
b) small paragraphs
c) a long story
d) novels
e) tales
f) poems
g) fables

3. How much time do you spend on each English reading task for practice per day?
e) Under 5 Min
f) 5 - 10 Min.
g) 10 - 15 Min.
h) More than 15 Min 


\section{To what extent do you agree or disagree with the following referring to your English reading strategy?}

\begin{tabular}{|c|c|c|c|c|c|c|}
\hline & Questions & $\begin{array}{l}\text { strongly } \\
\text { agree }\end{array}$ & agree & $\begin{array}{l}\text { neither agree } \\
\text { nor disagree }\end{array}$ & disagree & $\begin{array}{l}\text { strongly } \\
\text { disagree }\end{array}$ \\
\hline 1 & $\begin{array}{l}\text { I guess new vocabulary when } \\
\text { I read books in English. }\end{array}$ & A & B & $\mathrm{C}$ & $\mathrm{D}$ & $\mathrm{E}$ \\
\hline 2 & $\begin{array}{l}\text { I ask questions myself before } \\
\text { I read the story. }\end{array}$ & A & B & $\mathrm{C}$ & $\mathrm{D}$ & $\mathrm{E}$ \\
\hline 3 & $\begin{array}{l}\text { I participate in reading } \\
\text { activities in the classroom. }\end{array}$ & A & B & $\mathrm{C}$ & $\mathrm{D}$ & $\mathrm{E}$ \\
\hline 4 & $\begin{array}{l}\text { I read the story quickly and } \\
\text { choose key words. }\end{array}$ & A & B & $\mathrm{C}$ & $\mathrm{D}$ & $\mathrm{E}$ \\
\hline 5 & $\begin{array}{l}\text { If the story is long, I divide it } \\
\text { into small parts. }\end{array}$ & A & B & $\mathrm{C}$ & $\mathrm{D}$ & $\mathrm{E}$ \\
\hline 6 & $\begin{array}{l}\text { I predict the main idea of the } \\
\text { whole passage from its title or } \\
\text { subtitles. }\end{array}$ & A & B & $\mathrm{C}$ & $\mathrm{D}$ & $\mathrm{E}$ \\
\hline
\end{tabular}




\section{APPENDIX D \\ Sixth grade test}

Test 1

You are going to hear ten short dialogues. Listen to the people talking and decide where they are. You need to select the right place from three options. Put the letters in the grid. You will hear the dialogues twice. Now you have 90 seconds to look at the answers.

There is an example (0) at the beginning.

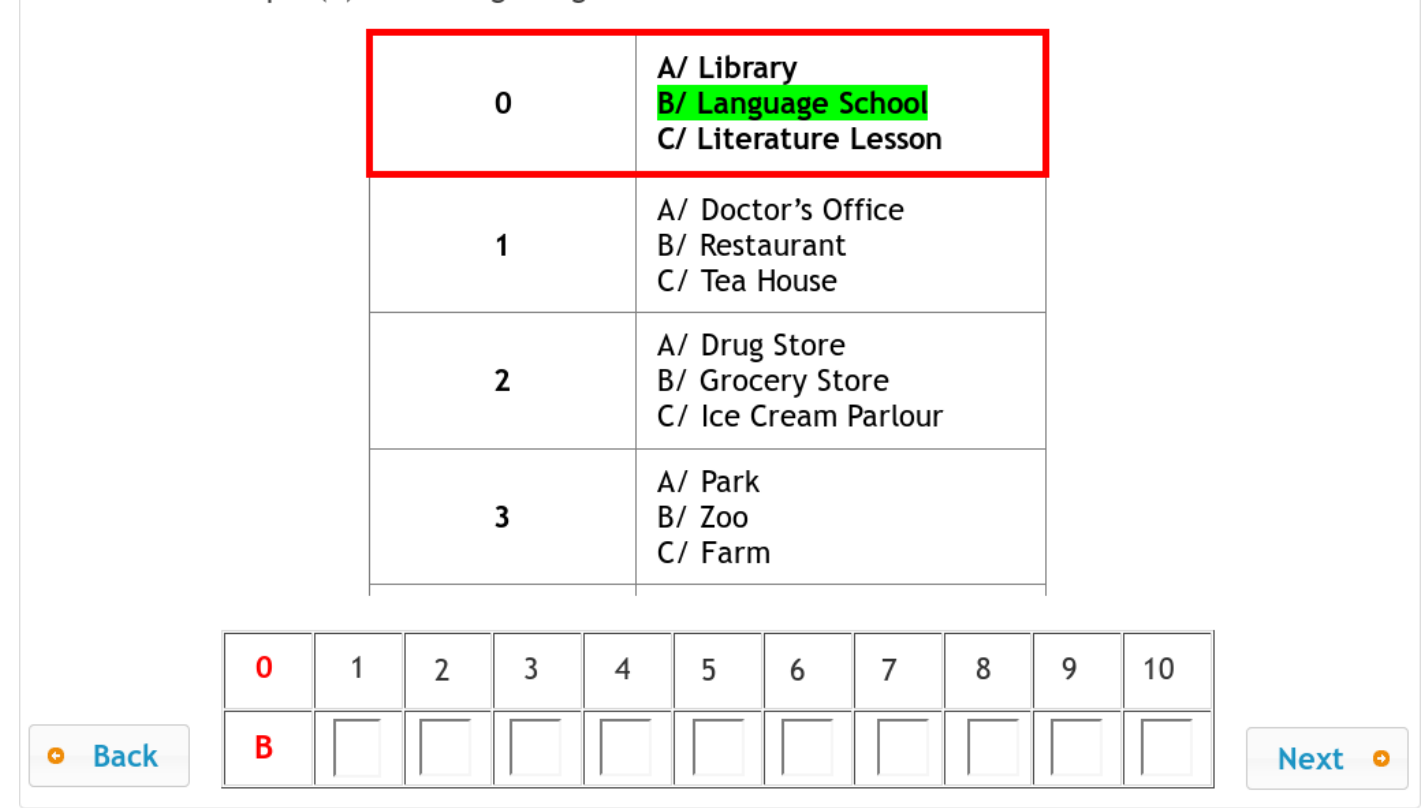

\section{Test 2}

You are going to hear ten short film trailers. As you listen choose a title for each film. Put the letters in the grid. There are twelve titles you can choose from, but you will only need ten of the titles. You will hear the dialogues twice. Now you have 90 seconds to look at the answers.

There is an example $(0)$ at the beginning.
A. Finding Love and Gold
B. The Young Clock Master
C. The End of a Sports Career
D. Making Films
E. Travelling with a Stranger
F. Books and Violins
G. From Rich to Poor
H. Pen Friends' Love
I. Car Racing
J. Famous Spacemen
K. Teenage Love
L. The Rich Driver
M. The Librarian

- Back

\begin{tabular}{|l|l|l|l|l|l|l|l|l|l|l|}
\hline 0 & 1 & 2 & 3 & 4 & 5 & 6 & 7 & 8 & 9 & 10 \\
\hline $\mathrm{J}$ & $\Gamma$ & $\Gamma$ & $\Gamma$ & $\Gamma$ & $\Gamma$ & $\square$ & $\square$ & $\square$ & $\square$ & $\square$ \\
\hline
\end{tabular}




\section{Test 3}

Below you will find the descriptions of books (0-10). Find the title of each book in the list (A-M) and put the letters in the grid. There are two titles you will not need.

There is an example $(0)$ for you at the beginning.

\section{Create fabulous paper models with projects including an air-to-surface guided missile and a spaceship. This gift box includes a book with basic instructions, 50 sheets of origami paper, one completed origami missile, and nine amazing projects!}

1. Written in glorious rhyme and illustrated in colour, this is a fabulous story, with drama, humour, originality - and a happy ending with balloons and a cake! Three friends throw a surprise party for Jerry, but complications almost ruin this special day.

2. ,Oink!' said the cats ... The farmyard is full of noise with all the MOOing and HISSing and BAAAing and CLUCKing. When Hefty Hugh and Lanky Len plan a plot to steal the fine prize cow, it's the quietest animal of all who saves the day! Spot the tiny red animal with her black spots on every page of this wonderful rhyming tale.

3. Harry runs away from his home to join the circus. The audiences love him but poor Harry, kept in a cage by the wicked circus owner Sam Sly, soon longs to return to the

\section{Answers}

- Back

\begin{tabular}{|l|l|l|l|l|l|l|l|l|l|l|}
\hline 0 & 1 & 2 & 3 & 4 & 5 & 6 & 7 & 8 & 9 & 10 \\
\hline $\mathrm{J}$ & $\Gamma$ & $\Gamma$ & $\square$ & $\square$ & $\square$ & $\square$ & $\square$ & $\square$ & $\square$ & $\square$ \\
\hline
\end{tabular}

Next $\odot$

\section{Test 4}

There are ten gaps $(0-10)$ in the text below. Find the missing parts in the list (A-M) and put the letters in the grid. There are two parts you will not need. There is an example (0.) for you at the beginning.

\section{First Day of School}

I don't want to start school. I don't want to do anything but stay in bed. Stay in bed, with the covers ______. All day.

“Take a shower, Dave,” my mother says, on the morning when school starts. “Wash ___ ${ }^{1}$ _. I'll bet it's been seven days. That's not like you."

She is wrong. It's been ___ $2 \ldots$ since I've bathed. I know I smell, but I don't care. I roll over and pull the bedsheet up over my ear.

“Please, honey," Mom says. “Don't wait too long to get ready for school."

As if I am planning to jump out of bed this moment and head right for the shower.

\section{Answers}

Back

\begin{tabular}{|c|c|c|c|c|c|c|c|c|c|c|}
\hline 0 & 1 & 2 & 3 & 4 & 5 & 6 & 7 & 8 & 9 & 10 \\
\hline $\mathbf{J}$ & & & & & & & & & & \\
\hline
\end{tabular}




\section{APPENDIX E}

\section{Eighth Grade Test}

Pair 12 words and 10 definitions. Write the number of the word into the box next to the correct sentence.
1 doctor
2 hospital 3 fly
4 watch
5 policeman
6 postman
7 station
8 sleep
9 climb
10 travel agent
11 walk
12 train

A place where you visit someone sick or ill.

A person who delivers letters.

You do this when you are tired and you want to relax.

You can do this in a park, street or forest.

You can do this if you want to see far and there is a tree near you.

A place where you go to buy your ticket if you want to travel somewhere.

B ack

Pair 12 words and 10 definitions. Write the number of the word into the box next to the correct sentence. See the example in blue.

$\begin{array}{cccccc}1 \text { doctor } & 2 \text { hospital } & 3 \mathrm{fly} & 4 \text { watch } & 5 \text { policeman } & 6 \text { postman } \\ 7 \text { station } & 8 \text { sleep } & 9 \text { climb } & 10 \text { travel agent } & 11 \text { walk } & 12 \text { train }\end{array}$

A person you visit if you have a headache or a sore throat. $\overline{1}$

A person who helps you with tickets and information.

This is what you do if you want to cross the ocean or travel a long way fast.

A person who takes criminals to prison.

This is a vehicle you take if you want to get from one town to the other. 
Here are some notices. What do they mean? Choose from the drop-down list.

There is one extra you don't need. See the example.

\section{Don't touch window don't go near this object!-}

Opening hours: $9 \mathrm{am}-5 \mathrm{pm}$ Please choose one.

Two hour photo service in here Please choose one.

Please keep it open Please choose one.

No eating or drinking in classroom Please choose one.

Read this short interview from a British youth magazine. Match the questions on the top with the answers in the list on the bottom. There is an extra answer you don't need. Write the number of the correct answer into the box next to the question. See the example in blue.

What's it like to be 12 in another country? We put the question to someone in the USA.

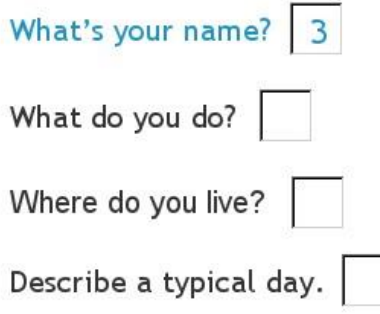

What do you do in your spare time?
What's your favourite TV programme?

What's your favourite magazine?

Your favourite food?

Any you hate?

Who are your best friends?

1 Up by 7am, go to school till 2.30pm. Some days I'll go out with friends till 5.30pm, some days I'll go to the movie. Then I'll be with my family for dinner, do my school work and go to bed by 10pm.

2 I don't read any. I prefer books like Harry Potter and the Philosopher's Stone.

3 Laura Hilius.

4 Anything sweet, I love cakes, and icecream.

5 Hang out with friends, play computer games, talk on the phone, listen to music....

6 I don't really like maths and science. 
Read the advertisements in the boxes and find the missing bit for each gap on the top. Write the numbers in the box next to the missing bit. See the example in blue.

BEST VALUE FOR TODAY'S EVENING PERFORMANCES $\sqrt{2} \quad$ DALMACIA HOTEL

Learn more. farn more $\square$

www.thepad-uk.com

YES, I WANT TO SUBSCRIBE TO TIME OUT

Experience different cultures
9000 words \& 350 topics for tablet

Open for Lunch and Dinner

solo artists \& bands

or contact your travel agent

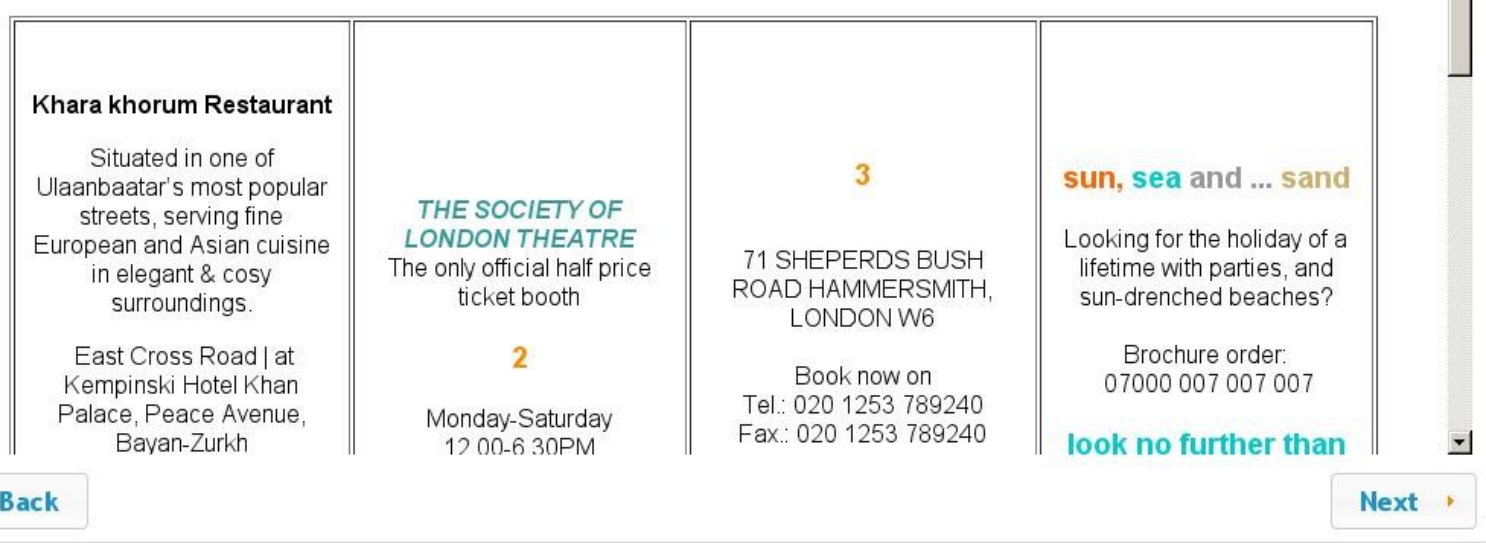




\section{APPENDIX F \\ School infrastructure survey}

1. Please select the type of settlement in which the school is located!

a. village or rural area

b.town or city

c.capital city

2. How many classes are equipped with computers in your school?

3. How many computers are in each computer room? /ICT room/.
a. /computer/ room 1
b. /computer/ room 2
c. /computer/ room 3
d. /computer/ room 4

4. Enter the average ages of the computers in each ICT rooms!
a. $0-1$ years
b. 2-3 years
c. 4-5 years
d. 6 years or more

5. Are the computers equipped with Internet connection and headset?
a. Yes
b. No

6. What is the screen resolution of the student computers?
a. $1024 \times 768$
b. $1366 \times 768$
c. $1280 \times 1024$
d. $1280 \times 800$
e. $800 \times 600$

7. Which browsers can be found in the majority of school computers?
a. Google Chrome
b. Mozilla Firefox
c. Internet explorer
d. Opera
e. Safari
f. Other 
8. What type of Internet package does the school use?
a. $56 \mathrm{kbit} / \mathrm{s}$ modem
b. ISDN
c. ADSL
d. ADSL2+
e. SDSL
f. Kabelnet
g. Optic
h. Other

9. Is there any Internet access in the classrooms equipped with computers (not ICT rooms)?
a. Yes
b. No
c. Only on the teachers' computers

10. How many of these devices are there in the non-ICT rooms?
a. Laptop
b. Desktop computer
c. Projector
d. Tablet
e. Classmate pc
f. Touch screen monitor
g. Response system
h. Microphone
i. Headset
j. Webcam

11. Information technology teacher provides the system administrator's tasks
a. Yes
b. No

12. Please specify, how many employees has the school among the following specialists:
a. Information technology teacher.
b. System administrator..........

13. Is the renewal of infrastructure of the computer rooms/fleet in your school in progress?
a. Yes
b. No 